$Q L$

666

0 6V62 REPT. 







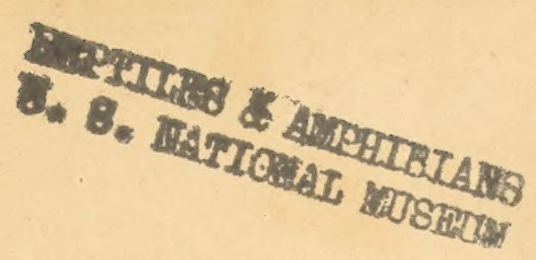

ĖTUDES MĖDICALES

S UR

\section{LES SERPENTS}

DE LA VENDÉE ET DE LA LOIRE-INFÉRIEURE 



\title{
ÉTUDES MÉDICALES
}

S U R

\section{LES SERPENTS}

\author{
DE LA VENDÉE
}

ET DE LA LOIRE-INFÉRIEURE/

PA R

\section{LE D A. VIAUD-GRAND-MARAIS}

Professeur de Pathologie interne à l'École de Médecine de Nantes

Membre de la Société Botanique de France, de la Société d’Émulatıon de la Vendée de la Sociétè Académique de la Loire-Inférieure

de la Société Centrale de Médecine du Nord, de la Société Linnéenne de Normandie

de la Société d'Agriculture, Sciences, Arts et Belles-Lettres d'Indre-et-Loire

et de la Société d'Acclimatation et d'Histoire naturelle de l'ile de la Reunion, etc.

DEUXIEME EDITION

Morsus virus habent et fatum dente minantur.

Pocula morte carent. . ........

Lucani Phars. Ix, vers. 6-14.

Nam venenum serpentis..... non gustu sed in vulnere nocet..... Ergo quisquis id vulnus exsuxerit et ipse tutus erit et tutum hominem præstabit.

CORN. CELsi de re medicâ, lib. v, cap. 2 , sect. 12.

SE TROUVE A NANTES, CHEZ TOUS LES LIBRAIRES

SAINT-GERMAIN

DE L'1MPRIMERIE L. TOINON ET Ge

$1867-1869$ 



\section{ÉTUDES MEÉDICALES}

SUR

\section{LES SERPENTS}

\section{DE LA VENDEE ET DE LA LOIRE-INTERIEURE}

La Vendée, le Bocage surtout, avec ses grands genêts, ses broussailles, ses champs entourés de haies vives et ses cours d'eau souvent encaissés entre des roches escarpées et buissonneuses, offre des conditions très-favorables aux serpents.

L'extension des cultures ef l'établissement des grandes routes en ont cependant diminué le nombre; mais ils sont encore assez communs pour que les chasseurs ne pareourent jamais ce giboyeux pays, sans craindre pour eux et pour leurs chiens.

La Loire-Inférieure, par ses niouvements de terrain et la manière dont on y cultive le sol, ressemble beaucoup à la Vendée, ct les reptiles s'y montrent aussi en abondance.

Les serpents que l'on rencontre dans ces départements appartiemnent à huit espèces, en y comprenant l'orvet qui n’a du serpent que la forme; deux seulement sont venimeux.

Il est done fort intéressant de les distinguer, puisque les uns sont inoffensifs el mème utiles à l'agriculture, et que les autres 
donnent lieu presque chaque année à des eas de mort chez l'homme et chez les animaux domestiques.

Les serpents à venin une fois connus, il importe de savoir quels sont les accidents qu'ils provoquent et quels sont les moyens rationnels de détruire les effets de leur poison.

Ces études seront divisées en quatre parties :

I. Considérations sur les serpents non venimeux de la Vendée et de la Loire-Inférieure et sur leurs morsures.

II. Histoire naturelle des serpents venimeux indigènes.

III. Considérations sur les blessures causées par les vipères dans l'ouest de la France.

IV. Des ennemis de la vipère et des moyens de la détruire.

Puis viendront les deux appendices suivants :

$1^{0}$ Une note sur l'emploi de la vipère et de sun venin comme moyens thérapeutiques. .

$2^{\circ}$ Le tableau synoptique des serpents de la Vendée et de la Loire-Inférieure.

Les espèces inoffensives de serpents de l'ouest de la France sont l'orvet et les couleuvres.

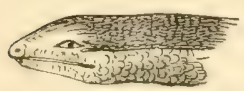

Fig. 1.

$\S$ I. - Orvet. - L'orvet, Anguis fragilis L. (fig. 1), appelé, stivant les localités, anvin, anvau, anvoie, anvais, anvronais, borgne et nielle (1),

(1) M. Littré, dans son dictionnaire, écrit envoye et donne pour synonyme le mot aveugle; mais les noms anvin, anvais, ete., employés jour orvet, dérivent du latin anguis, avec changement du gu en $v$, transformation de lettres beaucoup plus rare du latin en français que la transforma- 
a presque partout la plus mauvaise renommée. Un vieux pro. verbe fort accrédité dit :

\author{
Si bœuf voulait, \\ Si anvin voyait, \\ Et si sourd entendait, \\ Personne ne vivrait.
}

L'orvet n'est pas plus aveugle que la salamandre terrestre n'est sourde. Il doit cette répulation de cécité à son appareil l)alpébral qui, de mìme que celui des lézards, se compose de deux paupieres et d'une membrane clignotante. Cette disposition fait paraitre l'oeil de ce reptile très-petit et comme roilé, tandis que le regard des vrais serpents, sans paupières mobiles, est d'une fixité effrayante.

C'est un reptile homoderme, c'est-ì-dire à écailles du dos et du ventre semblables; clles sont lisses et luisantes, et offrent des reflets mélalliques. Sa robe, d'un jaune argenté en dessus, est noiritre en dessous. Sur son dos se remarquent trois lignes noir'es longitudinales, se transformant avec l'àge en séries de points ct finissant par disparaître. Sa tête est revêtue de cinq plaques entourées d'autres plus petites. Ses mâchoires ne sont pas dilatables. La longueur totale de l'animal adulte est de vingt-cinq à trente-cinq centimètres, dont la queue forme plus de la moitié.

Il mue en refoulant en arrière son vieil épiderme qui se fronce en plis serrés, mais ne se renverse point en doigt de gant.

tion inverse. Cependant un exemple de la même mitamorphose se prisente pour un autre dérivé d'anguis, anguille, qui, en picard, se dit anwile et en wallon anveie. Orvet dérivie du latin orbatus, sous-entendu lumine, d'oil orbut, orvut, orvet. Borgne n'a pas besoin d'explication. Nielle vient de nigellus, noiràtre. 
Il est vivipare et met bas, en juillet, de six à douze pelits longs de quatre centimètres à quatre centimètres et demi, et à livrée différente de celle de l'adulte. Ils sont blanes en dessus avec une ligne dorsale brune bifurquée sur la nuque; en dessous, leur coloration est d'un brun ardoisé.

L'orvet est un animal fort commun; on le rencontre sous la mousse des bois, dans l'herbe des prairies, parmi les décombres, partout, en un mol, nù il croit se dérober aux regards de ses nombreux ennemis. Au moment de la fenaison on le trouve quelquefois se chauffant au soleil sur des tas de foin, quand il s'y croit en sécurité; mais c'est surtout le soil', à la torubée de la nuit, qu'il prend plus librement ses ébats : on l'aperȩoit alors rampant dans l’ombre. S'il craint quelque agression, ou si le temps est mauvais, il se retire sous terre dans un trou, de plus d'un mètre de profondeur et à plusieurs ouvertures, qu'il s'est creusé avec son museau.

Il fuit timidement lorsqu'on l'attaque. Toutefois, quand il est fortement irrité, il se redresse et se domne un air de serpent dangereux, mais il cherche peu à se servir de ses dents; elles sont trop faibles, et sa bouche est trop pelite pour qu'il puisse blesser douloureusement. Un de nos amis fut cependant mordu au doigt par un orvet qu’il pressait dans sa main. Il n'éprouva qu'une faible sensation de pincement et les dents du reptile ne laissèrent point d'empreintes. Daudin parvint à faire mordre par' cel animal la cuisse écorchée d'un oiseau; la plaie, quoique imbibée de salive, ne présenta point les caraclères d'une morsure enverimée.

L'anvin saisi a un singulier moyen de défense qui lui vaut le surnom de serpent de verre. Ses muscles se roidissent au point qu'il se brise, abandonnant une partie de lui-même pour se sauver. La queue brisée se reproduit en quelques mois, mais se dis- 
tingue longtempis de la sanene primitive par une moindre longueur et une difformité au niveau de la cassure.

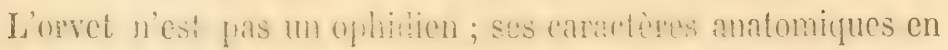
font un rériballe santrien de la famille dess scincoüliens. fest un sep̣s privé de fratles ou du moins diayant que des rudiment's de membres cachés sous la peau.

Animal fort doux, il ue eaues aucun tort aux prés ct aux mois-

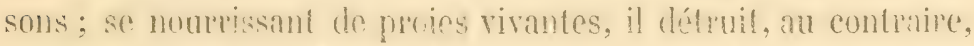

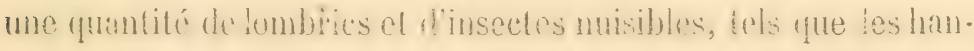
netons et leurs larves, les sauterelles, les chenilles, ete.

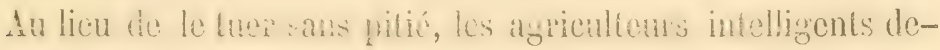
vraient done le protéger.

\$I. - Couleuvres. - Classification et description des espèces. - Les coulenres onl comm! candeteres communs, d'être hótérodermes, c'est-id-dire d'aroir les ćnalles dissemblables. Le dessus de leur corpes est couver de pulies écailles imbriyuécs. lisses

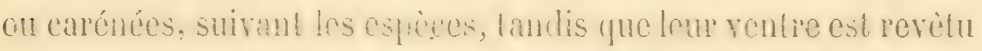

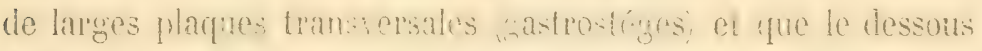

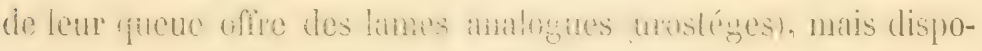
sées sur deux rangs. La tête de ces serpents est ovale et ornée de neut grandas planues an ícusson. Ils ont la pupille ronde et

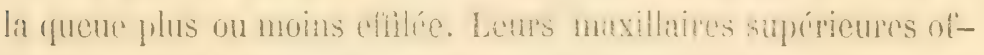
frent des denis ordinaires fammis de crochets ni camaliculés ni cannelés.

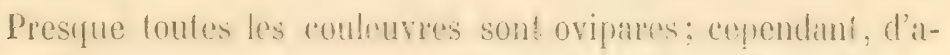

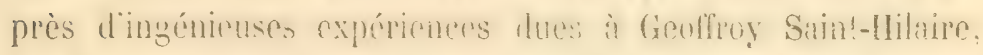
F. Prérost el Grïhe, on peut les rentre vivipares en les privant. d'eau.

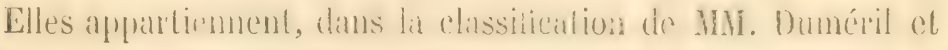
Bibron, au sous-ordre des aylyphodontes vis colutwiformes, serpents 
sans crochets renimeux, offrant, à chaque machoire, des dents coniques, pleines el arrondies. Les savants autrurs de l'Erpétolo. yie yinérule ont divisé les coulenves, non-seulement en plusicurs genres, mais anssi en plusicur's familles différenciées par leur système dentaire.

Voici, famille par famille, l'énuméralion des coulcures vendéennes et bretonnes qui sont au nombre de cinq.

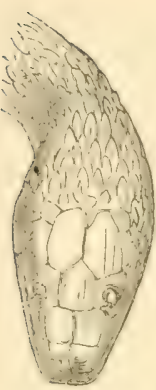

Fin. 2.

$1^{0}$ Dans la famille des isodontions, ou couleuvres à dents toutes semblables en longueur-et en intervalles, et dans le genre Elaphis Aldr., se trouve la couleuvne D'Esculape, Elaphis Esculapii Dum. (fig. 2). Ce grand serpent, de quatre-vingt-cinq cen. timètres à un mètre cinquante, a la tête petite, comprimée latéralement, et offre une tache noire post-oculaire. Un trait noir vertical placé sous l'œil lui traverse les deux mâchoires. Brun; olivâtre, ou roussâtre en dessus, l'élaphe présente sur le cioté du dos plusicurs séries de joints. Son rentre est jaune paille el cette teinte s'avance, à l'union de la tête et du corps, sur les côtés du cou en devenant plus foncée, mais sans donner lieu à un collier complet. La queue forme le cinquieme de l'individu. Les écailles de cettr couleurre sont décrites comme lisses; cependant queliques-unes de celles du dos possident in tubercule, rudiment de carène.

Lil couleurre d'Esculape porte. dans la campagne, les noms de sangle, de serpe. d'enfilundre, d'esterlonge et de rouabe. Elle hante les haies et les buissons, aime le voisinage les bois et grimpe facilement dans les ambes pour domer ha chasse aux oiseaux.

Après la moisson, cet agile serpent ride dans les chaumes, à la granile terreur des pạsans yui lui attribuent la faculté de sil. 
lomer et de se lancer ainsi à la poursuite de l'homme. Il nage fort bien el s'empare des grenouilles sur les eaux; ce n’est pas cependant un animal a moeurs aquatiques. Il a la singrulicre habitude, comme le dit M. Millet (Fume de Mnine-et-Loire, jage 63:3i), de se coucher à travers les sentiers pour barrer le chemin aux mulots, aux lézards et aux autres petits animaux qu'il veut surprendre. Il est souvent alor's victime de sa sécurité el tué par les passants.

Les oufs du serpent d'Esculape sont gros et eylindriques; il les dépose d'ordinaire dans le fumier, ou mème dans l'intérieur des étables.

Cetle couleurre est assez commune dans notre contrée, mais sculement par endroits : ainsi, aux environs te Challans, dans li: bassin du lia de Grandlieu, aux environs de Carquefou, de la Chapelle-sur-Erdıe, du Temple, ctc. Elle abonde dans certains bois : M. Arthur de l'Isle l'a prise dans ceux de Meilleraie et dans les forêtè d'Ancenis, de Saint-Mars et de Juigné.

C'est un animal assez farouche, mais il ne se jette pas sur l'homme, à moins que l'on ne tente de le saisir. Dans ce cas il mord avec force: «uoique sa blessure soit sans gravité, elle est un peu douloureuse et les dents entament la peau jusqu'au sang. M. A. de l'Isle, dans une excursion qu'il fit au Temple, en juin 1867, fut mordu par un élaphe qui l'atteignil au doigt avec les dents de sa màchoire supérieure. Le blessé nous montra neuf éraillures disposées sur deux rangs, cinq d'un côté et quatre de l'autre. La sensation qu’il éprouva fut celle d'une déchirure par une ronce. Les petites plaies guérirent, sans traitement, en trèspeu de jour's. Un des frères de II. de l'Isle fut, sans plus d'accidents, blessé à la main et au mollet par une autre couleuvre d'Esculape.

On dit l'élaphe susceptible de s'apprivoiser. 
I. do l'Jsle a lrouvé sur nos confuns, lans la forêt de Chanvaux

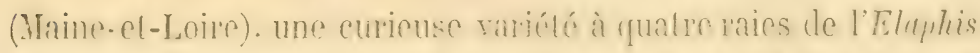

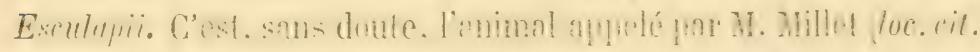

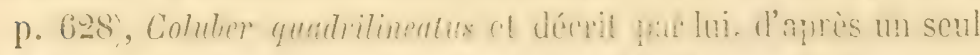
individu de dewa metres de lame, yne M. Treton du Inosscau avait pris dans le pare de la Terrie, près Saumur.

$2^{\circ}$ Dans la famille des syncrantériens, ou couleuvres à dents lisses, mas dunt les postótonmes ans-maxillaires, plus longues. ne sont frint súparées des frécidentes nar un intervalle libre. deux genres offrent des espèces indigènes.

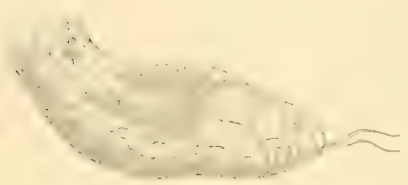

Fin. 3 .

Au genre Coronella Laur. appartient la couleuvre lisse, Coronella levis Dum. (fig. 3) C. austriaca Laur. qui doit son nom à ses écailles complétement lisses.

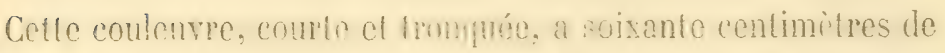

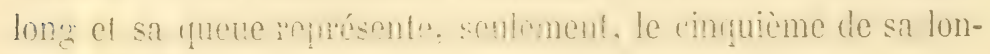
gueur totale.

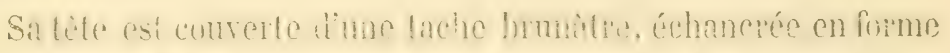

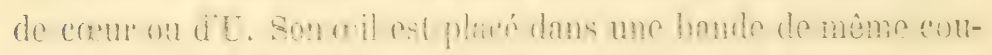
leur. Le dessus de son corps est gris ou rougeâtre avec quatre rangs de petites taches, et son ventre est noirâtre ou violacé.

Elle est vivipare et fréquente les lieux secs et pierreux. Ses

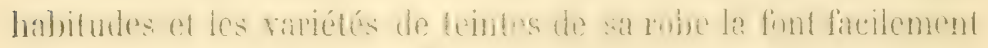

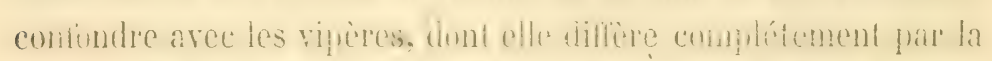
lorme et la disposilien de ees taches, ainei yne par ses écailles qui, loin d'être carénées, sont larges el lisses (1).

(1) Mis. Duméril et Bibron signálent sur nos confins une autre espèce de coronelle, la couleuvre bordelaise, Coronella yirundica Dum. Voisine de 
Moins commune que la couleuvre a collier, elle se rencontre cependant un peu partout dans les conditions que nous venons de signaler. Elle est plus agile que ses formes trapues ne sembleraient l'indiquer; aussi, quoiqu'elle ne vive pas dans les arbres, elle peut y grimper facilement. M. Arthur de l'Isle a pu le constater dans une expérience faite sur un chêne de dix mètres de haut, sans branches inférieures et n'ayant pour aspérités que quelques lichens.

La couleuvre lisse fait sa nourriture principale d'insectes. Elle est de mours douces, cherche peu à mordre, et ses dents n'éraillent que très-superficiellement la peau.

Le genre Tropidonotus Kulh. diffère des coronelles par la carène, ou saillie longitudinale de ses écailles. Deux espèces indigènes s'y rattachent : la couleurre à collier et la vipérine, toutes les deux sont fort amies des ruisseaux.

La COUleuvre a COLlier, Tropidonotus Natrix Kuhl. (fig. 4), vulgairement serpent nageur, couleuvre d'eau, anguilles de haies, etc., est la

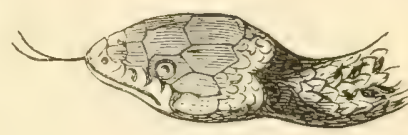

Fig. 4. plus commune des couleuvres de nos contrées. Elle se trouve partout et l'on en rencontre cinq ou six contre un autre serpent. Elle a sur la nuque un collier blanc, jaune pâle ou citrin, plus rarement orangé, et derrière lequel se montre, de chaque côté, une large tache noire. Sa tête est uniformément grise; son dos, plus ou moins cendré, porte trois ou quatre rangées de points noirs; son ventre noiràtre est tacheté de blanc, surtout la lisse, dont elle a les mours, elle s'en distingue par ses plaques suslabiales au nombre de huit et non de sept, par la série unique des taches noires de son dos, et par la couleur de ses plaques ventrales et caudalez à moitié noires. C'est un animal à rechercher en Vendée. 
vers les flancs. Sa longueur varie de cinquante centimètres à un mètre; mais les serpents croissant avec l'âge d'une manière presque indéfinie, cette couleuvre atteint parfois de grandes dimensions, principalement en grosscur. Presque toujours alors le collier disparait; c'est ce que nous avons constaté sur un iudividu très-gros et mesurant un mètre vingt-cinq centimetres de long, que nous avait envoyé M. Lecrac, pharmacien à Challans. La peur aidant à exagérer les objets, ces rieilles coulcuvres deviennent, dans les récits des paysans, des monstres affreux de la grosseur du bras ou de la cuisse et dont ils ne parlent qu'en frissonnant.

La couleuvre à collier fréquente les buissons, les bois ombragés, les prés humides et surtout le bord des ruisseaux. Elle nage avec la plus grande facilité et parait se comiplaire dans l'cau. Elle vit de petits mammiferes, d'oiseaux et de balraciens. Elle pond de vingt à quarante oufs de la grosscur de ceux d'une pie et les tlache les uns à la suite des autres, sous forme de chapelet, à l'aide d'une matière gluante. Elle dépose le tout en terre, dans de vicilles barges de foin ou dans des tas de fumier. Les petits éclosent au milieu de l'été; ils ont acquis avant lhiver quinze centimètres de longueur et sont en état de passer sans manger la mauvaise saison.

Le tropidonote natrix est de mœur's fort douces. Il se laisse im. punément caresser el. ne mord que lorsqu'il est agacé ; sa blessure est aussi peu doulourense que ceile de la coronelle lisse. La couleurre à collier est mangíe sans répugnance par quelques paysans du Bocage. M. Nivoche, receveur d'enregistrement, était à Pouzauges et venait de sauter un échallier, arec un paysan qui lui servait de guide, quand ce dernier aperesut un serpent de couleur cendrée, qu'il appela une anguille de haie, el qu'il tua imnédiatement avec une pierre. Le paysan ouvrit alor's sa chemise et y cacha sa capture, se promettant un bon diner. 
La COUleuvre vipérine, Tropidonotus viperinus, Schlegel (fig. 5̋), vulgairement serpent ou aspic d'eau, oflre de nombreuses variétés de couleur et de taches.

Elle n'a pas de collier, mais présente sur Fig. ร. la nuque deux lignes noirâtres imitant par leur jonction un $\mathrm{V}$ ouvert en arrière; une tache de même couleur sc montre derrière l'œil. Le dos est grisàtre ou roussâtre, avec une ligne en zigzag noile ef longitudinale. Sur les flanes se voit une série de taches noires entremêlées de macules jaunes. Le ventre est marqueté en damier ardoisé el grisâtre, ou ardoisé et jaunâtre.

La ligne zigzag du dos et les taches de la tête font confondre cette couleuvre avec les vipères, et de là lui vient son nom.

La vipérine a de cinquante à soixante-cinq centimètres de long. Elle est ovipare et dépose en terre, proche des caux, dix ou quinze oeufs non soudés en chapelet.

Elle est commune en Vendíe, surtoul dans les fossés du Marais septentrional. On la trouve mème clans l'ile de Noirmoutier, aux viviers de la Blanche.

Elle n'est pas moins commune dans la Loire-Inféricure, dans les boires de la Loire on de l'Erdre, et dans les étangs et les ruisseaux, à Y'ertou, à Oudon, à Riaillé. Plus aquatique encore que la couleurre ì collier, elle poursuit jusqu'au fond de l'eau les batraciens et les poissons, et se laisse parfois prendre à la ligne. Elle cherche peu à mordre et ses blessures sont complétement inoffensives.

Wagler a décrit, comme distinct du tropidonote vipérin, un serpent qui n'en diflère que par les deux raies longitudinales d'un jaune paile qu'il porte sur' le dos. Un reptile appartenant au musée 
du petit sćminaire de Tinnles el capturé à Maures (L.-Inf.) par l'abbé Delalande, répond complétenent a la description du Tropidonotus chersoüles Wiagler, domée par Mn. Duméril dans l'Erpritologie grimérale. La couleurre chersoüde n'est pour nous qu'une variété méridionale de la vipérine.

$3^{\circ}$ Dans la famille des diacrantériens, se rangent toutes les conleuves a dents lisses, mais dont le; postérienres sus-maxillaires plus longues sont séparées par un intervalle libre. Anx diacrantériens se raltache le genre Zumenis Wagler, qui offre une espèce indigène.

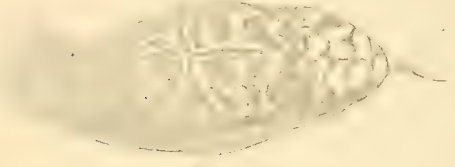

Iiı. 6.

La GoUleuVRE VERTE ET JAUNE, Zamenis viridiflavus Wagl. (fig. 6), partage avec la couleuvre d'Esculape le nom vulgaire de sungle. Elle a le dessus du corps noirâtre ou vert foncé, varié de lignes d'un beau jaune; sur sa lête ces lignes se transforment en mouchetures.

Elle est complétement jaune en dessous. Toutes ses écailles sont lisses. C'est le plus grand des reptiles du pays; il mesure un mètre quarante à deux mètres, of sa queue forme au moins le tiers de la longueur totale.

Ceite belle coulcure, si abondante dans certaines parties de la France qu’elle poric le nom de couleure commune, n’a pas été prise dans la Loire-Inféricure. Elle ne commence à se montrer un'en Vendée et surtunt dais la Plaine et dans le Marais méridional.

La coulente gluzcö̈de die Mil. Millet, Mauduyt et Delalande est la verte ef jaune dans sa livrée de jeune àge; en observani les zaménis depuis leur sortie de l'uuf, et en les comparant avee les couleuvres glaucoïdes de Delalande, Nili. Duméril sont arrivés à le démontrer. 
Ces jeunes serpents ont le corjs sans taches, cendré-bleniitre en dessus, avec écailles ombrées, et sont blanchâtres en dessous. Leur tìte est bleuâtre en arrière, plus pâle en avant, et marquée de lignes irrégulières et de taches blanches entourées de noir foncé.

La verte et jaune est un animal farouche et très-grand chasseur. Le crépuscule n'arrête pas ses courses el toute proie lui est bonne; elle dévore même les autres serpents.

Elle se défend avec courage et mord de manière à faire làcher prise à qui veut la saisir. On cite cependant des cas curicux d'apprivoisement de ce sauvage reptile, qui montre alors le plus grand attachement pour son maitre. M. Mauduyt (Erpétologie de la Vienne, page 27), dit avoir vu une couleuvre verte et jaune qui reconnaissait la voix de son maitre, le suivait partout et se montrait sensible à ses caresses.

Mours des couleurres. - Les couleuvres, comme tous les serpents, ne se nourrissent que de proies vivantes qu'elles font passer dans leur estomac sans les diviser. Elles peuvent, tant leurs mâchoires sont dilatables, ingurgiter ainsi des animaux plus gros qu'elles. Elles sont alors embarrassées dans leur marche et ont peine à rejoindre leur repaire pour y digérer en paix. A la vue d'un danger, elles rejettent leur proie pour s'alléger, et si l'animal avalé est une grenouille ou un crapaud, on le voit s'enfuir, tout meurtri, pendant que l'on poursuil la couleuvre. Les batraciens anoures offrent, en effet, une persistance incroyable de la vie dans un milieu confiné. Voici deux exemples choisis entre beaucoup d'autres, et qui prouvent qu'on peut extraire ces animaux encore vivants de l'estomac d'une couleuvre.

Le 4. avril 1861, MII. Henri et Émile Talvande rencontrèrent à la Madeleine, en Carquefou, dans un champ ensemencé, une couleuvre à collier, qui, gênée dans ses mouvements par le vo. 
lume de son ventre? faisait de vaing efhrits pour se défendre de leur chien. Deux conpes de pistulet à bout portant lui ayant déchiré les llanes, il cin sorill un epapaud commun assez volumineux, qui resta diburd inmobile, puis lout à coup remua une patte, coassa légèrement et se sauva.

Dans les lank's de Gunh s1. (41 1811, M. Baranger avait été

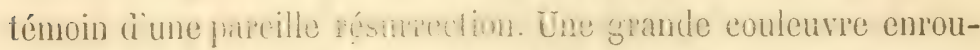
lée dans un buisson el paratranh endorinie, se laissa prendre sans résistance par les ćleics de la Ducherais. Joléc dans une mare pour ère noyée, elle san retim quoiple nageant avec diffienlté à cause du volune de sun rentre. Les enfants, ect ìge est sans pitic, rublan en linir arec etle, ia stispendirent à un arbre et la tuèrent à coups de pierres. Ils trouvèrent dans

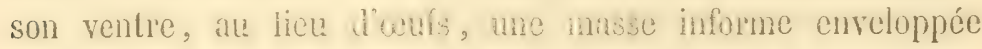
d'un liquide gluani qui la rendait nnécomnaissable. Celte masse, sous l'impression de l'arr, se wit it s'agiter, allonerea une patte, puis une autre, ol bienht, nu milien de l'élonnement général,

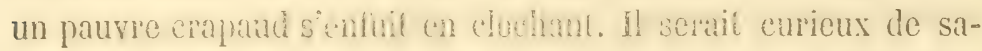
voir combien de tentrs, apres lour introluction dans l'estomac d'un serpent, les gyronouillesul les crapandis conservent la faculté de revenir it la vie, ef juapuir quel point ils be ressentent, plus tard, de ce commencement de digestion.

M. A. Duméril (1) a vu au Duséun. une conleurre repte et jaune avaler glontonneneni une conenwe lisise. La lisse, a force de renuer dans l'estumic de ann emmini, lni secasionna une indigestion mortelle et fut régurgitée vivante.

(1) Nous sommes heureux d'olfrir ici à notre excellent maitre, M. le prolesseur Auguste Duméril, l'hommage de notre gratitude. Il nous a dans ce travail aidé de ses conseils et a mis spontanément à notre disposition de rares ourrages d'erpétologie qu'il nous eût été ímpossible de nous procurer en provinee. 
Les couleuves en eaptivité se plongent avidement dans les vases d'cau ou de lait placés daus leur cage. Elles paraissent s'y baigner avec délices. Mais les auteur's sont loin d'ètre d'accord sur la manière dont elles introduisent des liquides dans leur estomac.

Ayant mis un jeune tropidonote à collier, qui venait de changer d'épiderme, dans un flacon contenant environ vingt grammes d'eau, nous vimes l'animal, altéré par suite de la mue, plonger brusquement la tête dans le liquide. Il le fit disparaitre en quelques secondes par des mouvements rapides d'allongement et de raceoureissement des livres. Jamais nous n'avons vu de serpents boire à la régalade, ni laper lígèrement un liquide avec leur langue à deux pointes. Cette langue bifide, malgré les comparaisons auxquelles elle a donmé lieu, n’est point un double dard servant d'arme aux serpents et ne peut blesser.

Les ophidiens passent pour très-avides de lait; nous n'avons pas remarqué quilis le prélérisient à l'eau. Iaien n’est plus absurde, en tout cas, que lit fable yui a couru le monde et qui veut que les coulcuvres aillent dhus les étables téter les vaches el les chères. Le lait alors se tarirail et aurait une teinte blene tant que la bête qui le fournit servirait de nourrice au serpent.

Le lait bleu doit sa coloratiun à des myriades de ribrio e'yanogenus Fusch. On ignore cncore la cause du développement de ces infusoires, mais certainement les serpents n'y sont pour rien. L'absence de langue charnue, de voile du palais ef d'épiglotte leur rendent la suecion impossible: la vache, du reste, ne supporterait pas la pression de leur's dents recourbées.

On ferait un live aree les cruyanees étrangers et les superstitions qui sont en honneme dars la campagne au sujet du lait et du beurre fournis par les animaux domestiques.

Toutes les coulenvies, lor'squion les force it se défendre, reti- 
rent leur tôte en arrière, sifflent et finissent par blesser. Les pelites plaies que font ces reptiles présentent l'injression des dents des deux màchoires quand ils ont mordu, de la mâchoire supúrieure seulement quand ils ont frappé, comme le fait un serpent venimeux. Dans le premier cas, l'ensemble des petites ćraillures forme deux courbes opposées par leur concavité, et le blessé ressent à la fois un pincement et une déchirure ; dans le second, la sensation de déchirure existe seule et une seule ligne courbe est marquée sur la peau.

La morsure de ces reptiles est toujours une plaie simple. Un chien, cependant, s'étant jeté sur un amas de couleuvres, en fut horriblement morilu à la tète et au cou. Ses plaies parurent s'enveniner el il resta longtemps malade. La multiplicité des blessures suffit ici pour expliquer la lenteur de la guérison.

L.es couleurres, quand elles ont peur, répandent un liquide doué d'une odeur alliacée et particulièrement désagréable chez quelques esperees. Il est sécrété par des glandes spéciales situées près de l'anus.

Cé liquide ne peut itre assimilé au venin cutané des crapauds et des salamandres. Il produit cependant un peu d'irritation sur les parties dépouillées de leur épiderme.

La sécrition glaireuse qui accompagne la ponte des couleuvres occasionne elle-même de légers accidents.

Des enfants aỹant ramassé des ceufs de serpents, et les ayant écrasés, curcut une inflammation assez vive des mains, mais le gonflement érésipélateux ne dépassa pas les avant-bras et n’eut pas de suite.

Les serpents du pays changent de peau au printemps, quand ils sntent de leur hivernage. Vere exeunte, exumt cxucius, dit Linnxus. Ils muent au moins une seconde fois dans le cours de l'été et avant de rentrer dans leur engourdissement. Aussi les 
poëtes ont-ils fait du serpent l'emblème de l'éternelle jeunesse.

La mue est un moment de crise; le serpent devient malade et engourdi; une sécrétion séreuse suinte sous le vieil épiderme qu'elle soulève et le reptile se frotte alor's la tète contre les corps durs qu'il trouve à sa portée. Dès qu'il a pratiqué un trou dans son enveloppe, il en sort en entier pendant que le fourreau épidermique se retourne en arrière comme un doigt de gant.

A la fin de l'été, les couleuvres vertes et jaunes font entendre des sifflements, et s'agitent beaucoup sans que l'on connaisse jusqu'ici la cause de ces manœuvres.

On ignore aussi la raison qui souvent réunit des serpents de diverses espèces, en quantité énorme sur le même point. C'est d'habitude vers le mois de septembre, et lorscu'ils se préparent à se retirer dans des cavités communes qu'ils se rencontrent ainsi agglomérés sur le talus d'un terrier ou dans tout autre endroit bien exposé au soleil. Ils sont alors tellement mêlés et entrelacés, que l'on ne distingue plus que des tètes et des queues.

Le 17 septembre 18309 , M. Louis Viau était à la chasse près du IIallay, commune de la Haie-Founssière, lorsug'il vit, sur l'épaulement d'un fossé, un amas considérable de serpents de couleur et d'aspect différents. Il l'évalue à un volume de trente décimètres cubes. La plupart de ces animaux lui parurent des couleures; mais quelques-uns, par leur livrée et la forme de leur tête, lui semblèrent être des vipères. Il empêcha son chien de se jeter sur' le tas de reptiles, et considíra pendant sept it huit minutes cette masse horrible et grouillante, qui ne se dissipa qu'en partie of len. tement dans toules les directions. Il dut se retirer ì cause de son chien qu'il ne pouvait plus retenir. Il lit signe à deux autres chasseurs, qui furent pareillement forcés de veiller su! leurs chiens el virent les derniers serpents se disperser. Un fraysan dit 
à II. Viau : "qu'il conmaissait parfitement ee parquet de mauvaises bûtes, et que, lo voyant grossir ehaque jour, il te surveillait, avec quelques roisins, espórant tuer toute cette rermine en une seule fois."

On rencontre aussi parfois des serpents en grand nombre vers le mois de mai lorsqu'ils se recheruent pour' s'accoupler. Ils se livrent même de véritables enmbals quand ils sont à la poursuite d'une même femelle. A Châtenu-Thébaud, nous écrit M. F. Renou, deux femmes, dont l'une, la veuve Bouillé, vit encore, descendaient vers la troine aux premicrs jour's de mai. Elles suivaient un chemin creux et ombragé, bordé de chaque côté de prés en pente et renant du pont de Bu-Abord. Eilles se trouvèrent là tout à coup cntouríes d'une légrion de serpents arrivant de tous chités pour se réunir ì un groupe principal qui, en colonne serrée, précipitait sa course vers la rivière. Ces animaux paraissaient tous mus par un même sentiment instinetif, et ne firent pas attention aux deux femmes; celles-ci, effrayées, crurent prudent de revenir sur leurs pas.

Les couleuvres passent la saisnn froile dans des cavités sèches où elles se tiennent d'orlinaire plusieurs ensemble afin de conserver leur pen de chalenr. On les rencontre l'hiver dans des trous creusés en terre, sous fles pierres, des racines d'arbre, ou sous la mousse. Eilles en sortent aux premiers rayons du soleil printanier.

Loin de fuir l'habilation de l'homme pour hiverner ou déposer leurs coufs, ces hites frileuses recherchent les fumiers des poulaillers et des étabires, à rause de la chaleur rqu’y développe la fermentation putride w des insectes quion y rencontre. On les a même trouvées dans des fermes, nichées sous la pierre du foyer, et efles envahisemt les abords de certaines proprićtés rurales au point d'ètre un viritable flíau. Nous extrayons, comme 
exemple, les lignes qui siriment d"un rapunt adressé, en 1860 , par M. Duret, maire de Bussway, ì M. le préfet de la LoireInférieure; les fiats nous ont anssi ché rapportés par M. l'ablé Briand, vicaire de cette commune :

"En aout 18.is, à la Clémencire, métairie récemment construite dans la partic marécageuse de Boussay, on trouva dans la maison un nombre prodigicux de serpents, rôdant partout, sifflant dans les murailles, se suspendant au-dessus des portes. Une femme put en tuer huit dans un jour. A force d'attention, on s'aperegut qu'ils sortaient de dessous, la pierre du foyer. Des fouilles y firent découvar me quantité si proligieuse d'œufs, qu'un double décalitre n’oui pas sufli ì les contenir, et quinze cents serpents de toute grandeur. Ces animaux, du reste, n'avaient donné lieu à aucun accident. »

Une lettre de M. Horel, curi de Boussay, nous apprend que les serpents ont reparu il la Clémencière, prescue aussi nombreux qu'autrefois, mais toujums inoffensifs. Celte ferme est isolée, au milieu dlune Innle à peine défrichée, et avoisine un ćtang qui, par défaut d'cntretien, est dexenu un marais boueux et plein de grandes herbes.

Un fait presigue idtonlinue nous a été mpporté de Torfou; les couleurres araime élu donicile el dóposé leur's nufs dans une chambre servant de poulaillor. Il surat facile de multiplier

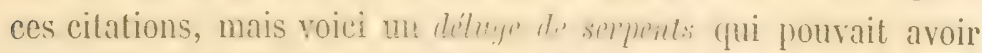
des conséquences autrement frave:s, puisque des vipères se trouvaient parmi les envahisseurs.

Au milicu des runes du chiteau do Vioreau, dans la forèt de ce nom, commun do Jonti-sur-Erdre, so frnuve une forme bitie

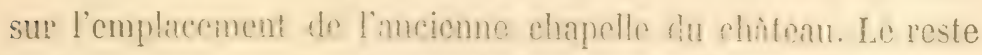
des ruine: ne ronciste plug quon um amas informe de pierres,

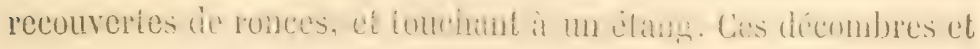


ces broussailles, voisines de l'eau, offraient des conditions si favorables aux serpents que couleuvres et vipères s'y multiplièrent d'une étrange façon. On trouvait partout des serpents dans la maison du fermier. Ils se glissaient dans les lits, dans les pots de lait et au fond des ustensiles de cuisine, si bien que, quoique personne n'eût été blessé, la situation était devenue intolérable. Il fallut, pour détruire de pareils parasites, couper les broussailles, déblayer le terrain de fond en comble et le transformer en champ ensemencé (M. l'abbé Lahue).

Aux environs de Luçon existait naguère, nous dit le docteur Lepeltier, une maison appelée "la maison des serpents ". Là, l'homme avait dû céder à l'envahissement de la gent rampante, et, pendant trente ans, cette maisonnette est restée inhabitée. Elle vient enfin de trouver un acquéreur qui l'a abattue et qui a mis le terrain en culture, faute de meilleur moyen de se débarrasser des reptiles.

On ne peut parler des couleuvres sans dire un mot des cocatris, ou ceufs de coq, et de la fable populaire qui les conreme. Cette fable se rattache à celle du basilic ou regulus, et est un reflet des croyances de l'Orient répandues dans toute l'Europe par les Zingari ou bohémiens errants, passés maitres en sciences occultes.

Les singuliers corps appelés cocatris, sont regardés par les paysans comme le résultat de l'accouplement d'un serpent et l'une poule, où d'un vieux coq et d'une couleuvre. Ils renferment, dit le peuple, un petit serpent fascinateur dont le regard seul cause la mort et qui est tué par son propre charme, quand on peut le forcer à se voir dans une ghlace polie. Chacun connầ à ce sujet la zracieuse légende à laquelle Nontmirail doit son nom. Le cultivateur du Bocage, yui trouve un coeatris dans sa basse-cour, se sisne et l'écrase du pied, de peur qu'il ne soil couvé par un chat: 
condition nécessaire pour qu'un basilic vienne au monde. Quand une poule a pondu un de ces mufs hardés, son instinct semble lui dire qu'elle n'a pas donné le jour à un être capable de vivre. Son chant, el ici ce n'est plus de la légende mais de l'histoire, prend un caractère tout particulier et se rapproche de celui du coq. On dit qu'elle est jalie et qu'elle chante le juu. (Le mot jau, en patois poitevin, est synonyme de coq.) Cette poule maudite est sacrifiée.

Un cocatris, qui nous fut remis par M. J. Vandier, se brisa dans nos mains, mais sans laisser sortir ni serpent ni vitellus de poulet. Long de huit centimètres, il était cylindrique et renflé aux deux bouts. Sous une première coque calcaire, il présentait une enveloppe membraneuse et de l'albumine, puis venaient une se. conde enveloppe calcaire, une seconde membrane et un contenu albumineux. Un corps albumineux, probablement un faux germe descendant dans l'oviducte de la pouie, s'était enveloppé d'albumine, d'abord liquide, puis condensée en membrane, et même d'une couche calcaire. Cet ouf. sans jaune, et réduit à ses parties accessoires, trop petit pour nécessiter une expulsion rapide, avait, en descendant lentement dans le conduit, acquis de nouvelles couches semblables aux piemières. La physiologie rend done parfaitement compte de cette anomalie, sans qu'il soit be. soin de recourir au merveilleux. Toute la fable repose sur deux fails: $1^{\circ}$ la présence assez fréquente d'œufs véritables de couleurres dans les poulailler's et leur ressemblance avec les oeufs avortés des poules; 2 la forme grossière d'un petit serpent, que présente le ligament dù à l'union des deux chalazes dans les œufs de poules sans germe.

Il résulte de ce travail que les couleuvres ne sont point dangereuses pour l'homme et comptent au nombre des animaux utiles à l'agriculture, à cause de la srande quantité d'insectes, de 
larves, de lombrics, de limaces, de rongeurs el de passereaux qu'elles détruisent. Il est done absurde de les tuer impitoyablement comme on le fait. Si re n'élaient même la manière dont elles se multiplient el la peur que leur vue oceasionne aux femmes et aux enfants, elles devraient être protégées par des règlements administratifs.

En résumé, les serpents non venimeux qui se reneontrent dans les deux départements de la Loire-Inférieure ct de la Vendée sont au nombre de six :

$1^{\circ}$ L'orvet ou anvin Anguis fragilis L.;

20 La couleuvre d'Esculape, Elaphis Esculapii Dum.;

$3^{0}$ La couleuvre lisse, Coronella levis Dum.;

$4^{0}$ La couleuvre à collier, Tropidonotus Natrix Kuhl.;

50 La couleuvre vipérine, Tropidonotus riperimus Schegel;

Et $6^{\circ}$ la couleure verte el jaune Zumenis riritifunus Wragler.

Il reste maintenant à éludier les deux espèces venimeuses. c'est-à-dire la vipère commune ou aspic, Tiperu Aspi.s. Nerrem, ef la vipère à trois plaques ou péliade, Tiperu Berus Daudin, complétant le nombre des huil serpents indigènes. 
§ I. - Des Vipères et de leurs caractères zoologiques. Classificution des espèces de ripères. - Les vipères sont les seuls serpents dangereux de nos contrées. Elles appartiennent au sous-ordre des solénoglyphes, c'est-à-dire aux ophidiens à crochets antérieurs, canaliculés et fixés sur des os sus-maxillaires mobiles (1). Elles sont courtes, trapues, et leur queue est brus-

(1) C'est aux auteurs de l'Ėrpétologie générale, à C. Duméril surtout, que l'on doit la méthode naturelle de classification des ophidiens. Elle a pour point de depart les différences offertes par leur système dentaire.

Les serpents venimeux s'y trouvent rangés en trois sous-ordres: les solénoglyphes, les protéroglyphes et les opistoglyphes.

Dans les deux derniers, les crochets, au lieu d'un canal interne, ne présentent qu'une rainure superficielle; ils ne sont point isolés comme chez les solénoglyphes, mais bien suivis d'autres dents; l'os sus-maxillaire qui les porte est soudé avec les autres os de la face.

Chez les protéroglyphes, les dents venimeuses sont les plus antérieures. Exemple : le serpent a lunette ou capelle, Nuja trimudiuns, si redouté des Indous.

Chez les opistoglyphes, les erochets sont les dernières et les plus longues dents de la màchoire supérieure. Exemple: le Coplopellis insignitus, des environs de Montpellier. Ces ophidiens, facilement pris pour des couleuvres, ne blessent à venin que lorsqu'ils saisissent à pleines màchoires, et sont peu dangereux pour l'homme. Ils forment la transition entre les 
quement rétrécie. Hétérodermes, elles ont, comme les tropidonotes, le dos et les flancs revêtus de petites écailles imbriquées et carénées, tandis que leur ventre est protégé par de larges lames, et leur queue, par deux rangs d'urostéges.

Leur tête est triangulaire et aplatie, forme due au peu de développement des os sus-maxillaires, et à la saillie postérieure des glandes à venin. Leur pupille est en fente verticale.

Deux vipères existent dans l'ouest de la France: la vipère commune ou aspic, et la vipère à trois plaques ou péliade.

Elles diffèrent l'une de l'autre non-seulement par la forme de leur museau, mais encore par l'écaillure de leur tête. En effet, tandis que l'aspic, comme tontes les autres espèces du genre Vipera, a la tête entièrement recouverte de petites écailles, le péliade porte entre les yeux trois larges plaques dites écussons, analogues à celles qui ornent, la tête des couleuvres.

Les erpétologistes s'accordent, en général, pour placer dans des genres différents les ophidiens, suivant que leur tête est ou non revêtue de plaques. Aussi Merrem, dans son Tentamen systemalis amphibiorum, sépare-t-il la vipère à trois plaques des autres, sous le nom zénérique de Pelias. M. Nauduyt, dans son Erpétoloyie de la Vienne, s'appuyant sur le mème principe, a créé pour cette même vipère le genre Echidnoïdes.

groupes précédents et le sous-ordre des aglyphodontes, dont toutes les dents sont lisses.

Les solénoglyphes se subdivisent en deux familles : les vipériens, à narines simples (vipères, échidnées, cérastes, échis et acanthophides), et les crotaliens, à narines doubles, c'est-à-dire offrant entre la narine et l'oeil une petite ouverture, dite fausse narine ou fossette lacrymale ì usages inconnus. Les crotaliens sont les plus redoutables de tous les serpents. Exemples: les crotales ou serpents it sonnettes, les bothrops ou ler-delance, le lachésis ou surucucu, ete. 
Le prince Chirles Bonaparte (Iconografü della Funnu italica) a adopté le genre Pelias de Merrem. Les auteur's de l'Erpétologie générale ont aussi suivi cet exemple, mais non sans hésitation (Voir Erp. gén., t. VII, pp. 1393 et 1414).

Schlegel, au contraire, ne trouve pas les caractères qui distinguent les vipères indigènes assez fixes ni assez constants pour permettre de les séparer, et il les réunit dans une seule espèce sous le nom de Vipera Berus.

Cet auteur est allé trop loin; le péliade et l'aspic sont deux espèces distinctes; mais nous croyons qu'ils appartiennent au même genre. Leur squelette n'offre point de différences notables et la présence des plaques n'a pas l'importance capitale que lui attribue Merrem.

M. Léon Soubeiran, dans sa thèse inaugurale (de la Vipère, de son venin et de sa morsure. Paris, 1855), et dans son Rapport sur les vipieres de France, lu à la Société d'acelimatation le 17 juillet 1863 (1), a aussi réuni toutes les vipères françaises en un seul genre.

M. Jan, si bon guide en erpétologie, ne conserve, dans sa grande Iconographie des Ophidiens, le mot Pelias, que pour représenter un groupe du genre Vipera.

Voici donc quels sont les caractères du genre Vipera, tel que nous le comprenons:

Solénoglyphes à tête déprimée, élargie en arrière, entièrement revêtue de petites écailles, plus rarement offrant au milieu de ces écailles trois plaques syncipitales. Narines à orifices latéraux simples, larges et concaves. Urostéges sur deux rangs.

(1) Parmi les naturalistes qui envoyèrent, à cette époque, des documents sur les vipères à la Société d’acclimatation, M. Soubeiran cite M. Brierre, receveur des douanes a Saint-Hılaire de Riez (Vendée), II. Iain, avocat au Tablier (Vendée), et M. Alc. Thomas, naturaliste à Nantes. 
Le tableau suivant résume les principaux caractères des trois vipères européennes.

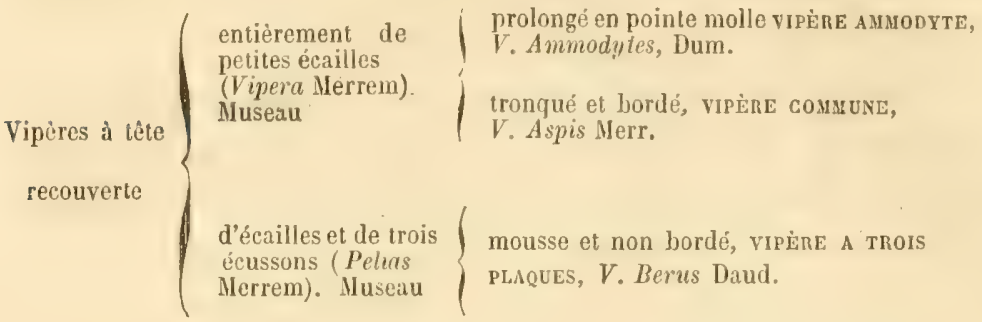

L'ammodyle n'existe ni en Bretagne, ni en Vendée. C'est mêne à tort, suivant nous, que ce reptile du milli de l'Europe est signalé par les̉ auteurs dans le sud-est de la France.

La VIPÈre COMNUNe oU ASPIC, $V i$ pera Aspis Merrem, V. communis Millet, Mauduyt, V. Berus Delalande non aliorum (fig. 7 et 10), a la tête trian.

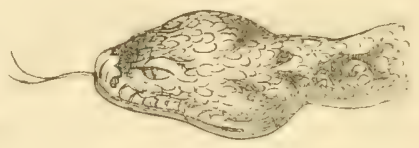

Fig. 7. gulaire et un peu en cœur en arrière. Son museau, termıné par une plaque trapézoïdale, est fortement retroussé. Le rebord saillant qu'il présente se prolonge jusqu'aux yeux et rend un peu concave le dessus de la tête, qui est couvert de petites écailles. Celles-ci sont allongées, carénées et imbriquées sur la partie postérieure du crâne, tandis qu’à la partie antérieure de la tête elles sont arrondies et ressemblent à des granulations.

Deux ou plusieur's rangées de petites écailles se trouvent entre l'œil et les plaques qui forment la lèvre supérieure. Un cou étroit sépare la tête du corps, qui est légèrement renflé à sa partic moyenne:

La vipère commune n'alteint jamais une grande longueur ef 
ne dépasse pas 70 centimc̀tres. Un fort individu mesure ordinairement 62 centimètres, dont 8 de queue.

Les aspies offrent une grande diversité dans la couleur générale de leur robe et dans la manière dont ils sont tachetés.

La coloration de leurs parties supérieures varie du verdâtre, du noiràtre et du gris cendré au jaunâtre, au fauve et au rouge brique, teintes sur lesquelles les taches tranchent par leurs tons plus foncés; celles-ci sont noires ou brunes et si diversement disposées, qu'il n’y a pas deux aspics tout à fait semblables.

Sur la tête, ces taches imitent des lettres, et sont dites hiéroglyphliques. Il est impossible de décrire toutes leurs variétés de configuration, d’autant plus que, vers l'extrémité du museau, il en existe souvent de supplémentaires. Les principales sont formées par deux croissants opposés par leur convexité; lor'squ’ils se touchent, ils donnent lieu à un $\mathrm{X}$; quand, au contraire, ils sont un peu écartés, ils ressemblent à deux $\mathrm{C}$ ou à deux J, l'une des lettres étant renversée. Le plus souvent les branches antérieures de l'X font défaut, et les vipères portent sur la tête la première lettre de leur nom, un V ouvert en arrière. Dans certains cas, on ne voit que deux ou quatre petits traits convergents, l’angle antérieur du V ou le milieı de l'X ayant disparu. Enfin, la tête peut être dépourvue de taches.

Après le V commence sur la muque, au niveau du rétrécissement qui unit la tête à l'échine, la ligne bi'isée dite le zigzay dorsal; elle se prolonge jusqu'à l'extrémité de la queue et se compose d'une suite continue de losanges. Cette ligne est eependant quelquefois interrompue; chaque losange s'arrondit alor's sur ses angles.

Le tatouage des parlies latérales dérive derrière l'oil d'une tache linéaire el horizontale, la bunte post-oculuire, qui est continue chez l'aspic et interrompue chez le péliade. Toutefois, ce caractère différentiel n'est pas assez constant pour distinguer, 
à lui seul, ces deux animaux; car la disposition inver'se s'observe et nous avons trouvé aussi, chez le même individu, la tache post-oculaire continue d'un côté ct interrompue de l'autre. Derrière la bande de l'œil commence Ta série des taches latérules dont chacune correspond à un angle rentrant de la ligne brisée du dos. Les lèvres des aspics sont blanches, grises ou roses; quand elles présentent des macules, celles-ci sont noirâtres et angulaires.

Les teintes du ventre varient presque autant que celles des parties supérieures; les plus communes sont le gris d'acier et le noir. Elles vont en se dégradant vers les extrémités, surtout sous la gorge, qui est blanchâtre ou rosée. Les gastrostéges offrent aussi sur leurs bords, et à leur jonction avec les écailles, une coloration plus faible; telle est l'origine de la série de petites taches d'un ton gris, rose ou paille, qui se remarquent souvent sur les côtés du ventre.

Les teintes roses des parties inférieures se voient surtout chez le mâle pendant la saison des amours.

La vipère commune a des races locales; ainsi une vipère des Alpes ou des Pyrénées, est, à première vue, distincte d'une vipère de la Vendée ou des Deux-Sèvres. Cependant, quand on étudie les variétés que l'on a essayé d'établir, on voit que ni la coloration, ni la disposition des écailles ne fournissent de caractères constants, et qu'entre les formes qui servent de types il y a une série d'intermédiaires. Nos paysans et nos chasseurs se bornent à diviser les vipères en rouges, en grises, et en noires, réservant pour les premières le nom d'aspic, et appelant les grises du nom de vipère (au masculin). Les rouges sont, à tort ou à raison, réputées plus dangereuses que les grises. Elles sont les plus nombreuses à Frossay, à Vue, et dans les communes voisines, tandis qu'elles sont rares à Challans. Ailleurs on les trouve vivant de 
compannie, et presque aussi nombreuses les unes que les autres.

Les noires passent pour avoir une malignité de venin encore plus grande, mais rien n’est moins prouvé. Elles sont, du reste, extrèmement rares; la plupart des serpents venimeux, à couleur très-foncée, que nos paysans disent aimer les lieux frais et humides, sont des péliades.

Les erpétologistes ont, d'après la coloration et la disposition des taches, subdivisé les vipères communes en einq groupes. La variété $a$, type du $\mathrm{V}$. Aspic, porte, sur une robe rougeàtre, orangée ou d'un brun foncé, un zigzag à losanges séparés. La variété $b, V$. Cherséa (I), a la mème teinte générale, mais sa ligne dorsale est continue. Les variétés $c$ et $d$ sont grises : la première V. Redii, présente un zigzag continu: la seconde, des losanges séparés : celle-ci se nomme $r$. occllata, Inrsque ses taches arrondies sont plus noires à leur circonférence qu’à leur centre. La variété $e, V$. Proster, est noire ou de couleur tellement foncée que ses taches ne se distinguent plus. Il existe une sixième variété $f$, non décrite dans les auteurs et que nous appellerons V. Delulundei. Elle est l'opposé du I. Prester qui est le mélanisme du serpent, car elle en est l'alhinisme ou la décoloration. Nous ne l'avons observée que chez des animaux de grandes dimensions, à crochets formidables et à tête offrant un rebord nasal et des granulations syncipitales très-prononcés, e’est-à-dire chez de vicux individus, et nous la décrivons d'après un serpent pris aux environs de Nantes, par l'abbé Delalande. La robe de cette vipère est gris cendré clair et

(1) La synonymie des deux espèces de vipères, dans les auteurs, est impossible à débrouiller. Le prince $\mathrm{C}$. Bonaparte a dépensé à ce travail beaucoup d'érudition, sans être arrivé à un résultat satisfaisant. Les mots Chersea et Prcester sont aussi souvent attribués à des péliades qu'à des aspics. 
sa tête ne porte point de átehes; le zigzag dor'sal est remplacé par deux séries de points noirs correspontant par leur position aux extrémilés des losanges qui derraient théoriquement exister; le trait post-oculaire est prespine efincé el ne dépasse pas la saillie de la tête; les laches latérales n'existent point; le ventre blanclıâtre est marbré de gris clair.

Les aspics qui vivent au nord de la Loire ont entre les yeux une écaille plus dévelopréce que les autres simulant un petit écusson. Celte disposition esi représentée dans la planche 79 bis, fig. 3 do l'Erpritoloyie gímírule domnce conme type de la vipère commune. Delalande, frappé de ce caraclire qu il avait observé sur des aspies, au buis de la Grunais, considérait les vipères à plaque intor-oculaire comine formant tmo espèce notivelle qu'il désignail d'apres Latreille, sous le min de Tinera Chersea (1). Le docteur Le Ray, de Blain, dans le raprort qu’il a adressé en 1860 à la préfecture de la Loire-Inférieure (2), appelle la

(1) Procès-verbaux de la section des sciences naturelles de la Société académique de la Loire-Inférieure, 19 mai 1851. Ces procès-verbaux contien-

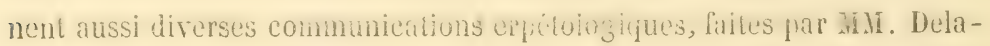
lande, Alc. Thomas, Pradal, A. de l'Isle, Rautou et autres membres de la même Société.

(2) Nous devons à l'extrême obligeance de MI. le baron de Girardot, secrétaire général de la préfecture de la Loire-Inférieure, la communication de ce rapport et de tous ceux qui lui furent envoyés à la suite de l'enquête ouverte par lui sur les vipères, au mois de juin 1860.

Voici les questions principales qu'il avait posées aux médecins, vétérinaires et naturalistes du département:

$1^{\circ}$ Existe-t-il un grand nombre de vipères dans votre commune?

$2^{\circ}$ Quelles espèces et quelles variétés y rencontre-t-on?

$3^{\circ} \mathrm{Y}$ trouve-t-on le péliade ou vipère à trois plaques?

40 Avez-vous observé des morsures de vipères sur l'homme et sur les animaux domestiques? 
même variété d’aspic 1 . Mhnnirnsis. La cherséc de Delalande ne peut être séprés, comme espiece, de la riprie commune dont elle a les caractires. Sun prónda écusson n’est jamais considé-

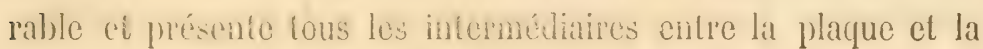
simple granulation.

Laspic est un dos mpnitus les phus commung de nos contrées.

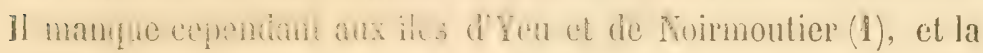
difliculie aree laquello il traverse des bras theau un peu considé-

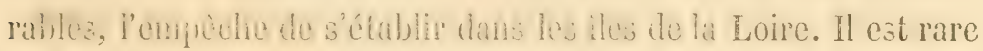
dans la blane, wi peu de terwins reztent sans culture, plus rare encore dans le Narais, entrecoupé de nombreux canaux. Les

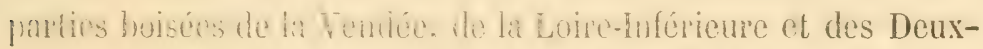

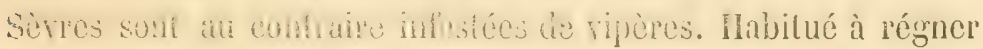
cn inaitre dhns les hallius du Buage, l'aspic y devient moins timide et plus dangercux que partout ailleurs.

Au nord de la Loire, il est la seule vipère que l'on rencontre dans les cantons de Nantes, de la Chapelle-sur-Erdre, de Carquefou, de Ligné, d'Ancenis, et en particulier dans les bois de

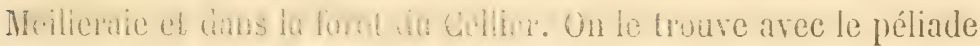

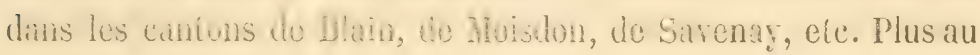

5० Quel est le traitement qui paraît avoir le micux réussi? Les blessés s'adressent-ils aux hommes de l'art ou à des empiriques?

$6^{\circ}$ Quels sont les destructcurs naturels des vipères?

70 Les accidents sont-ils assez nombreux et assez graves pour nécessiter des mesures administratives?

Suivait un tableau à remplir avec les observations des cas de piquûres.

Que M. le baron de Girardot veuille agréer nos remerciments respectueux pour la bienveillance dont il nous a honoré, et pour les nombreux encouragements qu'il nous a donnés dans le cours de ce travail.

(1) La ragè est, coïncidence singulière, inconnue à lîile d'Yeu et à Noirmoutiel' 
monl. it hougé, far uxemple, lautre vipire le remplace complétement.

Les playsans de la rive droite du fleuve disent que les ripères fuient la mer. Cela est vrai au nord de la Loire, à cause des marais salants aqui bordent la côte. Sur la rive gauche, au contraire, les aspies, à la chasse des rats et des mulots, se hasardent sur les falaises et même parmi les galets laissés à sec par la mer.

On peut juger par les chiffres suivants combien sont encore nombreuses de nos jours ces honnes ripères du Poitou dont la renonmée s'étendait jusyu’à Tenise, où elles s'exportaient comme médicaments.

NII. Barreau et Lecrac, pharmaciens à Challans, ont expédié à Paris, pour un fabricant de remèdes secrets, plusieurs milliers de vipères-aspics; depuis cetle époque, les vipères sont moins communes aux environs de cette ville.

II. de Níri du Rozet, conseiller de préfecture de la Loire-Inférieure, et II. Ruérin, instituteur, nous ont donné des détails curieux sur une chasseuse de vipères, demeurant à Faye-l'Abbesse (Deux-Sirres), et appelée la femme Moreau. M. Guérin est en rapports jourialiers avec elle, car cest à lui que doivent être apportéce les têtes de vipères pour lesquelles la prime de 80 c. est réclamée.

Depuis le 1:3 mars is6:3, la femme Horeau, année moyenne, a

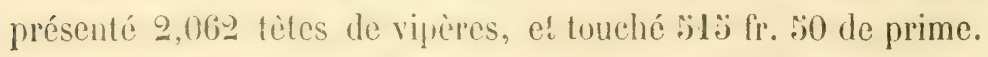
La rencontre d'une bìte pleine est pour elle tne bonne aubaine; les tètes de vipereaux comptent, en effet, comme les autres. Un bâton pour arriter le reptile, une petite pelle pour le décapiter, et un pot pour recevoir la tète, tels sont les engins de chasse de cette femme, qui, grâce à cette industrie, est sortie deala misère. Elle se plaint maintenant que les vipères deviennent rares et qu'il 
faut aller les chercher au loin, ce qui rend son métier moins lucratif.

La Côte-d'Or ne le cède en rien, au point de vue de l'abondance des serpents venimeux, à lat Vendée et au reste du Poituu: les chiffres qui suivent en font foi.

Dans sa séance du 26 août $186 \%$, le Conseil général de Dijon a constaté que le crédit de 7,900 franes qu'il avait allouí pour la destruction des animaux nuisibles a été insuffisant en 1861; les primes pour 26,161 vipères (à 30 centimes par tête) se sont élevées à 7,848 fr. 50 c. et celles pour la destruction de 70 loups à $963 \mathrm{fr}$.; total, $8,811 \mathrm{fr}$. อั0 c.

La vipère a trois plaques oll péliade, Viper Berus Daudin, Cuvier, etc., Pelias Berus Merrem, Vipera trilamina Millet, Delalande, Echidnoüles trilamina Mauduyt, petite vipère, vipère commune du Nord (fig. 8), a la tête cordiforme, quoique moins triangulaire que celle de l'aspic. Son museau, terminé par une large plaque trapézoïdale, n’est ni retroussé ni bordé.

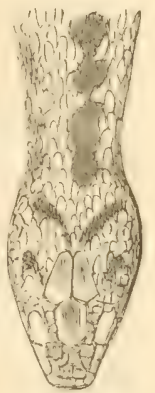

Fig. 8 .

Au milieu des petites écailles dont sa tète est revètue, se voit entre les yeux un groupe de trois plaques polygonales, lisses et rapprochées en triangle: l'antéricure ou impaire est la plus large.

Cette écaillure offre quelques légères différences suivant les individus. C. Bonaparte altribuait beancoup d'importance à la disposition symétrique ou irrégulière des granulations qui sont au-devant des plaques et avait divisé le guenre Pelirs, d'après

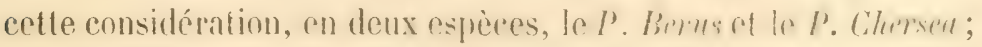
ces caractères n’ont pas plus de valeur une la préserec ou l'ahsence d'un écusson central, chez la vipère-aspic. 


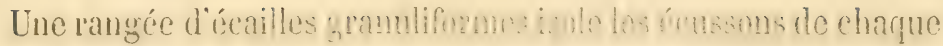
plaque sourciliere; mais clle peut manugue?: lo sommet to la tite

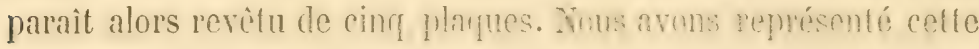
disposition dans un prócílent travai! su! los serpents indi-

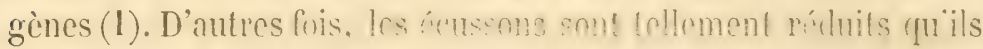

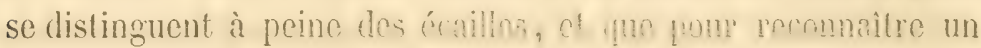
péliade, il faut recourir à d'autres caractères.

Certaines dispositions de l'x aillure snni do vírilables anmma-

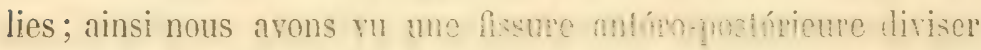
inégalement en deux l'úcnseon contml. Unz des wiprems plises

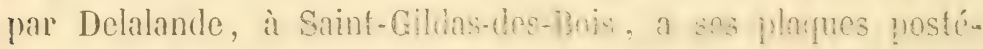
rieures dédoublées transversalement: luez une aulre, wne pelite

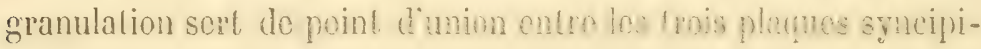
tales.

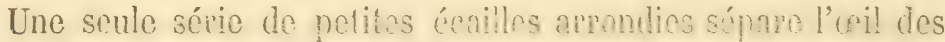

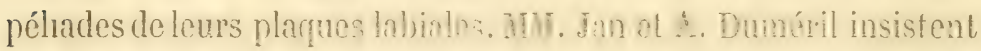
sur la valeur do ce cametire mour distingmer, dans los cas difficiles, nos deux serpents dangereux.

Les vipères à trois flargues attrignent arament les dimensions de la vipere commune, mais lour quene est relatirement un peu plus longue; ainsi un fort pélinde de :36 centimstres de long a 8 centimètres de queue.

Leur livrie a les phis arands mapmets avec colle do l'aspic. Leur robe est grise, vorditie, noime on ronilléc en dessus avee des taches brunes ou noires dons lesumbles on retrouve les hiéroglyphes, le zigzay, la bando post-oculaire ef les taches nirondies des flancs.

La partie antéricure de lihiónglyphe sc présente ordinaire-

(1) Etudes médicales sur les sorpents de la Vendée et de la Loire-Inférieure. Nantes, imprimerie Mellinel, 1860. PI. II, l. 1. 
ment sous forme de larmes taches irmónuliens, parfois réunies en une seule qui s'étend sur' les ícussons. Par derriere, Jo V est incomplet, ou bien s'unit à la tache antricicure de facon ì former un $\mathrm{Y}$, ou à manjeler la lache cordiljime de la coronelle lisse.

Le zigzag nait par une exitrémité conique dans l'échancrure de l'hiéroglyphe. Il est continu, el, dans les variétés grises, bordé d'une sorte de pénombre rougeâtre.

La bande post-oculaire est interrompue; les taches latérales correspondent aux angles rentrants de la ligne du dos.

Les lèvres tachetées de nnir sont hlanches on pousses; la gorne et le dessous de li? quene sont habituellement b]anchàtres avee des macules noires ou brunes.

Li couleur du venlre est différente suivant les variétés. Dans le type à dos gris on verdiure, r. Bripus, var. cineren, il est noir, mais parfois offre de pelites lachns blanches à l'extrémité des gastrostéges; chez les individus entierement noir's et à taches non distinctes, $V$. Berus, var. tartaren (V. Prcester de quelques autcurs), il ést d'un noir presque bleu; dans les variétés rouges ou rouillées, $\mathrm{I}$. Berus, rar. ruhiginnsn, le dessous du corps est roux et taché de brun.

Ces trois variétés de vipères se rencontrent dans nos départements.

Au nord de lin Loire le péliade nous a été signalé à Suint-Gildusdes-Bois! (1) (Delalande), dans la furèt du Grirre! (Delalande), à Blain! (Delalande et Thomes), à Frúmími et à Missillue! (Thomas), à Asserue (Sagot), à Bourron! (Maillard), anx environs de Surerny (Ohcix), à Rougé (ficquiau), dans la foret d'Ancenis,

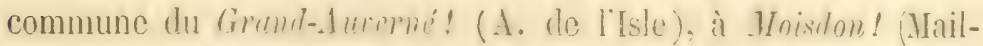

(1) Le signe ! indiçue que nous avons vu des pieliades tui's dans lia loealité dont il suit le nom. 
lard), à Issé! (Dauffy), à la ferme école de Grand-Jouan, commune de Nozay (Decorce).

Le musée des Eudistes de Redon renferme des péliades provenant des environs de celte ville et M. A. de l'Isle en a pris dans la forêt de Teilley. Mi. Millet indique aussi cette vipère comme abondante dans la partie nord du Maine-et-Loire.

Au sud du fleuve, le docteur Bourgeois nous écrit qu'il a rencontré la vipère à trois playues à la Verrie, département de la Vendée, et le docteur Delhoumeau, dans son rapport, dit l'avoir vue à Clisson. La faune de Maine-et-Loire constate sa présence sur plusieurs points de l'arrondissement de Chollet. Elle existe aussi dans les Deux-Sèvres et dans la Vienne.

Les deux vipères du pays se ressemblent au point qu'il est facile de les confondre.

Elles se distinguent, toutefois, par leur museau, par la présence ou l'absence des plaques syncipitales et par quelques autres caracteres de moindre importance, mais qui, dans les cas difficiles, viennent en aide pour déterminer l'espèce du reptile; tels sont la forme de la tète, le rétrécissement plus ou moins marrqué du cou, la disposition de la bande post-oculaire et le nombre des rangées d'écailles séparant l'ceil de la lèvre supérienre (1).

Il n’y a pas grand inconvénient, au point de vue pratique, à

(1) Deux vipères de Faye-l'Abbesse nous ont présenté un museau retroussé avec trois pelites plaques syncipitales; et deux autres de la inême localité offraient un museau mousse et portaient des écailles imbriquées, assez larges, sur toute la tête. Elles avaient, toutes les quatre, plusieurs rangées d'écailles sous l'œil et une bande post-ocular'e non interrompue.

Doit-on les considérer comme des ano:nalies de la vipère commune, ou comme des métis? Quoiqu'elles se rapprochent beaucoup plus de l'aspic que du péliade, certains autres faits nous font pencher vers la seconde opinion. Ce ne serait pas le premier exemple de métis produits par des animaux à l'état sauvage. 
confondre le péliade avec l'aspic, car ils ne valent guère mieux l'un que l'autre. Il est, au contraire, très-important de distinguer une vipère d'un serpent sans venin.

L'orvet ne peut danner lieu à la méprise; il est trop petit, trop diflérent de forme et d'écaillure; sa queue est trop longue par rapport au reste de son corps, et il a trois paupières mobiles.

Les couleuvres sont fréquemment prises pour des vipères, et l'erreur inverse n'est pas moins commune.

Nous avons reçu des coronelles lisses sous le nom de Vipera Berus, et nous avons tué le tropinodote vipérin, le prenant, à première vue, pour un reptile dangereux.

Il existe, lans les belles collections de l'École de Médecine de Nantes, un tropinndote vipérin fort curieux; il est d'une couleur noire uniforme, saul' sous le ventre, où il présente quelques taches blanches. Tué a Orvault (Loire-Inférieure) par notre bien-aimé maìtre M. le professeur Delamarre, il fut, avant l'examein des planques de sa tête, considéré comme un Vipera Prester.

Le péliade a plusieurs fois donné le change à des naturalistes éminents. C’est ainsi que C. Duméril, le premier erpétologiste de notre époque, fut blessé, daus la forèt de Sénart, par une vipère à trois plaques, en croyant saisil une couleuvre vipérine (Erp. gén., t. vir, p. 1399). La science profita de l'accident du savant professeur, et nous ne conuaissons pas d'observation plus intéressante de piøûre envenimée.

L'abbé Delalande faillit, à Saint-Gildas des Bois, être victime d'une parcille mésaventure, à une éporque où le péliade n'était pas encore connu des naturalistes bretons. Notre regretté maitre allail se jeter a pleines mains sur ce reptile nouveau pour lui, quand il fut garanti de sa morsure par le dérouement el la sagacité de san chicn. (Proc-verb. cit., 19 mai 183̈1.)

Le tableau suirant résume les principales différences qui permettent de reconnaitre les vipères des couleuvres. 
CARACTE்RES

DIFFÉRENTIELS. vipìres.

COULEUVRES.

$1^{\circ}$ Forme de la tête. $\left\{\begin{array}{l}\text { Triangulaire, plus large en } \\ \text { arrière, séparée du trone par } \\ \text { un cou rétréci, surtout chez } \\ \text { l'aspic. }\end{array}\right\}$ distinct la séparant du corps.

2o Écaillure.

(Tête couverte, soit entièrement de pelites ćcailles (aspic), soit de petites écailles et de trois plaques en écus-
son (péliade).

$3^{\circ}$ Pupille.

10 Dents.

6. Pelage.
I En fente verticale.

I Ronde.

Une seule entièrement díveIoppée, longue, courhe et mobile, de chaque côté de la mîchoire supérieure.

(Brusquement terminée, formant à peine le sixième de la longueur totale.
Têle couverte de neuf grandes plaques. ricure nombreuses et anilogues à colles de l'autro mikichuire.

Queue plus longuc et moins brusquement terminée.

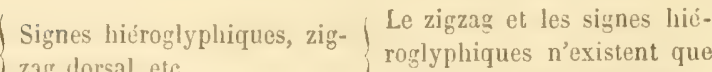
chez la couleuvre vipérine.

De tous ces caractères, ceux tirés des dents ont le plus d'importance, mais ils ne peuvent servir que lor'sque l'animal n'est déjà plus à craindre.

Les plus fugaces pris isolément sont donc ceux qui sont les plus utiles dans la pratique; nous voulons parler de la brièveté

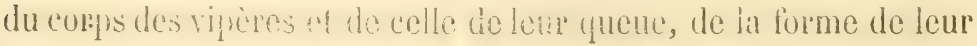
tête, de leur latouage, etc.

La pupille et l'écaillure de la tête sont des signes certains pour distingue! los serpunts venimeux du pays de ceux qui sont inuffensils, mas il ne limdmit pats généraliser celte proposition ot l'appliquer aux serpents étrangers.

Les grandes coulcurres telles que l'élaphe, ou le zamenis. 


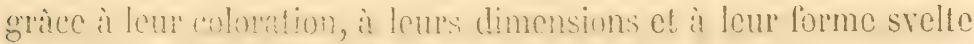
ne peuvent être prises pour des vipères.

La confusion n'est guère permise, non plus, pour le gracieux tropidonote natrix, à cause du collier blanc ou jaune, bordé de noir en arrière, qu’il porte sur le cou.

La coronelle lisse fréquente, comme l'aspic, les lieux secs et pierreux, ct a los teintes des vipires; rlle s'on distingue par ses écail!es lisses et par l’absence de zigzag sur le dos.

Le tropidonote vipérin a, comme les vipères, une bande

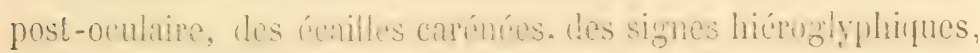
des taches latérales et un zigzag dorsal, mais il présente des macules jaunes sue lans flanes, porte neuf plaques sur lit tete, a la plupille ronde el sa ufueue esi plus allongée (1); c'est un serpent des lieux frais et humides.

La varítú chersuidle śáluigne plus enenre des vipères par ses bandes dorsales de couleur jaune.

Mours. - Le péliade et l'aspic passent la saison froide dans des excarations naturelles, sous des sonches, dans des fagots, dans des trones d'arbres cariés ou sous la mousse. Ils hivernent souvent plusieur's ensemble dans la même cavité.

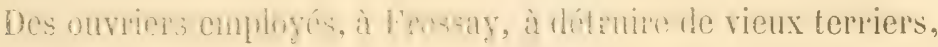
sur la propriété de M. Alfred Pineau, ont tué, cn un seul hiver,

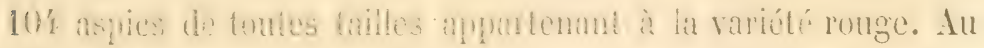

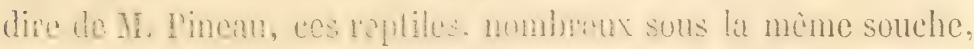

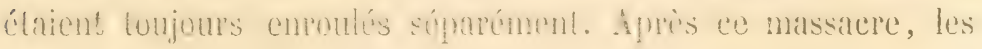

(1) Voici des mesures que nous avons prises nous-mêne sur trois serpents :

Aspic de forte taille: longucur totale, 60 cent. Queve 8 cent.

Péliade,

Vipérine,

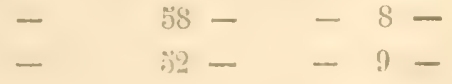


vipères ont presque disparu aux environs de cette propriété, pendant cing ou six ans. Elles y reviennent de nouveau, quoique en moins grand nombre, depuis que plusieurs hectares ont été plantés en châtaigniers.

Les vipères commencent à sortir de leur torpeur au mois de mars; quelques-unes se montrent dès le 10 février. Leur vie d'activité se prolonge jusqu'à la fin d'octobre, dans nos départements, où l'automne est doux et pluvieux.

M. G. Grignon du Moulin rapporta, en 1862, de Baréges, un aspic à livrée assez curieuse et dont il put, pendant trois ans, étudier les mour's dans une cage recouverte d'une glace oblique.

La chambre qu'habitait, à Nantes, M. Grignon du Moulin recevant le soleil à tous les moments de la journée, était toujours chaude. Dans ces conditions exceptionnelles, la vipère n'hiverna point complétement; elle sortait chaque jour de l'amas d'herbe sèche qui lui servait d'abri; et ne resta tout à fait renfermée que par les journées de pluie ou de froid excessif. Elle prévoyait le temps de douze à dix-huit heures à l'avance, car ses sorties se prolongeaient d'autant plus que la température allait être plus élevée.

Après leur hivernage, les vipères changent de peau comme les autres serpents du pays. Elles font une nouvelle mue à la fin de septembre quand elles vont rentrer dans leur retraite. Il en résulte des différences de ton pour le même individu, et le nouvel épiderme dans les variétés grises offre une teinte argentée sur laquelle les taches noires sont encore plus dictinctes.

Dans leurs premières sorties, les vipères s'éloignent peu de leur abri, afin d'y trouver un refuge à la moindre alerte. Chaque jour elles s'en ćcartent davantage, explorant les alentours de leur demeure. Pendant l'été, elles sont moins craintives et la chaleur les rend plus alertes; poussées alors par la laim et le besoin 
de reproduction, elles se hasardent au loin, mais en ayant soin de s'assurer une retraite en cas de danger. Elles sont par là même difficiles à surprendre, quand elles ne sont pas alourdies par une proie avalée ou par l'état de prégnation.

L'orage les surexcite, et, dis que le solcil reparait après la pluie, on les voit sortir de leur repaire et ramper avec rapidité.

Elles se tiennent surtout dans les endroits peu fréquentés, dains les buissons, les friches, les vignes, les champs de genêts, et les taillis. On les rencontre sur la lisicre des bois, dans les clairières qu'ils présentent, et le long des routes ou des sentiers qui les traversent. L'aspic recherche les licux secs, rocailleux, bien exposés au soleil et abrités du vent; le péliade, les endroits boisés et les forêts.

Des coteaux rocailleux, inclinés vers le midi et couverts de ronces ou de jeunes châtaigneraies, sont des lieux redoutés avec raison par les chasseurs, stirtout s'ils sont inclinés vers un ruisseau ou une rivière, car les vipères y foisonnent.

Au moment de la moisson, ces reptiles viennent dans les champs chasser les cailles et autres oiseaux qui déposent leur nichée par terre; l'on trouve sourent à cette époque des vipères cachées dans les gerbes et sous les javelles de blé.

Peu matineuses, elles ne se montrent, au printemps et à l'automne, qu'après la disparition de la rosée, c’est-à-dire rarement avant sept heures et demie à huil heures. La femme Noreau en a tué au contraire dis cinq heures du matin aux mois de juillet et d'août. L'été on les rencontre, en cffet, toute la journée : le matin, elles se chauffent au soleil sur les talus; vers le milieu du jour, elles se tiemnent dans les broussailles. Lor'sque la chaleur devient extrême, elles se réfugient dans les fourrés et descendent même dans les prés bas et sur le bord de l'eau. 
Vers les trois ou muatre heures, elles reprement leurs courses

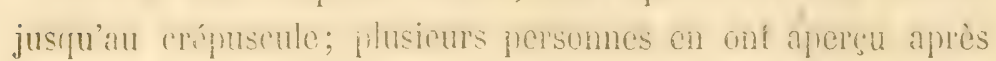
le coucher du soleil.

A la Bouvardière, près des coteaux de la Chósine, une jeune fille faillit à la nuit ètre mordue pror un aspic co croyant ramasser un ruban.

Le docteur houxcau a tué un aspie on sericmbre à segn heures

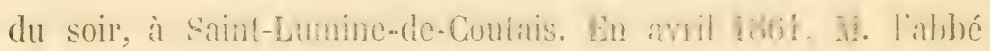
Gicquiau prit également, à Rougé, à sept "houres du soir, un

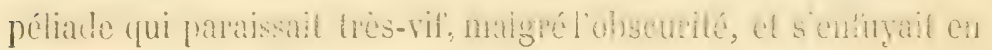
sifflant dans un buisson.

Un homme de Sautron, cité par M. Thomas, fut blessé à la main par une vipere, à neuf heures el denice du soir. M. L. Soli-

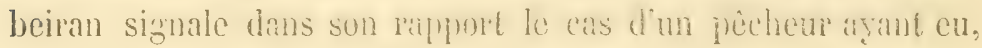
au milieu de la nuit, une pareille mésaventure.

Par une soirée chaude et orageuse du mois d'août 1867 ,

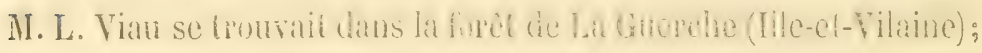

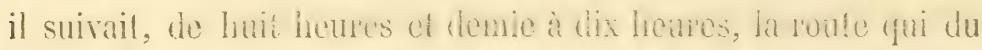

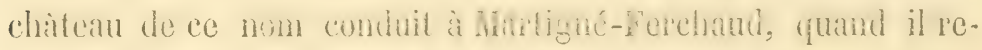
maryua sur la poussidic do liombrenses traces franswersales indiynant le passage de reptilew de divereco dimensions. Comme il savait la forèt pleine de vipères, il se tint sur ses gardes et

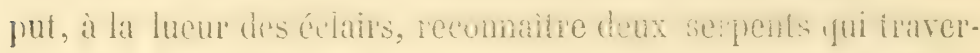

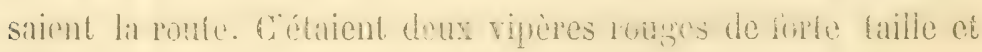
qui se mouvaient avec une extrême rapidité.

Au contraire, dans leurs chasses aux papillons dites à la micl. lée, MM. de l'Isle et Bureau n’ont jamais rencontré, la nuit, d'aspies ni fréliakes. Landis yuiis ont souvent pris des orsels rampant dans l'obscurité.

Les observations de M. Grignon du Moulin tranchent la question des habitudes diurnes ou nocturnes de ces serpents. 
Chargue soir, sa prismniire se retirait dins ses herbos scolies. Elle ne passa hors de son reparre que les nuits les plus chaudes de l'année.

Les vipures ne sortent done, la nuit. que l'ckí, et dans toute autre saison, clles somt des animans diurnes. Si lona: Ireur a domnó une pupille retrecir lour permellant de volr dans l'obscuritr, il les a créres frileuses, el l'abaissment de la tonuéralure les tient prisonnières au gîte.

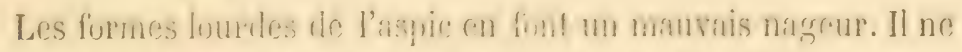

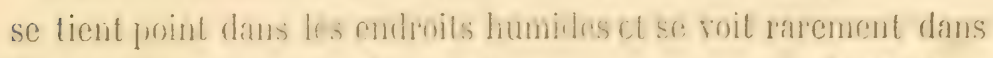

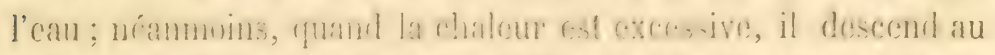
burd les pusscaux. Il ia mème, parait-il, jat les tomps dorage, se nicher dans los foufies de corex on se vaulrep dans les nares. Sous les yeux do M. Thomas, une Wperemaspie cotra dans l'etang

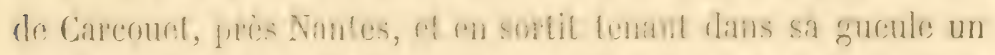

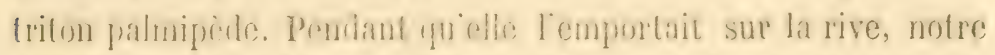
ami lui brisa la colome vertebrals d'un conp de pierre, et le triton s'échappa plein de vie. Pour nous, dans nos courses, nous navons jamais lanuve de vipurs dans l'eau: mais, nous avons

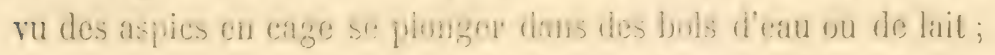
ils paraistient mome, apres le bain, fhus irascibies et plus farouches.

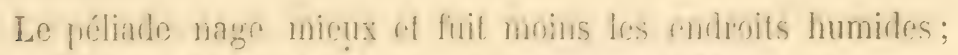

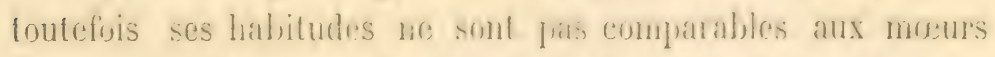

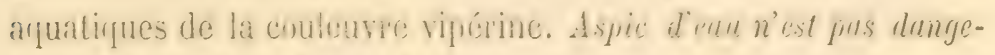
reux, dit un proverbe vendéen.

Les viperes ue grimpent jamin dans les arlores: celles se fiufilont eependant dans les haies turffues, jusquaux nids dont elles dévorent les couvées et vir eiles guettent le retour des oiseaux.

Elles ne pénetrent guire spontanément dans les fermes ct les 
étables, mais elles y sont introduites avec des figots ou des gerbes. Elles peuvent ainsi être transportées jusque dans les villes et y occasionner des accidents.

Au mois d'août dernier, M. Brisset, boulanger à Anger's, rue Toussaint, rentrait des bourrées pour son four. Par malheur, un des fagots renfermait une vipère-aspic, de la variété rouge. Elle blessa un des fils de M. Brisset au moment où il aidait à ramasser le bois. Ce jeune homme, d'une dizaine d'années, piqué à la main, succomba après vingt-quatre heures de souffrance, et malgré les soins qui lui furent prodigués.

Les vipères ne se nourrissent que de proies vivantes. Leur alimentation est assez variée. Elles avalent des animaux beaucoup plus gros qu'elles, et l'on trouve dans leur estomac des souris, des rats, des mulots, des campagnols, des musaraignes et même, dit-on, des taupes. Elles vivent aussi d'orvets, de lézards, et de batraciens. L'aspic et le péliade détruisent un nombre considérable d'oiseaux, surtout de cailles, d'alouettes et de passereaux, et sont friands de jeunes couvées; ils s'atlaquent surtout - à celles dont le nid est près du sol. Faute de mieux, les vipères se rejettent sur les insectes, et leur tube digestif contient souvent des débris de coléoptères.

Rien n'égale leur prudence extrême; aussi la Bible appellet-elle le serpent Callidior cunctis animantibus terre (Gen., chap. III, v. 1). Quoique les vipères perdent en captivité une partie de leurs facultés instinctives, clles sont des hòtes dangereux, et plus d'un expérimentateur a appris à ses dépens la conliance qu'on doit avoir dans la lenteur de leurs nouvements, et dans leur mine trompeuse.

En liberté elles sont toujour's sur leurs gardes et suppléent par la ruse à leur dófaut d'agilite. Elles ne poursuivent pas d'ordinaire leur proie, mais la guettent en vrais brigands. 
Rien de curieux comme leur affût. Le serpent est lové sur luimême dans la position la plus commode pour t'élan, el sa tête, placée au sonmet des cercles concentriques, veille immobile. On le dirait endormi si sun oeil ne laneait un éclair sinistre, au moindre bruit dans les herbes. Un animal puissant vient-il troubler l'aflùt, la vipère montre de l'inçuiétude, cependant elle ne quitte son poste que lorsqu'elle se voil sur le point d'être altaquée. Elle déroule alor's ses anneaux et fuit lentement. Le danger passé, elle retourne à son embuscade. Ses sens lui ont-ils signalé l'approche d'un être faible, pas un mouvement ne trahit sa joie; elle attend avec patience que sa viclime soit à portée, puis fond sur elle comme un trait (1). Si la proie est un animal à sang froid, le serpent se met immédiatement à la dévorer; mais s'il s'agit d'un oiseau ou d'un petit mammifère, la vipère le blesse d'un premier jet, puis se replie sur elle-mème pour ne revenir qu'au moment où, sous l'influence du venin, les dernières convulsions ont cessé. Elle engoufre alors l'animal tout d'une pièce, l'inonde de bave et le digère lentement. Le fond de l'estomac parait seul sécréter le fluide gastrique, car la partie de la proie la première ingurgitée est réduite en chyme, tandis que le reste de l'animal dévoré est encore reconnaissable.

Tous les ophidiens restent dans une espèce de torpeur pendant leur travail digestif et sont alors faciles à tuer.

Voici un curieux cas de survie d'un batracien avalé par une vipère :

M. F. Talvande ayant un jour écrasé d'un coup de botte une femelle d'aspic qu'il croyail pleine, en vit sortir une grenouille

(1) Les vipères, qu'elles soient lovées ou non, portent la tête en arrière avant de s'élancer pour blesser. Elles ne quittent jamais completement le sol, même quand elles se débandent comme un l'essort. 
d'abord un peu étourdie, mais qui se ravisa, coassa sourdement et prit la fuite.

C'est un étrange spectacle que de surprendre une vipère avalant un crapaud. Saisi par le train postérieur, le batracien se laisse engouffrer dans la gueule horriblement distendue du rep-. tile, sans faire le moindre effort pour se dégager, el, pour ainsi dire, avec un air de stupide satisfaction.

La scène est toute autre quand un crapaud aperçoit un serpent qui le guette. Dominé par cette vue, le malheureux animal se dresse sur ses pattes, qui se raidissent, pousse un coassement déchirant, et, malgré lui, va se livrer à son ennemi.

Les vipères paraissent, en effet, exercer par leur regard sur les petits animaux un pouvoir magnétique, que le vulgaire exagère encore et auquel il donne le nom de charme ou de fascination. C'est un phénomène de peur extrème faisant tomber dans le péril que l'on veut éviter. Ainsi l'on voit un enfant effrayé se précipiter sous les rones d'une voiture, ou de malheureuses femmes se jeter, par la peur du feu, dans les flammes d'un incendie.

Les oiseaux, glacés de terreur par la vue de ces yeux fixes, sans paupières mobiles, et par ce sifflement (I) sinistre, voltigent en poussant des cris plaintifs, et finissent par tomber dans la gueule de l'animal maudit.

(1) Le mot sifflement, malgré l'opinion de notre excellent maitre, M. A. Duméril, nous paraît être le seul à l'aide duquel on puisse exprimer le bruit que font les serpents en chassant l'aír par leurs narines. Ce sifflemen! ne se rapproche point de celui que lhomme produit avec sa bouche et qu'imitent certains oiseaux, qunoique les puëtes semblent les comparer et les expriment tous deux par harmonie imitative en mulipliant les S. C'est un bruit de souflle beaucoup moins fort et beaucoup moins aigu. Le sifflement des vipères a moins d'acuité que celui des couleuvres, quoiqu'tl soit de même nature. 
Les crapauds, les grenouilles et les petits mammifềes subissent le charme, el la couleuvre vipérine l'exerce sur les goujons et autres poissons de même taille.

A la Gaubretière (Vendée), Félix Panchot, cufint de treize ans, vit un jour, sur lherbe, un oiseau qui ne lui semblait pas disposé à s'enfuir; en voulant le saisir, il fut mordu au doigt par un aspic, dont la vue fascinait l'oiseau. Le blessé ressentit au point entamé par' le crochet de l'animal une douleur qu'il compara à une piqùre d'aiguille; la main et l'avant-bras enflèrent promptement. Un de ses amis lui mit de suite une ligature, et un empirique de Chambretaud, en renom parmi les paysans, fut appelé pour continuer le traitement. Panchot soigné, intìs et extri, avec une solution apportée par le conjureur, guérit en une dizaine de jours.

La terreur causée par la vue du reptile peut aller jusqu’à produire seule la mort. MIM. Duméril et Bibron voulant essayer sur un chardonneret l'aclion du venin de la vipure, le pauvre oiseau, tenu avec la plus grande précaution, mourut de peur, à la vue de l'animal et sans avoir été mordu.

Chose curieuse, la fascination du serpent n'existe plus sur ses victimes ordinaires, quand elles le voient avant d'en ètre aper. çues, et que, renfermées dans un espace étroit, elles nont plus de salut que dans l'altauue. C'est alors le reptile qui est démonté, parce qu'il n'a pu combiner son plan stratégique.

En avril 1861, une souris fut placée par M. l'abbé Sagot, dans une cloche en verre où se trouvait déjà un aspic. La courageuse petite bête se jeta intrépidement, dix à quinze fois, sur le replile. et le mordit de loutes ses forces. La vipère déconcertée ne cherchait qu'à fuir. Pour la forcer à mordre, on la saisil avee une pince, el on la mit en face de son agresseur, qui fut blessé à la poilrine. La souris poussa un cri aigu, s'échappa par l'ourer- 
ture de la cloche, et alla succomber, sept minutes après, à une quinzaine de mètres du champ de bataille. Avant de mourir, elle eut quelques mouvements spasmodiques dans une patte et offrit une tuméfaction considérable du thorax.

MI. Arthur de l'Isle renferma, en 1860, une souris dans une cage grillée contenant une vipère. Le lendemain, il fut for't étonné de trouver la vipère à moitié dévorée, el la suuris morte auprès d'elle. Un drame semblable au précédent s'était produit là, sans témoins.

MII. Maillard et Dauffy ayant placé dans un bocal étroit un aspic et un gros lézard vert, le lézard se jeta à la tète de la vipère, la mordant avec fureur. Il fallut une lame de couteau pour lui faire desserrer les dents et l'empêcher d'étrangler son ennemi. Le lézard saisit alors, avec l'énergie du désespoir, la lèvre inférieure du serpent, mais celui-ci, d'un coup de crochet, lui lit lâcher prise. Quelques heures après, le lézard ne présentait aucun phénomène d'intoxication, et regagnait les champs.

Les serpents n'ont besoin de nourriture qu'à de longs intervalles. Au Jardin des Plantes de Paris, ils font de sept à neuf repas par année. Les crotales et les vipères sont r'emarquables entre tous pour la longueur des jeûnes qu'ils peuvent supporter.

Jamais M. G. Grignon du Moulin n'a vu sa captive manger ni boire, quoiqu'il l'ait gardée trois ans et ne l'ait tuée que pour s'en débarrasser. De grosses mouches à viande introduites dans sa cage ont, il est vrai, disparu; mais on a plus tard retrouvé, sous la cachette de foin, celles qui ne s'élaiert pas échappées quand on ouvrait la cage. Des grillons, placés avec l'aspic, se prome. naient sans crainte sur ses anneaux et leur musi(jue semb) Jait lui faire plaisir ; ils ont été retrouvés, pareillement desséchés, sous le foin, ainsi qu'une petite vipère qu'on lui avait donnée pour compagne. 
Les ophidiens, en cas de diète prolongée, ne muent pas, en général, à l'époque où ils ont coutume de le faire. L'aspic de M. Grignon ne changea point de pean pendant toute sa captivité.

Le nom des viperes leur vient de leur mode de reproduction (viviparu, par contraction vipera). Elles mettent au monde des petits tout formés qui entrainent, dans leur sortie, les débris des cufs dans lesquels ils étaient renfermés.

Elles s'accouplent dès le mois de mars; on en voit toutefois se rechercher jusqu'à la fin de l'été (1). La délivrance a lieu du mois d'août à la mi-octobre. D’après M. Thomas, les pelits péliades sont moins longs à leur naissance que les petits aspics.

Leurs portées sont, de cinq à douze vipereaux mesurant chacun quinze à dix-sept centimètres, ce qui explique la grosseur et la gêne des mouvements des femelles pleines.

Les vipères mettent, dit-on, sept ans à acquérir toute leur taille, et grâce à leur fécondité, peuplent abondamment les lieux où l'homme les laisse en paix.

Les accolements de germes ne sont pas très-rares chez ces animaux et plusieurs musées possèdent des serpents à deux têtes ou à deux queues. Ces monstruosités ont donné lieu à la falıle des hydres.

Au mois de septembre, les vipères se réunissent parfois en amas, comme le font les couleuvres. Deux chasseurs vendéens, nous écrit le $\mathrm{D}^{\mathrm{r}}$ Guitter, en tuèrent dix-sept de rquatre coups de feu, tirés dans un de ces blocs d'aspics.

Les anciens aftribuaient aux serpents venimeux des mœurs de

(1) Une erreur, qui date des Grees et des Romains, a encore cours dans le marais septentrinual de la Vendée. Iorsque l'été l'anguille s'envase par suite du desséchement des canaux, le maraichin croil qu'elle mènr la vie des serpents el s'accouple avec eux. 
famille dignes des Atrides (1). Entre autres griefs is reprochaient aux viperes de dévorer leurs petits. La Providence, en donnant à ces animaux cel instinct pervers, empêcherait ainsi leur trop grande multiplication. Des vipereaux ont, en effet, été trouvés dans le tube digestif de leur mere; mais il y a eu erreur dans l'observation de ce fail singulier. Les femelles d'aspic et de péliade veillent sur leurs petits, jusqu à ce que leurs crochets soient soudés aux us qui les supportent. Elles les défendent avec courage et exposent leur propre vie pour les sauver; à la moindro alerte elles les reçoivent dans leur gueule et fuient avec eux.

II. Péligry, naturaliste à Nantes, étant à la chasse, entendit un fròlement sur le bord d'un terrier, puis de légers sifflements. S'élant approché de l'endroit d'où partait le bruit, il aperçut une vipere dans la greule de laquelle se réfugiaient ses petits. Il la tua et l'ouvrit de la tête à la queue; les vipereaux trìs -actifs circulaient dans l'intéricur du corps de leur mire, et s'enfuyaient devant le couteau vers l'extrémité du tube digestif.

Aux environs de Thouars, le commandant Toussaints herborisait an lieu dit la Cascale, quand il fut témoin d'un singulier spectacle. Au bas des rochers, près d'une flaque d'eau limpide, un serpent se chauffait au soleil et autour de lui jouaient cinq ou six petits êtres verniformes qui passaient et repassaient sur son dos. N. Toussaints s'élança avec sa houlette d’herborisateur pour détruire celte horrible nichée; mais, au bruit qu’il fit, la mère se mit à sifler, et les petits disparurent sans qu'il pût se rendre compte de ce qu’ils étaient devenus. Arrivé près du reptile, il

(1) Loin de là, les serpents venimeux paraissent pleins d'attachement les uns pour les autres.

La police indigène, chargée à Pondichéry de détruire les capelles qui s'introduisent dans la ville, sait fort bien, quand une femelle vient de succomber sous les coups, que le màle ne tardera pas à venir pour la délendre ou la venger. 
reconnut une vipère commune dont le ventre était très-gonflé. Il la coupa en deux et vit sortir de son abdomen six vipereaux qui cherchaient à s'enfuir, et qu'il parvint à tuer (1).

Les vipères se dressent avee une extrème difficulté pour mordre la main yui les tient suspendues par la queue et habituellement ne peuvent l'alteindre; cela est dù à la longueur de leurs apophyses épineuses; pareil jeu avec un animal aussi dangereux n'est qu'une fanfaronnade stupide.

Les vipères n attaquent point l'homme, mais elles se défendent de lui, surtout si elles sont blessées. Fortement irritées, elles poursuivent même l'agresseur.

a Vers la fin de septembre 1846, un enfant de sept à huit ans, le jeune Foucher, de Hachecoul, gardait des vaches dans un champ dont le chaume venait d'être arraché. L'enfant marchait pieds nus, suivant la coutume des petits villageois. Il rencontra une vipère endormie dans un sillon, et se mit à l'agacer avec un bâton. L'animal irrité s'élança plusieur's fois sur lui et le poursuivit. Foucher cruellement blessé, enfla de tout le corps, et suc. comba au bout de six jours » (II. B. Patron.)

(1) Il n’est pas plus vrai de dire, des serpents à sonnettes, qu'ils dévorent leurs petits. Comme les vipères, ils les reçoivent dans leur gueule pour les sauver. "Ayant aperçu, dit Palissot de Beauvois, un boïquira dans un sentier, je m'approchai le plus près possible; mais quelle fut ma surprise, quand, au moment où je levais mon bras pour le frapper, je le vis s'agiter en faisant résonner ses grelots, puis ouvrir une large bouche et $y$ recevoir cing pelits serpents de la grosseur d'un luyau de plume. Surpris de ce spectacle inattendu, je me retirai de quelques pas et je me cachai derrière un arbre. Au bout de quelques instants, l'animal, se croyant, ainsi que sa progéniture, à l'abri de tout danger, ouvrit de nouveau sa bouche et en laissa sortir les petits qui s'y trouvaient eachés. Je me montrai de nouveau : les petits rentrèrent dans leur retraite, el la mère, emportant son précicux trésor, s'enfuit à travers les herbes, dans lesquelles elle se cacha. „ (Transact. Phil. Americ. Society, t. IV, p. 360.) 
I)es cas analogues ne sont pas rares sur la rive vendéenne de la Loire.

MM. Moriceau et Doré ont vu pareillement des vipères leur tenir tête et se précipiter sur cux, au licu de les fuir. Dans l'ob. servation du Dr Moriccau, le serpent avait des petits eachés sous lui et telle étail la cause de son courage. N. Thomas a fait connầtre des faits du mème genre à la Suciété d'acelimatation.

L'aspic de H. Grignon, toujours au guet, appliquait sa tête contre les paruis de verre de sa prison dès qu'un bruil insolite avait lieu dans l'appartement. Il suivail, d'un oil inquiet, les moindres mouvements du garȩon mettant de l'ordre dans la chambre.

Souvent il se tenait à l'affût derrière des herbes, si bien cachó qu'on craignait qu'il ne fût hors de la cage. Il parvint mème plusieur's fois à s'échapper el ne s'apprivoisa jamais. A l'approche des gens de la maison, il se lovait, et sifllait d'un air menaçant. Sa tôte heurtait alors contre la glace, et retombait avec tous les signes du découragement.

Quoique sans oreille apparente, les vipères sont sensibles au bruit. Quand un son inconn! les frappe, après le premier sentiment de crainte, elles viennent souvent s'assurer de la cause qui le produit. Les notes harmonieuses de la flûte el le sifflement de l'homme les intéressent. On a vu des concerts en plein air troublés par l'arrivée d'un de ces reptiles. La conversation ou la lecture à haute voix paraissent aussi les attirer.

Le 16 octobre 1866, II. G. Grignon du Noulin éiail assis sur un cotean, à la Praudière, près Nantes, et lisait à haute voix, quand il entendit un léger bruit dans l'herbe. Une énorme vipère rouge renait à lui el passa sous sa jambe. Il frémit de peur que l'aspic ne se faulilat dans ses vètements et eut la présence d'esprit de ne pas bouger. La vipère qui ne paraissait point irritée frôla la cuisse de M. Grignon et continua sa route. Celui- 
ci, se levant alors, l'étourdit d'un coup de canne et la prit vivante.

Les vipères supportent mal la captivité. L'inanition et le spleen les tuent (1).

Elles se laissent parfois caresser impunément. A la Fénetière, commane du Loroux-Bottereau, une mère effrayée trouva un aspic couché en rond dans le tablier de son enfant, àgée de quatre ans; cette femme cut la présence d'esprit d'aller doucement derrière l'enfant, de secouer le tablier et de projeter ainsi au loin la vipère.

Une jeune idiote de Challans saisit un jour, près d'un lavoir, un aspic et se mit à le caresser, en l'appelant un bel oiseau. Le reptile paraissait se complaire à ce jeu, et ne blessa la pauvre fille qu'au moment nù, effrayée par les cris des autres laveuses, elle le pril rudement pour le rejeter au loin.

"Auguste X... domestique de II. F. Buron, aux Hautes-Places, en Saint-Mars-la-Jaille, se rendait un soir, à la fin de juillet $\mathbf{1 8 5 4}$, au bourg avec son maître. Chemin faisant, il aperçut une vipère étendue sur la route. Auguste s'était vanté, quelques jours auparavant, de conjurer tellement bien les reptiles, qu'il pouvait les prendre sans aucune espèce de danger. A la vue de celui-ci, M. Buron voulut mettre le talent de son domestique à l'épreuve. Auguste fit trois signes de croix sur le reptile, en prononçant à chacun de ces signes l'une des trois paroles suivantes : " $0 z i$, $0 \tilde{a}, 0 z 0 a$. " La vipère se laissa prendre. Auguste la garda quel-

(1) Au Nuséum de Paris, on a dû mettre les serpents à sonneltes dans l'endruit le plus retiri de la inćnagerie des reptiles, et mèıne voiler leur grillage avec une couverture. Connaissant leur force et voyant leur impuissance, ils se mettaient dans un état d'exaltation extrême, et mouraient de rage de ne pouvoir mordre, au moindre attouchement d'une baguette introduite à traver's les mailles serrées de leur prison. (A. Duméril, Notice historique sur la ménagerie des reptiles du Jardin des Plantes.) 
ques instants dans ses mains, la faisant glisser de l'une dans l'autre, puis la lança avec violence contre la terre. La vipère prit sans colère le chemin du buisson voisin. Mr. Buron, enchanté de l'expérience qu'il venait de faire du talent de son domestique, voulut pousser plus loin l'épreuve. Auguste élendit de nouveau la main vers la vipère, en renouvelant ses manœuvres cabalistiques, et l'arrèta sur-le-champ, puis il la plaça dans sa main gauche comme la première fois. Nais ici la scène changea; l'animal s'élança sur la main qui le tenait, et la mordit à la naissance des doigts. M. Jallot, médecin à Saint-Mars-la-Jaille, donna immédiatement des soins au blessé et employa l’ammoniarue; néanmoins Auguste crut devoir recourir à une espèce d'empirique, qui, après force signes de croix, fit avaler une nouvelle dose d'alcali. Pendant ce temps, la main, l'avant-bras, puis le bras tout entier enflèrent. L'œè̀me douloureux-livide gagna la poitrine el s'étendit au-dessous du sein pendant la nuit. Le lendemain matin, le malade était froid, d'une grande pâleur, et offrait un pouls d'une petitesse extrème; il fut confessé et administré. Le même jour, les accidents généraux disparurent; mais l'œedème persistant, le blessé s'adressa à deux nouveaux empiríques : l'un demeurant à Riaillé et ayant la réputation de guérir, le Vendredi-Saint, les humeurs froides, l'autre, à Ancenis. Mal. gré tout ce qu'on put lui dire, il préféra leurs soins à ceux d'un homme de l'art, et leur attribua sa guérison, qui survint quelques jours après. (Communication de N. DE TrÉméac.)

Rien de plus simple que de meltre une vipère hors d'état de nuire. Un coup de canne ou de badine lui casse les reins; elle devient alors facile à achever.

Comme tous les animaux à sang froid, les aspics et péliades ont cependant la vie très-résistante. Un facteur rural, M. Chéné, a fait don au Muséum de Nantes, d'un aspic mâle, qu'il avait 
trouvé, le 15 janvier 1862 , pendu à un arbre de Petit-Port. Pris sous une souche voisine, trois jours auparavant, ce serpent était encore plein de vie. Il est vrai que du 1ฯ au Iö janvier 1862 le thermomètre ne descendit pas au-dessous de +150 à +16 degrés centigrades.

Une vipère, que l'on croyait morte el qui fut placée dans du plàtre, s'échappa lestement à l'ouverture du moule. Enfin plus d'un naturaliste a trouvé vivant dans sa poche ou dans sa boite d'herborisation un dé ces animaux qu'il avait cru mort et 'qui n'était qu'étourdi.

La vie persiste quelque temps chez ces reptiles dans les parties séparées lu reste du corps. Coupées en tronȩons, les vipères donnent encore des signes de vie pendant dix ou douze minutes. Leur cœur mis sur une table continue à battre, et leur tête ne tenant plus au tronc a souvent donné lieu à de graves blessures.

«Le 2 juillet 1860, Joséphine M... du Landreau, àgée de vingthuit ans, d'une constitution débile et chlorotique, voulant aider son frère qui fauchait du trèfle, fut mordue à la première phalange du pouce droit, en ramassant l'herbe coupée. La faux avait divisé en deux un aspic, dont la tète se trouvait dans le paquet de trèfle saisi par la jeune fille. Joséphine M... éprouva immédiatement une douleur assez vive, puis un gonflement de la main, et bientôt survinrent des coliques, des selles, des nausées et des syncopes répétées. L'exaltation nerveuse était portée au plus haut point, phénomène dù à la peur et aussi au vin employé en grande quantité comme remède. Une ligature immédiate, une cautérisation au fer rouge et l'emploi de l'alcali amenèrent une promple guérison. „(M. B. Briand.)

1I. Thomas a fait connaitre à la Société académique de la Loire-Inféricure un eas analogue et qui fut plus malheureux encore. Il y a quelques années, en fauchant, un homme de Rouans 
sépara en deux une vipère; blessé par la tête de l'animal, il succomba cinq ou six heures après cet accident.

\$ II. De L'appareil venineux. - L'appareil venimeux atteint chez les solénoglyphes sa plus grande perfretion; il offre un type unique dans tout ce groupe d'ophidiens, et les organes à l'aide desquels les vipères sécrètent et inoculent leur venin sont, aux dimensions près, ceux du crolale durisse ou du lachésis muet.

Le poison se forme dans un organe spongieux, de couleurjaune, dit glande a vexin (fig. $9 \mathrm{G}$ ). Cette glande est située de chaque $\mathrm{G}$ côté de la tête, en arrière de l'œil et au-dessus du maxillaire supé-" rieur. Placée au fond de la fosse temporale, elle représente la pa-

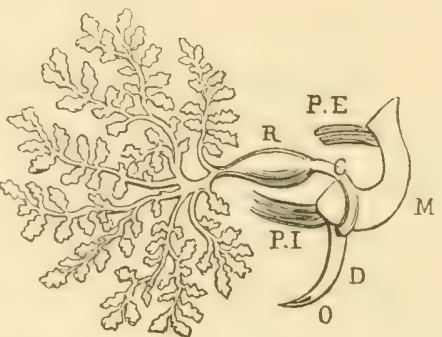

Fig. 9 (1). rotide des autres serpents; elle s'en distingue toutefois par des modifications de structure en rapport avec ses fonctions spéciales.

Les muscles qui l'entourent la compriment en se contractant, et elle est embrassée par la base dilatée du ptérygoïdien externe dont l'aponévrose lui sert de gaîne fibreuse.

(1) Fig. 9. Appareil venimeux d'une vipère considérablement grossi.

G. Glande en grappe sécrétant le venin.

c. Canal à venin.

R. Dilatation de ce conduit, dite réservoir à venin.

D. Crochet en exercice, ankịlosé avec l'os maxillaire ar et mobile avec lui.

0. Orifice externe du conduit de la dent.

P. E. Muscle ptérygoidien exteme filisant basculor en avant la base du maxillaire et saillir le crochet.

P. I. Muscle ptérygoidien interne attirant en haut et en arrière la base du maxillaire et faisant rentrer le crochet dans sa gaine. 
Sa structure est celle d'une gr'ande en grappe; le microscope la montre formée de granulations creuses ou acini qui se groupent avec régularité sur 6 à 8 conalicules, dans lesquels elles déversent le produit de leur sécrétion. La ghlande se trouve ainsi divisée cn lobes ou grappes secondaires, en nombre égal aux canalicules, et qqui se disposent de la mème façon autour du conduit principal dit canal à venin.

Le canal à venin (ig. 9 C), résultant de la réunion des canalicules, suit d'abord une direction horizunlale, à la manière du conduit de Sténon; mais, au lieu de s'ouvrir à la face interne le la joue, il va s'aboucher avec la cavité du crochet corrésumilnut. Il est étroit et cylindrique et du calibre d'un poil de barbe de chat. Il présente à sa partie moyenne, au-dessous du bord inlérieur de l'orbite, un renflement ovoïde, analogue aux dilatations ampullaires des conduits galactophores; c'est le réservoir à venin (fig. 9 R). M. Léon SouJsciran, qui a si bien décrit tout cet appareil (De la vipère, p. 43) et suivantes), a découvert dans les parois du réservoir des fullicules simples et tubuleux (follicules de Soubeiran) dont la sécrétion n’est pas sans influence sur le venin lorsqu'il séjourne dans celte cavité.

Le liyuide délétère se forme dans l'intérieur des acini; la membrane propre de ces culs-de-sac et la couche épithéliale qui les tapisse l'extraient (lu sany en laissant passer par endosmose certains éléments du sérum et en agissant par calalyse sur les substances protéiques qu'il contient.

Ciette sécrétion est lente et inullement comparable, quant à sa rapidité, à celle de ia salive. D'après .I. Cl. Bernard, un mor. ceau de grlande salivaire lavé et essuyé avec soin donne par macération ou légère décoction un liquide capable de transformer en glycose les matières amylacées. Rien de semblable n'a lieu pour la glande à renin. En traitant de la même manière la 
glande d'un serpent à sonneltes, le $\mathrm{D}^{\mathrm{r}}$ Weir Mitchell (Researches upon the venom of the rattlesnake - Smithsonian Institution. Washington, 1860) n'a point obtenu une dose de poison suffisante pour tuer un colibri.

En dehors des causes d'excitation, le produit des acini vient s'accumuler dans le réservoir. C'est ce premier liquide parfaitement élaboré qui est injecté par le reptile dans la première blessure qu'il fait, elle est par là même la plus dangereuse. Lors. qu'au contraire un serpent mord plusieurs fois de suite, il épuise son venin et la neuvième piqûre d'une vipère ne cause plus la mort d'un pigeon. Il est important de se souvenir de ces faits, lorsqu'on recherche la valeur d'un antidote à opposer aux morsures des serpents, sans quoi l'on s'expose à considérer comme tels des substances qui n'ont aucune action sur le venin.

La faim et la colère sont les principaux excilants de la sécrétion; l'élévation de la température et une forte tension électrique de l'atmosphère rendant l'animal plus actif, agissent aussi sur la rapidité avec laquelle se reproduit dans ses glandes la substance toxique.

Les serpents inoculent leur poison à l'aide de dents crochues et distinctes des aulres par la longueur, dites crochets a vexin ou Canines (fig. 9 D). Chez les solénoglyphes, elles sont seules sur les os maxillaires et présentent un canal interne, portion dentaire du canal excréteur de la glande.

La base du crochet s'unit à l'os peu de jours après la naissance; avant que cette soudure ait lieu, les serpents les plus dangereux sont incapables de blesser. L'extrémité libre se termine en pointe fine. La face antéricure ou convexe présente les deux orifices du canal interne que joint un léger sillon (d'où le nom de solénoglyphe de $\Sigma \omega \lambda \eta \eta$ canal et $\Gamma \lambda$ ug̣n rainure). L'orificesupérieur qui reçoit le conduit de la glande est situé près de l'al- 
véole; l’inférieur (fig. 90 ) est une fente étroite placée près de la pointe. La dent semble s'ètre repliée sur elle-même pour donner lieu à ce canal, et derric̀re elle offre un autre conduit terminé inférieurement par un cul-de-sac et contenant ses vaisseaux et nerfs nourriciers. Le crochet est composé de quatre lames de substance éburnée qu'une pression un peu forte sépare les unes des autres.

Une gaìne gingivale analogue au repli cutané de l'ongle des chats, entoure le crochet en exercice et les crochets de rechange

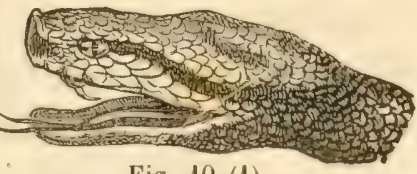

Fig. 10 (1). qui le suivent (Fig. 10). Elle se continue en arrière sous forme de sillon destiné à recevoir la dent à l'état de repos. Le crochet en exercice est le seul qui soit soudé à l'alvéole et qui communique avec le reste de l'appareil venimeux.

On trouve souvent derrière lui une dent de rechange plus développée que les autres et déjà, en partie, redressée et ankylosée; elle porte le nom de crochet d'attente; les suivantes, rudimentaires, molles et entièrement couchées au fond de l'alvéole, sont dites crochets de réserve.

Lorsqu'il existe des crochets d'attente, la vipère parait armée de trois ou quatre canines. Dans ce cas, on ne trouve, en général, sur la partie mordue, que l'empreinte de deux piquûres; les crochets supplémentaires sont trop mobiles et ne se redressent pas assez pour pénétrer dans les chairs. Cette règle souffre cependant exception. Sur un lapin mordu, une seule fois, par une des vipères de NI. Gicquiau, nous constatames trois traces de crochets. Voici une observation du mème genre, recueillie par M. A. de l'Isle :

(1) Tète de Vipera Aspis vue de profil pour montrer le crochet et sa gaine. 
Heurtin, cultivateur au village de la Caillerie, près la IIayeFouassière, était à neuf heures du matin à couper du blé, quand il se sentit mordu à la cheville par un aspic. Le reptile ne pressa qu'une seule fois de ses dents la partie atteinte, mais avec tant de rage, qu'il y resta fixé par ses crochets. Le blessé nc put s'en débarrasser qu'en tirant fortement dessus. La douleur primitive fut violente, et il y eut un écoulement assez considérable de sang. Un empirique conseilla de tremper la jambe malade dans du lait caillé, et appliqua au-dessous du genou une ligature tardive. Malgré l'emploi de ces moyens, l'œedème gagna le pied et la jambe. Heurtin se décida alor's à consulter le médecin, et ne pouvant plus mettre son sabot, il fit, pieds nus, un kilomètre pour se rendre à la Haye-Fouassière. Il était midi, l'œedème douloureux dépassait la hanche, et, sur la cheville se voyaient trois empreintes de crochets entourées d'une ecchymose. Une goulte d'ammoniaque fut introduite dans chaque piqûre; cette substance fut aussi administrée à l'intérieur dans du tilleul. Les nausées, cependant, se montrèrent de plus en plus fréquentes, il survint de l'accablement et du malaise. Le blessé ayant voulu travailler, l'œedème augmenta encore. Une fièvre violente se déclara le lendemain, avec des tranchées et des vomissements. La tuméfaction ne commença à décroître qu’au bout de quinze jours, et Heurtin, qui n'avait gardé ni repos ni précautions, souffrit de la chesille pendant plus d'un an, surtout quand il s'exposait à la rosée. Il eut longtemps de l'agacement nerveux, et son pied changea de peau.

Les solénoglyphes perdent parfois leur's crochets lorsqu'ils blessent; on en trouve aussi dans leur's excréments (1). Ces ca-

(1) La présence des crochets dans les excréments des serpents venimeux oblige, au Mluséum de Paris, les gardiens de la Mrénagerie des reptiles à nettoyer les cages des solénoglyphes avec les plus grandes précautions, et les mains armées de gants (A. Duméril, loc, cit.). 
nines tombent d'ailleur's d'elles-mèmes, dès que celles qui doivent les remplacer sont suffisamment développées.

En arrachant les croes d'un serpent, on le rend inoffensif jusqu'à ce que des dents de rechange se soient soudées avec l'alvéole. C'est un secret connu des jongleurs de tous les pays et de tous les temps: on le trouve même indiqué dans la version de la Bible dite des Septantè.

Quand, au contraire, al l'aide de ciseaux fins on enlève les deux maxillaires supérieurs du reptile, il devient pour jamais incapable de nuire, el meurt de chagrin.

L’os sus-maxillaire des solénoglyphes, aussi réduit que possible dans ses dimensions, jouit d'une grande mobilité, par rapport aux aulres os de la face. Le muscle ptérygoïdien externe (tig. 9, P. E.) lui fait éprouver un mouvement de bascule qui porte en avant et ru dehors sa face palatine et par là même redresse le crochet en l'éloignant de son congénère. Les empreintes laissées sur la peau far les canines d'une vipurre, sont à cause de cela toujours plus distantes l'une de l'autre, que ne semblerait l'indiquer la grosseur de la tète de l'animal. Le ptérygoïdien interne (fiıg. 9, P. I.) communique au maxillaire un mouvement en sens inverse qui ramène le crochet dans sa gaine.

Il est curieux de rapprocher de l'appareil venimeux que nous venons de décrire, celui des araignées. Chez ces animaux, la glande à venin est une glande salivaire et son conduit rentlé en réservoir traver'se une mandibule en forme de crochet.

Lorsqu'une vipère s'élance pour blesser, elle le fait avec tant de force que sa màchoire supérienre frappe comme un marleau l'objet atteint. La gueule du reptile largement ouverte laisse saillir les crochets qui pénètrent au loin dans les tissus, tandis que le venin est poussé dans la blessure prar les muscles qui compriment la golande et le réservoir. Cette injection a lieu avec d’au- 
lant plus d'énergie que l'animal est plus vigoureux el plus irrité.

La hlessure faite par la vipère est done, cn général, une double piqûre; elle mérite cependant parfois le nom de morsure. Quand par exemple le reptile est fixé sur le sol par le pied d'un passant, ou saisi à pleine main, ou bien encore, comme dans nos expériences, tenu près du cou avec des pinces, il supplée à son défaut d'élan, en prenant un point d’appui à l'aide de sa mâchoire inféricure; sa tête alor's s'aplatit, s'élargit, et les muscles se dessinant sous la peau de la face, donnent à l'animal, qui mord avec rage, la plus hideuse physionomie.

Tenue près de la nuque d'une manière inégale, une vipère peut encore blesser d'un seul de ses cruchets, tant est grande la mo. bilité des os de sa face.

M. Rautou, commissaire de police à Nantes, et âgé de trentesix ans, était d'une bonne santé et d'une forte constitution. Il rapporta, le 28 mai 1860 , de la Fournillière, un aspic rouge, de taille moyenne. Le lendemain matiu, ver's neuf heures, il se mit en devoir de lui arracher ses crochets, et déposa la vipère, alors très-vigoureuse, sur le plancher, pour la saisir plus facilement à la naissance de la tète, et ouvrir sa gueule de force. Il lui prit le cou entre le pouce et l’index gauche, mais inégalement, ce qui permit à l'aspic de faire basculer son os maxillaire gauche et d'enfoncer son rrochet dans l'index de l'opérateur. La douleur fut peu vive, et une simple gouttelette rosée apparut sur la peau.

M. Rautou garda son sang-froid, lia le doigt au-dessus de Ja blessure, agrandit celle-ci, ia fit saigner et y introduisit de l'ammoniaque. La pelite piaie devint rouge et ecchymosée; le blessé ne put laisser la ligature que fort peu de temps, à cause de la lumélaction du doigt; il l'enleva done au bout d'une demi-heure. et avala dix goutes d'ammoniaque dans un verre d'eau sucrée. 
Pensant par ces soins immédiats avoir neutralisé le venin, il dé. jeuna comme de coutume; mais il cut bientôt quelyues nausées qui n'allèrent pas toutefois jusqu'au vomissement. L'cedème s'accrut encore, sans pourtant dépasser le coude; l'avant-bras offrit des trainces lymplatiques verdâtres, puis des taches livides qui se montrirent aussi sur le bras. Nous constatàmes même un peu de tuméfaction du ganglion épitrochléen. Le soir, légère fièvre yui reparut le lendemain avec coliques et nausées. Les envies de vomir et la céphalalgie persistèrent pendant huit jours. Des infusions chaudes de camomille et de polygaha de Virainie, puis un purgatif finirent par triompher de ees symplômes. Un bain avec la vapeur s'échrpprant d'une décoction de lierre contribua à dissiper l'oedème, dont il n'y eut plus de traces à la fin de la semaine. La douleur du membre ne disparut qu'au bout de quarante jours et les taches livides laissèrent encore pendant deux mois des marques sur la pean.

L'empreinte des lents d'une vipere consiste en deux petites pirqûres à peine pereeptibles, par suite de la rétraction du derme. mais qu'une gouttelette de sang aide ì reconnaitre. Autour d'elles se forme un errele ecehymotique, et elles servent de point de départ à l'œedème qui envahit la partie blesséc.

Les auteurs admettent, en cas de morsure, que les dents de la mâchoire inférieure laissent sur la peau une séric d'éraillures en ligne courbe opposée par sa concavilé aux deux petiles plaies produites par les crochets. Dans nos expériences, nous n'avons jamais trouvé que les empreintes de deux canines, malyré notre précantion de dénuter les parties sur lesquelles nous faisions mordre lat vipere. Vous avons vainement aussi cherché les traces des dents palatines qui, en thérie, devraient exister sur la peau, quand la vipère mord à pleine gueule.

Il est facile de se procurer du venin, en recueillant les groutte- 
lettes laissées par un serpent qu'on fait mordre sur une tige de fer ou tout autre corps peu spongieux; mais le moyen d'obtenir une grande quantité de ce liụuide, consiste à saisir la vipère près de la nuque et à presser d'arrière en avant ses glandes à venin. Le poison est alors reçu dans une petite cuillère placée sous les crochets. Celte opération exige de la présence d'esprit et de la dexlérité, et pour récolter celui des serpents à somnettes, le docteur Burnett commençait par anesthésier, à l'aide du chloroforme, ces redoutables animaux.

Fontana examinant plus de 3,000 vipères en a trouvé deux dépourvues de venin, sans qu'il y eût la moindre lésion matérielle de l'appareil de sécrétion. Il y avait là un de ces troubles fonctionnels analogues à ceırx que présente la muqueuse gastrique dans les dyspepsies par défaut de pepsine. Chez cinq autres vipères, Fontana a constaté que le réservoir et la cavité des crochets étaient remplis par une matière blanche, visqueuse et concrète : cette substance sébacée, dont la découverte des follicules de Soubeiran explique la présence, jouait le rôle de la cire que les prétendus charmeurs de serpents introduisent dans les canines de ces animaux avant de s'exposer' à leur's morsures.

Une autre observation due à M. Weir Mitchell donne la raison de l'insuccès de diverses inoculations praliquées avec la tête d'un reptile privé de vie: quand le serpent a succombé après une lutte violente, il arrive parfois que le mouvement fluxiouncl qui a lieu vers les parotides venimeuses se transforme en suffusion sanguine. La sécrétion est alor's altérée, et le sanğ épanché vient par sa coagulation obstruer le canal à venin et la cavite dés crochets.

§III. Du vexrs. - Le venin des trois vipères européennes peut ètre considéré comme identique. Presque incolore ou légèrement 
jaunâtre, il ressemble, lorsqu'il est frais, ì de l'huile d'amandes douces ol n'a ni odeur ni saveur, à moins d'ètre altéré. Troja affirme, toutefois, que son contact prolongé laisse sur la langue un sentiment de stupeur et d'astriction.

Les poisons des autres serpents offrent les mèmes caractères physiques; leur couleur varie cependant un peu. I e venin que crachent les najas, lorscu’ils sont en colère, est grisàtre ; celui du fer-de-lance est transparent, et celui des crolales émeraude pàle ou jaune clair. Ce dernier, si consciencirusement étudié par M. Weir Mitchell, fournit un excellent terme de comparaison au venin de la vipère dont il a l'apparence extéricure, mais dont il diffère par l'abondance de sa sécrétion et par son activité plus grande.

D’après Fontana, la quantité de liquide sécrétée par les deux glandes d'une vipère serait de dix centigrammes. Ce chiffre n'est pas assez élevé, et l'auteur' des Éléments de Zoologie médicale. notre regretté maitre Moquin-Tandon, a obtenu, de la tète d'un fort aspic, quatorze centigrammes de venin, soit sept centigrammes par crochet; il a tenu compte, il est vrai. non-seulement de la liqueur contenue dans les canines, le canal excrétcur et le ráservoir, mais encore de celle que l'on retire des glandes par une pression modérée. Il évalue à deux centigrammes le venin que les vipères versent dans chacune de leurs piqûres.

Un crotale de grande taille a, au contraire, suivant le calcul de I. Weir Mitchell, soixante-quinze centigrammes de poison par crochet et en perd trois on quatre gouttes par dent toutes les fois qu'il s'élance pour blesser.

Au microscope, le venin se montre sons forme d'un liquide homogène, où nagent quelques rares cellules détachées de l'épithélium qui tapisse les culs-de sac sécréteur's et leur's conduits. Quand les solutions de ce poison s'altirent, on y voit apparaitre. 
des bactéries el autres proto-or'ganismes doués de mouvements.

Desséché sur une lame de verre, le venin a l'aspect d'une gomme; il s'écaille alors comme un vernis et présente des fissures irrégulières que Mrad a eu le tort de considérer comme des cristaux.

Il est encore actif après plusieur's mois de sćjour dans des tubes capillaires; la dessiccation, du reste, ne lui fait pas perdre ses propriétés malfaisantes. F. Redi raconte (Epistola de quibusdam objectionilus contru sutes de riperis obsercutiones) qu'ayant recueilli dans un vase le liquide vénéneux de deux cent cinquante vipères, il le vit en quelques jour's se prendre en une masse glutineuse de couleur ambrée. Au bout d'un mois, celte substance devenue friable et complétement sìche put ètre réduite en pondre. Tous les animaux sous la peau desquels ce venin pulvérisé fut introduit périrent en peu d'instants.

La conservation du poison des ophidiens à l'état sec a permis de l'utiliser comme moyen de rendre les armes plus dangereuses.

Les Peaux-Rouges du Rio-Grande et du Texas emploient poul cet usage, dit le docteur Johnston, de Saint-Louis, le liquide fourni par les glandes des serpents à sonnettes.

Les Indiens des bords de l'Orénoque se servent dans le mìme but du venin cutané des crapauds. Voici, d’après M. Roulin, cité par le professeur Cl. Bernard (Lecons sur les effets des substunces toxiques, page 25̋̇), comment ils s'y prennent. a Ils vont à la chasse des crapauds, armés de longues brochettes, à l'aide desquelles ils transpercent ces animaux à mesure qu'ils les rencontrent. Ils les exposent ensuite autour d'un leu qui ne doit pas les rôtir, mais déterminer une excitalion sous l'inllnence de layuelle leur peau sécrète une humeur quon ramasse avec des conteaux de bois et qui se cunserve dans de petits pols. Les daris que l'on veut empoisomer sont trempés dans ce jus de crapraud 
et séchés au soleil. Les Indiens s'en servent pour tuer des singres dont ils sont très-friands et qu'ils mangent ensuite. D

Le Dr Daniel Brainard (Essay on a new Method of treating serpent bite. Chicago, 18.5.) prétend que le curare lui-mème n'est que du venin conservé à l'aide d'un extrait gommeux de lianes. Il explique ainsi la quasi impunité avec laquelle il peut ètre avalé, tandis que ses effets sont foudroyants quand on l'introduit dans une blessure (1).

Nos pères les Gaulois comnaissaient l'art d'empoisonner leur's flèches avec des venins. "Venatoriu venenu, dit Celse, quibus Gulli precipue utuntur non gustu, sed invelnere, nocent. "Les Seythes, au dire de Pline, avaient une semblable recetto. a Scythip sargitas tingunt viperina sanie et humano sanguine : irremediubile id scelus, mortem illico levi tactu affert."

La légende des armes d'Ilereule trempées dans le sang de l'Hydre de Lerne, montre combien est vieille cette méthode d'utiliser.

(1) Le curare des Ticuñas et des Arecuñas, renommé entre tous, est un extrait aqueux de l'écorce de diverses plantes, en particulier des Strychnos toxifera, S. cogens et S. Castelnceana et du Rouhamon Curare. (Yoir la thèse du Dr E. Bureau, De la famille des Loganiacées et des plantes qu'elle fournit it la médecine. Paris, 1856.) On ajouterait au mélange, rapportent les voyageurs, des têtes et des crochets de serpents. Sa fabrication est entourie de mystire, et les vieilles femmes qui en sunt chargées se retirent au fond des bois pour s'y livrer, loin des regards profanes, à des pratiques de sorcellerie. On dit mème qu'elles meurent a la fin de leur cuisine infernale.

La curarine, alealoide auquel le poișon américain doit ses propriciétés, préexiste-t-elle dans les lianes à leur mélange avec les glandes des serpents, ou bien au contraire résulte-t-elle de l'action des principes des stryehmos sur le venin? C'est un point non encore élucide. Quoi qu'il en soit, et malgré de grandes ressemblances, les effets du curare et ceux des venins sont loin d'etre identiques. Ainsi, le premier poison ne donnt pas d'inflammation locale, symptome qui se montre toujuturs dans les plities envenimees. 
pour ia guerre et pour la chasse le terrible poison des ophidiens. Philoctète, héritier de l'are et des flèches du grand Alcide, se blessa au pied avec l'une d'elles pendant qu'il découvrait aux Grees l'endroit où il les avait cachées. Redi fait judicieusement remarquer que les symp̣tômes éprouvés par Philoctète, tels que les décrivent les auteurs, sont ceux d'une plaie contaminée par le poison de la vipère.

Qu'on nous pardonne cette digression; mais elle a bien son importance, car dans quelques localités de la Vendée et de la Loire-Inférieure, en particulier à Héric, on trempe encore de nos jours les faux dans une macération de têtes de serpents, de crapauds et d'autres animaux immondes, sous prétexte de rendre leur fil plus délié; elles devioment des armes dangereuses et peuvent donner lieu à des blessures empoisonnées.

Les crochets conservent pendant des années le venin avec sa couleur, sa transparence et ses propriétés toxiques. On ne saurait donc les manier avec trop de précautions, surtout s’ils proviennent d'un bothrops ou d'un crotale; mais, d'ordinaire, les dents venimeuses de ces animaux ne sont cxpédiées en Europe qu'après avoir subi plusieur's lavages.

La blessure occasionnée par un crochet détaché de l’alvéole n'est jamais, du reste, aussi grave que celle faite par le serpent lui-même. Dans le premier cas, il y a un simple dépồt au milieu du tissu cellulaire d'une petite quantité de venin; dans le second, ce liquide est injecté avec force et abondance.

La chaleur fait boursoufler le venin, qui ne prend feu que lorsqu'il est carbonisé.

Privé d'air dans un tube fermé aux deux bouts, il supporte sans šaltérer des températures extrêmes. Le Dr Weir Nitchell a tué des pigeons avee des solutions de venin de crotale portées successivement à $3^{\circ}$ Fahr. (-12 C.) at à $212^{\circ}$ Fahr. $\left(100^{\circ}\right.$ C. $)$. 
Mis dans l'eau Iroide, le venin de la vipère tombe au fond du vase, puis se mêle au liquide en lui donnant une teinte opaline: il finit a la longue par s'y altérer. Il se dissout au contraire com. plétement dans l'eau bouillante.

Il est en partie soluble dans l'alcool étendu, tandis que l'alcool absolu ne le dissout point. Ceci explique des expériences au premier abord contradictoires. Delalande (Procès-cerly. de la Sor. Acal. de la L.-Inf. - Juin 183̈1) ayant enfoncé sous l'aile de deux mésanges nonnettes une canine de péliade qui avait macéré plusieurs années daus de l'alcool très-fort, ces petits oiseaux succombèrent en dix minutes. Un geai traité de la mème manière en fut quitte pour un thrombus. D'autres expérimentateurs n'ont obtenu aucun résultat pour s'itre servis de crochets plongés depuis trop longtemps dans de l'alcool affaibli.

Les alcalis et les huiles n'opèrent point la dissolution du venin. Les acides puissants, ne font, quand il est à l'élat sec, que le diviser et le transforment en pate liquide. L'acide azotique le colore en jaune, à cause des substances protéiques qu’il contient. Les acides azotique, chlorhydrique et sulfurique, le précipitent de sa solution arqueuse, mais il est redissous par un excès de réactif. Ce précipité est blanc: il prend toutefois une faible teinte brune quand on opère avec l'acide sulfurique, ce qui indique un commencement d'altération. L'acide tannique précipite abondamment le venin en blanc; mais le dépôt se redissout dans l'ammoniaque. La plupart des acides vénétaux sont sans action sur Ie poison des serpents; ils ne le précipitent ni ne le dissolvent. Ia liqueur iodoiodurće le précipite pour le redissoudre dès qu’elle est en excès.

Il résiste à un commencement de putréfaction; II. Weir Mitchell a démontré que la présence de moisissures et mème de vibrioniens n'enlève pas à une solution venimeuse ses propriátés délétères. 
Sous l'influence de l'air humide, les principes actifs des venins finissent néanmoins par s'altérer et subissent la décomposition ammoniacale, quoique moins promptement rue les virus.

Tandis que la salive et le curare sont alcalins et le liquide cutané des crapauds et des salamandres acide, le venin de la vipère, telle qu'elle l'injecte dans ses blessures, est neutre. Dans la glande il teint, il est vrai, en rouge te papier lıleu de tournesol, mais, à sa sortie du crochet, il est neutralisé par les sécrétions du réservoir et de la muqueuse buccale.

Chez les crotaliens, suivant la remarque de M. Rousseau, la quantité du liquicle séerété par la glande est trop considérable pour que les fluides du conduit excréteur et de la bouche lui fassent perdre ses réactions. Cetle acidité est due simplement, ainsi que celle de l'urine, à des phosphates en solution.

Le prince Lucien Bonaparte a le premier (Gazeta toscana delle scienze medico-fisire, 1893, page 169) analysé d'une manière séricuse le poison de la vipère et en a découvert le principe actif, qu'il appelle ripérine ou échidnime. Nous avons ailleurs

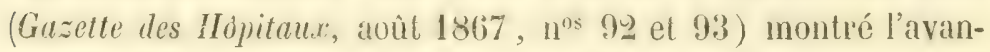
tage qu'il y a à ne pas considérer ces deux mots comme synonymes. Par échidnine nous entendrons non-seulement la vipérine ou poison de la vipère, mais encore les principes analogues fournis par les autres serpents venimeux.

Voici, d'après Lucien Bonaparte, la composition du venin des vipères :

Ce liquide contient en solution aqueuse :

$1{ }^{0}$ Une substance quaternaire voisine de la ptyaline de la salive normale : la vipérine;

$2^{\circ}$ De l'albumine et du mucus;

$3^{\circ}$ Une substance soluble dans l'alcool ;

$4^{\circ}$ Une matière colorante jaune; 
$5^{\circ}$ Une matière grasse;

$6^{\circ}$ Des sels analogues à ceux de la salive (phosphates et chlorures).

II. Cl. Bernard (Truité de's liquides de l'orgunisme, p. 2'22), dit que certains auteurs ont considéréle sulfocyanure de potassium comme la cause des effets mystérieux du venin de la vipère. Ce sel si vénéneux existe, chose étrangre,dans la salive normale de plusieurs animaux et même de l'homme, mais nous n'en avons pas trouvé de truces dans le cenin : le sulfate de sesquioxyde de fer n'y produit point le précipité rouge caractéristique du sulfocyanure, mais bien un précipité blanc.

On obtient la vipérine en coagulant le venin par une grande yuantité d'alcool; le dépôt resté sur le filtre, après plusieurs lavages alcooliques, est repris par l'eau distillée qui dissout la vipérine. L'évaporation laisse celle-ci comme résidu; l'éther lui enlève la matière grasse et les substances colorantes; enfin l'eau froide fortement acidulée et l'alcool la débarrassent des sels qu'elle contient encore.

Il est intéressant d'opposer au travail de L. Bonaparte l'analyse du venin des crolales faite par le $\mathrm{D}^{\mathrm{r}}$ Weir Mitchell (loc. cit., p. 37).

Le savant américain traite d'abord ce liquide par l'eau bouillante. It obtient ainsi un premier précipité blanc non venimeux, cuniposé d'albumine et de mucus, et un liquide opalin toxique. La solution ayueuse décantée est reprise par l'alcool qui donne lieu à un noureau précipité blanc très-venimeux, tandis que le liquide ne l'est plus. Ce dépôt est lavé trois ou quatre fois par de l'alcoul reetifié : il est jaune pàle, parfaitement neutre et conlient de l'azote. Les divers lavages l'ont débarrassé de la petite quantité de sel qu'il renfermait; l'éther lui enlìve un peu de matière grasse et des substances colorantes jaunes et vertes. Cette rehidnine a l'état de pureté ressemble presque en tous points à la vipérine : M. Weir Mitchell l'appelle crotaline. 
En résumé le venin des crotales se compose :

$1{ }^{\circ}$ D'une substance albuminoïde non coagulable à $212^{\circ}$ Fahr. $\left(100^{\circ} \mathrm{C}\right.$. $)$ : la crotaline;

$2^{\circ}$ De substances albuminoïles coagulables ì la température de l'eau bouillante;

$3^{\circ}$ De matières colorantes vertes et jaunes;

4. De traces de matières grasses;

$5^{\circ}$ De sels : chlorures et phosphates (en particulier de phosphate ammoniaco-magnésien);

(jo Enfin d'eau servant de véhicule.

La vipérine a l'aspeet d'un vernis gommeux et se présente sous forme d'écailles semblables à celles de l'acide tannique.

Composée d'oxygène, d'hydrogène et d'azote, elle est neutre, et rentre dans le même groupe que l'albumine. Son défaut d'ac. tion sur les réactifs colorés la distingue des alcaloïdes végétaux, près desquels certains auteurs ont le tort de la classer.

Les échidnines se putrélient facilement, et cependant, elles sont remarquables par la manière dont elles résistent aux agents chimiques et conservent leurs propriétés après avoir été mélangées avec eux. Elles sont néanmoins plus dangereuses dans leur véhicule naturel que dans tout autre.

La vipérine mêlée à l'alcool, à l'ammoniaque ou à une solution iodée, est à peu près aussi active que si elle était pure.

La crotaline est encore plus remarquable par sa résistance aux agents chimiques; elle conserve sa force, non-seulement lorsqu’elle est mélangée aux liquides dont nous venons ile parler, mais encore lorsfu'elle est mise en contact avec les acides sulfurique, nitrique et chlorhydrique, l'eau chlorée, la soude, la potasse caustique, le nitrate d'argent, etc.

M. Weir Mitchell avait soin de neutraliser le mélange avant de l'inoculer, de peur que la cautérisation des tissus, par le réactif 
cmployé, n’empèchât l'absorption ou que celui-ci, vénéneux luimême, ne donnât la mort. Sous l'influence du lannin ou de l'iole, les symptômes locaux observés étaient presque nuls, tandis que les accidents généraux suivaient leur's cours.

La vipérine est soluble dans l'eau froide ou chaude, colore, à la manière des autres substances protéiques, le bioxyde de cuivre en violet, et n'est pas précipitée de sa solution aqueuse par l'acétate de plomb.

Ses réactions chimiques ne la distinguent point de la ptyaline et de la pepsine avec lesquelles elle parait isomère. Elle agit comme elles, à la manière d'un ferment, mais son mode de calalyse est bien différent. È contact à une douce température avec des substances amylacées ou protéiques, elle ne transforme pas les premières en glycose et les secondes en chyme.

Elle ne produit, du reste, aucune modification sur les tissus morts et son action est presque nulle sur les membres récemment amputés. Dans ces deux cas, il survient à la longue des phénomènes de diflluence et de décomposition ammoniacale; ceux-ci sont un peu plus prompts que si la vipérine n'avait pas été employée, sans doute à cause de sa grande putrescibilité.

Le venin agit sur les ètres vivants avec d'autant plus d'énergie que la vie se manifeste chez eux par une chaleur naturelle plus considérable.

Le poison de la vipère n’a pas d'action sur les végétaux, mais Gilman a raconté d'étranges choses relativement aux efiets pro. duits sur les plantes, par l'inoculation du venin des serpents à sonnettes. D’après le docteur Salisbury, plus modéré dans ses aflirmations, des lilas et de jemes inarronnier's, blessés par les ratlesnalies ou crotales, seraient morts empoisonnís. M. Weir Mitchell a repris ces experiences, sans résultats positifs; il a 
toutefois constaté que, dans les solutions de crotaline, les graines pourrissent au lieu de germer. Nalrgré les contes débités par les panseurs de la Martinique, le docteur Guyon, puis le docteur Rufz ont démontré que les arbrisseaux mordus par le fer-de-lance, loin de dépérir, continuent à donner des feuilles et des fleurs.

De tous les animaux, les oiscaux sont les plus sensibles aux venins, ce qui tient à l'activité de leur respiration, qui développe chez cux ung grande chaleur naturelle. Les colibris el les oiseauxmouches sont les meilleurs de tous les réaclifs pour reconnaître des doses infinitésimales de ces substances.

Les êtres à sang froid, à moins que l'on n'élève artiliciellement lcur tempéralure, sont, au contraire, peu ou point impressionnés par les ćchidnines. Le poison de la vipère est sans effet sur les sangsues, les mollusques, l'anguille, l'orvet et les couleuvres. Il agit faiblement et avec lenteur sur les lézarts et les grenouilles. Ces dernières sont même d'excellents sujets d'expérience pour l'intoxication chronirjue par le venin des crotales, mais pour arriver à les empoisonner, il faut employer la substance toxique à doses considérables (1).

Fontana (Truité de lu Tipère, ge parlie, ch. V) a démontré que le poison de la vipère n'en est jas un pour son espèce. Nos expériences nous ont toujours donné le mème résultal. An mois d’avril dernier, M. l'abbé Giequiau el moi, nous avons fait mordre, entre autres, une vipère-aspic grise de moyenne grosseur d'abord par elle-même, puis deux fois par un très-fort aspic rouge à venin éprouvé; elle n’a présenté aucun signe d'intoxication el

(1) Les platycerques (hydrophides, hydres, etc.), serpents du groupe des protéroglyphes, qui. passent leur vie dans la mer et se nourrissent de poissons el de crustacés, ont par exception un venin très-puissant sur les animaux à sang froid, fait démontré par le $\mathrm{D}^{\mathrm{r}}$ Cantor, médecin de l’armée des Indes. 
n'est morte que trois mois après, d'inanition et de splecn. Dans les derniers temps, son venin moins actif ne luait un moineau qu'au bout de quinze minutes.

Le $\mathrm{D}^{\mathrm{r}}$ Guyon (Comptes-rendus de l'Institul, tome LIII, juillet 1861) a essayé d'inoculer à un certain nombre de serpents (bothrops lancéolé, céraste d'Égypte, échidnée ma!ıritanique, échidnée à queue noire, trigonocéphale piscivore, ete.' lenr propre poison et toujours sans suceis. Ses expériences ont ćté également négatives lorsqu'il a fait murdre un de ces reptiles par un serpent d'une autre espèce; il étend done à tous les ophidiens la loi de Fontana sur l'innocuité du venin pour l'animal qui le produit. Sans cela la moindre éraillure de la muyueuse buceale d'un serpent venimeux le mettrait en danger de mort. On peut, au contraire, blesser la gucule d'un de ces reptiles on le forçant à serrer les màchoires sur du verre brisé, sans qu'il lui arrive d'accidents graves.

Le $\mathrm{D}^{\mathrm{r}}$ Weir Mitchell est venu compliquer le jroblème en disant rue les crotales peurent être empoisomnés par leur venin employé à dose considérable; ce poison, toutefois, n'aturait pas d'action, appliqué sur des plaies, de leur muquense buccale.

MHI. Mangili et Cl. Bernard croient à l'auto-inoculation de's venins et ont vu des serpents mourir par suite de leurs propres morsures ou de l'inoculation artificielle de leur' poison. Ils accusent les adversaires de leur doctrine d'aroir méconnu l'empoisonnement, parce qu'il est lent à se produire sur ces animaux. Mais les reptiles qui ont servi aux expériences de M.M. A. Duméril, Guyon el aux môtres ont élé conservés vivants pendant. plusieurs mois. Il est done probable que les partisans de l'autoinoculation ont pris cux-mèmes des efiets de simple traumatisme pour des symptômes d'intoxication.

M. A. Duméril (loc cit., p. 2733) a élé frappé de l'innocuité des 
blessures que se font les ophidiens venimeux, quand ils se battent entre eux ou se mordent. Un jour cependant, à la suite d'une lutte entre deux échidnées heurfantes, l'un des combattants fut trouvé mort dans sa cage; l'autopsie démontra qu'il avait eu la pulpe cérébrale traversée par un des crocs de l'autre échidnée; le vainqueur, quoique couvert de blessures, ne présenta aucun signe d'empoisonnement.

Les venins n'agissent guère que par inoculation; non gustu sed in vulnere nocent. Appliqués sur la peau ou les muqueuses (celle des bronches exceptée), ils sont sans effet. Introduits dans l'estomac, ils ne donnent lieu à aucun accident. Les victimes de nos expériences ont servi de régal à diverses persomnes, et le poison de la vipère et celui du serpent à sonnettes ont été acalés purs avec la plus grande inpunité par Fontana, Weir Mitchell el autres courageux expérimentateurs.

Injectés dans une grosse veine, les venins causent une mort rapide, au milieu de convulsions et de symptômes inflammatoires vers le poumon et le tube digestif.

Dans le réseau capillaire, ils manirestent avec plus de lenteur leur action catalytique qui s'étend de proche en proche. Le sang altéré laisse transsuder son sérum et produit de l'œè̀me ou même s'extravase sous forme de taches livides.

C'est à la fibrine que s'attaque surtout le poison des ophidiens; soit qu'il la détruise par dédoublement, soit qu'il la transforme en une substance isomère, il lui enlève ses propriétés plastiques.

L'action dissolvante du venin n'est point immédiate. Ilèlé au sang, dans une éprouvette, il le coagule d'abord, comme le ferait du mucus ou du pus; le caillot sans consistance, se dissout au bout de vingt-quatre heures, et sa fibrine n'est plus susceptible de se coaguler.

Les globules, autre principe vivant du sangr, seraient aussi, 
modifiées par les solutions venimeuses. Ils cesseraient de se réunir en piles sous le champ du microscope et deviendraient dentelés sur leurs bords; mais l'isolement de ces corps cellulaires, quand ils se déposent, n'est point un signe d'altération. C'est un phénomène physique; le venin, par sa consistance gommeuse, joue dans le mélange sanguin le rôle de l'eau sucrée dont se servent les micrographes pour l'étude des globules.

La dentelure des bords de ces corps flottants n'a pas plus die valeur. Cette déformation ne se produit que si le contact du poison a été prolongé, et se rencontre rarement à l'autopsie, même dans les cas de morsure de serpents à sonnettes; enfin, on trouve des globules ainsi altérés, toutes les fois que le sang se décompose.

Le sang des animaux venimés est noir et chargé d'acide carbonique, par suite de l'asphyxie qui précède la mort. L'intoxication elle-même n'enlève point aux globules la faculté de s'oxygéner; le liquide tiré d'une veine et mélangé de venin devient rutilant par son exposition à l'air.

L'autopsie des animaux victimes de morsures de vipères démontre que le venin agit dans les vaisseaux, de la même manière que sur le sang tiré des veines. Quand la mort a été lente à venir (empoisonnements subaigu et chronique), le cour et les vaisseaux recèlent un liquide difluent, ou contiennent des caillots molasses et semblables à de la gelée; quand au contraire elle a été presque instantanée (empoisonnement suraigu), le sang ne présente aucune modification notable (1).

(1) Les grandes affections miasmaliques, et la fievre jaune entre autres, qui ont tant de rapport pour la symptomatologie avec les empoisonnements par le venin des serpents à sonnettes, prísentent à l’autopsie les mèmes différences dans l'étal du sang, suivant que la mort a été plus ou mions rapide. 
Le venin n'est done point exclusivement un poison du sang: dans les cas les plus graves, il agit en poison des nerfs. Les petits animaux qu'il atteint tombent comme foudroyés, et, en dehors de ces faits de sidération, il donne lieu à des symptômes d'adynamie et même d'ataxie.

La manière dont s'exerce sur le système nerveux l'action des échidnines n'est pas connue. Faut-il voir là un phénomène purement dynamique, ou le poison produit-il, dans le liquide que contiennent les éléments nerveux, des altérations matérielles?

Après la mort, la raideur cadavérique se manifeste promptement, mais dure peu; les muscles, du reste, perdent vite la faculté de se contracter sous l'influence du galvanisme. Le cœur est l'ultimum moriens et la respiration artificielle prolonge ses battements; la putréfaction est rapide. Au point traversé par les crochets, la peau offre une rougeur inflammatoire de mauvais aspect, analogue à celle qui entoure une blessure anatomique ou toute autre inoculation putride. L'épiderme est souvent soulevé sous forme de phlyctènes et le derme parfois se sphacèle au niveau des petites plaies; phénomène rare dans les morsures de vipères, mais fréquent dans celles du céraste et des crotaliens. Les muscles blessés sont ramollis et imprégnés de sang, et leurs fibres désagrégées se trouvent réduites à un état granuleux, sorte de décomposition moléculaire. Enfin des trainées de lymphangite indiquent la voie par laquelle s'opère en partie l'absorption.

Les effets des venins de l'aspie, du péliade et de l'ammodyte, ne présentent pas de différences sensibles. Les poisons des autres solénoglyphes ont une action identique, à l'intensité près. Toutefois cette intensité est non-seulement en rapport avec la quantité de liquide toxique sécrétéc par l'animal, mais elle varie encore suivant l'espèce du serpent. Ce que nous savons des protéro- 


\section{glyphes conocerques et en particulier des najas nous porte aussi à rapprocher leur venin de celui des vipères (1).}

(1) Au moment où nous revoyons une dernière fois ces épreuves, nous lisons, dans le compte rendu de la séance de l'Institut du 8 juin $\mathbf{1 8 6 8 ,}$ l'analyse suivante, faite par M. le Secrétaire perpétuel, d'un mémoire de M. G. B. Halford, extrait du dernier volume des Transactions de la Société royale de Victoria, et ayant pour titre : De l'état du sang après la mort occasionnée par la morsure du serpent:

"Quand une personne est mordue par le Naja tripudians, des germes de matières vivantes sont introduits dans son sang; ils y développent des cellules et s'y multiplient avec une promptitude telle, que des millions s'y pro. duisent en quelques heures, aux dépens sans doute de l'oxygène absorbé dans le sang pendant l'inspiration; de là viennent la décroissance graduelle et l'extinction de la combustion, les changements qui se manifestent dans toutes les parties du corps et qui sont suivis du refroidissement, de l'assoupissement, de l'insensibilité, du ralentissement de la respiration et de la mort.

"Les ceilules, qui rendent en si peu de temps le sang incapable de maintenir la vie, sont circulaires avec un diamètre d'environ $1 / 1700^{\circ}$ de pouce; elles contiennent un nucléus presque rond de 1, $2800^{\circ}$ de pouce de largeur; ce mucleus regardé avec un fort grossissement se montre rempli de sphérules de germes de matières vivantes encore plus petites. En outre, l'application du magenta révèle un petit point coloré sur quelques parties de la circonférence de la cellule. C'est ce qui, outre sa dimension, la fait distinguer du pus blanc ou des corpuscules de la lymphe.

๖ En sorte qu'il paraitrait que, tandis que les cellules végétales exigent pour se développer une nourriture inorganique et le dégagement de l'oxygène, les cellules animales demandent une nourriture organique et l'absorption de l'oxygène. Celte nourriture se rencontre dans le sang, et l'oxygène leur est olfert par les globules. Ainsi tout le sang se désorganise, et après la mort on le retrouve sombre et fluide: sa fluidité indique le manque de fibrine et sa couleur rouge sombre l'absence d'oxygène : le liquide absorbe immédiatement de l'oxygène quand on l'expose à l'air après la mort. »

Quelque séduisante que soit la théorie de MI. Halford qui expliquerait tous les faits de l'envenimation, elle a besoin, pour prendre rang dans la science, d'ètre contròlée par d'autres expérimentateurs. Nous n’avons jusqu'ici rien observé de pareil. 


\section{III}

Fontana termine son Traité du venin de la vipère par ces ad. mirables paroles (1): “J'ai fait plus de 6,000 expériences; j'ai fait mordre plus de 4,000 animaux, j'ai employé plus de 3,000 vipères, et je puis m’être trompé; quelque circonstance essentielle peut m’avoir échappé : je puis en avoir négligé quelque autre, ne la croyant pas nécessaire; mes conséquences peuvent être trop générales, et les expériences en trop pelit nombre. En un mot, il se peut très-bien que je me sois trompé, et il serait même impossible que je ne me fusse jamais trompé dans une matière si difficile, si obscure et encore si neuve. 11 me suffit de pouvoir certifier que je n'ai écrit que ce que j’ai vu ou du moins cru voir.

Depuis Fontana, beaucoup de médecins et de naturalistes, entre autres Mangili, MII. Duméril et Cl. Bernard, ont contrôlé ou discuté ses travaux avec des expériences nouvelles; mais il reste encore beaucoup à faire dans celte voie, surtout en employant les procédés suivis par les physiologistes modernes pour le curare.

On peut, du reste, se tromper gr'ossièrement dans l'élude des venins, en concluant d'une façon trop absolue de faits provoqués chez les animaux à ce qui doit se présenter chez l'homme. Les déductions de la méthode expérimentale. n’ont de valeur réelle que lorsqu'elles sont confirmées par l'observation directe, véritable pierre de touche au point de vue pratique.

Appuyé sur les travaux de Fontana el de ses imitateurs, nous

(1) Tome II, p. 63. Édition française. Florence, 1781 
avons cherché à les compléter à l'aide de données fournies par la clinique.

Déjà, pour un précédent travail (Études médicales sur les serpents de la Vendée et de la Loire-Inférieure, $\mathbf{1}^{\text {re }}$ édit., p. 37), nous avions réuni 203 cas de morsures d'aspic et de péliade, tous inédits et ayant eu lieu dans nos deux départements. Depuis celte époque (1860-1861), 118 cas nouveaux nous ont été communiqués, ce qui donne un total de 321 personnes mordues.

Les observations que nous avons recueillies nous proviennent de diverses sources; les plus nombreuses nous ont été fournies par des médecins exerçant dans des communes rurales, par des curés et des instituteurs de campagne; enfin, par des naturalistes, et en particulier, par MII. A. de l'Isle et Alc. Thomas. Ce dernier met entre nos mains, au moment où nous imprimons la troisième partie de notre travail (juin 1868), toutes ses notes, ct, entre autres, celles qui ont servi au rapport qu'il adressa, en 1860, à la Société d'acclimatation (1).

(1) Nous regrettons de n'avoir pas eu plus tôt communication des notes de M. Thomas, car elles contiennent des détails curieux et souvent nouveaux sur les mœurs des serpents et en particulier sur celles du pitiade. Ainsi, nous croyons qu'il est le premier à avoir remarqué que le péliađe peut, pendant le repos, s'aplatir et s'élargir considérablement. \& Au mois de mai 1861, je surpris, dit-il, dans un taillis près de Blain, une de ces vipères ainsi aplatie; je la crus morle, mais, saisie par le cou avec mes pinces et suspendue en l'air, elle s'agita et reprit sa forme cylindrique. „

Le 18 mai 1864, M. A. de l'Isle n'ayant point connaissance du fair observé par M. Thomas, fut témoin de quelque chose de plus curieux en core: * J'étais, nous écrit-il, en course erpétologique, avec un de me: frères, à Juigné-les-Moutıers; ayant quitté la route de Châteaubriant, nous nous enfoncions dans les tirrains boisés qui s'étendent entre SaintHubert et la Blisière, el díjà nous avions aperçu un premier péliade, lorsque nous en rencontrâmes, près d'une clairière schisteuse, un second, à robe pâle et à zigzag très-foncé, qui nous présenta un singulier phénomène. Un crapaud, que l'on menace, gonfle rapidement ses poches 
Le dépouillement des documents envoyés à la préfecture de la Loire-Inférieure nous a donné à lui seul 67 cas d'empoisonnement venimeux. Enfin, nous avons observé nous-même trois faits de ce genre : celui de M. Rautou, cité plus haut, page 66 , et les deux qui suivent:

Le 24 mai 1860, par un temps chaud et un peu orageux, à trois heures du soir, M. l'abbé H..., professeur à la pension SaintStanislas, âgé de trente-neuf ans, et d'une assez bonne santé, se promenait, deux heures environ après son repas, à la Desnerie, sur les rochers qui bordent la rivière de l'Erdre. Au sortir d'un taillis en partie défriché, il fut mordu au-devant du coude-pied gau* che par une grosse vipère-aspic grise, qui disparut dans le fourré.

\section{Désireux de se mettre au plus vite entre les mains d'un homme}

sous-cutanées et devient presque invulnérable; cette vipère, privée de la précieuse faculté d'isoler sa peau et ses muscles, s'effaça, quand je levai le bâton sur elle, et s'aplatit soudain contre terre comme pour atténuer le coup. Je fus obligé d'appeler mon frère à mon aide pour m'en rendre maître. Cette ruse de guerre sert sans doute aussi au péliade pour se dérober à la vue de ses ennemis et des animaux dont il fait sa proie.

II. l'abbé Chabirand, vicaire de Champagné, ignorant la découverle de MM. Thomas et de l'Isle, a fait une observation analogue sur la couleuvre vipẻrine.

Nous trouvons dans les notes de M. Thomas un exemple d'un mode de progression de l'aspic assez anormal : "Par une chaude soirée de juillet, je me promenais, avec un botaniste étranger, dans la belle vallée qu'arrose la Chésine. En passant par une prairie située entre le ruisseau et le taillis de Carcouet, nous aperçumes une grosse vipère rousse qui traversait cette prairie avec une vitesse incroyable pour un serpent de son espèce et se dirigoait vers la Chésine. Il n'y avait absolument que son ventre qui touchàt la terre. Sa tête el sa queue étaient fortement relevées. J'cus un peu de peine à l'atteindre; je réussis cependant à l'arrêter avec mon bâton, sur lequel elle donna quelques coups de crochel, en laissant échapper trois ou quatre gouttelettes de venin., 
de l'art, le blessé descendit vers la rivière pour se faire transporter en canot jusqu'à Nantes. Il n’appliqua point sur sa jambe de lien constricteur, et son bas imbibé de venin fut laissé en contact avec la plaie. Durant la traversée, aucun accident général ne se manifesta; le pied ne se tuméfiant que très-modérément, MI. l'abbé H. ne songea point à le laisser pendre dans l'eau.

Arrivé à Nantes, il reçut les premiers soins de 11 . Besnier, pharmacien au Port-Communeau, qui lui donna une potion contenant vingt gouttes d'ammoniaque, lotionna les piqûres avec cette substance, et conseilla au malade de rentrer chez lui et d'appeler son médecin.

Appuyé sur le bras d'un ami, M. II... rejoignit son domicile, où il élait temps qu’il arrivât, car sa jambe, se tuméfiant progressivement, allait lui refuser service. Il commençait, du reste, à éprouver des nausées et se sentait défaillir.

Dès les premières cuillerées de potion, les vomissements survinrent fréquents et douloureux, d'abord composés de substances alimentaires, puis de bile et de glaires sanguinolentes. Quelque vive que fût la soif, aucun liquide n'était supporté. Le malade accusait une douleur épigastrique atroce et de violentes tranchées; il se refroidissait et avait de la tendance à l'évanouissement.

Depuis la marche, la tuméfaction de la jambe, lente jusque-là, avait augmenté avec rapidité; elle dépassait le genou et la peau tendue était lisse et violacée.

A cinq heures, le $\mathrm{D}^{\mathrm{r}}$ Thibeaud, professeur à l'École de médecine, arriva près du blessé. Il reconnut avec un peu de peine deux empreintes de crochuis déjà effacées par la rétraction dủ derme, et assez distantes l'une de l'autrr; il les agrandit, en tira quelques gouttes de $\operatorname{san}_{\delta}$ el y introduisit de l'ammoniaque. II appliqua ensuite sur la cuisse une ligature tardive qui ne put être supportée plus d'une heure. 
Les symptômes devenaient effrayants et étaient encore exagérés par l'inquiétude bien légitime du malade. L'effort des vomisse. ments avait amené des soubresauts tendineux; le pouls était formicant et à peine sensible; le corps se couvrait de sueurs visqueuses et glaciales; la face livide prenait une teinte subictérique, et l'état syncopal se prononçait de plus en plus. M. le professeur Letenneur fut appelé en consultation par M. Thibeaud. Ils décidèrent qu'un mélange d'eau-de-vie, d'eau et de sucre remplacerait la potion ammoniacale.

En même temps, des sinapismes furent posés sur l'épigastre et promenés sur les cuisses. Grâce à l'emploi de ces nouveaux moyens, les contractions de l'estomac se calmèrent, et un peu de réaction commença à se montrer. Cet ensemble de phénomènes alarmants avait duré une heure.

Une légère fièvre parut dans la soirée, et le malade eut de l'agitation pendant la nuit. En dehors de ce mouvement fébrile, il ne présenta ni trouble intellectuel, ni altération de la sensibilité, ni même de céphalalgie.

Le lendemain, la tuméfaction, tout en conservant ses caractères, était descendue au-dessous du genou; des traînées lymphati. ques se montraient à la face interne de la cuisse; le pouls était relevé, mais encore dépressible, et il y eut de nouveau de la fièvre vers le soir.

Le vin de Malaga fut administré à la place de l'eau-de-vie.

Le 26, la teinte subiclérique avait en partie disparu; mais, à cette époque, on vit se dessiner sur le membre malade des taches livides, violacées et comme ecchymotiques.

La tuméfaction augmenta toute la semaine, atteignit les côtés du ventre et gagna le thorax; après quoi elle décrut et devint indolente.

Le dix-huitième jour, MI. l'abbé H..., ayant cessé de maintenir 
sa jambe étendue, fut pris d'érésipèle au voisinage des piqûres, avec fièvre assez intense. Des compresses imbibées̉ d'eau de sureau et la position élevée du pied firent disparaitre ces accidenls; l'élat général continua à s'améliorer, tandis que le mal local suivait une marche décroissante.

La convalescence n'allant point assez vite au gré du blessé, il recourut aux empiriques. Le premier appelé lui fit boire, en qua. rante-huit heures, cinq litres d'un vin médicamenteux obtenu par la macération dans du vin blane ordinaire d'une quantilé considérable de Galium rerum, plante servant de base au plus grand nombre des recettes employées dans l'Ouest contre les venins. Le remède provoqua des romissements et de l'excitation; mais, dès le lendemain, le gonflement avait diminué, et il n'existait plus qu'autour des petites plaies.

Charmé du résultat, N. H..., ayant essayé, quelques jours après, de reprendre ses travaux, la tuméfaction reparut et gagna de nouveau la cuisse. Alors intervint un autre guérisseur, maréchal ferrant à Château-Thébaud. Il couvrit les parties tuméfiées de feuilles fraîches de molène (Verbascum Thapsus L.); une sueur abondante se manifesta sous ces feuilles, effet que le coton et le taffetas gommé n'avaient pas obtenu. L'empirique ordonna, en outre, de prendre par verres, dans la journée, une macération dans un litre de vin blane des plantes suivantes formant un volume énorme (deux ou trois fois celui du vin): Galium verum L. (vulg. miélite), G. Aparine L. (gratteron), G. Mollugo L. (croisette verte), G. cruciatum Scop. (croisette jaune) et Rubia peregrina $\mathrm{L}$. (prend-nain). Le remède contenait, de plus, un morceau de tige de frêne broyée, un brin de genêt à balais, une racine de panais sauvage, une feuille de bardane el quelques feuilles d'aigremoine. Le liquide jaunâtre avait le goût amer et l'odeur de miel des deux plantes principales, les Galium verum et cruciatum. 
Malgré l'emploi de ce vin et les nouvelles scarifications pratiquées par l'empirique, l'œè̀me ne se dissipa qu'avec une extrême lenteur.

Le 8 août, M. H... put enfin sortir, en se servant d'un bas lacé, et vaquer à ses affaires. Il ne cessa l'usage du bas lacé que le 12 novembre; à cette époque (six mois après la morsure), le pied présentait encore un léger engorgement à la suite de l'exercice forcé.

Lorsque, en 1861, nous publiâmes cette observation, tout le monde considérait le blessé comme guéri, mais sa santé ne s'est jamais complétement remise. Chaque année, aux premières chaleurs, il éprouve un peu d'œedème douloureux du coude-pied, des pesanteur's d'estomac et des envies de vomir. Ses digestions sont restées pénibles et le portent à la somnolence; ses gencives sont fongueuses, et sa peau prend souvent une teinte subictérique. Il résiste mal au froid et supporte difficilement les fatigues physiques et intellectuelles. Grâce à une hygiène sévère et à peu de travail, il semble cependant depuis quelques mois marcher vers une amélioration notable.

Le 30 avril 1868, à dix heures du matin, au même lieu dela Desnerie, Julie Renaudin, âgée de vingt-neuf ans, fut mordue au médius droit par un aspic, pendant qu'elle sarclait dans un jardin. La vipère, petite et de couleur grise, avait élé saisie à pleine main dans une poignée d'herbe. Les premiers soins consistèrent dans l'emploi d'une bonne ligature qui ne fut gardée que quelques heures, dans une application d'une compresse imbibée d'aleali, et dans l'administration de quelques gouttes de celte substance avec de l'eau. Le surlendemain, cefte fille nous fut envoyée par M. le comte 0. de Sesmaisons. Elle avait éprouvé, la veille, de légers malaises. Sa main était enflée, et le gonflement remontait jusqu'au milieu de l'avant-bras, mais la peau n'offrait ni marbrures ni taches 
livides, et le ganglion épitrochléen était à peine tuméfié. Les deux petites piqûres siégeaient à la partie externe et postérieure de la deuxième phalange, distantes, l'une de l'autre, de six millimètres. Nous prescrivimes des frictions sèches et aromatiques, l'enveloppement de la main et de l'avant-bras par du coton à poil et du taffetas gommé, l'emploi d'un vin chaud à la cannelle, puis d'un autre vin médicamenteux préparé avec du vin d'Espagne et l'Aristolochia odoratissima L. (1). Sous l'influence de ce traitement qui produisit une sueur abondante, l'œdème disparut au bout de quelques jours, et cet accident n'eut aucune suite.

$\mathrm{Au}$ lieu de donner d'une manière succincte et sans grand profit pour le lecteur le récit de nos autres observations de morsures de vipères, nous nous bornerons à ne citer que les plus curieuses, et à indiquer les principales considérations qui ressortent de l'examen comparatif des cas observés. Il deviendra alors facile de décrire cliniquement l'affection venimeuse, et d'instituer le meilleur traitement à lui opposer.

§I. Examen comparatif des cas obsenvés. - Quelques faits de notre statistique remontent à une trentaine d'années; la plu- . part sont de date assez récente. Nos correspondants s'accordent à constater que le chiffre annuel des morsures de vipères devient, dans chaque commune, de moins en moins élevé.

L'année 1860 est celle qui nous en a fourni le plus grand nombre. Son printemps et son automne ont été particulièrement favo-

(1) Cetle aristoloche se trouve depuis quelque temps dans les pharmacies sous le nom inexact de Guaco. Elle porte en Guyane celui de Liane contrepoison, et comme le véritable Guaco (Mikania Guaco H. et B ), elle est employée dans la médecine créole contre les morsures des serpents. C'est un sudorifique énergique. Le principe aromatique qu'elle contient a de plus une action remarquable sur le système nerveux, et nous en avons obtenu de bons résultats contre les affections convulsives. 
rables aux reptiles et elle correspond à l'enquête préfectorale. Les deux dernières années 1866 et $\mathbf{1 8 6 7}$, fort pluvicuses, ne nous ont, au contraire, donné que peu de morsures.

Voici comment se rangent les cas recueillis d'après les divisions territoriales.

Arrondissement de Fontenay-le-Comte.......... 4 't

Arrondissement de Napoléon.............. 39

Arrondissement des Sables-d'Olonne........... 23

Total pour la Vendé........ T106 106

Arrondissement de Paimbœuf............... 42

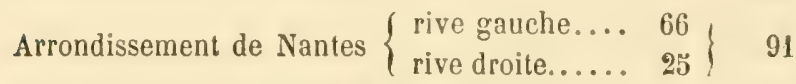

Arrondissement de Saint-Nazaire (Savenay)....... 40

Arrondissement d'Ancenis................. 22

Arrondissement de Châteaubriant............ 20

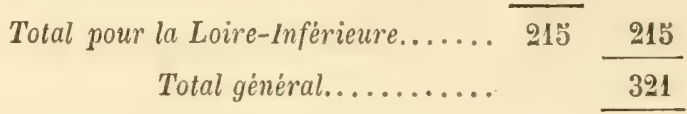

Soit 214 au sud de la Loire et 107 au nord du fleuve (1).

Ce tableau ne représente pas la fréquence relative exacte des accidents produits par les vipères dans les diverses divisions territoriales, et d'après le nombre et la léthalité des blessures, on devrait ranger ainsi les arrondissements : $1^{\circ}$ Napoléon, Fontenay et Nantes, $2^{\circ}$ Paimbueuf et les Sables-d'Olonne, $3^{\circ}$ SaintNazaire, $4^{\circ}$ Ancenis et Châteaubriant.

La rive gauche de la Loire est, avec juste raison, plus redoutée des chasseurs que la droite, et le Bocage vendéen, où règne l'aspic, fournit la plus grande quantité de morsures et les plus gra-

(1) Dans cette statistique ne sont pas comprises un certain nombre de morsures recueillies dans les départements limitrophes. 
ves, tandis que l'arrondissement boisé de Châteaubriant, hanté par le péliade, en offre très-peu, et surtout très-peu de sćrieuses.

La contradiction entre ces conclusions et le tableau qui les précède n'est qu'apparente. Il nous a élé plus facile de nous mettre en rapport avec les campagnes voisines de Nantes, où nous habitons, qu'avec les parties éloignées de la Vendée, et il ne faut pas oublier que les faits fournis par M. le baron de Girardot et M. Thomas ont tous eu lieu dans la Loire-Inférieure.

Il est difficile d'établir une moyenne annuelle de morsures de vipère dans l'un et l'autre département, tant le nombre de ces blessures varie suivant les localités. A droite du fleuve, on n'en c smpte guère qu'une par commune dans l'espace de deux à trois ans (1). Sur la rive gauche, la propurtion est plus furte et s'élève de un à trois par an. Certaines communes privilégiées n'en ont pas présenté depuis près d'un quart de siècle.

La moyenne à Saint-Père-en-Retz est, d'après le Dr Boucheron, d'une piqûre flar année; il en est ainsi dans beaucoup d'autres communes. A Saint-Aignan et dans les localités que baigne le lac de Grand-Lieu, on compte deux empoisonnements venimeux par an, suivant le $\mathrm{D}^{\mathrm{r}}$ Drouet père; le même chiffre est indiqué jour les environs d'Arthon, par le rapport du $\mathrm{D}^{\mathrm{r}}$ Touaille de la Rabrie (2). Dans les communes du Bocage, le nombre annuel des accidents causés par les vipìres s'élève à deux, trois, quatre et même cinq, mais les deux derniers chiffres ne représentent guère que les résultats d'une année exceptionnelle et ne peuvent servir de moyenne.

(1) M. Thomas admet pour la Loire-Inférieure environ soixante morsures par an, calcul approximatif peu inférieur au nôtre.

(2) Le Dr Touaille de la Rubrie, qui déclarait, en 1860, avoir soigné trente morsures de vipère dans l'espace de treize ans, nous écrit n’avoir pas vu de nouveaux accidents de ce genre depuis cette époque. 
Il ne se passe guère d'année que les vipères n'occasionnent la mort de plusieurs personnes dans nos départements.

Trois faits douloureux de ce genre nous ont été communiqués de l'arrondissement de Fontenay-le-Comte.

$1^{\text {er }}$ Cas. - Au mois d'avril 1832, un enfant de Luçon, âgé de onze ans, nommé Ronflet, fut mordu à la main par une vipère, pendant qu'il soulevait un fagot de sarments et le jetait d'une charrette; il enfla de tout le corps, eut des nausées, des lipothymies et un refroidissement général, et succomba le troisième jour. (Le $\mathrm{D}^{\mathrm{r}}$ Lepelletier, de Luçon.)

$2^{\mathrm{e}}$ Cas. - A Saint-Laurent-la-Salle, un homme de soixantesept ans fut, en 18599, blessé au pied par un aspic. Malgré l'emploi de l'ammoniaque intus et extra, il mourut en sept ou huit jours. Son fils, âgé de douze ans, mordu par le même reptile, guérit au contraire sans avoir présenté d'accidents sérieux. (II. David, curé d'Angles, ancien professeur d'histoire naturelle au séminaire des Sables-d'Olonne.)

$3^{\text {e }}$ Cas. - A Saint-Michel-Mont-Mercure, un enfant succomba à une morsure de vipère, quoiqu'il eût été traité par l'alcali. (M. l'abbé David.)

Quatre autres viennent de l'arrondissement de Napoléon.

$4^{*}$ Cas. - A Chavagnes-en-Paillé, en 1848, le Dr Papin-Clergerie reçut la visite d'une paysanne qui, en coupant du blé, ve. nait d'être atteinte au poignet par une vipère. Cette femme, dont le bras était déjà gonflé, se plaignait d'élancements dans la partie blessée, de défaillances et d'envies de vomir. Il lui fit avaler quelques gouttes d'alcali dans un verre d'eau sucrée et cautérisa la blessure avec du beurre d'antimoine; il prescrivit, de plus, la 
continuation de l'empioi de l'ammoniaque de deux heures en deux heures, à la même dose et dans la même quantité d'eau. Ceci se pas. sait dans l'après-midi d'une des journées les plus chaudes de l'été. Le lendemain, II. Papin apprit avec étonnement la mort de cette femme. (Le Dr Papin-Clergerie, médecin des hôpitaux de Nantes.)

ت̈ Cas. - En août 183̈7, Marianne Brochard, âgée de douze ans, habitant à la Gaubretiere, fut mordue par un aspic; ses parents demandèrent de suite un empirique de Chambretaud, renommé dans tout le Bocage pour son habileté a constater par la simple vue, si une plaie doit sa spécificité au venin du crapaud, du lézard vert, de la rinsoire ou salamandre, du quatre-épées, au venin d'eau ou à un venin composé de plusieurs des éléments précédents. Le guérisseur rangea en cercle la famille de la malade et entonna une hymne d'église que l'assistance répéta en chœur avec la plus grande gravité. Le lendemain, même cérémonie; mais cette fois la pauvre fille nattendit pas la fin de cette misćrable jonglerie; elle mourut à la deuxième strophe. (Le $D^{\mathrm{r}}$ Bourgeois de la Verrie.)

6 Cas. - A Rocheservière, le 5’ mars 1861, Narie Bouhier, àgée de six ans, enfant d'une forte constitution, était vers les deux heures du soir à cueillir des hozannes (I) (Primula acaulis L.) le long d'une haie, lorsqu'elle se sentit blessce par un serpent qui lui fit trois piquares à la face dorsale de la main droite. La douleur ne fut pas très-vive. De peur d'ìtre grondée, l'enfant se borna à laver avec de l'eau fraîche les plaies d'où coulaí un peu de sang. Le gonflement, qui envahit la main et l'avant-bras, la décida, au bout d'une demi-heure, à rentrer chez elle el à tout

(1) Les hozannes ou jozannes (de hozanna) doivent leur nom à ce qu'elles fleurissent aux Rameaux, comme la pâquerette tire le sien du jour de Paques; divers orchis, pour une raisun semblable, sunt appelées pentecôtes par nos paysans. 
raconter à son père. Celui-ci courut au lieu indiqué, où il tua une vipère commune assez grosse de 53 centimètres de long. Un empirique, appelé près de l'enfant, pratiqua sur la main malade un certain nombre de scarifications et rapporta, d'un endroit voisin, une herbe qu'il appliqua sur la blessure après l'avoir pilée et mélangée de sel; il conseilla, comme boisson, du vin chaud et froid. On ne mit point de ligature et l'alcali ne fut pas administré. Vers le soir, des taches livides apparurent, tandis que la tuméfaction gagnait dans la nuit la partie droite du thorax. Les remèdes du premier empirique restèrent sans effet, et Marie Bouhier fut confiée le lendemain à un second guérisseur. Celui-ci apporta, dans une bouteille, une macération de plantes de couleur brunâtre et d'odeur aromatique, devant être employée à l'extérieur el en boisson. L'enfant mourut trente-six heures après la morsure, ayant éprouvé un refroidissement général, des nausées, des vomissements, de la somnolence et une grande gêne respiratoire. Le $\mathrm{D}^{\mathrm{r}}$ Clochard ne fut appelé près d'elle qu'aux derniers moments. (Lettres des $\mathrm{D}^{\text {rs }}$ Clochard et Guitter, de Rocheservière.)

$7^{\text {e }}$ Cas. - Le 8 septembre 1865 , Jean Aubert, âgé de soixante ans, du village de la Grimaudière, en Saint-Philbert-deBouaine, vendangeait dans une vigne. Au moment où il détachait une grappe de raisin, une vipère enroulée autour du cep se jeta sur sa main gauche et le blessa à la face interne du pouce. L'aspic allait aussi piquer la fille Aubert, lorsqu'il fut lué sur un autre cep, à quelques pas plus loin. Quoique la chaleur fût étouffante, le malheureux vigneron se rendit ì pied consuiter une guérisseuse qui demeurait à plus de deux kilomètres; elle lui prescrivit l'emploi d'une macération vineuse de diverses plantes. Au bout de trente-six heures, se sentant plus mal, le blessé consentit à appeler le Dr Drouet, de Saint-Philbert-de-Grand-Lieu. L'enflure avait tellement aug- 
menté, qu'il fallut fendre la chemise pour voir les taches livides dont la peau de l'avant-bras et du bras était couverte. Le refroidissement était général; le pouls se sentait à peine; il y avait de la dyspnée el de fréquentes nausées, mais celles-ci ne donnaient pas lieu à des vomissements.

Le traitement ammoniacal prescrit par le médecin ne put sauver Aubert, qui succomba le septième jour. (II. Brouard, curé de Saint-Philbert-de-Bouaine, et M. Ie $\mathrm{D}^{\mathrm{r}}$ Drouet.)

Trois accidents mortels nous ont été signalés dans l'arrondissement des Sables-d'Olonne.

$8^{e}$ cas. - En 1845̆, la petite-fille d'un métayer des Moutiers-les-Mauxfaits fut mordue par un aspic, et succomba le lendemain. (M. Brethomeau, médecin à Aizenay, au service duquel était le père de l'enfant.)

$9^{\text {e }}$ cas. - A la fin du mois de mai 1862, Hermance Boquir, âgée de six ans, fille d'un pauvre journalier, demeurant au village du Petit-Beaulieu (commune de Moutiers-les-Mauxfaits), se promenait, avec un autre enfant, dans une prairie, lorsqu'elle fut mordue au coude-pied par une vipère. Les soins médicaux ru'elle reçut furent à peu près nuls; une vieille femme lui administra toutefois un spécifique dans lequel entrait beaucoup de napperon ou de bardane. Les symptòmes les plus graves ne tardèrent pas à se montrer. Il survint des taches noirâtres, un gonflement qui s'étendit jusqu'au ventre, des vomissements et des syncopes. La malade lutta ainsi jusqu'au septième jour et finit par succomber. (.I. Duchaine, maire des Moutiers-les-Nauxfaits.)

$10^{e}$ cas. - $\Lambda u$ mois d'août 18306 , la femme Biron, habitant le Coteau, commune de Commequiers, fut piquée au doigt par un aspie pendant qu’elle relevait une javelle de blé. La tuméfaction, déterminée par le venin, gagna tout le corps, s'ac- 
compagna de taches ecchymotiques et d'un abaissement de la température analogue à celui qu'on remarque dans le choléra . Les vomissements se répétèrent au point qu'il ne fut pas possible d'administrer des remèdes internes, et la blessée succomba le surlendemain: (M. Léopold Fruchard.)

$11^{\circ}$ cas. - En juin 18588, le jeune Merseron, de Challans, âgé de dix ans, ayant aperçu un nid dans un buisson, y porta la main et fut au mème instant piqué par une vipère qui s'était logée dans ce nid. On adressa l'enfant à un guérisseur dont les remèdes ne produisirent aucun effet. L'œedème gagna tout le corps; il survint des taches violettes, des vomissements à la fin sanguinolents, des faiblesses, puis de la fièvre et l'enfant succomba le septième jour. (Renseignements recueillis par nousmême, à Challans, de divers témoins oculaires.)

Onze des cas de mort de notre statistique ont eu lieu dans l'arrondissement de Paimbœuf.

$12^{\circ}$ cas. - Au mois de juin 1827, le jeune Vilain, âgé de six ans, du village de la Gouyère, en Sainte-Pazanne, fut mordu, à onze heures du matin, par une vipère de coulcur l'ougeâtre; quelıues heures après il offrait un odème général. Son père avait envoyé à Chémeré prendre conseil d'un homme redouté pour ses sortiléges, portant le nom de guerre d'Ilenry du GrandHoux. Le sorcier se rendit dans un champ, lit des invocations et consulta son oracle, bøuf noir désigné par les paysans suus le nom de Grand-Diable. Le bouf levait la patte droite ou la gauche suivant que sa réponse était aflirmative ou négative. Henry dı Grand-Houx pronit la guérison du blessé qui, pendant toutes ces manouvres, n'avait reçu aucun soin. Au retour du messager l'enfant était dans un coma profond. Il succomba le jour mème, malgré le cataplasme de lait caillé prescrit par le conjureur et 
sans avolr pu prendre les drogues qu'il avait ordonnées. (Le $\mathrm{D}^{\mathrm{r}}$ Bourdin de Sainte-Pazanne.)

$13^{\mathrm{c}}$ cas. - $\mathrm{Au}$ mois d'août 1827, Opportune Mauriceau, âgée de vingt ans, habitant le village du Poirier, en Saint-Pèreen-Retz, fut mordue par un aspic à une veine du talon, pendant qu'elle cueillait des noisettes dans un taillis. Elle mourut vers le huitième jour. (Le $\mathrm{D}^{\mathrm{r}} \mathrm{G}$. Boucheron de Saint-Père-en-Retz.)

$14^{\mathrm{C}}$ cas. - Le 14 août 1849, vers midi, Virginie Soreau, enfant de sept ans et demi, demeurant à Basse-Paragère, commune de Saint-Père-en-Retz, récoltait du prend-main dans une haie, quand elle fut mordue à la main gauche par une vipère rouge. On fit demander le Dr Boucheron, qui ne put arriver que deux heures après. Il trouva la malade sans connaissance, refroidie et à pouls presque insensible; les vomissements avaient été continuels depuis l'accident. Il ne découvrit qu'une petite plaie à la racine du doigt médius, l'agrandit et y introduisit de l'ammoniaque. La forme de la partie ne permit pas l'applicalion d'une ventouse. Des frictions furent pratiquées sur le membre avec de l'huile d'olive tiède. Les vomissements s'opposìrent à l'emploi de remèdes internes. La respiration devint de plus en plus difficile, et l'enfant mourut ver's huit heures du soir. (Le D $D^{r}$ Boucheron) (1).

$13^{e}$ cas. - Le 13 août 1838, à Saint-Viaud, près de Fros. say, Jean Simon, homme d'une excellente constitution, fut mordu au pied par une vipère, en coupant du blé dans une piece joignant le jardin du Plessis. La jambe enfla immédiatement et d'une façon considérable; elle se couvrit de taches livides. Ces phénomènes locaux s'accompagnèrent des symplômes géuéraux

(1) Depuis vingt-sept ans qu'il exerce à Saint-Père-en-Retz, notre conlrère a suigné une vinglame de morsures de vipères, el n'a eu connaissance que de ces deux cas de nort. 
les plus graves, et, malgré les soins qui lui furent prodigués, le blessé succomba le 4 septembre, c'est-à-dire trois semaines après la morsure.

$16^{\circ}$ cas. - Quelques années auparavant et presque au même endroit, à Frossay, sur la limite de cette commune et de celle de Saint-Viaud, Morin, cultivateur au village de la Valliais, fui piqué au doigt par un aspic en allant à son. champ arroser du lin. S'étant baissé pour tuer l'animal avec une pierre, il tomba évanoui, enfla de suite, et mourut en quelques heures.

$17^{\mathrm{e}}$ cas. - Au mois de mai 1850 , le jeune Gautier, de la Catelerais, en Frossay, âgé de dix à douze ans, fut mordu au petit doigt en cueillant des fraises. Le lendemain il n'existait plus.

Ces trois faits, par leur gravité, ont laissé dans la population des environs de Frossay une vive terreur des serpents, et en particulier de la vipère-aspic rouge, qui s'y trouve commune. Ils nous ont été rapportés, le premier par M. Boucard, supérieur du collége des Couets, les deux autres par notre regrellé ami le $\mathrm{D}^{\mathrm{r}}$ Noriceau, qui nous a pareillement confirmé les circonstances de la mort de Jean Simon, fermier de sa fiamille.

$18^{\circ}$ cas. - Un laboureur de Rouans, blessé à la jambe par la tête d'une vipère coupée en deux, mourul le jour mème. (Voir plus haut, page 59.)

$19^{\mathrm{e}}$ cas. - En juin 1841, Rose Grellier, âgée de onze ans. demeurant à la Rédunière, commune de Chauvé, traversirit une des prairies de cette ferme, quand elle fut mordue au pied par une vipère. La douleur fut vive; l'enfant s'élendit sur l'herbe et s'y endormit. Ses parents la trouvèrent dans cet état quelques heures après et la portèrent dans leur maison. Là ils lui frrent avaler qualre ou cinq goutles d'alcali, sans toutefois cautériser 
la plaie avec cette substance. Aucun médecin ne fut appelé, et le lendemain Rose Grellier, toujours dans le coma, s’éteignit vers le soir.

$20^{\circ}$ cas. - $\Lambda u$ mois d'août 1849, Louis Baconnais, âgé de neuf ans, demeurant au village de la Hâterie, commune de Saint-Michel-Chef-Chef, se sentit mordu au talon pendant qu'il aidait à couper le blé dans un champ; il poussa un cri et appela son père qui fut obligé de l'emporter dans ses bras. Les autres moissonneurs aperçurent la vipère qui s'enfuyait; c'était un aspic de couleur rouge. Les pelites plaies furent touchées avec de l'alcali et l'enfant avala quelques gouttes de ce liquide. Malgré ces soins, la douleur persista, la jambe s'œématia de plus en plus; bientôt survinrent des nausées et de la somnolence. L'enfant mourut vingt-quatre heures après la morsure; aucun homme de l'art n'était intervenu.

$21^{\mathrm{e}}$ cas. - a En 1850 , ajoute le $\mathrm{D}^{\mathrm{r}}$ Trochon, en nous communiquant les deux observations précédentes, un accident presque identique advint dans une famille voisine des Bacon. nais. Il s'agissait aussi d'un jeune garçon mordu par une vipìre. Je fus appelé près de lui, mais seulement le lendemain. La plaie avait été faiblement cautérisée et les symptômes qui se manifestèrent furent en tous points ceux du jeune Baconnais. Je conseillai des excitants, du thé, du rhum, du café, mais l'enfant n'en succomba pas moins le jour de ma visite.

$22^{\circ}$ cas. - En juin 1830̈, au village de la Corniliais, commune de Sainte Maric, près Pornic, deux enfants avaient été laissés seuls à la maison; l'ainé, Clair Sédineau, était âgé de vingt-deux mois, l'autre de cinq. Une vipère se glissa dans leur berceau, et, épargnant le plus jeune, mordit son frère à la main. Ceci se passait à midi; à neuf heures, l'enfant était morl. Les piquù'es avaient été cautérisées avec de l'alcali, et un 
médecin fut appelé, mais trop tard. Les symptômes éprouvés par le jeune Sédineau s'étaient présentés dans l'ordre suivant: douleur au niveau des piqûres, gonflement de la main, qui bientôt gagna le bras, algidité générale, pâleur du visage, somnolence, coma et mort sans convulsion. (Le $\mathrm{D}^{\mathrm{r}}$ Trochon de Pornic.)

L'arrondissement de Nantes nous a fourni 21 cas de mort par' la vipère: 19 sur la rive gauche, et 2 sur la droite.

$23^{\circ}$ cas. - Vers 1818, une femme mordue au pied par un aspic. dans la commune de Rézé, succomba le lendemain, ayant offert un gonflement énorme de la langue. (M. Thomas.)

$24^{\mathrm{e}}$ cas. - Le jeune Foucher de Machecoul, mort en six jours. (Voir plus haut, p. ๖ั5.)

$25^{\mathrm{e}}$ cas. - Vers le milieu du mois de septembre 1836, un homme de Vertou labourait un champ près des Sorinières et suivait nupieds sa charrue. Le soc heurta un aspic rouge de forte taille, qui se rua sur le malheureux cultivateur et lui enfonça profondément ses deux crocs au-devant du coude-pied gauche. Le blessé, vigoureux el dans la force de l'âge, ne put continuer son travail. Il plaça au-dessus de son genou une ligature qui n'empêcha pas la tuméfaction d'envahir en moins d'une demi-heure le membre entier. Transporté chez un propriétaire voisin, il fut traité intus et extra avec de l'alcali, et, de là, conduit à son propre domicile. Six semaines après, il boitait encore; les ecchymoses n'avaient point complétement disparu, et les piqûres, transformées en ulcères, laissaient suinter un liquide sanieux; les troubles digestifs et même les nausées revenaient de temps en temps. Le blessé avait vieilli; il manquait de force pour les travaux des champs, et mourut dix-huit mois après, sans avoir pu se remettre de cet état valétudinaire. (II. Thomas.) 
26 cas. - En 1819, Céleste Ariail, femme Babonneau, âgéc de quarante-sept ans, domiciliée en la métairie de Coinsaule, en Boussay, fut blessée par un aspic. Prétendue guérie par un conjureur, cile resta souffrante depuis lors. Chaque année elle éprouvait, à l'époque anniversaire de sa morsure, des troubles digestifs, à la suite desquels elle devint de plus en plus débilitée. Sa santé alla ainsi en déclinant jusqu'au $4^{\text {er }}$ février 1853 , jour où elle fut trouvée morte dans son lit. (M. Merel, curé de Boussay.) $27^{\circ}$ cas. - En 1853 . à la fin de juin, une jeune fille de quatorze ou quinze ans, demeurant à un village voisin de SaintÉtienne-de-Mer-Morte, ramassait du foin dans un pré, lors. qu'elle fut piquée par une vipère; il était sept à huit heures du matin. La paurre enfant n'osa pas se plaindre, et à midi elle était morte. Son maitre vint à Paulx prier II. Palvadeau, alors malade, de constater le décès. ( $\Lambda^{\mathrm{m} \ominus}$ Gobert, veuve de M. Palvadeau.)

$28^{e}$ cas. - Au mois de juillet $183 \% 4$, le jeune Hérie, âgé de huit ans, du village de l'Eticr, commune de Bouaye, jouait sur les bords du lac de Grand-Lieu tindis que son père travaillait dans un champ voisin. Le petit garȩon aperçut, au fond d'un fossé en partie desséché, des animaux qu'il crut être des anguilles; il appela son pìre pour l'aider à prendre ces prétendus margains et fut mordu à la jambe par une des vipères qu'il cherchait à saisir. On eut recours aux soins d'un empirique, et trois heures après, l'enfant n'était plus. (II. Thomas el M. Olive, médecin à Saint-Aignan.)

$29^{\mathrm{e}}$ cas. - En 18ว̈6, une jcune fille de la Chevrolière, âgée de vingt ans, d'une forte constitution, fut piquée au pied gauche par une vipère. Ses parents coururent aussitôt trouver un guérisseur qui lui fit faire des lotions aromatiques, mais elles n'empêchèrent flas l'œdème de devenir énorme. Il survint des nausées, des romissements et des syncopes. Le Dr Drouet père fut appelé vers le quinzième jour pour être témoin de la mort de la malade 
et mettre à l'abri la responsabilité de l'empirique. (Le Dr Drouet de Saint-Philbert de Grand-Lieu.)

$30^{\circ}$ cas. - En 18557 une petite fille, âgée de dix ans, de la commune de Saint-Jean-de-Corcoué, blessée à la jambe par une vipère, succomba en quatre jours. (M. Thomas.)

$31^{\mathrm{e}}$ cas. - Félix Nerrière, âgé de cinq ans, et demeurant à Boussay, avait suivi, le 4 juillet 18132, son père qui allait couper le blé. En jouant avec ses frères, il fut renversé dans un sillon au milieu du chaume et tomba sur une vipère qui le blessa au visage et probablement à la langue. Le $\mathrm{D}^{\mathrm{r}}$ Coiffard, qui se trouvait dans un village voisin, arriva au bout d'une demi-heure, mais l'œedème douloureux avait déjà gagné tout le corps de l'enfant; sa langue était tellement enflée qu'elle remplissait la bouche et rendait la respiration presque impossible. Le blessé entièrement cyanosé expirait une heure après. (M. le curé de Boussay.)

32 cas. - Le 28 juin 1865 , vers sept heures du matin, la veuve Brelagne, âgée de soixante-un ans, du village de la Renouerie, commune de Saint-Mars-de-Coutais, gardait ses vaches le long d'une haie ; elle était pieds nus dans ses sabots et marchait en filant sa quenouille. Tout à coup elle ressentit une vive douleur au bas de la jambe gauche et recula effrayée : une vipère rouge, sur laquelle elle avait monté, s'enfuyait dans le buisson voisin. La femme Bretagne regagna avec peine son domicile, situé à un kilomètre de là. De relour chez elle, elle lava à l'eau salée l'endroit mordu et enleva ainsi une petite quantité de sang répandue au voisinage des piqûres. La tuméfaction, d'abord limitée autour du point atteint par les crochets, s'étendit avec rapidité ; à neuf heures on appliqua au-dessus du genou un mouchoir plié en cravate. Cette constriction assez làche n'empêcha pas l'œedème de gagner la cuisse. Le mal progressant toujours, on envoya chercher M. Pa- 
try, médecin à Port-Saint-Père, et ancien interne des hôpitaux de Nantes, auquel nous devons cette observation.

Notre confrère n'arriva près de la malade qu'à midi, c'est-àdire cinq heures après l'accident, et voici les symptômes qu'il constata :

La veuve Bretagne offrait beaucoup d'agitation et d'anxiété. Elle avait de la difficulté à respirer, des lipothymies et des nausées suivies de vomissements bilieux. Elle était entièrement refroidie et couverte d'une sueur glacée; ses yeux hagards donnaient à sa physionomie une étrange expression de terreur ; son pouls était fréquent et petit. La malade répétait sans cesse qu'elle allait mourir.

L'examen de la jambe fit reconnaître, à trois centimètres environ au-dessus de la malléole interne, deux piqûres profondes, distantes de quelques millimètres et entourées d'un cercle inflammatoire. Une douleur aiguë s'étendait de ce point à tout le membre et était exagéréc par la pression; la tuméfaction gagnait la hanche; il y avait gêne très-prononcée des mouvements; la peau de la jambe offrait une teinte jaune verdâtre, plus marquée à la cuisse, où la lividité prenait l'aspect de marbrures.

A sa première visite, M. Patry administra vingt gouttes d'alcali dans une infusion de tilleul, conseilla une potion à l'acétate d'ammoniaque, des infusions aromatiques alcoolisées et du vin chaud. Il fit une incision cruciale sur la blessure, et, par la succion directe pratiquée à plusieurs reprises, en retira une certaine quantité de sang. Il la cautérisa ensuite avec de l'ammoniaque et prescrivit des frictions aromatiques chaudes et fréquemment renouvelées sur tout le corps. Une compresse imbibée d'eau ammoniacale fut maintenue sur la malléole.

Le 29 juin, mêmes symptômes généraux que la veille, mais exagérés. L'anxiété est extrême et le refroidissement complet. La veuve Bretagne, dans un état d'anéantissement profond, a un 
pouls misérable; l'œdème s’est généralisé; le membre gauche devenu énorme est couvert de plılyctènes.

M. Patry fait envelopper la partic malade dans des feuilles de lierre chauffées au four et continuer les boissons excitantes autant que le permet l'état de l'estomac.

Le 30 juin, l'oedème a pris une telle extension que la blesséc ne peut plus soulever ses paupières. Elle répond à peine aux questions qu'on lui adresse, tant est grande sa torpeur ; son intelligence, du reste, est affaiblie. Son pouls est filiforme et internittent ; les syncopes se rapprochent; il y a une frostration générale des forces. La malade refuse de prendre le moindre lípuiche et accuse une violente douleur dans le côté gauche dı thorax. Ce triste état va en s'exagérant el se termine à quiltre heures du soir par la mort, précédée de deux heures de pénible agonie.

$33^{\text {e }}$ cas. - François Peltier, âgé de dix-neuf ans, demeurant à la Gautrie, vỉlage de la commune de Saint-Étienne-de-Corcoué, ćiait occupé, au mois de juillet 186อ̃, à réunir du blé en gerbes, lor'squ'il se sentit piqué par une vipèèe à la jambe gauche, un peu au-dessus de la malléole cxterne. Il poussa un grand cri et tomba évanoui. On le transporta chez lui dans une chaise; trois goultes d'alcali lui furent données avec un peu d'eau, et il fut frictionné au point mordu avec de l'ammoniaque.

Un messager, envoyé au bourg, ramena en moins d'une heure le prêtre et le médecin. Le blessé n'avait pas encore repris connaissance; les remèdes prescrits ne furent point administrés.

La jambe enfla beaucoup le lendemain et la tuméfaction douloureuse envahit le membre jusqu’à l'aine. Un guérisscur fit prendre au malade, dans du vin blane, un jus d'herbes pilées et en appliqua le mare sur la morsure. 11 n'employa aucun des autres moyens à la mode dans le peuple, pas même les piqûres à l'aide du groseillier, et n'usa point de pratiques superstitieuses. Le breu- 
vage parut redoubler les vomissements et colora la langue en noir. Aucune anélioration ne se manifestant, les parents eurent recours à une frmme de la Gerhaudière, en Bouaine, renommée surtout au loin, comme prrfaite guérisseuse de venins. Elle exposa le membre blessé à la vapeur s'échappant de feuilles de lierre passées au four et le couvrit de ces feuilles. Un mélange de vin blanc et de suc d'herbes fut aussi donné en boisson. A la suite de ce traitement, la jambe désenfla, et, le quatrième jour, l'œedème avait presque disparu; des points noirs se remarquaient toutefois au lieu traversé par les canines. Le malade put se lever et commenȩa à manger. On le croyait en convalescence, quand, le septième jour, il fut pris, à la suite d'une soupe trop copieuse, de gêne extrême et de suffocation, symptômes qui allèrent en empirant. Un troisième guérisseur appelé in extremis pratiqua, au point mordu, cing̣ à six scarifications, à l'aide d'un canif. Le lendemain matin, vers les six heures, le malade expirait. (Le $\mathrm{D}^{\mathrm{r}}$ Clochard, de Rocheservière.)

$34^{\circ}$ cas. - Le 13 septembre 1866, à sept heures du matin, par un temps pluvieux, Modeste Gatoil, veuve Garnier, de Boussay, âgée de cinquante-quatre ans, fut mordue à l'index droit par une vipère-aspic, pendant qu'elle saisissait une poignée d'herbes. Les parents de la malade appliquèrent de suite de l'alcali sur son doigt, et la conduisirent, dans la soirée, à deux kilomètres de chez elle, consulter un conjureur, qui prescrivit, comme breuvage, une macération vineuse de diverses plantes et ordonna de répéter les lotions ammoniacales. Le lendemain, l'œedème s'étendait jusqu'à l'épaule. M. le curé de Boussay, appelé près de cette. femme, la trouva calme et presque sans prostration; elle n'avait encore éprouvé ni nausées ni vomissements. Il insista pour qu'on fit venir un médecin, et le $\mathrm{D}^{\mathrm{r}}$ Delhoumeau, de Clisson, fut demandé. Les remèdes cpu'il conseilla, trente six heures après 
l'événement, ne furent point administrés. Pcut-être craignait-on, en les employant, de détruire le charme de ceux du conjurcur. Les romissements se déclarèrent vers le soir, et, à sa seconde visite, II. Delhoumeau obtint de cautériser les deux piquares. Ce traitement tardif ne sauva point la blessée, qui succomba le quatrième jour, avec dles symptômes d'adynamie. (M. l'abbé Pestre.)

$33^{\circ}$ cas. - Le ¿ juin 1868, Joseph Nercier, âgé de douze ans, domicilié au Breil, commune de la Narne, fut mordu à la main par une vipère, pendant qu'il écartait de grandes herbes entourant un arbre, auyuel il voulait grimper. La mère dit avoir sucé sa plaie et avoir employé l'ammoniague. La fièvre et l'enflure du bras étant survenues, on conduisit le blessé sur une charrelte à bœufs, à plus de seize kilomètres, vers un conjureur de PontJames. Ramené beaucoup plus mal de chez l'empirique, il dut subir les divers traitements proposés par les commères du village, et aucun médecin ne fut appelé près de lui. Iluit jours après, l'œè̀me ayant gagné le cou et la figure, l'enfant trépassait. (M. Meynier, vicaire de la Marne.)

$36^{\mathrm{e}}, 37^{\circ}, 38^{\mathrm{e}}, 39^{\mathrm{e}}, 40^{\mathrm{e}}, 4 \mathrm{1}^{\mathrm{e}}$ el $42^{\mathrm{e}}$ cas. - Sept autres cas de mort par la vipere, ayant eu lieu dans le sud de l'arrondissement de Nantes, se trouvent indiqués sans beaucoup de détails dans les notes de M. Thomas.

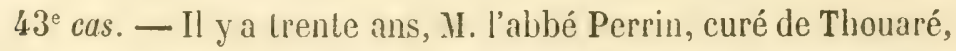
lut appelé pour administrer une femme, mordue par un aspic, ct apprit le lendemain sa mort.

$44^{e}$ cas. - En 1858, Jeanne Pinelle, âgée de dix ans et demi, habitant à la Grande-Cheminée, près de Nantes, suivait au mois $\therefore$ mai un chemin qui, du Pont-du-Cens, remonte vers la route l'Orvault, quand elle fut atteinte à la cheville par une vipère. La petite fille poussa un cri aigu et s'évanouit. Elle fut trouvée par des passants qui la firent revenir à elle. Le gonflement dou- 
loureux de sa jambe l'empêchant de marcher, ils la transpoptèrent dans une maison voisine et lui placèrent une ligature. Un médecin appelé ensuite cautérisa l'endroit blessé avec la pierre infernale et ordonna une polion contenant quelques goultes d'ammoniaque; mais la pauvre enfant ne put être tirée de l'état de syncope et de torpeur dans lequel elle se trouvait et succomba le matin du quatrième jour. (Une amie de la blessée, témoin des faits.)

Deux cas de mort seulement nous ont été signalés dans l'arrondissement de Saint-Nazaire.

$4 \breve{3}^{\wedge}$ cas. - En 18̈̈3̆, un enfant de cinq ans, du village de Beaufremais, à Saint-Gildas-des-Bois, accompagnant son père sur la lisière de la forêt, fut mordu au pied par un péliade qui se trouvait caché sous les feuilles mortes. Il enfla de tout le corps, fut pris de nausées et de prostration et, n'ayant reçu au début aucun soin rationnel, mourut le troisième jour. (M. Delpuech, ancien curé de Saint-Gildas.)

$46^{\circ}$ cas. - Le 17 mai 1860, dans la commune de Plessé, canton de Saint-Nicolas-de-Redon, l'enfant Tessier, âgé de onze ans, fut mordu à la jambe par une vipère à trois plaques, cachée dans un buisson. Il survint une tuméfaction énorme, avec couleur livide de la peau, des nausées, des vomissements, de la céphlalalgie, une anxiété précordiale très-grande, de la prostration, des sueur.s froides et des syncopes. Le blessé fut d'alsord traité par un empirique, puis par M. Ménager, qui ne le vit que quatre jours après l'accident. A l'arrivée du médecin, l'haleine étail fétide, et les accidents si graves, que la mort eut lieu le septième jour. (M. Ménager, médecin à Plessé.)

Les arrondissements de Chàteaubriant et d'Ancenis ne nous 
ont point fourni de cas authentiques de mort par blessure de vipère. Il nous parail peu probable, cependant, qu'aucun fait de ce genre ne se soil présenté dans ces deux circonscriptions, depuis vingt ans.

Nous avons parlé déjà, page 48, du mallıeur arrivé en 1867, à un enfant, dans une rue d'Anger's; ce n'est pas le seul cas de mort par plaie envenimée, que nous ayons recueilli en Maine-et-Loire; en voici deux autres.

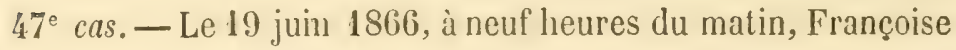
Audouin, de La Chapelle-Saint-Florent, était occupée à faner dans une prairie, sur les bords de l'Eve, quand elle se sentit piquée à la cheville par une vipère. Les premiers soins qui lui furent donnés, vingt minutes après, consistèrent en une ligature audessus du genou et dans l'application de compresses d'alcali. Le lien constricteur ne fut probablement pas assez serré, car l'œuème envahit la cuisse, et, dans la soirée, les vomissements se mon. trèrent, accompagnés d'une soif ardente. Bientôt la blessće se plaignit d'étouffements et d'angoisse, symptômes qui ne la quittèrent plus; elle devint froide et se couvrit d'une sueur glacée. Un conjureur, appelé le lendemain, incisa la jambe en deux points, puis introduisit de l'alcali dans les scarifications, accompagnant 10 tout de signes de croix et de mots cabalistiques. La malade succomba, à la suite d'ćtouffements, au bout de trente-six heures de souffrances. (MI. Léonce Arnous-Rivière.)

$4 \mathrm{~S}^{\mathrm{e}}$ cas. - A la Boissière-Saint-Florent, commune voisine de celle dans laquelle fut mordue la tille Audouin, et presque à la mème date (premiers jour's de juin 1866), Florence Ĺriau, âgée de quinze ans, traversait une prairie artificielle pour porter une faucille à des travailleur's, lorsulu'elle fut piquée par une vipère, 
un peu au-dessus des malléoles. Elle retourna de suite chez ses parents, où elle reçut presque immédiatement les soins d'un médecin; mais tout fut inutile, et elle succomba le lendemain soir, environ trente-six heures après avoir été piquée. (M. Ernest Arnous-Rivière.)

Les faits de mort par blessures de vipère sont communs dans les Deux-Sèvres.

$49^{\circ}$ cas. - A Saint-Amand, sur la Sèvre Nantaise, il y a une quarantaine d'années, un petit garçon de dix ans, mordu par une vipère, succomba en une ou deux heures. (Le Dr Sallé, des Herbiers.)

Nous croyons être dans le vrai en fixant à 2 pour la Vendée et à 1 ou 2 pour la Loire-Inférieure, le chiffre annuel des décès causés par Irs serpents. Cetle conclusion est aussi éloignée des opinions préconçues des théoriciens que de celles de nos campagnards. Les premicrs, en effet, écrivent, d'après Fontana (1), que la morsure d'une seule vipère n'a jamais de terminaison fitale, et les seconds considèrent cette blessure comme habituellement mortelle.

Les cas de mort que nous avons recueillis sont au nombre de

(1) Voici sur quel raisonnement Fontana (loc. cit., IV part., ch. II) appuyait son assertion. D'après ses expériences, un cinquantièıne de graiu $(0,01)$ de venin tue un passereau, un dixième de grain $(0,030)$ fait pétir un pigeon; la dose nécessaire pour tuer un animal augmentant en raison de son poids, il faudrait, à ce compte, trois grains ou quinze centigraımmes pour faire mougrir un lomme, quantité de poison que ne possède ni le péliade, ni l'aspic, qui n’en perdent du reste que deux centigrammes par coup de crochet. D'après ce calcul, un homine pourrait donc survivre à la morsure de plusieurs vipères et ne serail jamais tué pa: une seule. 
49; soit 34 ayant eu lieu dans la Loire-Inférieure, 11 en Vendée, 3 en Maine-et-Loire el 1 dans les Deux-Sèvres.

Dix fois la mort a eu lieu dans les vingt-quatre heures, vingt et deux fois du second au sixième jour, et douze fois du septième au vingt et unième. Trois blessés ont succombé à la cachexie, au bout de plusieurs mois. La durće de la maladie, chez deux des victimes, n’a pas été suffisamment indiquée; mais jamais la mort n'est survenue d'une manière instantanée, el l'intervalle entre la blessure et le décès a toujours été au mọns d'une heure.

Deux des blessures âvaient été faites par le péliade; toutes les autres doivent être attribuées à l'aspic.

La cautérisation immédiate au fer rouge n'a point été pratiquée; une fois, la plaie a élé traitée de bonne heure par le chlorure d'antimoine; presque toujours, au contraire, on a employé l'ammoniaque, du moins à l'extérieur. En général, les premiers soins ont été nuls ou dirigés par des empiriques.

Sur les victimes, 27 appartenaient au sexe masculin et 22 au sexe féminin; soit $\mathbf{1}$ ว’ petits garçons au-dessous de quinze ans, 11 petites filles, 2 jeunes gens de quinze à vingt ans, 3 jeunes filles, 8 hommes de vingt à cinquante ans, 6 femmes du même àge, 2 hommes de cinquante ans et plus, et 2 femmes pareillement du même âge.

Les enfants offrent donc à eux seuls plus de la moitié des cas de mort; néanmoins, la blessure de la vipère ne produit pas nécessairement chez eux une terminaison funeste.

En juin 1860, un enfant de dix mois, de la commune de HauteGoulaine, fut piqué à l'annulaire de la main droite par une trèspetite vipère. La tuméfaction envahit le bras et la poitrine, qui se couvrirent de taches violacées, et l'enfant vomil beaucoup dans la nuit. Il fut immédiatement traité par l'ammoniaque intus et extra; puis, dès qu'il fut mieux, on lui fit prendre l'infusion vi- 
neuse de Galium. Il guérit en quelques jours. (M. Baconnais, curé de Haute-Goulaine.)

Sur les 321 blessés, 132 présentèrent des symptômes généraux inquiétants, chez les autres tout se borna à de la prostration et à quelques nausées.

L'observation suivante, recueillie par le $\mathrm{D}^{\mathrm{r}}$ Bourgeois de La Verrie, rappelle, par la gravité des accidents, les blessures des crotaliens et en particulier du bothrops lancéolé. La double pneumonie est en effet un symptôme fréquent de la morsure du fer-de-lance.

« En 18\%̈, écrit II. Bourgeois, l'enfant Jamain, de Saint-Aubindes-Ormeaux, fut piqué par une vipère au pouce du pied droit. Les deux premiers jour's, il fut soigné par l'empirique de Chambretaud; mais, comme le mal faisait des progrès, on m'envoya chercher sur la recommandation du guérisseur; j'étais destiné à lui servir de paratonnerre et à délivrer le certificat de décès. Je trouvai le pied tuméfié et d'une couleur livide; la blessure était le siége d'une plaque gangréneuse assez étendue; mais, chose extraordinaire, et que je n'avais encore jamais vue dans les cas de morsures de vipère, il existait une pneumonie double (1). Je fis administrer au blessé du vin de quinquina, du café, du vin de Bordeaux; en outre, des incisions multiples furent pratiquées sur le pied et la plaie fut cautérisée. La guérison fut complète au bout de trois semaines de traitement. „

La piqûre de la vipère est souvent, au contraire, une lésion presque insignifiante.

(1) La pneumonie indiquée dans les cas de morsures de serpent n'est pas une veritable inflammation des cellules pulmonaires, mais bien une de ces congestions graves analogues à celles que l'on rencontre dans les autres empoisonnements septiques et désignées dans les auteurs sous le nom de peripneumonia notha. 
Au mois de juin 1867, Pierre Guillon, de Saint-Legé, travaillant dans une vigne, fut blessé à la jambe gauche par une vipère grise. Malgré sa terreur extrême, il n'éprouva qu'un peu d'anxiété, quelques nausées et de l'œdème douloureux à la jambe. Les crochets, au lieu de pénétrer dans les chairs, avaient éraillé la peau sur une surface d'un demi-centimètre. M. Patry appliqua extérieurement de l'ammoniaque et ordonna des boissons aromatiques; le malade fut mis dans un bain de vapeur, enveloppé de couvertures de laine, puis placé dans son lit. Une sueur abondante survint, et, le lendemain, Guillon était beaucoup mieux. Une bouteille d'eau de Sedlitz le débarrassa des symptômes d'embarras gastrique, ce qui lui permit deux jours après de reprendre ses travaux, ne conservant qu'un peu d'engourdissement de la jambe et le souvenir de sa frayeur. (M. Patry, médecin à Port-Saint-Père.)

Au mois de septembre 1866, Félix Baubrit, domestique à Boussay, fut mordu à la main par une vipère cachée dans une brassée d'herbe qu'il distribuait à ses bestiaux. Sans perdre de temps, il incisa lui-même la plaie, la fit saigner et lava sa main à grande eau. Il renouvela plusieur's fois cette opération et n’éprouva aucun symptôme d'empoisonnement venimeux. Baubrit prétend avoir été plusieurs fois mordu par des vipères el n'avoir jamais usé d'autres remèdes. (MI. le curé de Boussay.)

Un garçon du canton de Pouzauges, piqué par une vipère pendant qu'il se rendait à un préveil, ou assemblée, lia fortement sa jambe avec une réorthe, sorte de lien de bois qui sert à former les fagots; puis il cueillit, dans le pré où il se trouvait, une herbe dont il frotta sa blessure jusqu'au sang. Il rejoignit ensuite ses camarades et dansa tout le jour sans se préoccuper davantage de ce qui lui était arrivé. (M. Baudry, curé du Bernard.)

Nous pourrions mulliplier les exemples, mais ceux que nous 
venons de ciler suffisent pour démontrer que souvent la piqûre de la vipère est sans gravité.

Les morsures des membres inférieurs, au nombre de cent soixante-douze, siégeaient presque toujours au voisinage des malléoles ou sur le dos du pied et à gauche. Dans cent huit cas, la blessure a été faite à l'un des membres supérieurs et d'ordinaire à droite et à la main. Dix-neuf fois la lésion a porté sur le trone (cou, poitrine, abdomen, etc.). Les piqûres au visage sont au nombre de deux : l'une, dont nous avons parlé, s'est terminée par la mort; l'autre, que voici, a guéri en peu de jours :

En 18ö6, la femme Brianceau, du village de la Fauconnière, commune de Landeronde, effrayée à la vue d'un serpent, prit un morceau de bois pour le tuer; mais son chien voulant la dé. fendre se rua d'un bond sur le reptile, le saisit entre ses dents et le secoua avec violence. La vipère, pendant celte lutte, fut projetée à la figure de la femme Brianceau qu'elle mordit à la joue. Cette blessure, traitće immédiatement, n’eut pas de suite. (II. Viaud, curé de Landeronde.)

Dans 20 cas, le siége de la blessure n’était pas désigné.

108 des accidents ont cu lieu aux mois de mars, d'avril ou de mai; 162 pendant les chaleurs de l'élé; 40 à l'automne, et 6 en plein hiver; deux de ces derniers furent la suile d'une imprudence bien connue, qui consiste à réchauffer une vipère engourdie.

Les blessures automnales ont été, en général, moins graves que celles du printemps et de l'été.

Il est rare d'ètre piqué par une vipère arant la disparition de la rosée, et les paysannes mettent à profit cette particularité pour faire, dès l'aube, l'herbe de leurs bestiaux. M. Logeais, ancien interne des hôpitaux de Nantes, nous a toutefois communiqué le fait qui suit:

Au mois d'août 1860, à six heures du matin, un homme de 
Moutier-les-Mauxfaits se promenait, à la rosée', cherchant des limaçons, lorsqu'il fut mordu à la main par un aspic. Il se lia fortement le poimnet avec une chandelle de résine, et, s'étant soigné de suite, guérit en dix jours.

Trois fois, l'obscurité du crépuscule empêcha d'éviter le reptile; une fois il faisait complétement nuit.

Parmi nos blessés, 108 étaient occupés à la moisson ou à la coupe des foins; 8 aux travaux de la vigne; 64 longeaient une haie ou un buisson, y cherchant des fleurs ou des nids, et, en particulier, des nids de merle; 10 soulevaient des fagots de bourrée ou de sarments; 5 distribuaient du fourrage vert aux bestiaux; 27 dormaient ou étaient assis dans la campagne; 26 parcouraient des bois, des laillis, des champs de genêts ou d'ajone, nombre relativement faible, mais qui s'explique par les précautions dont on s'entoure pour pénétrer au milieu de ces repaires de serpents; 6 imprudents par forfanterie ou par amour de la science avaient saisi le reptile entre leurs doigts; sept fois la vipère incriminée avait élu domicile dans un jardin; une fois elle s'était glissée sous les draps d'un enfant endormi. Dans un cas le serpent se chauffait au soleil sur le bord de la mer.

La femme Gusteau, de la Chaume, âgée de cinquante-quatre ans, se rendait à la côte au mois de mai 1838 ; elle était pieds nus, suivant la coutume du pays, et marchait parmi les galets de la plage, lorsqu'elle se sentit mordue au pied par une vipère. La douleur primitive fut très-vive; dès le soir, le gonflement atteignit la base de la poitrine. Il survint des nausées violentes, mais sans vomissements; une prostration extrême, des syncopes, et, plus tard, de la fièvre. Le docteur Michclot ne vit la malade que deux heures après; il cautérisa néanmoins les piqûures, fit des scarifications sur' la partie tuméfiée, el conseilla une potion ammoniacale. Ce traitement n'empècha pas de recourir à des re- 
mèdes secrets qui furent administrés par un capitaine de navire. La tuméfaction du membre persista jusqu'à la fin de juillet, et la femme Gusteau resta valétudinaire durant plus de six mois. (M. Jaulin, ancien interne des hôpitaux de Nantes.)

Les blessures causées par des têtes encore vivantes, quoique séparées du tronc, sont au nombre de cinq; celles dues à des crochets de vipères mortes, au nombre de deux.

Parfois le reptile n'a frappé que d'une seule canine, ou s'est borné à érailler la peau. Sept fois il a multiplié ses morsures, et trois fois, dans ce cas, la mort s'en est suivie.

Notre statistique ne contient aucune observation de blessure par plusieurs vipères, quelque.grande que soit l'imprudence de certains chasseurs de serpents.

" L'un de ces industriels, raconte M. Grignon du Moulin (Union bretome, 31 décembre 1867), se rendait à la foire de Beaufort, portant un sac plein de vipères vivantes. Entré dans un cabaret, il le déposa dans une chambre du premier étage et sortit. Des buveurs attablés voyant grouiller le sac l'ouvrirent, curieux de savoir ce qu'il contenait. $\Lambda$ l'aspect des serpents qui s'élançaient de toutes parts, il y eut un sauve qui peut général, et les buveurs descendirent l'escalier en se culbutant; les plus effrayés sautèrent même par une fenêtre. Si l'un d'eux ne se fùt pas blessé grièvement dans sa chute, l'histoire eût été fort comique; car le chasseur, instruit de ce tapage, vint reprendre ses bêtes une à une, et, les remettant dans son sac, partit les vendre chez un pharmacien. »

Aux temps barbares des invasions scandinaves, la mort par l’exposition aux vipères était un supplice en usage. Ainsi périt le farouche pirate Ragnar Lodbrog, dont le chant de mort servit d'hymne de combat aux bandes daroises et normandes qui, au $\mathbf{I x}^{0}$ siècle, envahirent l'Angleterre et la France. 
Avee des observations plus détaillées que ne le sont la plupart de celles qui nous ont été transmises, on aurait pu tirer d'autres considérations intéressantes sur la durée de la maladie dans les cas heureux. La chose nous est complétement impossible: certains de nos correspondants, en effet, terminent leur récit à la disparition des symptômes généraux, tels autres, au moment oì cesse l'oedème; très-peu ont suivi le blessé jusqu’au r'etour complet de la santé. (uuand les accidents graves sont passés, le médecin de campagne n’est plus rappelé près du malade et le perd de vue.

L'espèce du reptile, dans le jlus grand nombre des cas, n'est pas suffisamment désignée, pour qu’il soit possible d’indiquer d'une manière certaine les piqûres qui sont a la charge de l'aspic, et celles qui doivent être portées au dossier du péliade (1).

Le venin de ces deux vipères donnant lieu aux mêmes phénomènes, nous étudierons, sous un seul titre, la symptomatologie de leurs morsures.

\$ II. Deschiption de L’afeection venimeuse. - Les phénomènes auxquels donne lieu l'introduction à traver's la peau du

(1) a Sur vingt-trois morsures de Pelias Berus, que j’ai recueillies, nous écrit M. Aleide Thomas, dix m’ont été communiquées par des médecins et treize par les parents de's malades. Sur ce nombre, une seule a ité suivie de mort; les autres ont oceasionné des aceidents plus ou moins sérieux, et, trois surtoul, des symptômes alarmants. Un jeune homme, entre autres, a été malade plus d'une annie. Les blessés, dont le docteur Fid. Cornudet m'a donne l'observation, étaient âgés de quinze à trente ans; ils ent tous présenté des romissements, des lipothymies et de la tuméfaction du membre mordu, accompagnée de douleur brùlante et de marlirures. Aucun d'eux n'est mort, mais une jeune fille d'une vingtaine d'années a enflé d'une façon si extraordinaire qu'elle donna de vives inquiéludes. La durée de l'affection a été en moyenne de yuinze à vingt et un jours. J'ai consigné tous ces faits dans le travail que j'ai adressé à la Société d'acclimatation. " 
poison versé par les crochets, se subdivisent, suivant le moment de leur apparition, en symptomes immeilints ou primilifs et en symptimes secomduires; certains blessés prónentent en outre des accidents plus éloignies que nous appelons symptomes tertinires.

Symptrimes primitifs on de hlesure. - A celte première cate-

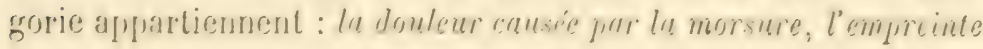
des dents venimeuses el l'écoulement sanguin.

La douleur primitive est modérée; le blessé la comprare à une déchirure de ronce wu à une pingure d’aiguille. Quelyuefois cé pendant elle est vive, aigue, et laisse aprics elle une sensation de brûlure qui se répand dans tout le membre. Elle est due moins à l'écartement des téguments par une pointe arérce qu'à la fénétration du venin dans les vaisocaux. Mead a piçué des chiens arec des aiguilles fines et recrubbes, sans qu'ils manifestassent l'agitation et les signes douloureux qu'ils offraiont lorsudu'il les faisait mordre par des viperes. Les résultats de nos expéricuces sont en complet accord avec ceux du savant anglais. Les lajpins blessés par un crochet sans venin ou par une vipere épuisée ne donnent aucune margue de douleur, tandis qu'atteints par les canines d'un reptile dont le poison a toute sa force, ils poussent en général un cri aigu du plus sinistre augure.

L'aspect de la plaie a céte décrit ; nous re reviendrons proint sur ces deux petites piqueres assez rapprochées l'une de lautre, et souvent difficiles a reconnaitre à cause de la rétraction des tissus. Chez neuf blessés, un des croes abamlonne par le serpent faisait corps étranger dans les chairs; chez cing autres, les traces de la morsure noffraient, au contraire, rien de caractíristique; les canines, au lieu d'écarter les fibres du derme, n’avaient fait qu'érailler la peau.

L'écoulement sanosuin est d'ordinaire insigniliant; is peiur: une: 
gouttelette indique-t-elle les points traversés par les crochets. Le liquide qui sort en dernier lieu des blessures agrandies a l'aspect sanieux.

Aucun accident général n’accompagne ces phénomènes initiaux, à moins qu'une veine n'ait été lésée; la peur extrême peut toutefois donner lieu, au moment de la blessure, à une syncope ou à de l'exaltation nerveuse.

Symptômes secondaires. - Ils se subdivisent en accidents locaux consécutifs ou d'inflammation spécifique, et en accidents généraux ou d'intoxication, suivant qu'ils résultent de l'action du venin au point où il a été inoculé, ou qu'ils se manifestent au loin sous son influence.

Dans le premier groupe se rangent: la tuméfaction inflammatoire, la douleur secondaire, l'engourdissement et le refroidissement de la partie blessée, les taches livides et diverses autres lésions ayant leur siége au voisinage des piqûres.

La tuméfaction de la partie blessée est un phénomène constant; elle ne fait défaut que dans les cas où une médication énergique et immédiate, la succion ou l'incision, par exemple, a enlevé le venin avant qu'il ait eu le temps d'agir.

Elle ne mérite point au début le nom d'œdème que lui ont donné les auteurs, car elle s'accompagne de rougeur et de chaleur. Elle commence par une aurćole violacée, ayant pour centre les piquûres, puis s'étend de proche en proche, tantôt se bornant dux parties voisines, tantôt envahissant une portion considérable du corps. Elle ne dépasse guère la ligne médiane; elle peut cependant devenir générale, gagner le tissu cellulaire sous-muqueux, et produire la mort en atteignant les replis qui forment l'orifice supérieur du larynx.

C'est une grande erreur de confondre, comme le font nos mé- 
dicastres campagnards, la diffusion réelle du venin avec la marche en étendue de l'infiltration séreuse ; fandis qu'une partie du poison s'épuise ainsi localement, le reste de la substance toxique, entrainé par le torrent de la circulation, excree au loin ses ravages sur le système nerveux et sur les globules.

La tuméfaction est parfois instantanée, rarement elle tarde plus d'une heure à se produire; elle rend les parties dures, tendues, rénitentes et d'un volume double ou triple de leur volume normal. Elle disparait au bout de quatre à huit jours, ou bien persiste pendant plusieurs septenaires, perdant alors ses caractères propres pour prendre ceux d'un véritable cedème.

La douleur consécutive est une douleur d'inflammation; elle est accompagnée d'un sentiment de tension, et disparait en général plus vite que le gonflement. Chez quelyues sujets, toutefois, elle conserve, plusieurs scmaines, un certain degré d'acuité; elle est exagérée par le jeu des muscles.

L'engourdissement est en rapport avec la distension du membre ; il est produit par la compression que fait éprouver aux cordons nerveux le tissu cellulaire infiltré.

L'abaissement de la température qu'accuse le blessé se constate facilement par l'application de la main ou du thermomètre; ce dernier instrument, placé sur la partie malade, marque de 31 à 30 degrés centigrades. Le refroidissement est dû à une action particulière du venin sur le sang, par laquelle les combus. tions organiques se trouvent diminuées : il remplace rapidement la chaleur qui accompagnait le gonflement inflammatoire, et, d'abord limité au voisinarge de la blessure, il finit par'se généraliser.

Les taches livides, moins constantes et plus tardives que la tuméfaction, sont cependant un des symptômes les plus caractéristiques de l'empoisonnement venimeux. Rouges, violacées, noi- 
râtres ou bleuâtres, elles sont très-rarement uniformes de teinte et varient d'intensité, de dimension et de nombre. Elles commencent à se montrer le soir ou le lendemain de l'accident, près des piqûres, puis sur le membre et la partie correspondante du tronc. Avant de disparaître, elles passent au verdâtre et au jaune sale; elles laissent souvent des traces pendant une quinzaine de jours. Elles sont dites ecchymotiques, mais le sang altéré qui les forme les rapproche bien plus des pétéchies propres aux affections pestilentielles, que des épanchements sous-cutanés produits par la contusion.

Elles affectent parfois l'aspect de marbrures, d'autrefois celui d'une gangrène commençante. Souvent elles semblent suivre le trajet des vaisseaux lymphatiques et veineux. L'abbé $H$. nous offrit même un léger degré de lymphite, et chez II. Rautou nous constatâmes une tuméfaction du ganglion épitrochléen. Un malade dont le Dr Saillard nous a fait connaitre l'histoire, piqué deux fois à la main, dans une chasse au furet, présenta une série d'abcès de l'avant-bras. L'angioleucite est done loin d'être une complication bien rare des morsures de vipères.

Sept blessés offraient des collections purulentes au siége mème des piqûres; la formation du pus reconnaît alors pour cause la plus ordinaire la présence dans les tissus d'un débris de crochet.

Les phlyctènes constituent un phénomène fréquent; elles doivent presque toujours être attribuées aux applications ammoniacales employées comme moyen thérapeutique.

Un point gangréneux se montre quelquefois sur l'empreinte laissée par les canines, mais des escharres plus considérables peuvent survenir sous l'influence combinée du venin et d'une ligature trop serrée et trop longtemps maintenue.

Nous connaissons quatre faits de ce genre. Les deux que nous citons ici, sont extraits des notes de $\mathrm{H}$. Thomas et ont été re- 
cueillis par M. le professeur Delamarre de 1820 à 1826, pendant qu'il était interne des hôpitaux de Nantes.

Un jeune homme de Brains, àgé de dix-huit ans, fut mordu à l'index droit, en metrant du blé en gerbes. On lui appliqua de suite une ligature au-dessus du coude, à l'aide d'un lien de tablier serré sans modération, et, vingt-quatre heures après, on se décida à le conduire chez un médecin qui, trouvant le bras violacé, noiràtre et tuméfié d'une façon étrange, se hàta d'enlever le lien constricteur; mais il était trop tard, déjà la gangrène commençail à se manifester. Le malade se fit alor's transporter à l'HôtelDieu, dans le service de Cuchard; sa main paraissait entièrement sphacélée et de larges escharres se montraient sur son avantbras. Il refusa énergiquement l'amputation qui lui fut proposée, cut une suppuration effrayante et de vastes décollements, perdil plusieurs phalanges, et dut rester cinq mois à l'hôpital. A sa sortie, il n'avait plus qu'un moignon informe à l'extrémité d'un avantbras atrophié. Ceci ne l'empêche point, avec la main qui lui reste. de se livrer à un petit commerce de colportage.

Le second sujet était un homme d'une trentaine d'années, habitant aussi les environs de Nantes et qui avait été piqué par une vipère en déchargeant du bois. Une ligature trop serrée cl trop prolongée lui détermina des escharres à la main et à l'avantbras. Conduit à l'Hòtel-Dieu, il fut amputé au-dessus du coude el guérit en peu de jours sans autres accidents.

Les phénomènes généraux de l’empoisonmement échidnique peuvent manquer, mais il est rare qu'ils fassent complétement défaut. Dans les cas graves, ils se subdivisent: $1^{\circ}$ en troubles fonctionnels des voies digestives; $2^{\circ}$ en s!mmptumes typhoüdes (adynamiques et ataxiques); et $3^{\circ}$ en symptômes de réaction.

Peu après la morsure (d'une heure à deux), surviennent, à la suite de grandes angoisses, des nausées firéquentes, souvent atroces. 
Une douleur épigastrique ou ombilicale, tantôt réduite à un sentiment d'anxiété, tantôt violente, les accompagne. Les nausées amènent d'ordinaire des vomissements si répétés, dans certains cas, que le malade, malgré la soif ardente qui le dévore, ne peut supporter l'ingestion d'aucun liquide. Les matières dont se débarrasse l'estomac sont formées d'aliments en partic digérés, de bile, puis de glaires sanguinolentes; quelques blessés ont aussi des tranchées et même des selles diarrhéiques.

A ces symptômes se joint souvent un peu d'ictère; mais il est loin d'avoir la valeur que Linné et Barthez lui attribuaient. Malgré l'aphorisme des Amonitates academicre (1), ce signe ne peut servir à distinguer les morsures de vipères de celle des autres serpents. Il est même beaucoup plus marqué à la suite des blessures faites par les crotaliens, et on le retrouve chez des enragés et autres malades atteints d'affections virulentes.

La teinte de la peau est cachectique et jaunâtre, plutôt que véritablement bilieuse; quelquefois cependant il y a une jaunisse locale ou générale beaucoup plus nettement caractérisée et que M. Gubler (Mémoires de la Société de biologie, t. V, p. 263) attribue à un spasme des voies biliaires occasionné par la frayeur.

Quelque ingénieuse que soit cettc théorie, nous croyons qu'elle est loin de rendre compte de tous les faits, et elle ne nous est point suffisamment démontrée. Les teintes subictériques ou cachectiques nous paraissent dues à une altération du sang, soit qu'au contact du venin la substance colorante propre de ce li-

(1) Morsus aspidis inducit somnum, cerastis tetanum, vipere icterum, sepis gangranam, dipsadis polydipsiam, moster is tumorem (Amanitates academiece, tome II). Ici le grand naturaliste écrivant, non plus d'après ses observations, mais bien d'après le récit d'autrui, s'est complétement trompé. Les signes qu'il donne pour distinguer les morsures des divers serpents sont illusoires. 
quide éprouve une modification spéciale, soit que les pigments biliaires, que l'absorption intestinale ramène dans les vaisseaux, n'y soient plus qu'incomplétement détruits. Quant aux teiutes franchement bilieuses, elles sont le résultat d'une perversion des fonctions excrétoires du foie, suite des troubles de l'estomac et du duodénum.

L'action élective des échidnines sur le tube digestif est un fait remarquable, et il est d'autant plus important que les symptômes éloignés de tout empoisonnement se montrent d'une manière prédominante vers l'appareil destiné à débarrasser l'économie des substances nuisibles introduites. Depuis les belles et nombreuses expériences de-N. Cl. Bernard, nulle loi de toxicologie n'est micux démontrée. L'estomac (chez l'homme et les carnassicr's du moins) nous semble donc être la principale voie d'élimination des venins et de leurs produits, comme il est la porte de sortie de l'urée en excès dans l'urémie; mais les échidnines ont des réactions chimiques si insignifiantes et sont tellement rapprochées de la pepsine, que la démonstration de leur présence à la surface de la muqueuse ou parmi les matières vomies nous parait impossible.

Pendant qu'une certaine quantité de poison tend ainsi à disparaître, celle qui reste unie au sang modifie la composition chimique et les propriétés vitales de ce liquide et agit en même temps sur les nerfs. On voit alors survenir des lipothymies et des syncopes; le refroidissement, d'abord limité au membre blessé, se généralise; la peau se couvre de sucurs froides et visqueuses. Le pouls se déprime; il est petit, misćrable, irrégulier, et souvent même imperceptible. La respiration s'embarrasse; les poumons s'engouent passivement; les yeux sont cares; le facies prend les caructères hippocratiques, et la prostrution decient extrême. Habituellement alors les urines sont complétement supprimées.

Le retour et l'abondance de la sécrétion des reins constituent 
au contraire une crise heureuse ; tel parait même être le mode d'élimination du poison chez les rongeurs et autres animaux qui ne vomissent point (1). Malheureusement il est aussi difficile de reconnaitre une échidnine dans la vessie que dans l'estomac.

L'étude chimique de l'urine des venimés est du reste toute à faire. La seule substance qu'on y ait recherchée est la glycose, que MM. Cl. Bernard et Alv. Reynoso avaient signalée dans cette excrétion à la suite de l'empoisonnement par le curare. Il est curieux de rappelęr ici que les Grecs attribuaient le diabète à la morsure d'une espèce de vipère à laquelle ils donnaient le nom de dypsade.

On arrive dans la recherche de la glycosurie, suite de morsure de serpents, à des résultats contradictoires, suivant les conditions dans lesquelles on opère.

Si l'on recueille après la mort, surtout quand la dernière lutte a été longue et pénible; le liquide peu abondant que renferme la vessie, ce liquide mis en contact dans une éprouvette avec le réactif de Barreswil réduit le sel de cuivre et en précipite l’oxyde, preuve qu'il renferme une substance sucrée dont les phénomènes asphyxiques de l'agonie expliquent parfaitement la présence.

En dehors de tout embarras respiratoire, l'urine, et surtout celle qui est rendue en grande quantité, ne contient pas de sucre, ce qu'il nous a été facile de vérifier. Pendant l'année 1868, nous avons réussi à sauver un certain nombre de lapins blessés par la

(1) Le docleur Guyon (Comptes-rendus de l'Institut, t. LX, p. 19) considere aussi la supersécrétion urinaire comme un symptôme de bon augure et une véritable crise chez les herbivores mordus par des scorpions. Le docteur Touchard (Riviere du Gabon et ses maladies. Montpellier, 186's) raconte que, dans l'empoisonnement juridique și en usage parmi les tribus africaines, il arrive parfois qu'une diurèse considérable sauve le prévenu et devient, dans celte sorte de jugement de Dieu, un signe certain d'innocence. 
vipère-aspic, en leur inoculant aussitôt la morsure une solution très-concentrée d'acide phénique. Leur urine recueillie lors de son émission a été traitée en présence de nos aides ordinaires (1) par le réactif cupro-alcalin de Fehling. Le mélange maintenu près d'une minute à la température de l'eau bouillante ne s'est point coloré en violet et n'a pas donné de précipité d'oxyde de cuivre ; il ne contenait par là même ni albumine ni glycose. Ajoutons que la potasse caustique chauffée à $\mathbf{1 0 0}$ degrés avec ces urines n'y a point développé la couleur brune et l'odeur spéciale de l'acide caramélique.

Aux signes d'adynamie viennent s'unir dans les cas graves des phénomènes d'ataxie, tels que des crampes, des soubresauts de tendons, quelques mouvements convulsifs surlout dans les membres inférieurs, de la révasserie, du délire, etc. Si la terminaison doit être funeste, la langue devient fuligincuse et l'haleine fétide. L'intoxication par le venin de la vipère a donc, au point de vue symptomatique, les plus grands rapports avec le choléra et. l'empoisonnement arsenical, où se remarque aussi une grande dépression du système nerveux.

Telle est la description de la maladie dans sa forme la plus sérieuse; mais elle présente tous les degrés, depuis le simple trouble de l'estomac et la lipothymie jusqu'à cet ensemble effrayant de symptômes.

Un pareil état ne saurait se prolonger; si les forces de la vie

(1) MI. Gicquiau et Dauffy, professeurs à la pension Saint-Stanislas, et MII. Dupont et Cado, internes des hôpitaux de Nantes. Que ces messicurs veuillent bien recevoir ici nos remerciments, ainsi que M. Sagot, professeur au collige des Eudistes de Redon; M. Luneau, prosecteur à l'École de Médecine, et M. B. Lamy, étudiant en médecine, qui, eux aussi, ont pris part à plusieurs de nos dangerenses expériences, et nous ont été d'un très-grand secours par leur adresse et leur sang-froid. 
n’ont pas été complétement éteintes par le venin, on voit en peu d'heures survenir un mouvement de réaction. Un sentiment de chaleur se répand dans tout le corps; le pouls se relève, devient fort et plein; la peau présente de la tendance à la moiteur, puis elle donne passage à des sueurs qui n'ont plus le caractère visqueux de la période adynamique. Ce mouvement fébrile, presque toujours léger, apparait le lendemain de la blessure et se renouvelle le surlendemain. Dans une observation que nous devons à notre confrère le docteur Bourdin de Sainte-Pazanne, la fièvre persista pendant quelques jours sous forme d'accès réguliers, et nécessita l'emploi d'antipériodiques.

Le 28 mai 1860, le jeune Julien Epervrier, de Sainte-Pazanne, âgé de neuf ans, fut piqué à un des doights de la main droite en essayant de prendre un nid au milieu d'une haie touffue. Il n'eut pas le temaps de reconnaitre le reptile, mais c'était bien une vipère, car le membre blessé se tuméfia presque aussitôt jusqu'au delà du coude et se couvrit de taches livides; puis survint de la cardialgie, des nausées et un refroidissement facile à constater au toucher, surtout sur la main mordue. Tous ces symptômes furent combaltus par M. Bourdin à l'aide de l'ammoniaque, de boissons excitantes et de frictions aromatiques. Le malade eut une fièvre de réaction assez forte qui offrit, les jours suivants, les caractères intermittents et dont il guérit au moyen du quinquina administré sous forme de bols.

Notre statistique ne contient aucun autre fait dans lequel le mouvement de réaction se soit ainsi transformé.

Symptomes tertiaires. - Ils se divisent en symptomes périodiques ou à répétition et en symptomes cachectiques.

Un grand nombre de blessés éprouvent, plusieurs années de suite et presque à jour fixe, le retour de troubles morbides ana- 
logues à ceux que produit l'inoculation venimeuse : du gonflement et de la douleur dans le membre autrefois pirué par la vipère, un état saburral des premieres roies, de l'inappétence el même des nausées; leur peau prend une teinte subictérique.

Une jeune fille, soignée à l'Ilospice-Général de Nantes par le docteur Deluen, alors interne, présentait tous les ans à l'époque de sa morsure une éruption de taches livides sur le membre blessé.

a Jean Coulonnier, de Boussay, nous écrit M. le curé Mérel, fut

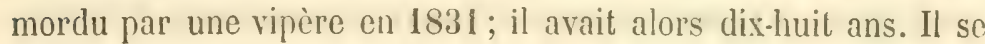
mit entre les mains d'un conjureur, aux remèdes duquel il attribua sa guérison, et depquis lor's il jouit d'une bonne santé; mais chaque année, au jour anniversaire de sa blessure, il ressent un malaise général, sa jambe enfle et il s'y forme parfois des plaies.

Le docteur Demeurat de Tournan (Gazette hebdomalaire, 6 novembre 1863, t. X) a publié une observation d'accidents périodiques, suites de morsure de vipère, qui se reproduisaient depuis trente-neuf ans arec une régularité parfaite. La mąlade, piquéo le 28 mai 182̌́, éprourail chaque année, à pareille époque, de l'anxiété, des nausées, de la céphalalgie, puis, au bout de six à huit jours, royait appraraitre des bulles de pemphizus au lieu de la blessure. Arant sa rencontre avec le serpent, elle n'avait rien ressenti de semblable.

Nous pourrions, en dénouillant les rapports médicaux envoyés à la Préfecture de la Loire-Inféricure, multiplier les exemples do ces faits sur lesquels aucune explication n'a encore été donnée, mais qui n’ont rien de plus extraordinaire que la régularité des aceès de la fière paludéenne et la périodicité de certains actes physiologiques.

Les symptomes de cachexic, heureusement beaucoup plus 
rares, peuvent se présenter dans trois conditions différentes.

Ainsi, on rencontre des blessés qui ne se relèvent jamais d'une morsure de serpent. Les accidents aigus passés, ils déclinent, restent valétudinaires, el finissent par succomber au bout de quelques mois. D'autres semblent d'abord guéris et reprennent leurs habiludes; mais, après un temps plus ou moins long, on voit survenir chez cux un amoindrissement successif de toutes les forces vitales : la calorification est diminuée, et ils résistent mal au froid; leur peau prend une coulcur jaune-paille; ils ont de la tendance à la somnolence, de la torpeur intellectuelle, et un engourdissement de la sensibilité ; ils digèrent avec lenteur, et leurs gencives sont saignantes comme celles des scorbutiques. Les hommes faits vieillissent d'une façon prématurée, et les jeunes sujets sont arrêtés dans leur développement. Qui ne reconnaîtrait là une modification des fonctions hématopoïétiques sous l'influence du venin? La fibrine est altérée, et les globules sont moins propres à l'échange gazeux qui constitue leur principal rôle dans l'économie. Le liqquide recueilli par nous à la suite d'une épislaxis abondante avait l'aspect du sang des veines sus-hépatiques, et ne se coagulait qu'imparfaitement.

Il existe un demier groupe de blessés, peu nombreux, il est vrai, chez lesquels le drame morbide offre encore une marche difiérente. Aux symptômes d'empoisonnement aigu succède un long entr'acte qu’ils prennont pour de la guérison; puis, au bout de dix-huit mois à deux aus, ils tombent comme frappés d’apoplexie. La mort, dans ce mode de terminaison, a-t-elie lieu par cengestion ou hémorrharie cérébrale, ou par une sorte d'encéphalopathie particulière? C'est ce qu'aucune autopsie n'est venue encore élucider.

Outre ces faits de cachexie que nous appellerons générale, ou par viciation de l'économic tout entière, il y a des cas de cachexie 
locale, consistant dans une altération permanente des parties mordues. Ainsi, lorsque la piyûre siége aux membres inférieurs, il s'établit parfois, au point où les crochets ont traversé la peau, des ulcères de longue durée. Un jeune homme, vu par le docteur Guitter, a conservé à la jambe une tuméfaction telle qu'il a été, au conseil de révision, jugé impropre au service.

La cachexie par le venin a été observée non-seulement dans les piqûres des vipères indigènes, mais aussi dans celles de divers autres serpents : les crotales, le fer-de-lance, le céraste ou vipère cornue de nos oasis algériennes, l'échidnée mauritanique, etc. D'après F. Azara (Voyage dans l'Amérique méridionale), la plupart des personnes qui, atteintes par les serpents du Paraguay, ne meurent pas de leur's morsures, restent à moitié imbéciles.

Marche, durée, terminaisons. - Au point de vue de sa marche, l'empoisonnement échidnique est suraigu et se juge en peu d'heures, aigu on d'une durée de quelques jours, ou bien encore plus ou moins chronique; cette dernière forme, chez l'homme et chez les autres animaux à sang chaud, est toujours secondaire.

La maladic, quels qu'aient été les symptômes généraux, se termine d'ordinaire par la guérison; les phénomènes alarmants disparaissent alors du second au quatrième jour, mais la douleur locale et l'œdème sont de plus longue durée.

Quand le retour à la santé est frane et complet, l'économie ne garde aucune trace de la secousse qu'elle a éprouvée; mais la guérison peut être imparfaite et laisser le malade exposé à des symptômes éloignés.

Chez plusieur's blessés, la maladie du venin est remplacée, après les accidents aigus du début, par une sorte d'état valétudi. naire qui persiste toute leur vie. 
Plus rarement elle finit par la mort, tantôt dès les premières heures, et ordinairement alors par pénétration directe du venin dans une veine, tantôt du second au cinquième jour par obstruction des voies respiratoires ou gêne de l'hématose; d'autres fois, dans le cours de la seconde ou de la troisième semaine, par symptômes typhoïdes; d'autres fois, enfin, après plusieurs mois, par accidents cérébraux ou autres phénomènes liés à l'altération du sang.

Pronostic. - Parmi les causes qui modifient la gravité de l'affection venimcuse, les unes tiennent au reptile et les autres au sujet.

Les conditions du côté du reptile sont la dose du venin qu'il a versé dans la plaie et la force de ce liquide.

La quantité de poison inoculće varie : $1^{\circ}$ d'après le nombre des blessures, et $2^{\circ}$ d'après la profondeur à laquelle ont pénétré les crochets et le degré de la pression exercée sur les glandes. N'oublions pas qu'il y a des vipères sans venin et d'autres à crochets brisés ou obturés.

Des blessures répétécs par un serpent sur une même personne sont toujours plus graves qu'une simple morsure; elles le deviennent encore davantage quand elles sont l'oeuvre de plusicurs vipères. Cetle dernière circonstance ne doit pas faire complétement désespérer du malade; Fontana a connu un chercheur de vipères qui jadis avail été mordu à la main par deux de ces reptiles, au moment où ils cssayaient de s'échapper de la boîte dans laquelle il les avait renirumés. La piqûre d'un seul crochet offre une gravité moitié moindre que celle des deux. La simple érail. lure des couches superficielles de l'épiderme est une lésion à peu près inoffensive.

Jamais la blessure d'une dent détachée, sèche ou fraîche, n’esí 
comparable à la morsure même de l'animal; dans le premier cas, il y a simple insinuation sous la peau du poison de la canine, tandis que dans le second il y a de plus injection du venin de la vésicule.

Plus le serpent est gros, plus d'ordinaire il a de poison; aussi les localités redoutées pour leurs vipères sont-elles principalement celles où ces animaux trourent de sûres retraites et peurent se développer en paix (1).

Le degré d'excitation du reptile doit ètre pris en considération. Une vipère irritée s'acharne sur sa victime et lui déverse une plus grande quantité de renin. Les blessures qui ont licu par les temps chauds et orageux sont pires que les autres.

Si un serpent se jette sur divęrs individus, le péril pour chacun d'eux sera d'autant moindre qu'il y aura cu déjà plus de piqûres; nous sarons en effet que le venin s'ćpuise vite et qu'il se forme avec lenteur.

L'espèce de la vipère change peu la nalure et la force du poison; le péliade est presque aussi malfaisant que l'aspic et nous a donné des cas de mort. Rappelons, sans y attacher d'importance, qu'aux yeux des paysans les variétés rouges de la vipère commune passent pour plus dangereuses que les grises.

Le pronostic du côté du blessé varie en raison de direrses circonstances qui se rangent sous quatre chefs principaux : $1^{\circ}$ la facilité qu'éproure le renin à púnétrer dans lus sphère d'artion des vaisseaux lymphatiques et reineur ; 20 i"artivitri plus ou moins granle de l'ahsorption; $3^{\circ}$ la résistunce aux agents-déléterres opposié par l'é.

(1) Parmi les lieux dont les vipères ont le plus mauvais renom, nn doit citer les coteaux de la Sère, ceux de l'Erdre, surtout an voisinage du rocher de Barbe-B!eue, le bois de la Groullais, ceux de Saint-Aignan et le Bocage vendéen. 
conomie; $4^{0}$ la plus ou moins grande facilité avec laquelle s'opère l'élimination des produits toxiques.

Si la partie sur laquelle portent les crochets est nue, ces organes inoculateurs ne rencontrent d'autre obstacle que la résistance de la peau; si au contraire elle est protégée par un vêtement, celui-ci par son tissu et son épaisseur s'oppose à la pénétration des canines qui souvent alors ne font qu'effleurer l'épiderme. La plaie produite, le vêtement devient au contraire plutôt nuisible qu'utile; ainsi le bas imbibé dụ venin et laissé en contact avec une morsure de la jambe, favorise l'absorption d'une nouvelle quantité d'échidnine.

Les piqûres siégcant à la tête ou au tronc sont en général moins graves que celles des extrémités; le reptile saisit à pleine gueule les parties de petit volume; puis les doigls et les orteils sont riches en veinules et en lymphatiques, et, d'autre part, le coudepied, les malléoles et le poignet possèdent des veines superficielles assez grosses, dans lesquelles le venin peut pénétrer direclement. Les morsures des oreilles et du museau chez les chiens, les chats et les lapins, offrent une innocuité remarquable dont il faut tenir compte quand on expérimente avec les vipères. Presque toujours les blessures de la langue sont mortelles par la glossite œeémateuse qu'elles déterminent.

Le poids du blessé n'est pas sans influence sur la gravité ou la bénignité de l'envenimation; il constilue un des éléments de résistance de l'économie, mais il n'est pas le seul, ni le plus important. Fontana est arrivé à des résultats erronés en calculant à priori, d'après la masse de l'animal mordu, la quantité de venin nécessaires pour le faire passer de vie à trépas.

L'âge a une tout autre importance. Les échidnines impressionnent plus vivement les jeunes sujets; l'absorption chez eux est rapide, tandis que leur résistance aux poisons ani- 
maux est très-faible (1). Le vicillard résiste moins bien que l'adulte, mais chez lui l'absorption est moins prompte que chez

\section{l'enfant.}

Le sexe n'a pas la valeur que nous lui avions allribuée, avec les auteurs classiques, dans notre première édition, et le venin des serpents n'est pas plus dangereux pour la femme, malgré la faiblesse de sa constitution et son moindre volume. Les chiffres de 27 victimes du sexe masculin contre 22 du sexe féminin sembleraient même indiquer le contraire, s'ils n'étaient rectifiés par ceux de notre statistique générale, qui montrent que les deux tiers environ du nombre des morsures ont lieu chez l'homme. La léthalité des blessures de vipère reste donc, en réalité, un peu plus élevée chez la femme.

Les conditions physiologiques dans lesquelles la femme se trouve, quand elle est mordue, sont loin d'être sans influence sur la gravité de cet accident. La grossesse, toutefois, n'est point une complication qui autorise à considérer la malade comme perdue.

Au mois de juin 18:̈9, la femme Nosset, des IIautes-Landes, à Aigrefeuille, âgée de vingt-sept à vingt-huit ans et enceinte de six mois, fut piquée au pied gauche par un aspic pendant qu'elle aidait à faire le foin. On exprima aussitôt sur sa blessure le jus de plusicurs feuilles de molène (2), et l'on donna à boire à la malade

(1) A poids égal, un vieux lapin de petite taille soutient mieux l’épreuve d'une morsure de vipère qu'un lapereau de forte race. Tout animal à sang chaud trop jeune est voué d'avance à la muit quand on expérimente sur lui avec le venin.

(2) Par le mot moline, les paysans d'Aigrefeuille et des cantons voisins désignent aussi fréquemment le Lappa minor D. C. ou bardane que le Verbascum Thapsus Schrader, ou molène proprement dite. Pour eux, le suc des larges feuilles des Lappa constitue la véritable panacée du venin. Une belette luttant contre une vipère, aurait ćté vue se frottant après chaque coup de croc sur un pied de molène. Sans crainte sur l'effet du venin, elle 
une grande quantité de vin chaud et sucré. Deux hommes vigoureux, la saisissant alors par les bras, la firent courir jusqu'à ce qu'elle tombât épuisée de fatigue et de vin ; elle fut ensuite mise au lit sous plusicurs courertures. In sommeil de quinze à vingt heures s'empara d'elle, tandis qu'une sucur profuse perlant à la surface de sa peau traversait couette et matelas. A son réveil, la blessće n'arait qu'un souvenir confus de ce qui s'était passé, et ne conservait qu'un peu d'engourdissement et d'œelème de la jambe malade. L'enfant vint au monde à son terme et en parfait ćtat de viabilité. (II. Lihoreau, médecin à Aigrefeuille.)

Il faut avoir l'audace de l'ignorance pour obtenir un pareil succès. Les moyens sudorifiques ont évidemment sauvé la malade, mais ils avaient toute chance d'occasionner un avortement mortel.

Une constitution robuste et une susceptibilité nerveuse modérée sont d'excellentes conditions de lutte; les maladies, qui débilitent l'organisme, ou diminuent la plasticité du sang, constiluent, au contraire, de déplorables prédispositions.

Il est de croyance populaire, que les morsures sont plus dangereuses pour le blessé, quand son estomac est plein que lorsqu'il est vide, fait qui a besoin d'être confirmé par des observations et des expériences, mais à priori parfaitement d'accord avec ce qui a été dit de l'élimination probable des produits échidniques par les voies digestives.

revenait alors à la charge avec un nouveau courage. Un spectateur ayant arraché la précieuse plante, la belette mordue en aurait vainement cherché un autre pied dans le roisinage, et, faute d'en trouver, serait tombée morte. (II. Lihoreau.)

Celle légende populaire rappelle ce que raconte Pline, au livre VIII, ch. XLI-97, de son Histoire naturelle: Testudo cunile, quam bubulam rocant, pastu, vires contra serpentes refovet; mustela rutce, in murium venatu, cum iis dimicatione conserta. 
D'après M. Millet (loc. cit., p. 611), on aurait aussi remarıué que le laitage avalé peu de temps arant ou après la morsure aggraverait l'action du venin. Il serait bon de soumettre à l'expérimentation celte opinion en rogue parmi nos paysans, pour juger de sa valeur.

L'imagination joue un grand rîle dans les suites des blessures par les serpents, comme du reste dans la plupart des maladies infectueuses (choléra, lyphus, peste, vomito-negro, etc.); les symptômes de l'intoxication sont augmentés par la peur qui, déprimant le système nerveux, favorise l'action des échidnines. Le docteur Rufz, dans son Enqurte sur le serpent de la Martinique, rapporte des faits bien remarquables de l'influence de la terreur sur la gravité et la rapidité des accidents causés par le fer-de-lance.

Quoique Fontana, le maître el le guide de tous ceux qui écrivent sur la vipère, ait démontré que la morsure de ce reptile guérit plus souvent qu'on ne le croit par les seules forces de la nature, il n'est pas indifférent, pour établir le pronostic, de savoir si le malade a été ou non traité de suite avec énergie et d'une manière rationnelle. Nous verrons, en effet, combien les soins intelligents diminucint les chances de mort et d'accidents graves, et combien, au contraire, une médication maladroite rend plus critique la position du blessé.

Envisangé d'une manière absolue, le pronostic de l'empoisonnement par la vipère est toujours séricux, puisqu'il peut occasionner la mort et amener ce résultat non-seulement chez des enfants et des femmes, mais encore chez des vieillards et des adultes vigoureux.

Le chiffre de quarante-neuf pour trois cent vingt et un blessés (soit environ un septième) nous semble forcé, quoique donné par notre statistique. Il ne faut pas oublier que les cas graves serecueillent plus facilement que les autres qui souvent passent inaperçus. 
La proportion vraie, dans nos départements du moins, doit être d'un décès pour vingt-cinq ou trente personnes mordues (1).

Les symptômes généraux les plus graves, l'adynamie même, ne doivent pas toujours faire condamner le blessé. Tel a été consi-

(1) Nous aurions été heureux de faire connaitre d'une manière succincte la mortalité relative due aux morsures des autres serpents, et aussi de donner un aperęu de la fréquence des accidents qu'ils occasionnent, mais les renseignements nous manquent, et nous sommes forcé de nous borner aux indications suivantes.

Dans l'Inde anglaise, les documents officiels de 183 ö $^{\prime}$ ont fourni au docteur Inlach (Trans. of the med. and phys. Soc. of Bombay) soixante-quatorze cas de morsures de serpents (naja, liuppur, etc.) pour la seule province du Sind, en une seule saison, et dix-sept en une semaine. Sur trois cent huit cas, réunis par Mr. Inlach, il y a cu soixante-trois décès. La statistique effrayante du receveur de Jerruch porte vingt décès pour quarante-huit morsures. Du dernier rapport sur la mortalité des possessions anglaises de l'Inde, il résulte de plus qu'en 18681,127 personnes sont mortes par la morsure de serpents dans le royaume d'Oude, et 1,874 dans les provinces centrales, de 1866 à 1868 'inclusivemənt.

A la Martinique, d'après M. Rufz, le fer-de-lance fait cinquante victimes par an, sur une population de 150,000 habitants.

Au Brésil, dans la province du Para, nous écrit le docteur Lemos, le jararaca (Bothrops Jararaca Dum.), les divers serpents à s'nnettes, l'élaps corail, les trigonocéphales et autres ophidiens venimeux, causent fréquemment la mort des hommes, surtout des nègres qui marchent pieds nus et se livrent aux travaux de la campagne. Dans l'intérieur du pays el sur certaines habitations composées de cent ì deux cents personnes, il meurt presque chaqque année un nègre, de piqùre de serpent. Le jararaca détermine la mort en vingt-quatre heures; le boïquira (Crotalus horridus, L.), en trois quarts d'heure. Le bruit des grelots des crotales, analogue au froissement des feuilles sèches, permet d'éviter ces dangereux animaux.

Dans une oasis du Sahara, le R. P. Henri de Regnon a vu un homme se pencher pour boire sur la margelle d'un puits et ne plus pouvoir se relever. Ce malheureux, inordu au poignet par une échidnée, poussa un cri, eut des convulsions dans un orteil, puis de la contracture; ses yeux devinrent hagards, et sept minutes après il expirait, présentant des marbrures violettes sur tout le membre blessé. 
déré comme perdu, chez lequel ces phénomènes alarmants se sont dissipés en quelques heures.

En voici un curieux exemple, qui nous est fourni par M. Lebossé, professeur à l'institution Richclieu, près Luẹon.

"Le soir d'une chaude journée de juillet 1866 , nous écrit ce savant distingué, le sicur Gautrot, âgé de quarante ans, était occupé à ramasser du froment dans les champs de Beugné, à deux kilomètres de Luȩon. Il réunissait le blé en gerloes, quand il fut piqué à l'origine du petit doigt de la main gauche. Le reptile s'altacha si fortement à la partie blessée, qu’il y resta quelques instants suspendu, malgré les secousses imprimées à la main. La douleur fut très-vive. Après un monent de repos, le laboureur reprit toutefuis son travail, mais il fut forcé de l'interrompre, et, sur les instances de sa lemme, il se dirigea ver's la ville pour consulter un médecin. Il cut beaucoup de peine à fitire les trois quarts de la route et s'affaissa en face de notre collége. C'est là que nous le trouvàmes tout gonflé, engourdi, froid et ne paraissant pas avoir plus d'une demi-heure à vivre. Nous lui administrâmes de l'ammoniaqque à forte dose dans un verre d'eau sucrée et la main fut frottée avec la même substance. Voyant que le malade prenait difficilement la solution alealine, nous la remplaçâmes par un mélange d'eau sucrée et d'esprit de .Iendérérus. Le docteur Merland approuva ce que nous avions fait et prescrivit de continuer l'aleali, mais à doses plus modérées. En peu de temps, Gautrot se trouva mieux; vers la nuit nous le reconduisimes en voiture à son domicile. Il garda le lit quinze - jours, sans autres remèdes que ceux yue nous lui avions donnés, et au mois d'octobre il revint nous remereier de lui avoir sauvé la vie. Depuis cette époque il jouit d'une bonne santé.

Diagnostic. - Le diagnostic d'une morsure de vipère est en général facile, mais il n'en est pas toujour's ainsi, par suite de 
l'absence de l'une ou de plusieurs des principales données du problème. Ce problème peut se présenter, en effet, sous quatre conditions différentes : $1^{0}$ Le reptile autcur de la morsure est montré ou est bien décrit; $2^{\circ}$ le reptile n'a pas été ru ou est mal décrit, mais il a imprimé, comme un cachet, la marque de ses dents sur la peau; $3^{\circ}$ la rétraction du derme rend méconnaissable l'empreinte des canines; 4 l'inoculation venimeuse a été faite arec tout autre instrument que la dent du reptile.

Dans le premier cas, la question est singulièrement simplifiée. Les caractères zoologiques de l'animal (configuration de la téte, disposition des écailles ou des plaques syncipitales, forme des pupilles, dents, dessins de la robe, etc.) permettent de reconnaître une vipère d'une couleuvie, et un aspic d'une péliade. Sans eux il est impossible de distinguer d'après les symptômes les morsures des deux vipères indigènes.

L'empreinte des dents du reptile suffit lor'squ'elle est bien marquée pour différencier une blessure de vipère d'une morsure de couleuvre.

Dans le premier cas, on observe deux piquires profondes dont les bords se tuméfient et s'ecchymosent rapidement; si, ce qui est rare, les dents de la mâchoire inféricure ont aussi laissé des traces, on trouve de plus une série d'éraillures en ligne courbe opposée par sa concavité aux deux piqùres.

Les couleuvres donnent, au contraire, lieu à deux rangées d'éraillures superficielles sous forme de courbes se regardant par leur concavité, plus rarement à une seule rangée quand elles ne blessent qu'avec la mâchoire supérieure. Leurs morsures s'accompagnent d'une sensation de déchirement, quelquefois même de pincement mais jamais de piqûre profonde.

Si la rétraction de la peau a effacé l'empreinte de l'un ou des deux crochets, le diagnostic se fait encore sûrement à l'aide des 
conditions étiologiques et des symptômes. La tuméfaction, les taches livides, le refroidissement el les phénomènes gastriques et adynamiques, sont là pour faire reconnaître une morsure de vipère d'une piqûre d'épine ou d'insecte (1).

Quand l'empoisonnement n'a plus pour cause une morsure, mais bien une inoculation due à un instrument abandonné par un expérimentateur ou dirigé par une main criminelle, le problème, quoique plus compliqué, n’est point insoluble. Là encore l'aurćole point de départ de la tuméfaction, les taches lirides, le refroidis-

(1) Voir, comme difficulté de diagnostic, dans le Joumnal de la Section de Médecine de la Société acalémique de la Loire-Inférieure, année 1812, t. XVIII, p. 238, l'article intitulé : Observations de plaies par morsures d'animaux venimeux, par le docteur Baré, médecin des prisons de Nantes.

Quatre détenus, jeunes, bien portants, renfermés dans la geòle de Montaigu, ont été, aux premiers jours de juillet 18ł2, successivement piqués durant leur sonmeil, dans une chambre basse, humide, entourée de lambris de planche. Ils ont prisenté six plaies qui tuntes ont donné lieu à du pus et dont quatre ont troublé pilus ou moins la circulation lymphatique. Chez trois d'entre eux, les syinptômes n'unt pas thipassé le membre blessí, et la guẻrison, quoirque tardive pour de si petites plaies, s'est effectuie du dixième au vingtième jour. Chez le quatrième, au contraire, atteint à la partie interne de la cuisse, les aceidents finirent par occasionner la mort avec adénite, collection purulente dans la fusse ilisanue et hépatisation du poumon droit. L'animal, cause de ces désordres, n'a pas été vu, mais les detenus aflirment avoir eté pịués. M. Baré crut done devoir attribuer les accidents a l'araignée des caves, vu le lieu ou la seine s'était passie, la nature de la blessure et les principaux symptômes; des cas analogne: du reste, avairnt été rubliés peu de temps aupsarusaut ians le journal de M. Lucas-Championnière. Un rapport sur ce sujet fut demande par M. le Ministre de la Guerre à l'Académie de .Iédecine. La commission, par l'organe de Duméril, émit un avis différent el vit la une inoculation de m?tières putrides. Nous n'avons point à intervenir dans le débat; mais, en éerivant ces ubservations qui sint certainement au nombre des plus intiressantes du journal, II. Baré a parfaitement fait d'éliminer lis. questions des morsures de vipères; les phienomènes décrits ne sont point reux d'un empoisunnement échidnique. 
sement et les symptomes généraux pourront mettre sur la trace de l'affection venimeuse et la faire diagnostiquer.

Les autres plaies compliquées de l'introduction d'une substance toxique ont chacune, du reste, leurs signes spéciaux.

Le curare donne lieu à un empoisonnement qui offre quelque ressemblance avec l'envenimation, mais des différences beaucoup plus grandes. Ses symptômes locaux sont presque nuls. Le blessé n'accuse aucune autre douleur que celle due au traumatisme; la rougeur est légère et s'accompagne de la saillie des papilles de la peau; l'empâtement est insignifiant; la température s'élève d'un degré. En mains d'un quart d'heure, la démarche devient chancelante, et les symptomes paralytiques com. mencent par les membres abdominaux pour envahir ensuite tout le corps. Les sphincters relàchés laissent échapper le contenu des organes creux; la pupille se dilate et la respiration diminue de fréquence et d'amplitude. Au milicu de cel ensemble de phénomènes, l’intelligence et la sensibilité générale paraissent conservées, quoique leurs manifestations soient de plus en plus difficiles. Enfin le cœur se paralyse à son tour et la vie s'éteint. Elle peut toutefois se ranimer encore si l'on pratique immédiatement la respiration artificielle, qui rappelle les battements du cœur et permet au poison de s'éliminer par les urines (1).

Le sung-sig, dont les Malais se servent pour leurs lances et leur's kriss, n'a pas non plus d'effet local trìs-inanifeste; il occa-

(1) Consulter pour le curare les ouvrages suivants : Mémoire sur le poison américain appelé ticunas par Fontana. - Expériences pour servir à l'histoire de l'empoisonnement par le curare par Alv. Reynoso (Comptesrendus de l'Ac. des sc.). - Cl. Bernard, OEuvres diverses. - Martin-Magron et Buisson, Action comparie de la noix romique et du curare (Journal de Broun-Sequard, 1859 et 1860). - (Curare, Nouvean Dictionnaire de méd. et de chir. pratiques, t. X), par MM. P. Bert et Voisin; etc. 
sionne, peu de minutes après son introduction sous la peau, des accidents tétaniques dus à l'upas-tieuté qui entre dans sa composition (1).

Les plaies contaminées par une substance putride, telles que les piquires anatomiques, sont surtout caractérisées par la lymphangite. Des traînées d'un rouge vif se montrent autour de la blessure, accompagnées de douleur. Elles suivent la direction des lymphatiques, et les ganglions auxquels se rendent les vaisseaux enflammés s'engorgent à leur tour. De la fièvre, de l'insomnie et souvent du délire accompagnent ces symptômes locaux, mais on ne voit point survenir l'abaissement de température auquel donnent lieu les venins. Ce qui domine, c'est la tendance à la suppuration, soit dans les ganglions, soit au milieu du tissu cellulaire et sur le trajet des lymphatiques.

Il est done assez facile, avec un peu de méthode, de diagnostiquer une plaie envenimée de toute autre blessure empoisonnée; mais reconnaître l'espèce de venin auquel elle doit ses caractères est souvent d'une grande difficulté.

Nous n'avons aucune donnée un peu sûre permettant de distinguer d'après leurs effets les poisons des diver's serpents. Ils sont de mème nature et ne diffèrent guère que par leur énergie.

Le liquide qu'inoculent les arachnides (scorpions, grosses araignées, etc.) et les myriapodes (ex. les scolopendres) produit une douleur extrêmement vive, au lieu même de la piqqûre.

Le contenu des glandes cutanées des crapauds donne lieu à des symptômes épileptiformes et à de l'ivresse, l'humeur des tritons (en particulier du triton crêté, Triton cristatus Laur.) à des con-

(1) Pour le sung-sig et sa préparation, voir la note placée à la fin de ce travail, et qui est extraite des Lettres curieuses sur la Cochinchine par M. Raoul de G., commandant du navire anglais le Fumpire, publićes en 1859 par le journal l'Illustration. 
vulsions terribles et celle de la salamandre terrestre (Salamandra maculata Laur.) à de la somnolence et à des convulsions (1). Anatomie pathologique. - Il resterait, pour compléter la description de l'affection venimeuse chez l'homme, à décrire ses lésions cadavériques. Tout ce que l'on connaît sur ce point a été cxposé plus haut, en particulier aux pages 80 et suivantes, à propos de l'action des échidnines sur le sang et les tissus.

Il s'en faut bien, du reste, que la chimie et le microscope aient dit lcur dernier mot sur ce sujet; l'état des cellules et des tubes nerveux n'a pas été étudié, la nature de la transformation subie

(1) Les crapauds, les tritons (vulg. remoires, sourds, crus) et les salainandres, animaux à aspect repoussant et considérés dans le peuple comme venimeux, secrètent par leurs glandules cutanées une humeur acide, plus ou moins lactescente et variable suivant les espèces. Los expériences de MM. Gratiolet, Cloez et Vulpian, ont démontré que ce liqquide est toxique et qu'il tue un verdier en cinq minutes et un chien en deux heures. Comme le poison des serpents, il n'agit pas sur la peau dunt l'épiderme est intacl; aussi les naturalistes qui ont étudie les luatraciens pustuleux, les ont-ils longtemps maniés sans crainte, et avaient fini par croire que leur venin n'était qu'une erreur populaire.

Nous avons observé nous-même un cas de contamination d'une plaie par le liquide toxique du crapaud. Une vachère des environs de Nantes voulant cueillir avee une faucille une poignée d'herbe, trancha du mêtne coup un gros crapaud commun (Bufo vulgaris Lac.), et se blessa à la main gauche. La plaie s'envenima, il survint de la fièvre, et au lieu même de la blessure apparul un ecthyma dont les pustules se renouvelèrent pendant plus d'une année.

Quoi qu'il en soit, ces animaux ne cherchent point à nuire à l'homme et ne peuvent se servir de leur venin puisqu'ils manquent d'appareil d'inoculation.

Leur principale nourriture se compose de vers, dinsectes et de limaces. Pourquoi done les massicrer avec des ralfinements de barbarie, simplement parce qu'ils font horreur? Les agriculteurs anglais, plus pratiques que nous, protégent les crapauds et en font mème venir de France à prix d'argent pour les mettre dans leurs pares. 
par la fibrine n'est pas connue et aucune recherche chimique un peu sérieuse n'a été faite sur la plupart des excrétions.

Pathologic comparée. - Nous ne reviendrons pas sur les effets du venin de la vipère dans les différentes classes du règne animal. Il est funeste, mais à des degrés différents, pour tous les vertébrés à sang chaud. Le professeur Lenz, de Schnepfenthal, affirme toutefois, (Schlangentiunte), que lo hérisson est impunément mordu au museau, aux lèvres et à la langue, ce que nous n'avons pas été à même de vérifier.

Rien de plus variable que les résultals obtenus par la morsure même du serpent. Pour avoir des faits que l'on puisse mettre en regard les uns des autres, il vaut mieux procéder, comme Fontana, en blessant à l'aide d'un appareil renimcux détaché du reptile et en injectant le venin par pression sur la glande. On opère d'une façon plus sûre encore arec la seringue de Pravaz, qui permet de calculer la dose de poison employée.

Les moineaux, les verdiers et les chartonnerets, iraités ainsi, chancellent et tombent morts; les oiseaux plus volumineux ré-sistent quelques instants. Les pigreons ne s'affaissent qu'au bout de dix minutes; les poules survivent une demi-journée.

On peut établir une échelle analogue de mortalité chez les mammifères, mais, comme nous l'avons déjà dit, tout en reconnaissant l'importance de la masse de l'animal mordu, il ne faut pas se l'exagérer. La résistance au venin, dans les différentes espèces, est un problème beaucoup plus complexe et dont nous ne possédons pas toutes les ${ }^{*}$ lonnées. Tantôt elle tient à des obstacles s'opposant à la péuétration du poison, tantôt à la manière plus ou moins active dont s'opèrent les fonctions sécrétoires, ailleurs à une línacilé particulière de la vie; ainsi tel animal est virement impressionné par le venin, qui cependant guérit presque toujours. En général, les mammifères qui 
rejettent avec facilité le contenu de leur estomac supportent mieux la morsure que les autres (1).

Choisissons nos exemples parmi les serviteurs de l'homme.

Les oiseaux de nos basses-cour's, prolégés par leur's plumes, craignent peu la vipère et la pourchassent avec courage quand elle s'attaque à leur couvée; ils sont cependant parfois blessés par elle.

Dans la cour de M. le comte de Fonmartin, à la Dixneric, commune du Loroux-Bottereau, se trouvait un amas de pierres et de mauvaises herbes; les jeunes canards qui s'en approchaient revenaient blessés, enflaient et succombaient rapidement. Une douzaine périrent ainsi. On fouilla les décombres et l'on y tua une vipère de couleur rougeâtre.

Les chats jouent avec tous les reptiles dont ils se rendent maîtres, mais, gràce à leur agilité, ils sont rarement, mordus; d'autre part nul animal domestique n'a la vie plus dure. Málgré leur's griffes et leur caractère peu facile, Fontana s'en est servi comme sujets d'expérience. Ils ont presçue tous guéri, même ceux qui avaient été piqués par six vipères.

Blessés, ils deviennent doux et faciles, cessent de se servir de leur patte malade et se couchent sur le ventre. Ils offrent les symptômes locaux et généraux de la maladie, vomissent d’ordinaire plusieurs fois et ne recommencent à manger et à boire qu'au bout de deux ou trois jours; à partir de ce moment, on doit les regarder comme sauvés.

M. Gicquiau a observé les mèmes faits sur un chat blessé par

(1) Sur ce point, nos observations sont en accord complet avec celles de Fontana qui, ayant remarqué (Traité sur le venin de la vipère, t. II, p. 8) que les chiens et les chats citaient d'autant moins malades qu'ils vomissaient davantage, essaya sul eux, non sans quelque succès, l'émétique pour combattre les efiets du venin. 
un aspic vigoureux. La bête fut au plus mal pendant trois jours, mais elle se tira d'affaire.

En battant les broussailles et les bois, les chiens sont frèsexposés aux morsures de la vipère; celle-ci, du reste, irritée par leur's aboiements, souvent leur tieni tête et même les joursuit. Il est, en Vendée, peu de chiens de chasse qui n’aient été blessés au moins une fois.

Sitôt piqué, l'animal pousse un cri, cesse de chasser, ct revient vers son maitre, triste, la bave à la bouche el la queue basse. Il s'étend par terre sur le côté sain el reste sans mouvenent. Les symplômes locaux sont les nếmes que chez l'homme; les nausées n'amènent pas toujours des vomissements ou ne les provoquent qu'au bout de quelques heures; la prostration cí la tristesse sont extrêmes.

L'affection venimeuse suit, chez le chien, une marche rapide; quelques.uns succombent en jeu d'heures; d'autres survivent deux ou trois jours; lo plus grand nombre, après avoir donné de vives inquiétudes, offrent une amélioration presque subite dès le lendemain ou le surlendemain et guérissent sans cunvalescence. Il n'est pas rare qu'ils soient en ćlat de chasser an buut d'une semaine. Cependant la blessure peut laisser des suites; certains d'entre eux offrent des intirnilés précoces (tioubles de la vue, de l'odorat, de l'ouie, elc.), ct meuren! jeunes. Une chicme in docteur Bourgeois est devenue sourde et afiectéc d'une carie du maxillaire supérieur, à la suite de morsures répétér. M. Geerges Villers, cité par M. L. Subbeiran, a vu des chiens présenter, chanque année, des phénomènes à répétition du genere de ceux que nous avons décrits.

Une envenimation antérieure ne préserve pas ces animanx d'un nouvel empoisonnement. À chaque pirquere, la fumb́ation reparait, accompagnée des autres phénomènes de la maladie. 
Citons quelques exemples choisis parmi les nombreuses observations qui nous ont été communiquées.

Le premier est dû à Mi. B. Lamy, étudiant en médecine.

- Nous chassions, mon frère et moi, dans un bois taillis de notre campagne de Rezé, ayant avec nous deux épagneuls et un petit king-charles âgé de trois ans. Tout à coup, nous vìmes ce dernicr, qui furetait dans les broussailles, faire un bond en arrière en poussant un cri comme s'il était blessé. Apercevant un aspic qui s'enfuyait, nous lui brisâmes la colonne vertébrale. J'emportai de suite à la maison le petit chien, dont la tête commençait à enfler. Il avait été mordu au côté droit du museau, au-dessus de la lèvre supérieure. Non premier soin fut de raser les poils, afin de mettre la plaie à découvert; puis, avec une lame de canif bien aiguisée, je lui fis une incision cruciale assez proionde. Cette scarification, jointe à la pression que j'exercais sur les parties environnantes, donna lieu à beaucoup de sang, ce qui, je crois, a fait le plus de bien à l'animal. A l'aide d'une plume, j’imbibai ensuite la plaie d'alcali volatil, mais celui que nous avions était tellement vieux et évaporé qu'on le respirait sans qu’il produisit le moindre larmoiement. La tête continua à enfler, doubla de volume : on ne distinguait plus les yeux, ni les narines; la lèvre surtout était énorme. Le chien soufflait péniblement et paraissait en proie à une fièvre intense; il frissonnait, avait des spasmies de l'œsophage qui se traduisaient par des envies de romir el présentait un tremblement convulsif des extrémilćs inféricures. He rappelant l'effet prophylactique de l'ivresse sur les gens mordus, je fis boire au chien du vin rouge sucré et assez fortement alcoolisé. Je dois dire qu'il en a avalé une bonne dose. Il est resté deux jours en proie à la fière el sans faire de mouvements, ne vivant que d'un peu de lait of du vin qu'on lui faisait avaler à grand'peine. Le 
troisième jour, l'enflure de la tête commença à diminuer et l'animal prit de la nourriture. A partir de ce moment, il eut un mieux progressif et la convalescence fut rapide; mais, deux mois après, on remarquait encore une déformation du muscau. Co king-charles n'a jamais joui depuis d'une parfaite santé; il parait moins intelligent et moins alerte. o

L'abbé Delalande, herborisant, au mois de septembre 1839 , dans la commune de Saint-Gildas-des-Bois, aperecut son chien en lutte avec un reptile. Malgré une morsure à la tête, Médor ne lâcha prise qu'après avoir tué son adver'saire. Delalande ramassait le vaincu qu'il prenait, à cause de ses ćcussons, pour un tropidonote, quand il vit son chien enfler, se trainer au ruisseau le plus proche et s'y plonger jusqu'au museau; ouvrant alors la gueule de la prétendue couleuvre, il y découvrit deux crocs acérés. Le bon abbé venait de rencontrer le péliade ou vipère à trois plaques qui n'était pas une espèce nouvelle pour la science, mais dont la présence dans la Loire-Inférieure était signalée pour la première fois.

Mlédor, malgré l'appel de son maitre, s'obstina à rester dans l'eau et ne reparut à la maison que trois jours après, guéri, mais très-amaigri. Depuis cette aventure, l'intelligent animal empêcha plusieurs fois Delalande de saisir sans précaution des péliades aux formes trompeuses. Il se jetait sur les couleurres de toute espèce et les rapportait ; mais, à la vue d'une vipère, il se tenait à distance, en aboyant, et semblait par ses gestes avertir de s'en défier.

Plus tard, mordu par un chien enragé, il fut abattu en l'absence de son maitre. "Cela sut lieu à mon grand regret, ajoute Delalande, car j'y étais altaché. J'aurais désiué qu'on l'eut enfermé et mis à l'observation, pour vérifier s'il est vrai, comme le

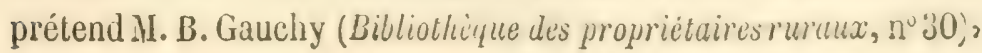


que les animax bordus par une vipere ne soient plus susceptibles d'enrager $\triangleright$ ( 1 ).

Nous reviendrons sur ce prétendu antagonisme entre l'envenimation et la rage.

Une chienne braque d'un an, appartenant à M. II. de l'Isle, fut mordue au mois d'août 1860 par un aspic, dans un taillis de la Haye-Founssière; les crochets avaient pénétré entre les doigls de la patte antérieure gauche. Leste, c’élait son nom, ne pouvant plus marcher, dut être portée jusqu’à la demeure de son maître, où lui furent faites les premières applications d'alcali, tandis que dix goultes de la même substance lui étaient administrées dans un verre d'eau. Vers le soir, prostration complète; l'animal couché sur la paille respire avec peine; il a l'ceil abattu, la palte roile el enflée jusugùa l'épaule. Les piqùres sont agrandies; on en chasse un peu de sang par la pression, et l'on clome is la chienue une infusiun vineuse de galium. Le lendemain l'adynamie est moins grande, mais l'œdème a gagné le cou et les mamelles. Il persiste le surlendemain quoique l'infusion de galium ait élé continuée. Ters la fin de cette troisième journée, l'animal accepte la nourriture qui lui est offerte et se soulève sur ses pattes. Le (quatrième jour il a repris son entrain, et à partir de là l'enflure diminue avec rapidité.

a Par une matinée humide el chaude de septembre 1367, M. Augresto Gaudineau chassait aux environs de Nareuil, quand

(1) Extrait de la dernière communication faite par ce regretté naturaliste, à la Société académique de la Loire-Inférieure, le 19 mai 1851, et intitulée: Lecon d'erpétologie domnée par un chien. Dans ce travail, Delalande dit avoir aussi capturé des vipères à trois plaques à la forêt de Groullais (Blain), áu bois de Reslin (Sévérac) et en ceux de Lézay (Morbihan). 
il entendit son chien pousser des cris plaintifs et le vit secouer son cou. Il courut à lıi et lua une vipère, qui s'enfuyait après avoir mordu l'animal à la gorge où se montraient deux gouttelettes de sango. Les piqûres élargies furent soignées par l'ammoniaque; puis blessé et chasscur revinrent cn voiture à Luçon. Là, un vétérinaire fit de nouvelles scarifications, en exfrima un peu de liquide sanieux et y introduisit de l'ammoniaque. Celte substance fut aussi administrée dans un excipient aqueux. A partir de ce moment la tuméfaction diminua par degrés, le chien se ranima, et le cinquième jour il était guéri. (M. Ch. Gaudineau, élève en pharmacie.)

- Le 8 octubre 1867 , nous écrit M. Patry, le chien de chasse d'un de mes parents fut piqué, aux environs de Port-Saint-Père, par une vipère rouge, à une des pattes antérieures. Tout son corps enlta aussitôt, et il fallut ramener la pauvre bête dans une brouette. Quelques grouttes d'alcali furent aussitòt appliquées sur la plaie, ce qui n'empêcha pas l'animal de tomber, dès le soir, dans un grand accablement, d'aroir des syncopes et d'offrir une respiration très-anxicuse. Je conscillai l'ammoniaque à l'intérieur, et dès lor's son état s'améliora. Le troisième jour, le chien était gai et paraissait guéri. Sa palte, toutefois, resta plus grosse que l'autre et douloureuse pendant une quinzaine. o

Le docteur C. Verland a eu souvent des chiens mordus. Ils se sont presque tous tirés d'affaire, mème ceux qui araient présenté les symptômes d'adynamie la plus grave.

Un d'eux, animal de petite taille, tomba comme foudroyé; on dut l'apporter sur les bras, quoique la maison ne fùt dislante que de 300 mètres. A peine arrivé, il vomit plusieurs fois, et semblait n'aroir que quelques heures de vie. Cependant le quatrième jour il recommençait à mangerer, et dès lors était sauvé. 
Le dernier chien perdu par notre confrère avait été piqué une première fois, et avait présenté des symptômes très-inquiétants qui se terminèrent par la guérison. Mordu de nouveau, il offrait une maladie, si légère en applarence, ru’on ne s'en occupa pas, et le lendemain il était mort. I a vipère l'avait atteint à l'une des pattes de devant, et l'enflure s'était étendue de là jusqu'à la gorge, de telle façon que le cou était devenu presque aussi gros que la tête.

Le docteur Guitter, qui connaît si bien les mours des aspics et leurs méfaits, a eu pareillement un certain nombre de chiens blessés. Chez les uns, il a employé la prétendue cautérisation par l'alcali, et chez d'autres il a négyligé ce moyen, sans observer de différences dans les suites de la piquure.

M. Gobcrt soignait autrefois ses chicns par des scarifications, des pressions exercées au voisinage pour en faire écouler du sang et des applications d'ammoniaque; il leur administrait concur-. remment dix gouttes de ce denier remèle dans un verre d'eau. Depuis la publication de notre premier travail sur les serpents, il a substitué à l'usage externe de l'alcali celui du perchlorure de fer.

C'est ainsi qu'à la Chataigneraie il traita une jeune chienne mordue le 27 mai 1862. Le lendemain elle courait, sans faire cas de ce qui lui était arrivé; muis elle devait avoir mauvaise fin. Dans les premiers jours de septembre, un voisin de notre ami amena, sans lui demander permission, cette chienne sur un coteau exposé au sud, vrai repaire de lapins et de serpents, par une température da 28 à 30 derrés. L'animal, gai et alerte, cessa fout à coup de baltre le terrain et s'étendit sur le ventre. Remis deux fois sur ses pattes, il se laissa retomber, haletant et la gueule pleine d'écume; cependant son museau enflait à vue d'œil. Le pauvre chasscur, ne sachant que faire, 
saigna la chienne sous la queue (1), et quelques secondes après elle expirait.

Un autre voisin de M. Gobert, M. Bailly du Pont, perdit une fois deux chiens dans une seule chasse. Le lièvre venait de traverser une muse (2); trois chiens lancés à sa poursuite furent successivement mordus par une vipère à leur passage dans le buisson. Le premier dut s'arrêter au bout de trois cents pas, et une demi-heure après il était mort. Le second essaya d'abord de chasser, mais bientôt il s'étendit et expirait à son tour en deux heures. Le troisieme ne put suivre la chasse; il fallut le ramener à la maison, où il guérit en quatre jours.

Nous connaissons plusieurs faits du même genre ayant eu lieu en Vendée et dans les Deux-Sèvres, où les chasseurs voient trop souvent leurs meutes décimées.

Le liève poursuivi peut être parfois lui-même blessé par la vipère, et tomber mort avant d'être rejoint par les chiens.

La mortalité d'un quart que nous avons établie pour la race canine, d'aprìs un confrère du Bocage, nous semble trop élevée depuis nos nouvelles recherches. La proportion d'un dixième est plus vraie, même au sud de la Loire.

Les moutons que l'on mène paître dans les prés hauts et sur les coteaux pierreux sont assez souvent piqués, surtout au nez et aux lèrres. D'après Mi. Abadie, ils relìvent alor's brusquement la tète, et essaient de se remettre à manger; mais bientôt la partie

(1) Cette saigुnée à la queue consiste en une incision transversale faite à la face inféricure de cet organe. Elle est surtout employée sur les porcs atteints de congestiın, pour s'etre trouvés trop mal à l'aise dans les mues qui servent à les porter au marché.

(2) On appelle muse, dans l'Ouest, les trous par où passent, à travers les buissons, les lièvres et les lapins, d'où le verbe se musser pour se blottir dans une haie, mots dérivés du latin mus, souris. 
morduc se tumélie; il survieut des convulsions et des selles bilieuses; la bouche se remplit d'écume el l'animal se laisse choir par terie. Le mouton, comparalirement à sa masse, résiste mal au venin. En 1849, dans le dépiartement de l'Aveyron, raconte M. Roche-Lubin, sur un Iroupeau de soixante-dix têtes, quatorze brebis moururent de piqûres de vipères.

Le pore esi tris-rchelle à l'envenination; sa peau, désignée sous le nom de concnue, doublée t'une épaisse couche de tissu graisseux, ne permet que très-difficilement aux crochets d'atteindre les capillaires. Nous n'avons pu r'ecucillir aucune observation de maladie venimcuse chez cet animal, malgré l'avidité avec lacuelle il se jette sur toute sorte de serpents.

Les chevaur ef les boufs se tiennent principalement dans les prés bas après la fenaison; ils offrent, à cause de cela, peu de plaies envenimées.

Nous avons cejiendant recucilli quelques cas de piqûres sur le cheval; aucune ne causa la mort.'

M. Ahodie fut appelé, an mois de juillet 1860, par M. Laurent, maître de poste à Aigrefeuille, pour un de ses chevaux mordu à la fesse, peudant qu’il paissait dans un verger. L'animal présentait une tuméfaction qui, d’abord circonscrite, envahit bicntôt tout le membre cé même la partie déclive de l'abdomen, le poilrail et la base de l'cneolure. Il resta quatre jours dans un ćlat de faiblesse et de stupeur profunde; ayant été soumis à un traitement ammoniacal inlerne el externe, il fut à peu près rétabli au bout d'une semaine.

Chez lo boul et lit vache, ces plixies envenimées guérissent aussi toujours, mais quelquolbis présentent des accidents assez scricux. Plusieurs observalions de piquure sur ces animaux nous ont été rapportées par M. Milcent, curé de Froisfond.

En 1861, wne de ses vaches ćtant au pacage, près du Bois- 
Moreau, fut mordue par un aspic. Sa tête et son cou devinrent énormes, et elle resta pendant deux jours dans un abattemen tel, que le vétérinaire l'abandonna comme perduc. Elle se remit néanmoins peu à peu; mais, durant plus de six mois, elle conserva la tête pesante et des mouvements cmbarrassés.

Une autre vache, dont nous devons l'histoire au docleur Guitter, ayant été piquée ì la mamelle, la sécrétion lactée s’altéra et devint sanguinolente, mais sculement au trayon alteint par les crochets. Le lait conscrva ce caraclère pendant cinç ou six jours, puis redevint normal, et la vache guérit sans autre accident.

$\S$ III. Traitement. - Le traitement des morsures de vipères, comme celui de toute afection qui lélunle l’une manière brusque, tombe trop souvent entre les mains des empiriques (yuririsseurs de renin, conjureur (1), sorciers). L'homme, déjà enclin à la recherche du merveilleux, y semble encore plus porté quand il a été mordu par la bête maudite, tant est grande l'horreur qu'clle inspire. C'est alor's surtout que l'on voit employer des formules étranges que la médecine a délaissées depuis des siècles, des recettes de commères el des pratiques superstitieuses de toutes sortes. Les signes de croix mullipliés, les invocations aux esprrits, les aspersions d'eau bénite, les chants sacrés, les cercles divinatoires, les mots cabalistiques, les oracles d'un bœuf noir, etc., font encore partie de mystéricuses et sombres pratiques que les condamuations de la religion et les efforts de la seience n'ont pu b) nnir de nos campagnes. Elles s'unissent à des médications pareillement dignes des temps barbares; par exemple, à l'em-

(1) On Trontera aux notes finales hes détails sur les guérisseurs de venin et les cunjurcurs de la Vendée, el aussi sur les charmeurs de serpents en général. 
ploi de poulets éventrés laissés sur la plaie jusqu’à putréfaction, dans le but, disent les guérisseurs, de soutirer le venin, ou bien à l'usage des plantes administrées d'après la doctrine des signatures (1).

Laissant de côté tous ces moyens, dont la longue énumération serait aussi triste qu'infructueuse, nous nous bornerons à examiner la valeur des diverses médications, en particulier de celles qui sont en honneur dans nos campagnes, puis à formuler le traitement qui nous semble le plus rationnel.

Examen des divers remèdes employés contre les morsures. - Les moyens thérapeutiques dirigés contre les venins se rangent en quatre groupes, suivant les indications qu'ils sont appelés à remplir :

$1^{0}$ Les uns sont administrés comme de véritables contre-poisons (l'iode, le perchlorure de fer, etc.), c'est-à-dire dans le but de neutraliser chimiquement l'échidnine et de la transformer en substance inerte. On comprend qu'ils puissent agir ainsi lorsqu'ils sont instillés dans les piqûres; mais il est difficile d'admettre, qu'introduits par une autre voie, ils aillent chercher le venin au milieu des diverses substances protéiques contenues dans le sang. $2^{\circ}$ D'autres sont de simples antidotes; sans action spéciale sur la substance toxique, ils s'opposent à ses manifestations, tantôt en provoquant des mouvements de la vie en sens inverse, tantôt en

(1) La doctrine des signatures, fort célëbre au moyen âge, consistait à croire que le Créateur avait voulu indiquer les propriélés thérapeutiques de certaines plantes, en leur donnant une forme ou des taches ressemblant à une partie du corps, ou à des lésions d'organes. C'est pour cela que l'Arum Dracunculus et diverses espèces d'Echium étaient appelés vipérines et considérés comme propres à combattre le venin des serpents; leur tige, en effet, rappelle grossièrement la robe de la vipère et les taches livides des personnes mordues. 
accélérant l'élimination, ou bien encore en rendant nos humeurs des milieux moins propres aux catalyses (ex. les alcooliques). $3^{\circ}$ D'autres font disparaitre le poison avant sa diffusion, par le sacrifice de la partie blessée. Ils agissent, soit physiquement (le cautère actuel, l'excision, etc.), soit en vertu d'affinités chimiques (les caustiques potentiels); ces derniers, tout en mortifiant les tissus, peuvent altérer le venin lui-même, sans pour cela devoir être confondus avec les contre-poisons proprement dits, dont l'action sur l'économie est nulle. $4^{0}$ D'autres enfin se bornent à faire sortir de la plaie une partie du liquide toxique (succion, scarifications, etc.), ou à le maintenir en quarantaine sur un point limité du corps (la ligature).

Quelque naturelle que soit cette classification, nous suivrons un ordre plus arbitraire, et nous grouperons les agents thérapeutiques plutôt d'après leur origine et leur nature que d'après la manière dont ils agissent. Le véritable mode d'action de plusieurs d'entre eux n'est pas, du reste, suffisamment connu, el quelquesuns répondent à plusieurs indications à la fois.

I. - La nature, dit-on, place toujours le remède à côté du mal. Une singulière interprétation de ce proverbe a fait employer contre le venin diverses parties de la vipère. C'est ainsi que l'on a successivement vanté le sang, la chair, les ceindres et surtout le foie du reptile sur la plaie, ou en préparations pour l'usage interne. De nos jours, les homœopathes ont proposé l'emploi du venin à doses infiniment petites. Ces prétendus remèdes, moins toutefois la formule homœopathique, conservent encore un certain crédit parmi nos paysans.

Un laboureur des environs d'Ancenis, dont on n'a pu nous donner le nom, ayant été piqué par une vipère, excisa immédiatement la partie blessée et appliqua sur la plaie l'aspicic fendu longitudi- 
nalement. Il n'eut aucun symptôme d'envenimation, et sa blessure suivit la marche des plaies simples.

Cetle observation el d'autres semblables, sur lesquelles s'appuicnt nos campagnards pour recommander l'emploi de la chair de vipiere dans le traitement de ses morsures, n'ont aucune valeur. L'application de la chair de reptite n'a été pour rien dans celte prompte guérison; l'excision suffit pour l'expliquer.

Une recette plus absurde encore conseille d'écraser la téte de la vipère sur sa blessure. Elle cxipose à un second coup de crochets et met en contact avec la plaie le venin contenu dans les glandes réduites en pulpe. Ainsi, loin d'ètre utile, cette méthode de traitement peut avoir des suites déplorables.

La thériaque, malgré sa réputation séculaire, se range près du bouillon d'aspics, et du cerur du reptile avalé palpitant. Monstrueux mélange de toutes les drogues des anciennes pharmacopées, elle ne doit qu'aux têtes de serpents, qui entrent dans sa composition, son renom contre leur's morsures. Elle jouit de propriétés sudorifiques douteuses, qui seules pourraient la faire admettre comme adjuvant dans la médication et qu'elle doit à l'opium, 4 grammes de cet électuaire représentant 203 milligrammes d'extrait thébaïque. Le nouveau Codex n'a conservé dans la thériaque les têtes de vipères, que pour encourager la destruction de ces reptiles.

Le devoir du médecin ne se borne pas à indiquer les vrais remèdes ; il doit aussi prévenir contre ceux qui, nuisibles ou inefficaces, font perdre un temps précieux. Sans celte considération, nous ne nous serions pas arrèté sur les moyens précédents, ineples recettes en usage du temps de Natthiole, et abandonnées de nos jours aux empiriques el aux sorciers. Nous faisons la même réflexion pour les formules homoopathiques dont il reste à parler. 
Les disciples d'Inahnemann administrent le renin des serpents contre diverses maladies, et en frarticulier contre celle que produit le venin lui-même. Ils le donnent en potion, à duses iufinitésimales, quand on sait qu'introduit par l'estomac il est rappidement détruit par les séerétions gastriques! Ils ne donnent done en réalité aucun remède.

M. L. Soubeiran a découvert, dans le Jourubl de la Socirté yallicane de médecine homeropulhique,, . V, p. 36?, un article du dieteur Demeure qui mérile dière cité. Le blessé, ayant sucé aree courage son doigt alteint par les cruehels l'une vipère, go rit heureusement. Il n'y a là rien de bien rermeilleus, ajoule arce raison M. Subberan, si ce n'esi l'explication domée par le médecin homoopathe. "Le malade, dit celui-ci, a été satuvé prar la suecion, non pour avoir fail ainsi sortir le renin de la plaie, mais pour l'avoir avalé, dilué par le sang ct les liquides contenus dans le doigt! " Puis l'auteur ajoule: "Serail-ce trop arancer, que de dire qu'en s'ingérant le venin du serpent on se rendit insensible à sa piqûre? $n$

Des proprositions du genre de celles de M. Deincure ne mérient pas d'ètre réfutées. La succion a les mèmes résultats quand clle est pratiquée par une autre personme que celle qui a élé mordue.

Il nge faut pas confondre cette prétendue action curative du renin sur le renin aree une question d'un orko différent et dont il sera parlé plus loin, l'immunité que donneraient des piqûres antérieures.

II. - Les spécifiques véyétanx reconmandés contre les morsures forment de longues listes en tous pays.

Ceux qui jouissent dans l'Ouest de la plus grande vogue sont les suivants :

$1^{\circ}$ Divers ignlicis (par corruplion sulli-lnit, en particulier, la miélite (Galium cerum L.), la croisette jenne (G. erucintum Scop.), 
la croisette verte (G. Mollugo L.), et le gratteron (G. Aparine L.); $2^{\circ}$ une garance, dite prend-main ou roube, (Rubia peregrina L.); $3^{\circ}$ les parties vertes du fréne (Fruxinus excelsior L.); 4.0 la bardane ou narpron (Lappa minor D. C. el L. major Gæern.);

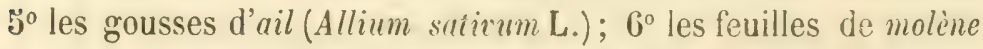
(Verbascum Thapsus L. et V. Schruderi Mey.); $7^{\circ}$ l'uigremoine (Agrimonia Eupatoria L. et sa var. oflorata); $S^{0}$ les sommités du genèt à balais (Sarothamnus scoparius Kioch), et $9^{\circ}$ la racine de panais sauvage (Pastinaca sylvestris Mil.)

Les galiets et le prend-main, réputés antispasmodiques et diurétiques, ne renferment aucun alcaloïde comparable à ceux de certains végétaux exotiques de la même famille, mais simplement une substance amère, colorant, dans plusieurs espèces, les urines en rouge, et de plus, pour les Galium verum et cruciatum, un principe à odeur de miel.

Le frêne, tant vanté par Dioscoride, ne fait pas fuir les serpents, quoi qu'en ait dit cet auteur. Ses feuilles, ses jeunes pousses et sa seconde écorce' sont les parties dont on se sert. Leur infusion, couleur de vin paillet, est amère, astringente et jusqu'à un certain point fébrifuge. Elle doit ses propriétés à la fraxinine et est légèrement laxative. La ressemblance de la fraxinine avec la grenadine, principe extrait de la racine de grenadier, explique l'action vermifuge des feuilles de frêne, mais ne rend point compte de la prétendue spécificité du frêne contre les venins.

Beauregard, de la Rochelle, donnait 8 onces dé suc de feuilles aux personnes mordues, et appliquait le mare sur les piqûres. Malgré les cas de guérison qu'il a cités dans l'ancien Journal de médecine, t. VI, p. 233, celte médication incertaine a été abandonnée.

La bardane, que Mérat regardait cornme un dépuratif comparable à la salsepareille, offre dans sa racine de l'inuline, des sels 
à base de potasse, une matière extractive et de l'amidon; ses tiges et ses feuilles contiennent du nitrate et du sous-carbonate de potasse en quantité considerahle. Tuut cela n'explique point les vertus alexipharmatques qu'on lui attribue sans raison.

La molène est émolliente; le panais, aromatique; les feuilles et les sommités fleuries d'aigremoine renferment un principe astringent.

A. Paré appliquait des bulbes d'ail pilés sur les morsures; ainsi réduits en pulpe, ils produisent de la rubéfaction à la peau, propriété qu'ils doivent à leur huile essentielle, sulfure d'allyle $\left(\mathrm{C}^{6} \mathrm{H}^{5} \mathrm{~S}\right)$, voisine de l'essence de moutarde $\left(\mathrm{C}^{6} \mathrm{Il}^{5}, \mathrm{C}^{2} \mathrm{Az} \mathrm{S}^{2}\right)$, sulfocyanure du même radical. Employés à l'intérieur et à l'état cru, les aulx et les oignons sont diurétiques.

La scoparine des fleurs de genêt modifie aussi la sécrétion du rein, et de la façon la plus heureuse en cas d'albuminurie; mais, pas plus que les substances précédentes, elle ne peut passer pour un contre-poison, ni même pour un antidote un peu énergique des échidnines.

L'observation de M. II., pages 86 et suivantes, a fait connaitre deux recettes populaires où les Galium jouent un grand rôle; les exemples suivants suffiront pour juger de ces formules.

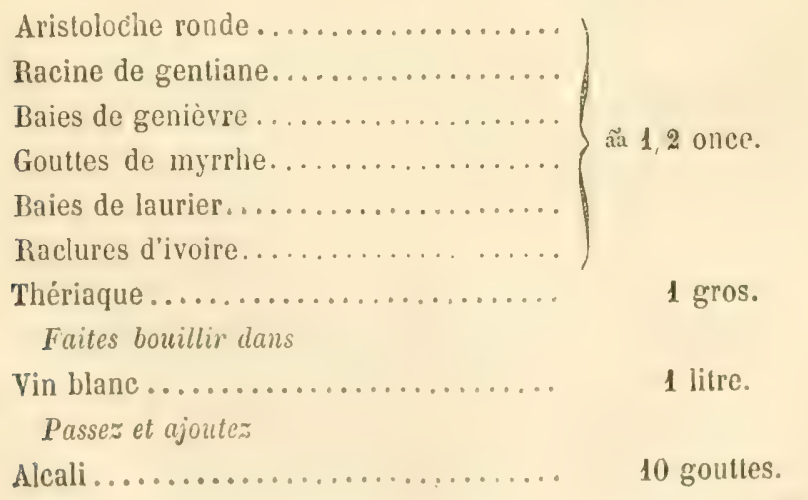


Le tout constitue un vin tonique, aromatique et très-amer.

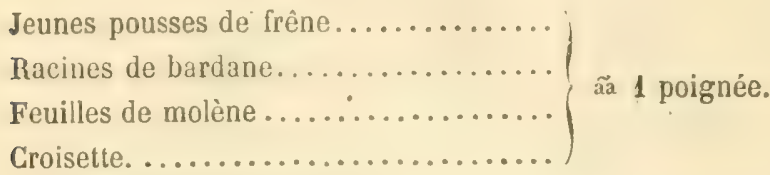

Pilez et exprimez dans

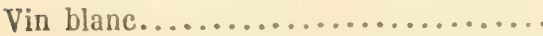

3 verres.

Dans cette recette, en vogue au pays de Retz, le frêne et la cloisette nous paraissent seuls, avec le vin, avoir quelque activité.

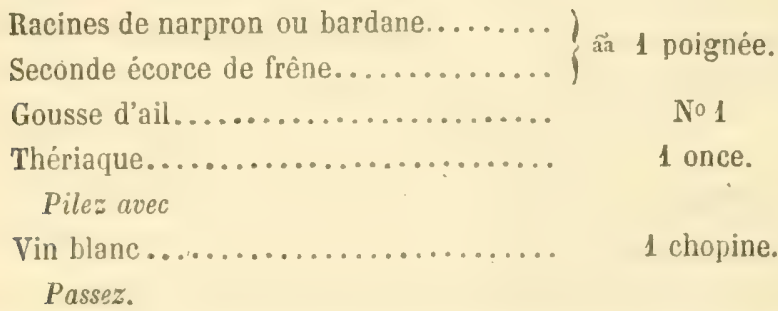

En usage dans la partic méridionale et le Bocage de la Vendée.

Quatre à cinq racines de bouillon blanc.

Trois racines de bardane ou glouteron.

Trois gousses d'ail.

Une bonne poignée de croisette.

Une once de thériaque, ou la moitié du corps d'une vipère sèche.

Pilez el faites bouillir dans

Une chopine et demie de vin.

Réduisez à une chopine ou un demi-litre et passez.

A prendre par verie de deni-henre en demi-heure. Pour un enfant, la dose sera moilić moindre; on la domnera double pour un boeuf ou un chevil, el on y ajoulera, dans ce cas, un coup de poudre à tirer.

Toute vipère n’est pas pronne à cntrer dans ce médicament; 


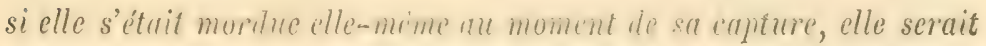
dangereuse au lime d'itre sululaive! On peut, du reste, la remplacer par une poignée d'aigremoine.

Pendant l'adminishration du breuvage, le nare doî̀ ètre appliqué sur la partic mordue, préalablement fustigée avec des branches de groseillier épineux.

Cette formule, en honneun dans le Finuí Poilou, porte le nom de remède du père Gallet.

Gallet, cortionicr à Béruges (Vienne), arait 80 ans quand, en 18\%0, il confia son secret à II. le curé de Vouneuil-sur-Briard. Nous le devons au frère Florent de la congrégation de SaintGabriel (1).

Toutes ces recettes ont entre elles de grands rapports. On y trouve loujours des substances amères et aromatiques unies à du vin. Le liquide esí domné par verres dans la journée, en quantité parfois assez considérable pour produire un commencement d'ivresse, ef le résidu est placé sur la morsure. Elles agissent comme ioniques, en soutenant l'économic contre l'action déprimante de la vipérine, el favorisent l'úlimination du poison, en portant à la sueur et à la diurèse.

Ces anolés, conposés en dehors de lonte règle théraneutique rationnelle, ne sont-ils jamais dangereux? Nous n'oserions en répondre. Lor'su'ils ne sont point irop chargés de sucs de plantes, et que les galiets y dowincnt, ils nous paraissent préférables à l'alcali. Leui effet heurcux est surtout dû au vin; notons

(1) M. le supirieni griniral des frèes de Saint-Gabriel a eu l'obli-

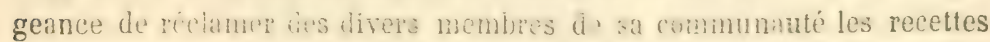

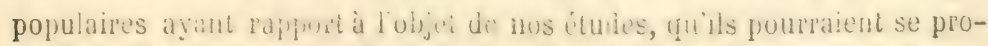
curer dans la canymgne. Nous avons ublenu ainsi dez notes précıuses que nous avons reçues avec reconnaissance. 
toutcfois qu’à doece ćlevées ils provoquent des nausées et des vomissements.

Point de rapprochement curicux! les spécifiques étrangers tirés du règne végétal sont tous stimulants amers et diaphorétiques, et en même temps plus ou moins nauséeux. Nous ne parlerons parmi ces dernicrs que du sínétu, lu cédron et du guaco, car ils sont au nombre dé plus de cent.

La racine parfunce du polygala de Virginie (Polygala Senela L.), cmployée par les Pecux Rouges contre la morsure des crotales, doit ses nrincivales propriétés à deux acides odorants: l'acide virginéinue ct l'acide polygulique. Tonique et excitant diurétique à faiblè doses, le sénélia augrmente le mouvement vers la peau et le purinon; à doses fortes, il purge et fait vomir. Son emploi est done narfaitement indiqué dans l'empoisonnement par les ophilicus. L'ipécacuanha (Caphelis Ipecacuunha Rich.), dont le polygala n’esi qu'un succédané, mériterait d'être essayé comme lui contre les venins. C'est un vomitif frane et en mème temps un diaphorílinge qui, loin de prostrer comme le tartre stibié, soulient plutôt les forces.

Le cédron est la graine, ou plus exactenent les cotylédons d'un arbre de la famille des Simaroubées, le Simaba Cedron Planch. Il a été apporié en France par M. Herran, chargé d'afiaires de la république de Costa-Rica (1).

En 1898, quelques sauvages, munis de ces graines, s'exposèrent, à Carthagène, aux piquires de divers serpents et en particulier du conail. La promptitule aree laquelle le poison fut neutralisé jeta un tel cngouenont dans la fonle qu'on paya chaque graine jusqu’à quatre-vingt-trois francs. M. Ilerran, témoin de ces

(1) Graine de cédron employice dans l'Amérique tropicale comme reméde contre la morsure des serpents. (Journ. de pharm., 1850, p. 296.) 
faits, se procura le précieux antillote et l'employa huit fois heureusement. Le cédron, râpé et délayé dans un peu d'eau-de-vie, s'administre par la bouche à la dose de 20 à 30 centigrammes. On en saupoudre de plus un linge imbibé d'eau-de-vie, que l’on pose sur la plaie. Donné sans mesure, il devient vénéneux. MM. Lewis et Dumas en ont isolé la célrine, substance neutre, cristallisable, et l'une des plus amères connues.

Le docteur G. Dumont a entrepris avec ee remede une série d'essais dont M. Aug. Duméril a publié le résumé dans la Nolice sur la ménagerie des Reptiles, p. 276. Administré à des lapins plusieurs heures avant la morsure, il les rend inaptes à subir l'influence du venin; pris au contraire après l'accident, il n'arrête point les effets du poison. Les échidnines agissant avec beaucoup plus de lenteur sur l'homme, Mr. Dumont en conclut que l'antidote, employé aussitôt la morsure faite, pourrait encore chez lui prévenir l'envenimation. Ses expériences n'infirment point les faits avancés par M. Herran.

Depuis le travail que nous venons de ciler, nous n'avons plus entendu parler du cédron. N’aurait-il pas tenu ce qu'il semblait promeltre? ou son prix toujours élevé aurait-il cmpêché sa vulgarisation?

Le guaco (Miliania Guaco II. et B.) est une composée voisine des eupatoires. Il a pour principe actif une résine amère applelée la guacine. Le doctcur Andrieux (Journal des conn. mél. et pharm., 1849, p. 181) dit l'avoir essayé avec succès sur des chiens mordus par nos vipères de France; mais les expériences de N. Rufz, entreprises à la Martinique dans des cas de morsures du fer de lance, n’ont pas étć lavorables à son enunlni. Daprès qualques-uns de ses proneurs, il suffrait d'on pourar des feuilles. selon d'autres, de s'en inoculer le suc frais [mur lnaver la colere des solénoglyphes les plus puissants. 
Le professeur Delamarre, auquel le musée d'histoire naturelle de Nantes doit un grand nombre de reptiles de la Guyane, a reçu ces animaux d'un cordonnier ayant à Cayenne la réputation de les saisir impunément à pleines mains. La piưure des oplidiens venimeux ne lui causait quine légrire inflammation locale sans phénomènes généraux. Il avait suin de prendre, avant de se livrer à ses chasses périllcuses, trois loses d'une infusion de plantes dont il a gardé le secret. Le capitaine qui donna ces détails à M. Delamarre essaya le remède, el fut tollement malade des deux premières doses qu'il n'osa continuer.

MIM. Bar, naturalistes nantais, ćlablis en Guyane, ont eu aussi une fièvre violente et des accidents sérieux pour avoir voulu se soumettre à un mode analogue d'expérimentation.

Une seconde plante, qui n'a aucun rapport avec celle dont nous venons de parler, nous arrive aussi de l'Amérique du Sud sous le nom de guaco, la lime contre-poison des Cayennais (Avistolochia odoratissima L.). Ses tiges volubiles, à couches subéreuses très-prononcées, ont une odeur el un goût fortement aromatiques. Son principe actif est soluble dans l'cau bouillanto et dans les excipients alcooliques, en particulier le fafia. Elle jouit d'un grand renom contre les venins à la Guyane, aỉsi gl au Brésil, où elle est connue, d’après M. Enrique Onfroy (1mérinue méridionale), sous le nom de bejuco de guaco. Le meme auteur indirue, dans les pays arrosés par l'Amazone, un autre préservatil de la morsure des serpents, doué de proprićtés merveilleuses, le bejuco ou bejuquillo de vivora dont nous ignorons le nom scicistilique.

Nous avons employé avec avanlazo, lans les accidents consécutifs dus à la vipere, la liane contre-joison que nous avait procurée M. Dom. Hougel, et il nous a ćlé facile l'arriver à sa détermination botanique sur des ćchantillons d'herbier provenant de M. Leprieur, pharmacien à Cayonne. 
III. - Le tabac, d'un tout autre groupe que les remèdes précédents, a été aussi préconisé contre les venins.

Une des recelles, recucillies dans le Poilou par le frère Florent, conseille de màcher une forte pincéc de c'ette substance, d'en avaler le jus et d'en mettre le résiclu sur les pirfûres agrandies.

M. Vauver't de Méant, dans une lettre adressée à la revue Lamb and water de M. Franck Buckland, en date du y2 juin 1867, raconte çu'à Cawerpoor, un vicux nusulman, son pourvoyeur de reptiles, plusieurs fuis blessé par des najas, appliquail sur leurs morsures la cendre imbibée de nicoline du fond de sa pipe et ne s'en préoccupait pas davantage. Le même olsservatcur ajoute qu'en Afrique un homme ayant été mordu par un preff-adder (Echidne arietans Merr.), un sorcicr cafre lui pratiqua sur les piqûres, avec un morceau de verre, une incision dans laquelle il introduisit le culot d'une vieille pipe. Ce traitement, aidé d'une forte rasade d'eau-de-vie mélangée de poudre, sauva le malade.

Nous ne connaissons aucune expérience régulière permettant de juger de la valeur alexipharmaque de ce moyen.

IV. - Les ammoniacaux ont longtemps joui d'une réputation sans conteste. Ils ont été considérés comme les véritables contrepoisons des venins et transportís à ce titre dans les cinq parties du monde.

Il y a une dizaine d'années, tout chasseur avait son flacon d’alcali renfermé dans un élui spécial, achelé chez l'armurier; tout voyageur partant pour les pays intertropicaux faisait provision de ce liquide. Dans la Vendíe et les départements voisins, méderins et guérisscurs s'accordaient pour en pròner l'usagre.

Les préparations ammoniaciales liss plus employées sont : l'alcali, l'eau de Luce et l'acétate d'ammonaque.

L'aleali ou ammonicune liquide est une sulution aqueuse de gaz ammoniac au cinquième, devant marquer $22_{20}$ a l'aréomètre. 
A l'intéricur, on le donne de deux heures en deux heures, à la dose de 6 à 8 goultes ( 30 ì 40 centig.) dans une infusion de thé, de fleur de sureau, de camomille ou de feuilles d'oranger.

A l'extérieur, on en use de diverses manières : le plus souvent on l'introduit dans la piquure agrandie; d'autres fois on le fait pénétrer dans les scarifications pratiquées au voisinage de la blessure. Enfin, quoiqu'il soit démontré que l'ammoniaque n'agit pas comme réactif à traver's la peau, même sur des sels de cuivre placés sous celte membrane, certaines gens se contentent d'en frotter la partie blessée.

L'eau de Luce est un liquide d'aspect émulsif, à odeur forte et à saveur caustique, dont voici la formule :

Ammoniaque médicinale....... 70 grammes.

Mélez avec la teinture suivante :

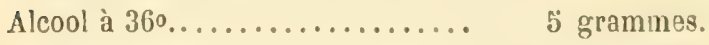

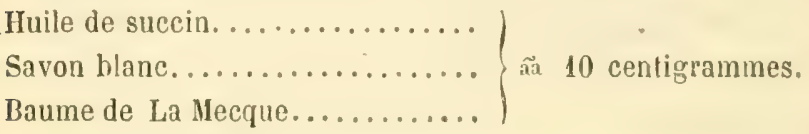

Nêmes doses que l'alcali, mais beaueoup moins usitée.

Si l'on voulait employer une solution d'alcali ponr l'usage interne, nous préférerions à toute autre la formule désignée dans les vieux formulaires sous les noms d'esprit de sel ammoniacal dulcifié ou d'alcool ammoniacal, soit :

Ammoniaque médicinale............. 1 partie.

Alcool à $86^{\circ} \ldots \ldots \ldots \ldots \ldots \ldots \ldots \ldots \ldots . . \ldots . .2$ parties.

L'acétate d'ammoniaque médicinal ou esprit de Mindererus (I)

(1) L'esprit de Mendererus, ou mieux de Mintererus, tel qu'il était fabriqué par R. Minderer, médecin d'Augrbourg au xvrı siècle, différait un pu de l'accitate d'ammoniaque actuel. (oblenu par l'oction du vinaigre rectifié sur le carbonate d’ummoniaque retiré de la distillation de la corne decerf, 11 contenait des produits empyreumatiques. 
est une solution aqueuse d'acétate cristallisé, marquant $5^{\circ}$ à l'aréomètre. Au point de vue physiologique, il doit être séparé des solutions précédentes.

La réputation de l'alcali repiose sur une erreur de Mead et sur une observation de Bernard de Jussicu, dont ce grand naturaliste a tiré le premier des conclusions fausses.

Mead considérait le venin comme acide, et, partant de là, lui opposait une substance à réactions contraires. Or il est démontré que ce liquide ne doit pas ses propriétés à un acide, et le savant anglais l'a reconnu lui-même plus tard.

Dans une herborisation sur la butte Nontmartre, le 23 juillet 1747 , un étudiant en médecine fut mordu par une vipère. Jussicu, qui portait sur lui un flacon d'eau de Luce, lui en fit prendre et en frotta la plaie. Le blessé guérit, mais après avoir été horriblement malade. L'ammoniaque n'avait done pas neutralisé le poison, et le fait, apprécié à sa juste valeur, loin d'être une démonstration de l'efficacilé du remède, est une preuve de son inutilité.

L'alcali, employé extérieurement, n’est qu'un faux caustique ou, pour ètre plus exact, un caustique superficiel, se bornant à soulever l'épiderme et n'empêchant pas l'absorption des venins et des virus.

Mèlé â la salive parotidienne de la vipère, il ne décompose point l'échidnine. Fontana a fait mourir de petits animaux en leur ino. culant le poison délayé dans de l'ammoniaque, presque aussi rapidement que s'il eût employé du venin pur.

Ces arguments sont sans réplique. Aussi M.M. Trousseau et Pidoux (Traté de thérupeutique, $8^{\circ}$ édition, t. I, p. 462) condamnent-ils l'ammoniaque, quel que soit son mode d'administralion, dans l'empoisonnement venimeux, et la considèrent-ils comme plus nuisible qu'utile. 
Moins sévère, nous n'osons en proscrire d'une façon absolue l'usage interne. Elle relève rapidement le pouls et excite les fonctions de la peau, des poumons et des reins. Elle peut done être un bon adjuvant de la médication générale, surtout si elle est unie à l'alcool, mais il faut se garder de voir en elle un spécifique.

Voici un exemple de son association avec l'alcool dans une potion stimulante :

\begin{tabular}{|c|c|}
\hline Ammoniaque médicinale............ & 1 gramme. \\
\hline 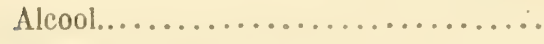 & 2 grammes. \\
\hline 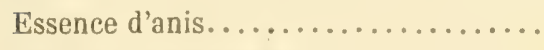 & 2 gouttes. \\
\hline Hydrolat de menthe.............. & 16 grammes. \\
\hline Eau distillée.................... & 120 grammes. \\
\hline Sirop de sucre................ & 30 grammes. \\
\hline
\end{tabular}

A prendre par cuillerée d'heure en heure.

Malheureusement, si l'alcali soutient les forces et agit sur les sécrétions, il rend le sang diffluent, et MI. Pasteur a démontré qu'étendu il favorise les fermentations plutôt qu'il ne les entrave. Nalheureusement aussi, à doses cxagérées, il cautérise la muqueuse gastrique et provoque des vomissements, parfois presque incoërcibles. Entre des mains inexpérimentées, il peut même devenir vénéneux, tant par son action sur l'estomac que par l'introduction dans le sang de mollécules véritablement toxiques.

L'acétate étant neutre, n'a pas les propriétés caustiques de la base et passe pour un excelient diffusible. Il est prescrit avec avantage contre les accidents ataxiunues et contre la tuméfaction persistante.

Néanmoins on doit en user avec modération, car lui aussi diminue la plasticité du sang. 
V. - Les alcooliques sont de puissants cordiaux parfaitement indiqués contre les venins.

En 1761, ils étaient déjà préconisés par Williams Paterson, qui assurait avoir guéri des Cafres avec un mélange d'eau-de-vie et de vin de Madère.

L'eau-de-vie est le remède par excellence des borders de l'Amérique du Nord, et Dieu sait à quelles doses en usent ces riverains du désert dans l'empoisonnement par la crotaline : ils administrent à des enfants jusqu'à un quart de brandy.

M. Mar, du Tennessee, sauva par le whisky (eau-de-vie de grain) un homme mordu d'un serpent à sonnettes. Il est vrai qu'il perdit un autre malade soigné de la même façon.

NI. Weir Nitchell (1) considère les alcooliques comme un des meilleurs antidotes du venin des crotales.

En 1861, notre regretté compatriote M. de la Gironnière, établi aux Philippines, communiquait à l'Académie des Sciences le fait suivant (2):

Un homme, qui travaillait au milieu des forèts de Cabaocing, fut mordu au doigt par un serpent très-redouté, à peau jaune, à tête triangulaire et plate, et à crochets d'un centimètre et demi de longueur. II. de la Gironnière cautérisa la blessure avec des charbons ardents, mais inutilement. La tuméfaction s'étendit de la main morlue jusqu'au-dessus du coude; le malade poussait des cris ef accusait des douleurs dans les muscles pectoraux. Ne sachant comment le soulager, M. de la Gironnière imagina

(1) On the treatment of rattlesnutie bites, with experimental criticisme, upon the various remedies now in use, par le docteur Weir Mitchell. - Philadelphie, 1864.

(2) Heureur effels de l'artion des alrooliques portis jusgnu'a l'ieresse dans le cas de la morsure de certuins serpents, par le docteur de la Gironniere. (Comptes rendus de l'Académie des Sciences, t. LII, p. 740.) 
de lui donner à boire une bouteille de vin de eoco (alcool à $14^{\circ}$ ou 16 ${ }^{\circ}$. L'irresse fut instantanée; la douleur et la tuméfaction diminuèrent peu à peu, mais les accidents reparurent, dès que le malade revint à la raison. Fort de son premier résultat, M. de la Gironnière lui fit avaler deux nouvelies bouteilles, à quelques heures de distance, et bientôt il ne resta pour tout symptôme que les traces de la inorsure et de la cautérisation.

II. Fumouse, pharmacien à Paris, et le docteur Déider (Journ. des Conn. mél. et ph., t. XXVIII, p. 324) ont soigné, dans l'Amérique du Sud, avec succès, à l'aide d'alcooliques, plusieurs individus blessés par des serpents, tels que les crotales, les trigonocéphales, le jararaca, etc. Le doctcur Déïder donnait le cognac ou le rhum à la dose de 50 à 100 grammes dans une infusion aromatique el appliquait sur la morsure des compresses alcoolisées.

a Le fond des remèdes employés par les panseurs des Antilles, dit le docteur Encognère (Des accidents causés par la piqûre du serpent de la Martinique et de leur traitement, p. :57), est le même partout, e'est-ì-dire le tafia mêlé au suc de certaines plantes... Nous croyons que toute l'action revient au tafia, tant la quantité est comparativement considérable. »)

A Sidney, le champagne, le bordeaux et le sherry font partie de la médication conseillée par $M$. W. Blaud $(O n$ the bite of the venenous serpents of Australia. - Austr. med. journ., janv. 1861) contre les morsures des serpents de la NouvelleHollande.

La plupart des recettes de nos campagnards contiennent du vin dans de forles proportions. Le vin pur, du reste, est souvent administré jusqu’à l’ivresse par les guérisseurs, et avec avantage.

Nous n'en voulons pour preuves que les observations citées aux pages $\check{9} 9,135$ et autres de ce travail. 
Les préparations dont on doit espérer le plus grand profit sont les vins généreux (porto, madère), le vin chaud, les infusions vineuses aromatiques, les grogs (mélanges d'eau, d'eau-de-vie et de sucre), et les sungris au madère (mélanges d'eau, de madère sucré et de râpure de noix muscade), ete.

Le vin composé suivant nous a paru aussi d'un usage heureux :

Porto alcoolisé...................... 800 grammes

Liane contre-poison (aristolochia odoratissima). 30 grammes

Quinquina calysaya.................. 20 grammes

Faites selon l'art un vin médicamenteux.

A prendre par verre à liqueur de deux heures en deux heures jusqu'à stimulation; en continuer l'usage pendant quelques jours à dose de 150 à 20 grammes matin et soir.

On associe quelquefois l'ammoniaque au vin blanc du pays dont on connait les vertus diurétiques. L'ammoniaque, au contact des acides libres du vin, passe à l'état de sel et perd ses propriétés irritantes. Le docteur Sortais, de Blain, a obtenu de bons résultats de ce mélange.

Lorsque le malade ne peut pas avaler, on lui administre l'alcool en inhalations.

"Chacun, dit M. Maurice Perrin (Dict. enc. des sc. méd., art. Alcool), connaît le réveil merveilleux des forces qui suil de près l'emploi approprié des alcooliques, la stimulation qu'ils exercent, le sentiment de bien-être (qu'ils procurent. "Ils élèvent la température du corps que le venin tend à abaisser, surexcitent le système nerreux qui se déprime, et luttent contre la tendance à l'aủynamie. Arrivés dans les vaisseaux, où on les retrouve en nature, ils s'opposent aux catalyses. Enfin, en s'éliminant par 
les transpirations cutanée et pulmonaire et par les urines, ils favorisent la sortie des produits échidniques.

Quelque grande que soit la tolérance des venimés, on ne doit point abuser des spiritueux, et il n'est pas nécessaire de les pousser jusqu'à la perte de la raison; la prudence défend même de dépasser le premier degré de l'ivresse. Au delà ils deviendraient dangereux et faciliteraient les congestions qui n'ont que trop de tendance à se produire. Une ébriation profonde abat et n'excite plus; elle agit d'ailleurs dans le sens de l'empoisonnement au lieu de le combattre. L'excitation alcoolique d'autre part peut être portée au point d'augmenter la fièvre de réaction et offrir ainsi un péril d'un autre genre.

VI. - Le café doit à ses huiles essentielles des propriétés stimulantes qui le font associer avec avantage aux alcooliques. Son action varie suivant la manière dont il est préparé. D’après M. Offret (1), une décoction prolongée enlève au marc de nouveaux produits à effets narcotiques. On les évite en obtenant le café par infusion ou par décoction de quelques minutes.

VII. - L'huile d'olive était placée par Linné parmi les antidotes des venins au même rang que l'alcali (2). Elle s'administre aussi à l'intérieur et à l'extérieur.

On la donne par cuillerées, jusqu'à ce que l'estomac ne puisse plus la supporter ; on l'emploie en même temps en lavements et en frictions.

Prônée par un marchand de vipères anglais, elle a cu une

(1) Observations sur l'action pllyssiologique du café selon ses diverses torréfactions. - Nantes, 1862.

(2) Voici la phrase aphoristique de Linné sur les ennemis des serpen et les antidotes à opposer à leur venin, dans les difírentes parties du monde: Imperans benefucts homini dedil, Indis ichneunonem cum ophirhiza, Americanis suem cum senega, Europeeis ciconian cum oleo et alcali. 
grande vogue de l'autre côlé de la Nanche, où Nortimer et Burton s'en servirent dans des cas heureux. En 1737, l'Académie des sciences de Paris voulut sassurer de sa valeur et nomma, pour faire des expériences, Ilunaud et Geoffroy. Ils conclurent que l'huile ne peut préserver de la mort les petits animaux, et qu'elle ne produit aucun mieux sensible chez les grands.

La question semblait jugéc, lorsqu'en 1819, le docteur Dusourd, de Saintes, publia, dans le Bulletin général de thérapeutique, quatre observations lerminées par la mort en cinçuantesix heures, malgré la cautérisation au fer rouge, la thériaque, le quinquina, les ammoniacaux, ete., et sept autres où la guérison lui parut le résultat de l'huile d'olive.

Malgré le travail remarquable de M. Dusourd, l'huile n'a jamais acquis dans l'Ouest la popularité de l'alcali ; c'est un antidote douteux, qui ne prévient point l'apparition des phénomènes généraux.

VIII. - L'arsenic ou plutôt l'acide arsénicux entre dans la composition des fameuses pilules de Tanjore, dont se servent les gounis ou charmeurs de serpents indous. Il s'y trouve uni au mercure, au poivre, à diverses cuphorbiacées et asclépiadées, et au suc de coton sauvage.

Chaque pilule contient $3 / 4$ de grain ou 38 milligrammes d'acide arsénicux. Elles sont donnćes, au nombre de deuy, à une heure de distance l'une de l'autre. C'est done une dose formidable d'arsenic qui est ainsi ingurgitée.

Malgré les faits cités par Travers, W. Paterson, Sommerat et Ireland, l'emploi des arséniaux ne peut être vuigarisé; ils exposent à remplacer un empoisonnement par un autre non moins grave. Liussel, qui a si bien étudié la question dans l’In. doustan, les condannc l'une façon absolue, et personne, à 
notre connaissance, n’a eu l'idée de les essayer contre la piqûre de la vipère.

IX. - Le chlore, l'iode et le brome sont les contre-poisons les plus sûrs des bases organiques; ils les neutralisent en se substituant à une partie de leur hydrog̀̀ne. On pouvait donc espérer qu'ils seraient utiles contre les renins, quoique les poisons animaux ne soient point des alcaloïdes et offrent un autre groupement moléculaire.

Les lotions d'eau chlorée, que Brugnatelli, Schonberg et Semmola considéraient comme un spécifique de la rage, sont de nulle valeur, et maintenant délaissées. Le brome, violent caustique, altère profondément les tissus, ct il n'est pas facile d'en limiter l'action. Restent les solutions iodo-iodurées, la teinture d'iode et les solutions bromo-bromurées. Introduites dans une plaie contenant du curare, elles détruisent le poison sans causer de désordres au voisinage de la blessure.

Le docteur Withmire, de l'illinois, les a le premier proposées contre la morsure des serpents à sonnettes. Son exemple a été suivi par ses compatriotes MI. Brainard et Green qui, en 1853, communiquèrent leurs recherches à l'Académie des sciences (Compt. rend., t. LVII, p. S11). L'année suivante, M. Brainard les réunit en corps de doctrine sous le titre d'Essay on new method of treating serpent bite, and other poisoned wouds, publié à Chicago.

Le mode d'expérimentation du docteur Brainard était assez compliqué. Une ligature étant placée entre le cocur et le point où devait mordre le reptile, l'inoculation avait licu et était immédiatement suivie d'une injection de quelques gouttes de la liqueur médicamenteuse faite à l'aide d'un pelit trocart et de la seringue d'Anel; puis l'on posait une ventouse sur la blessure pendant cing à dix minutes, pour entraver l'absorp- 
tion et laisser au remède le temps d'agir; après quoi ventouse et ligature disparaissaient et le blessé n'avait plus rien à craindre de l'envenimation.

En Vendée, le docteur Bourgeois, d'après les mêmes vues théoriques, a eu pareillement recours à l'iode dans un cas de morsure envenimée, mais il s'en est servi d'une manière assez différente de celle des médecins américains. Voici son observation, telle qu'il a bien voulu nous la transmettre.

a Le 21 juillet 1860, je fus appelé en toute hâte dans une maison du bourg de la Verrie pour donner des soins au nommé Coudrin, âgé de quarante-sept ans à peu près. Cet homme, occupé le matin à labourer un champ, sentit une piquûre assez vive à la partie externe du pied droit, et, ayant fait un pas en arrière, il aperçut une vipère pendue à sa peau. Il saisit le reptile des deux mains, l'arrache avec violence et le déchire. Il fut vivement blàmé devant moi de n'avoir pas eu la présence d’esprit de dévorer aussitôt le cocur de la vipère; il n'aurait plus rien eu à redouter du venin !.... Hais le pauvre homme n'ayant pas eu ce courage, le poison fit son effet ! Peu d'instants après la piqûre, le pied devint le siége d'une tuméfaction considérable, et le blessé se hâta de se mettre en route pour Chambretaud, où le sieur Gaufrefaud, grand hippocratc du pays, rendait ses oracles.

» Par malheur, ou plutòt par bonhcur pour Coudrin, la route était longue, et arrivé au bourg de la Verrie, ses forces lui firent défaut et l'obligèrent à s'arrêter chez ses parents.

»Bientôt survinrent des faiblesses et des vomissements; le pauvie malade, incapable désormais d'aller jusqu'à Chambretaud, se décida à apyeler le médecin; mais cette fois encore ce ne fut pas moi. On consulta un mélecin de bêtes, vétérinaire non breveté, qui plaça au-dessous du genou une écorce de genêt, en forme de jarretière, d'une façon très-lâche et incapable d'ar- 
rêter le venin. Je crois que l'artiste pensait agir d'une manière spécifique et que ses idées en physiologie n'allaient pas jusqu'à lui expliquer l'action de la compression. Le venin absorbé con. tinua donc son action toxique; les faiblesses et les vomissements persistèrent, augmentèrent même, et l'on dut enfin me prier de voir le malade. J'arrivai promptement près de lui et le trouvai dans un état très-grave. La face pâle, hippocratique, présentait en quelques points des teintes bleuâtres; les yeux étaient enfoncés dans l'orbite; le pouls petit, irrégulier et lent; la peau froide. Le pied et la jambe offraient déjà une tuméfaction énorme; une coloration noirâtre, nuancée de bleu et de stries rougeâtres, se montrait sur tout le membre blessé. La douleur ressentic au moment de la morsure persistait el s'étendait des piqûres à l'aine; des erampes se produisant par intervalle arrachaient des cris au malade; le moral était affecté d'une façon fàcheuse, car il ne faut pas oublier que ce pauvre Coudrin n'avait pas grande confiance en moi au point de vue du venin, et ne m'avait appelé qu'à défaut de mon voisin le guérisscur. Ajoutez à ces inquiétudes les allées et venues des empiriques en jupons alarmant le malade et déclarant que si le venin n'était pas conjuré tout serait inutile.

» Je commençai par rassurer Coudrin et je réussis assez bien à le tranquilliser; puis j'examinai la blessure. Deux petits trous trèg-distincts indiquaient l'endroit où les crochets avaient pénétré. L'épiderme autour de la plaie était soulevé et la peau comme frappée de mort. Jugranan à propos de débrider, j'enfonçai ma lancette profondément, et je réunis les deux piqûres. Dans cette opération je reconnus et je parvins à extraire un des crochets du reptile. Je montrai cette dent au public et de suite je vis la confiance me revenir. Des goutles d'un liquide séro-sanguinolent scmblable à du sirop de groscille altéré 
s'écoulèrent de l'incision. J'appliquai une ventouse, et le liquide commençant à monter en moussant, l'admisation ne connut plus de bornes. N'ayant aucune foi dans l'alcali, il me vint à l'idée que l'iode, cet antiseptique prar cxcellence, ce contrepoison sans pareil des bases organicues, pourrail arec avantage être employé contre les venins; j'administrai done à mon malade, par cuillerées données d'heure en heure, la potion qui suit :

\begin{tabular}{|c|c|}
\hline Iodure de potassium........ & 4. grammes \\
\hline Iode... & 30 centigrammes. \\
\hline Essence de menthe......... & 4 gouttes. \\
\hline Sirop de gomme.......... & 30 grammes. \\
\hline Eau $\ldots \ldots \ldots \ldots \ldots \ldots \ldots$ & 125 grammes. \\
\hline
\end{tabular}

- En liniment composé d'jodure de potassium et de vin blane fut employé sur le pied et la jambe que je fis recouvrir aussi de morceaux de flanelle très-chauls. Je prescrivis on outre du vin, du café, et du bouillon de boeuf.

„Pendant les deux preniers jours, les accidents généraux demeurèrent stationnaires, exeepté loulefois les romissements qui ne revinrent julus. Pen à peu la gravité des symuthmes diminua; la doulcur ne s'en aila que très-lentement; l'ademe et les traînées violacées cédèreni la place à des ecchymoscs jaunâtres qui ne disparurent qu'après un mois de soins el de repos. L'état général, sous l'influence d'un purgalii ci d'un régime tonique et dépuratif (iodure de potassium continué pendant une quinzaine de jour's à doses déeroissanics), s’améliora d’une manière sensible, et deux mois après Coutin araí recourré son état de santé ordinaire. ”

Les résultats obtenus par les médecins américains contre la morsure de reptiles autrement redontables que les vipères européennes étaient faits pour séduire. Aussi, dans notre pre- 
mière édition, page 93, après avoir parlé de l'inutilité de l'ammoniaque comme contre-poison des venins, écrivions-nous ces lignes :

- Les succès de MM. Brainard et Green doivent lui faire préférer la solution aqueuse d'iodure de potassium et d'iode. Cette substance mérite d'ètre vulgarisée d'autant mieux qu'elle peut rendre de grands services dans les empoisonnements par la ciguë, les fausses abrenotes (OEnanthe crocata L.), la jusquiame, la pomme épineuse et autres plantes vénéneuses de nos contrées.

La solution dont nolis indiquions la formule n'était autre que celle de M. Brainard.

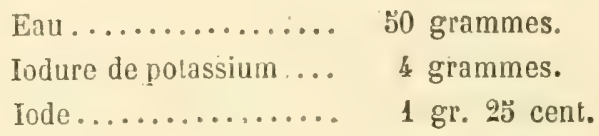

Nous proposions dès lors pour contenir les liqueurs anti-venimcuses et les introduire dans les piqûres, un appareil assez simple et qui s'est vulgarisé depuis cette époque.
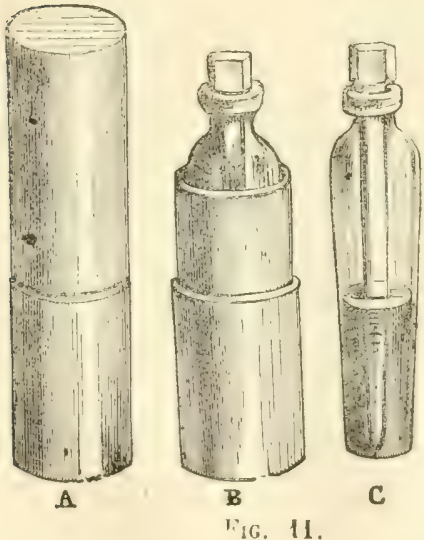

C

Il se compose d'un petit

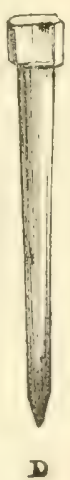

D flacon (fig. 11, C) entouré d'un étui en cuir (A et B), fermant à l'émeri et dont le bouchon (D) long et conique plonge dans le liquide. $\mathrm{Ce}$ bouchon, légèrement renflé près de la pointe, sert de porte-goutte, et permet de déposer le contre-poison jusqu'au fond des piqûres. 
Quand, au mois d'août 1861, la Société botanique de France vint herboriser dans l'Ouest, la plupart des botanistes qui prirent part à ses travaux étaient munis du petit flacon et de la liqueur de Brainard.

Depuis lors, nous avons expérimenté, plusieurs années de suite, la solution iodo-iodurée et une solution analogue de brome et de bromure potassique sur des lapins et des pigeons. Un de nos aides entourait d'un lien constricteur le membre où devaient porter les crochets, le dépouillait de ses poils ou de ses plumes, et le présentait à la vipère. La morsure faite el agrandie, nous y introduisions quelques gouttes du liquide à essayer. Aucune ventouse n'était mise sur la blessure, et l'enlèvement de la ligature suivait l'instillation du remède.

Presque tous nos animaux ont succombé ! et ceux qui se sont échappés n'ont dù leur salut qu'à un écoulement sanguin ayant entraîné le venin au dehors (1).

Des chiens mordus à la chasse ont été soignés par la solution iodée; ils ont guéri en trois ou quatre jours appès avoir offert des accidents d'intoxication, c'est-ì-dire comme ils cussent probablement guéri avec l'ammoniaque ou sans aucun remède.

M. Weir Mitchell a perdu tous les animaux blessés par des scrpents à sonnettes, qu'il a traités à l'aide de la teinture d'iode ou de la solution de Brainard. D’après ses observations, l'iode n’empêcherait point l'empoisonnement général' de se produire, mais, ainsi que le tannin, il diminuerait l'intensité des phénomènes locaux.

(1) Voir aux notes finales le résumé de nos expériences.

La solution iodo-iodure reste le meilleur contre-poison à opposer aux plantes vénéneuses indigènes, quand ellcs sont encore dans l'estomac. Elle s'administre à la dose de 10 à lö gouttes dans un verre l'eau sucrẻe. 
Ce n'est done point un contre-poison des venins, et M. Brainard doil ses succès, non à son spécifique, mais au maintien prolongé de la ligature et à l'application de la ventouse.

Le brome, abandonné comme remède externe, nous est revenu d'Amériqque sous forme d'antidote dans la recette suivante attribuée à Bibron.

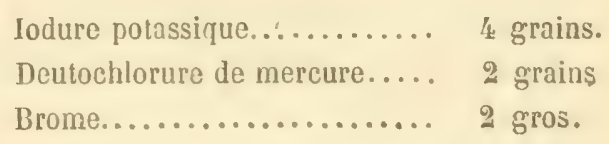

Dix gouttes à prendre, en une seule fois, mélangées à deux cuillerées d'eau-de-vic ou de vin généreux et le plus près possible de l'instant de la morsure.

C'est une singuliere histoire que celle de ee prétendu antidote Bibron.

Le docteur Xanthus (II. de Yesey), qui l’a préconisé le premicr aux Ĺtats-Unis, le tenait, disait-il, du prince P. de Wurtembery. Le prince, excellent naturaliste, aurait eu connaissance d'expérienecs entreprises à l'Académie des sciences de Paris par Bibron, qui, après aroir avalé son spécilique, se serait fait mordre par des crotales!

Personne au Muséum ni à l'Institut n'a entendu parler de semblable chose (1).

- Quoi qu'il en soit, Ianthus cite à l'appui de l'cfficacité de cette

(1) L'antidote Bibron porte, je ne sais pourquoi, ce nom, et tenez pour absurde que M. Bibron se soil exposi a des pi fures de serpents pour en essayer l'effet. J'ai cru un moment que j'arriverais à savoir quelque chose de pricis i ce sujet en icrivant, en 1862, au duc Paul-Guillaume de Wurtemberin de qui II. do Verey, cite par S. Weir Aitchell, disait tenir ses indications; mais le duc venait de mourir quand parvint en Wurtemberg ma lettre, qui me fut retuurnće sans avoir été ouverte. ) (MI. le professeur Aug. Duméril. - Lettre du 7 mai 1869.) 
dangrereuse formule un certain nombre d'expériences qui prouveraient, qu'administrée avant la morsure, clle garantiraitde l'envenimation. Le docteur Ilammond s'en est servi deux fois avec bonheur et une troisième sans succès, et MI. Coolidge lui attribue la guérison d'un de ses malades.

M. Weir Mitchell, à qui nous empruntons ees détails, l'a employée avec des chances diverses; il la regarde comme un antidote douteux et en lout cas bien inféricur aux alcooliques.

X. - Le perchlorure de fer, que ses propriétés hémostatiques rendent déjà un précieux médicament, serait, d’après le docteur Rodet, un excellent destructeur des virus et des venins. Son action s'explique en partie par le précipité insoluble qu'il forme avec les substances protéiques, en partie aussi par le chlore qu'il contient.

Voici sous quelle forme on l'administre contre les poisons animaux :

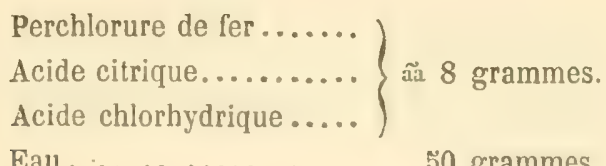

Eau............... 50 grammes.

On introduit une ou deux gouttes de cette solution dans la plaie, et on administre une potion contenant aussi du perchlorure.

L'emploi extcrne de ce médicament paraît logique. Quelques observations recueillies sur des chiens et les expériences qu'a bien voulu faire pour nous M. Giequiau (1) semblent en confirmer la valeur.

Quant à son administration par la bouche, elle est mauraise,

(1) Voir aux notes finales. 
car il s'agit ici, non pas d'un antidote destiné à combattre les effets de l'échidnine, mais d'un contre-poison devant opérer chimiquement sur le venin lui-mème. Conseillé comme remède interne à l'abbé H..., il dérangea ses fonctions digestives et n'eut aucun résultat thérapeutique heureux.

M. Rodet a proposé, pour faire pénétrer sa solution dans les plaies, un petit entonnoir à pavillon évasé et à tube capillaire pouvant s'introduire profondément.

XI. - Pravaz (Acad. de méd., sept. 1828) a tenté de combattre le venin par l'électricité, dont on connait les propriétés décomposantes. Après avoir fail mordre des pigeons par des vipères, il mettait en contact avec lcurs blessures les réophores d'une pile à trente éléments. Il parvenait ainsi à détruire la substance toxique quand la galvanisation était immédiate et suffisamment prolongée. Ce moyen lui a paru préférable à la cautérisation par le fer rouge ou les escharotiques, parce qu'on peut s'en servir avec sécurité mème dans les régions où se trouvent des vaisseaux et des nerfs qu'il importe de ménager. Au reste, il avance de bonne foi que ses expériences ne sont ni assez nombreuses, ni assez concluantes.

La galvanisation restera toujours une méthode de cabinet; car, au moment de la morsure, il est rare qu'on ait à sa disposition une pile de Volta ou de Bunzen (1).

(1) Ml. Delahaye, dessinant dans une des salles de la Sorbonne une tête de crotale d'après nalure, le ressort qui tenait ouvertes les màchoires du reptile empaillé se relerma lout a coup sur ses doigts, et il fut cruellement piqué à l'index gauche par l'un des crochets.

Le sang jaillit aussitôt en abondance. MI. Helahaye s'empressa de sucer la blessure et de faire une ligrature à son doigt afin d'arrêter la circulation du sang; puis il courut demander du secours au laboratoire de MI. Jamin. L’ammoniaque lui fut administré intus et extru, et l'on introduisit dans 
XII. - Les applications froides ont été aussi vantées contre les morsures. Boccone avait grande confiance dans les ablutions. A. Moiseau, de Challans (Dissertation sur les animaux venimeux de la Vende), conseillait de tremper la partie mordue dans la source la plus roisine. C'est un moyen que l'instinct indique aux animaux.

L'eau agit de deux façons: comme liquide elle entraîne le venin hors de la plaie, et comme corps froid elle contracte les capillaires et retarde l'absorption.

Les cataplasmes de lait caillé, en grande vogue aux environs de Savenay, agissent aussi par leur température et n'ont pas d'autres vertus.

XIII. - Les incisions, les scarifications, les piquires par les branches de groseilliers sont des moyens douloureux et d'une valeur tout à fait secondaire. Ils sont parfois utiles en dégorgeant la partie par la sortie des liquides altérés, et en permettant l'introduction des contre-poisons.

On doit cependant en être assez sobre, Fontana ayant remarqué qu'ils farorisent la gangrène au voisinage de la blessure.

XIV. - La compression circulaire entre la plaie et le coeur, nommée aussi ligature, retarde l'absorption du venin en arrêtant la circulation des veines sous-cutanées et du réseau lymphatique superficicl. Le poison se trouve ainsi mis en quarantaine.

la piqùre une aiguille de platine que l'on fit rougir instantanément à l'aide des piles électriques qui ne cessent jamais de fonctionner dans ce sanctuaire de la science. Lne heure apris, tout danger ayant disparu, II. Delahaye regragnait son domicile, sans autre mal qu'une émotion bien justifiée du reste, car, apres sun dérirt, un matheureux lapin, sur lequel on essaya la dent de crotale qui avait produit la blessure, succomba en peu d'instants. (Extrait du journal le Pays, 7 août 1868.) 
On la fait à l'aide d'un lien un peu laroge et modérément serré. Trop serré et laissé trop longlempes en place, il étranglerait les parties qui s'ocdématient el causerait la gangrène; nous en avons cité des exemples.

Il y a deux manieres de s’en servir. Daus la plus usitéc, que nous appellerons liguture temporture, le lien constricteur est appliqué provisoirement comme obstacle à la diffusion du venin, et pour donner le temps de recourir à d'antres remèdes. Il ne doil être maintenu qu'une demi-heure, trois quarts d'heure, ou une heure au plus.

Dans le second mode, ligature intermitente du professeur Irolbrook et du doctcur Ogier de Charteston, te lien est d'abord établi le plus prís possible de la blessure, puis de temps à autre détaché el replacé plus loin pour éviter l'étranglement et ne laisser le venin envahir la circulation que par petites doses à la fois, ce qui permet a l'économie de lulter avec avantage et de l'éliminer plus facilement.

Les Peaux-Rouges, auxquels les médecins américains ont emprunté la ligature intermittente, administrent au blessé, chaque fois qu'ils relichent le lien, une forte dose de polygala, pour combattre les effets de la petite quantilé de poison qui passe dans le sang; on peut avec avantage r’mplacer le sénélia par de l'eau-de-vie.

XV. - La suecion faisait tout le mériic des fameux guérisscurs de l'antiquité. des ophiogines de l'Hellespont qui disaient devoir leurs vertus i leur origine, des peylles de la grande Syrte, dont la salive passait frour un contre-poison des venins (1), et des

(1) D'apris Pline, la nature aurait dune les psylles d'humeurs funestes aux serpents. Fin Vendie, on attritme, sans plus de raison, la même propriété aux personnes à cheveux rongess; quand clles sont mordues par un serpent, c'est, dit-on, le reptile qui crève et non le blessé. 
marses de l'Italic méridionale, se prétendant issus de Circé et, depuis le christianisme, parents de saint Paul.

C'est une des plus sûres méthodes, à condition qu'on la mette en usage immédiatement apprès la piquîre. "Tenenum serpentum, écrit Celse (De re medicu, LV, ch. II), non gustu, seed in rulnere nocet. Ergo quisquis, eremplum priylli seculus, int rulnus exsuxerit et ipse tutus eril el tuhum hominem prerstabit. " Qu'on suce sur ma foi et je réponds de lout, » disail Marce-Aurèle Séverin. Beaucoup d'animaux lèchent l'endroit où ils ont été mordus quand ils peuvent l'atteindre.

La succion fait, par aspiration, sortir le venin avant qu'il ait eu le temps d'envahir la masse du sang. L'opérateur doit, par prudence, cracher chanue fois qu'il applique ses lèves sur la plaie. Il est rare que quelques ulcérations de bouche empêchent de recourir à ce moyen.

En 1858, Civel, âgé de trente-rqual'e ans, et demeurant aux environs de Blain, fut mordu par une vipère commune de couleur rouge, pendant qu'il saisissait dans ses mains une gerbe de blé. Arrivé au moment mème, le docteur Sortais placa une liga- * ture et sura la plaie qui siécencail au pouce druit, puis il conseilla l'alcali en applications locales el en boisson. La pirqûre suivit la marche des plaies simples el le lendemain le malade était complétement guéri.

- A la fin du mois de juillet 18:3:), Mime G... ćtant à sa campagne des Granges de Villeneuve (commune du Bignon), entendit, ver's une heure de l'aprè-midi, des cris déchirants poussés par son neveu el sa nièce qu’elle savait occupés à jouer dans le jardin. Elle trouva les drux cufants tellement effrayés que clle ne put toul d'abord se rendre conple de la cause de tout ce bruit. Enfin, elle finit par comprendre que le pelit garçun, âtré de sept ans, avait roulu firendre de la main gauche une vipere, et 
que le reptile l'avait mordu à l'extrémité du pouce, où se voyaient deux piqûres saignant à peine.

- $\mathbb{I}^{\mathrm{m}_{0}} \mathrm{G}$... m'avait souvent entendu dire que si l'on pouvait, dans les premiers moments de la morsure des serpents, exercer sur la partie mordue une énergique succion ou appliquer une ventouse, on éviterait les dangers bien connus de ces blessures. Elle n'hésita pas un seul instant, et suça de toute sa force le pouce du petit blessé pendant environ un quart d'heure, puis elle crut bien faire, en appliquant une ligature sur le milieu de la première phalange de ce doigt. Pendant ce temps, la jeune fille, âgée de neuf ans, n’avait cessé de pleurer, et même de crier. $M^{\text {me }}$ G... apprit seulement alors qu'après l'accident de son frère, elle avait voulu saisir à son tour la vipère, et avait été mordue au niveau de la partie moyenne du premier métacarpien gauche, où il n'existait qu'une piqûre. $\mathrm{H}^{\mathrm{me}} \mathrm{G}$... pensant que le venin était déjà absorbé, plaça une ligature fortement serrée à la partie moyenne du bras et m'amena les deux enfants mordus depuis environ quatre heures. Le garçon ne présentait pas le moindre accident local ou général. J'enlevai le lien et je n'eus plus à m'en occuper. Quant à la jeune fille, son avant-bras et sa main avaient presque doublé de volume; cet oedème était rénitent, élastique. De larges taches bleuâtres couvraient tout le membre jusqu'à la ligature que je détachai. Je prescrivis à la malade d'abondantes boissons chaudes aromatiques, et du vin en aussi grande quantité qu'elle pourrait le supporter. Pendant la nuit, fièvre forte, nausées, transpiration. Le lendemain, l'état général devint meilleur, le gonflement s'étendit jusqu'à l'aisselle, ainsi que les pétéchies qui prirent une teinte plus foncée. A partir de ce moment, la fièvre, les nausées, la faiblesse disparurent peu à peu, mais le gonflement persista toute la semaine, et quinze jours après on voyait encore des taches livides ayant fini par prendre toutes les 
teintes de l'ecchymose. „(Le docteur Chenantais, professeur de pathologie externe à l'École de médecine de Nantes.)

Ce double fait est d'autant plus remarquable que la jeune personne offrait deux conditions devant rendre le venin moins actif pour elle que pour son frère : elle était plus âgée et fut mordue la seconde, c'est-à-dire quand la vipère était déjà privée d'une partic de sึon poison. Chez le petit garçon comme chez Civel, la succion immédiate a enlevé à la plaie ses caractères spécifiques et empêché l'envenimation de se produire.

Dans les deux cas suivants, communiqués par M. l'abbé Mleynier, vicaire à la Marne, l'aspiration du venin, quoique plus tardive, n’a pas été sans effets heureux.

"Le 29 mai 1866, à six heures du soir, François Rousseau, du village de la Touche, âgé de neuf ans, traversait avec son père un champ de trèfle, quand il fut mordu au bas de la jambe droite par un reptile. Le père transporta aussitôl son fils chez lui et courut au presbytère emprunter une voiture pour aller chez un sorcier. MI. le curé se refusa à coopérer à l'exécution de ce caprice déraisonnable, offrit de conduire le malade à Nachecoul consulter un médecin, et me pria de l'accompagner auprès de l'enfant.

- Une demi-heure à peine s'était écoulée entre l'accident et notre arrivée. La jambe, siége de la piqûre, était enflée jusqu’à l'aine, et les empreintes des crochets se distinguaient difficilement. Les maux de cœur et les syncopes ne s'étaient pas encore manifestés. La mère poussail des cris lamentables. Je l'assurai qu'elle pouvait, sans danger pour elle, sauver son fils en suçant sa blessure, et qu'une compresse d'alcali achìverait la guérison. Elle me refusa net.

n Indigné de la froideur avec laquelle avait été accueillic ma proposition, j'appliquai mes lèvres sur la plaie et je la suçai avec 
énergie sans reconnaître le goùt, du venin, ni me préoceuper de celui de la crasse. Je plaçai ensuite une compresse d'ammoniaque sur la piqûre et je mis cquelyues goultes de ce liquide dans un verre d'cau, que je fis boire à l'enfant. Le blessé fut alor's conduit dans la voiture de MI. le curé chez le docteur Martin qui approuva le traitement provisoire, et engagea liousseau à lui ramener son fils le lendemain.

„Le lendemain, je me rendis près du petit malade pour savoir ce qu'en pensait le médecin. On arail négligé de relourner chez lui, les parents ayant préféré recourir au reboutcur. Je vis que ma présence gênait et je me retirai. L’enfant eut un léger mouvement de fièvre el l'enflure gagna les cuisses, puis elle disparut, et les piqûres se fermèrent après avoir offert un peu de suintement. Au bout de huit jours, le petit Rousseau retournait à l'école.

"Par une coïncidence singulière de date, le 29 mai 1867, pareillement à six heures du soir, Mélanie Michaud, âgée de neuf ans, du village de Brandais, marchant pieds nus sur le milieu de la grande routc, fut inordue par une petite vipère. Son frère consentit à sucer lo pied blessé (vingt minutes après l'accident). J'agrandis ensuite les piquures aree mon canif et je plaçai dessus une compresse d'alcali. Puis, après aroir donné à l'enfant quelques gouttes d'ammoniaque dans in verre d'eau, je la conduisis à Machecoul près du docieur Fortineau, qui débrida la plaie plus largement et prescrivit un liniment ammoniacal. Je recommandai au père de ne pas emplojer d'autres remèdes que ceux du médecin, et je l'engageai à venir me donner des nouvelles. Il n'en fit rien. J'ai su depuis qu'il élait allé à Bouaye chez un guérisscur ei que, ledit guérisseur étant mort, sa veuve avait ordonné certaines herbes en lotions et en fumigations. La jambe enfla jusqu'à l'aine; la fièvie fut nulle ou à peu près; il n'y eut 
ni maux de coeur, ni synenje, el le huilième jour, Mélanie Michaud revenait en classe. „

Ainsi, vingt minules après la mor'sure, la succion n'arrête point la tuméfuction, mais elle peut encore empicher le venin d'infecter l'économie.

Nous ne connaissions aucun accilent produit par la succion, quand tomba sous nos yeux l'article jublice, dans l'Lnion bretonne, par M. Grignon-Dumoulin, le 31 décembre 1867, et où se trouvaient relatées les lignes suivantes:

* Vers la fỉn de juin 1867, ćtant à me promener à Oudon, j'appris qu'un boulanger d'Ancenis, dichargeant une charretée de bois, soudain se vit la jambe enveloppée par une vipère. Prompt, il la saisit pour la rejeter ati loin, mais elle le mordit au doigt, qu'il porta aussitût à sa bouche pour le sucer. C'était bien, mais par malheur il avait une écorchure à la langue qui lui enfla tellement qu'il étouffa le lendemain.

Ce fait nous intéressant à plus d'un titre, nous priâmes Mi. le docteur Puibaraud te prendre à son sujet loutes les informations qu'il lui serait posible de rimir of de nous les transmettre. Nous reçûmes de lui cette réponse :

"Les renseignements sur lesquels s'est appuyé î. GrignonDumoulin sont heureuscnent inexacts. Co n'est pas un boulanger d'Ancenis, mais bien un corlonnici du nom de Janneau, qui, le 7 mai dernier, a été mordu par une vipère.

- Il passait dans une mo oli se trourait déchargée une charretée de fagots; deux vinueres on étaient sorties et se réchauffaient au soleil; ne les vuyant pas, il marcha sur l'une d'elles qui se redressa pour s'crrouler autour de sa jambe.

„ C'est alors qu' un mourement instinctif lui fit saisir le reptile de la main gauche, pour s'en débarrasser. Mais déja il avait été 
mordu au doigt qu'il se mit à sucer; puis il l'exposa à la lumière d'une petite lampe et le lia au-dessus de la plaie.

¿ Ces premières précautions prises, il courut chez trois médecins sans en rencontrer un seul, et ce ne fut qu'au bout d'environ vingt minutes que rentra notre confrère Hautreux, qui le trouva vomissant en abondance.

, J'arrivai trois heures après. Le membre mordu, le cou, la tète, la langue et l'arrière-gorge offraient une luméfaction des plus inquiétantes. Déjà des lotions d'alcali avaient été faites, et un litre de quinquina, prescrit par mon confrère, était absorbé, les amis qui entouraient le malade jugeant qu'on n'en pouvait jamais trop donner.

\L'engorgement augmentait toujours, tout le côté gauche se prenait, Janneau était dans une anxiété et une agitation indicibles. Le malade était d'autant plus déraisonnable qu'il était complétement ivre. J'obtins néanmoins qu'on diminuât la quantité de vin, et je me bornai à des fomentations émollientes sur les parties engorgées et à des dérivatiís intestinaux.

„Je fis délier le doigt qui menaçait de se sphacéler et je fus assez heureux pour voir les accidents du côté de la bouche céder et être suivis de la diminution graduelle des autres. Puis il ne s'est plus rien passé qui ne se passe habituellement dans les empoisonnements de cette nature, ct le malade a parfaitement guéri.

- Janneau m’a affirmé ne pas avoir d'écorchure à la langue. "

Le docteur Thoinnet de la Turmelière nous a donné sur ce malade des renseignements identiques à ceux de M. Puibaraud. Ces deux messieurs n'ont jamais eu connaissance de cas de mort par la vipère, dans la commune d'Ancenis, depuis qu'ils y exercent la médecine.

Le venin, momentanément déposé sur une muqueuse à épithé- 
lium intact, n'est pas absorbé. Janneau aura donc eu quelque aphthe de la bouche ou quclque fongosité des gencives dont il ignorait l'existence, à moins que la tuméfaction, malgré la ligature, ne se soit propagée de la main à l'épaule, au cou et à la tête, ce qui est moins probable.

En tout cas, l'histoire de ce cordonnier est extrêmement curieuse, et nous sommes heureux que M. Grignon-Dumoulin nous ait mis sur sa voie.

On doit en rapprocher l'observation suivante du docteur A Bourdin, quoique les accidents vers la bouche ne reconnaissent point ici pour cause l'aspiration du venin.

"Le 21 avril 1862, journée très-chaudo, Rousscau (François), ầé de dix-huit ans, domicilié au village de la Sostière, commune de Sainte-Pazanne, est mordu au pied droit par une vipère rouge. Très-effrayé de cet accident, il se hâte de venir me consulter; mais il est obligé de s'arrêter en chemin, éprouvant des nausées, de la suffocation, et près de tomber en syncope. Il est conduit par la personne qui l'accompagnait dans la ferme la plus voisine, où je lui fis ma première visite. Ce qui me frappa tout d'abord, ce fut l'enflure de la face, surtout de la lèvre supérieure et de la langue. L’extrémité antérieure de celle-ci faisait saillie hors de la bouche. Rousseau conservait sa pleine connaissance, et, ne pouvant parler, répondait par signes. La déglutition était difficile; il existait aussi de la dyspnée.

„A première vue, je crus que la morsure avait eu lieu à la lèvre supérieure, el, lorsque j’cus constaté son siége véritable, la cause de l'enflure de la face, de la lèvre supérieure et de la langue me parut difficile à saisir. D'après ce que m'a dit plus tard le blessé, je pense toutefois l'avoir découverte. Il est probable que peu de temps après avoir été mordu par le reptile, dans son trouble et par inadvertance, ce jeune homme a touché 
avec le bout du doigt sa plaie encore fraiche, et mis ce doigt en contact avec sa lèvre supérieure qui était, comme je m’en suis assuré, accidentellement dépouillée de son épithélium dans une certaine étendue de sa surface muqueuse et qu'une nouvelle inoculation s'est produite en ce point.

"Sans attacher d'importance à mon explication, il m'a semblé qu'il était à propos d'insister sur cette particularité remarquable, savoir : le gonflement de la face, de la lèvre supéricure et de la langue, survenu chez une personne blessée au pied par une vipère.

"En résumé, l'état de Rousseau était, au moment de ma première visite, fort alarmant, et le gonflement de la langue m'inspirait des appréhensions très-fondées. Cependant tout se passa mieux que je ne l'avais espéré. A la période de dépression et de prostration succéda une réaction favorable el des sueurs copieuses qui soulagèrent beaucoup le blessé. L'œdème seul du membre inférieur droit persista assez longtemps; il ne céda qu'au bout de six semaines à des applications résolutives, aidées par des boissons diurétiques et sudorifiques.

"Aujourd'hui (21 mars 1868) Rousseau semble bien portant el assez vigoureux, quoiqu'il se plaigne d'être moins fort depuis sa morsure.

Nous avons pratiqué la succion sur un pigeon, alors que nos gencives étaient saignantes par suite d'un peu de scorbut. L'oiseau eut un léger trombus à la cuisse blessée, mais ne présenta point de symptônes d'empoisonnement; pour nous, nous n’éprouvâmes rien de particulier.

Cetle petite opération est donc un des meilleurs remèdes de la morsure des serpents venimeux, et l'on ne saurait trop la vulgariser. Elle est facile et souvent peut ètre exécutée par le malade lui-même. 
Une ventouse remplace assez bien les lèvres dans l'aspiration du venin, surtout par la ventouse à pompe; mais cet instrument ne se trouve pas toujour's sous la main, et les parties du corps le plus souvent atteintes (les doigts, les orteils et les malléoles) n'en permettent pas l'emploi.

A défaut d'instrument spécial pour l'application de la ventouse, on peut employer une petite bouteille à parois minces et à long col, que l'on échauffe et dont on applique le goulot sur la morsure. L'air intérieur en se refroidissant produit un vide et par suite une aspiration. Les panseurs de la Martinique se servent dans le même but de petites calebasses.

L’appel fait au dehors par ces divers moyens a donné des résultats heureux dans un grand nombre d'observations.

Que dire des fameuses pierres à serpents, qui passaient pour extraites de la tête du Cobra di capello? Il fut un temps où les chasseur's n'osaient se hasarder dans certains cantons giboyeux, sans porter au cou une de ces amulettes enchâssée dans un métal précieux, et qu'ils avaient payée à prix d'or.

Redi (Experimenta circa res diversas naturales, p. 16) a démontré que ces disques, d'ordinaire d'une couleur vert noirâtre, n'étaient que des lentilles d'argile. Appliqués sur la plaie, ils attirent les liquides par leur porosité, mais cette aspiration est trop faible pour être véritablement utile.

XVI. - La médication antiphlogistique ou broussaisienne ne doit être citée que pour mémoire. Les sangsues en grand nombre, placées sur le point tuméfié, loin d'apporter du soulagement, sont en général nuisibles. Nous n'en eussions point parlé sans une observation assez étrange par ses détails, publiée, en 1828, par un journal scientifique de nos départements, et dans laquelle la guérison leur est attribuée. 
XVII. - La cautérisation est une méthode cruelle, mais qui, en désorganisant les tissus, détruit le venin qu'ils contiennent et produit au voisinage un mouvement violent de la vie, modifiant les conditions locales de l'absorption et de l'élimination.

Son effet est certain, pourvu qu'elle soit appliquée immédiatement, et qu'elle altaque toute la partie imbibée par le poison.

Le fer rouge est le meilleur caustique connu; il agit rapidement et a de plus l'immense avantage d'être facile à trouver, et de se prêter à une prompte application.

On avait proposé de se servir des cautères à distance, pensant que par ce moyen la chaleur détruirait le venin, sans mortifier la partie blessée. L'expérience n'a pas justifié ces données théoriques.

La poudre entre les mains des chasseurs remplace au besoin le fer rouge, mais sa déflagration est irrégulière et la cautérisation qu'elle produit superficielle.

Les charbons incandescents et la lumière d'une lampe brûlent aussi irrégulièrement.

Les substances escharotiques en vertu de leurs affinités ont élé souvent une précieuse ressource, entre autres, la potasse, dont Fontana avait constaté les bons effets par de nombreuses expériences, le deuto-chlorure ou beurre d'antimoine, conscillé par Fouré, et les acides minéraux, en particulier l'acide chlorhydrique. Tous ces corps sont de violents poisons, dangereux à employer, el ne pouvant pas par là même être abandonnés à des mains étrangères à la médecine.

Le docteur Merlet d'Apremont laissait à demeure, dans une incision faite sur les piqûres, un morceau de crayon de nitrate d'argent, moyen dans lequel nous aurions moins de confiance.

$\mathrm{Au}$ nombre des caustiques chimiques, se range l'alcool phenylique ou phénol, plus connu sous le nom d'acide phénique, et qui 
jouit de propriétés remarquables. Appliqué sur la peau, il la blanchit en amenant une contraction vive des capillaires, puis il s'unit aux substances protéiques et les mortifie, produisant une eschare décolorée. Il tue les organismes inférieurs tant végétaux qu'animaux, et arrête la plupart des fermentations.

Il semble donc en théorie offrir toutes les conditions d'un bon remède contre le venin; mais en thérapeutique, on ne doit admettre pour certain que ce qui est démontré d'une manière expérimentale.

M. J. Lemaire (1) a essayé, avec M. Gratiolet, l'acide phénique sur des piqûres d'hyménoptères et sur des plaies contaminées par le venin du crapaud. La neutralisation lui a toujours paru avoir eu lieu, mais le médicament en excès a occasionné parfois des accidents toxiques d'un autre genre.

Pendant le printemps et l'été de l'année 1868, nous nous sommes livrés à une série d'expériences sur ce contre-poison. L'acide employé était impur et de couleur rougeâtre, et provenait de la maison Thiboumery et Dubose, qui en fúurnit l'École de médecine de Nantes pour la préparation de certaines pièces anatomiques.

Le procédé opératoire a été celui que nous avons déjà décrit en parlant des solutions iodo-jodurées.

Quoique nous n'ayons pris pour sujets que des animaux de petite taille, tels que des pigeons et des lapins, ils ont presque tous guéri, ainsi que l'on s'en assurera en lisant les notes placées à la fin de ce travail. Les rares cas de mort sont explicables par

(1) De l'acide phénique, de son action sur les végétaux, les animaux, les ferments, les virus et les miasmes, par le docteur Jules Lemaire. Paris, $186 \%$. 
toute autre cause que la non-neutralisation du venin, et quelquefois par l'effet local ou général du phénol lui-même.

Le remède a été appliqué avant la diffusion de la substance toxique, condition qui, il est vrai, est rare en dehors des expériences, mais il faut se rappeler que l'on opérait sur de petits animaux, et que chez eux l'absorption est rapide. Chez l'homme, la cautérisation phénique a encore chance de réussir quinze minutes après l'accident, et l'acide n'offre pas les mêmes dangers.

Le phénol se liquéfie dès qu'il fait chaud; on peut done l'introduire sans mélange dans les piqûres; mais, sous cette forme, il n'est pas très-maniable et brûle souvent plus loin qu'on ne le voudrait.

L'eau phéniquée au vingtième, obtenue à l'aide d'une décoction de Quillaya saponaria ou bois de Panama, nous paraît trop faible. Nous préférons un mélange à parties égales d'acide phénique et d'alcool, mélange dont deux ou trois gouttes suffisent pour obtẹnir l'effet désiré (1).

(1) Le docleur Quesneville (Moniteur scientifique, ler juin 1868), a proposé contre les piqûres venimeuses une solution très-concentrée de phénol pur cristallisé, qu'il désigne sous le nom d'acide phénique médicinal liquéfié. Elle est incolore, moins infecte que celle dont nous nous sommes servi et paraît avoir les mêmes propriétés. Il la renferme dans de petits flacons à bouchon plongeur, semblables aux nôtres et contenus dans des étuis en buis.

Le phénol a été aussi administré à l'intérieur comme antidote des venins. On lit dans les Mondes, t. XVIII, p. 196, 8 octobre 1868 :

* Nous empruntons les quelques détails qui suivent à une lettre écrite de Melbourne (Australie) à M. le professeur Calvert, de Manchester : - Un jeune garçon ayant été mordu par un serpent-tigre, le plus veni- meux de nos colonies; six heures après l'accident, le docteur Boyd lu ${ }^{\mathrm{i}}$ - donna dix gouttes d'acide phénique pur dans de l'eau-de-vie coupée - d'eau. A quelques minutes d'intervalle, l'effet fut magique : une grande 
XVIII. - Nous terminons cette longue liste des alexipharmaques préconisés contre les blessures envenimées par l'indication d'une méthode cruelle, barbare, et qui n'est mise en usage par la science que pour les blessures des serpents étrangers les plus dangereux, nous voulons parler de l'ablation de la partie mordue, soit par l'amputation du membre, soit par l'excision.

Expérimentée par Fontana sur les animaux, avarst que le venin ait envahi les veines, elle a toujours empèché l'apparition des symptômes d'intoxication.

Plusieurs fois, des paysans vendéens, s'exagérant la gravité d'une morsure de vipère, ont cu le courage d'amputer immédiatement le doigt ou l'orteil atteints par les crochets, et se sont préservés ainsi de tout phénomène d'ćchidnisme. Nuns regrettons de ne pouvoir donner de détails sur quelques-uns de ces cas intéressants.

Traitement rationnel des morsures de vipires. - Les plaies enve- nimées exigent des soins immédiats, car il importe de neutraliser le poison avant qu'il ait pénétré dans le torrent circulatoire. Trois indications se présentent donc tout d'abord: $1^{0}$ interrompre la communication de la partie blessée avec la circulation générale; $2^{\circ}$ enlever le venin de la plaie; $3^{\circ}$ le détruire sur place.

$1^{\circ}$ La première chose à faire, lorsqu'on a été mordu par un serpent venimeux, est de placer une ligature entre le cœur et la blessure à cinq ou dix centimètres de celle-ci. On se sert d'une cravate, d'un mouchoir, de la garelette, à l'aide de laquelle les femmes de la Vendée maintiennent leurs cheveux, d'une jarre-

s pâleur, un pouis lent, une apparence à demi comateuse firent place à " une expression animée, à des couleurs vives et à un pouls accéléré, - symptômes qui furent le prélude du retour de la santé., 
tière ou de toute autre bande un peu large, de préférence à un lien étroit. La ligature doit être assez scrrée pour faire gonfler les veines, mais jamais de façon à produire un sillon dans les chairs, car elle augmenterait l'engorgement et exposerait à la gangrène. Ce moyen n'est que temporaire et il ne faut pas le prolonger au delà de trois quarts d'heure à une heure. Le lien constricteur sera même relàché ou porté plus haut sur le membre, s'il parait aggraver les accidents locaux.

Quand la partie atteinte par les crochets (par exemple la tête, le cou ou le tronc) ne permet pas la ligature, on exerce provisoirement avec les deux mains une compression autour de la plaie.

$2^{\circ}$ L'écoulement sanguin et la sortie de la substance toxique seront favorisés par une incision élargissant les piqûres, et par des pressions sur les parties voisines. Si un des crochets du serpent s'était brisé dans la plaie, il faudrait se hâter de l'extraire. La partie blessée sera plongée dans l'eau froide, dont la température diminuera la rapidité de l'absorption, et qui entraînera une partie du venin, puis à l'aide de la succion prolongée ou d'une ventouse, on attirera au dehors le reste du poison.

$3^{\circ}$ Pour remplir la troisième indication, on introduit dans los piqûres un agent chimique capable de décomposer l'échidnine. L'ammoniaque, nous le répétons encore, n'est qu'un moyen illusoire; le liquide iodo-ioduré n'est pas plus actif (voir p. 181); il est préférable de se servir de la solution de perchlorure de fer, ou mieux d'un mélange à parties éçales d'acide phénique et d'alcool, qui agit en mème temps comme caustique et pénètre plus loin. Ces derniers remèdes doivent être maniés avec prudence.

Si ces caustiques ont été employés assez à temps et assez rapidement, la morsure de vipère n'est plus qu'une plaie simple ; elle se borne à de légers accidents locaux, et ne laisse aucune trace le lendemain. 
Le traitement que nous venons de formuler pour l'homme devra être pareillement appliqué aux animaux. On ne s'exposera pas pour eux aux chances de la succion, mais on sera moins sobre du fer rouge.

Trop souvent les premiers soins ont été nuls ou dérisoires, et la tuméfaction douloureuse a envahi la partie blessée. Tout espoir d'empêcher l'empoisonnement général n'est point encore perdu, si l'on a recours à une ligature plus éloignée de la plaie, à l'incision pratiquée sur les piqûres ê à la succion ou à une ventouse. Des scarifications peu nombreuses seront faites au voisinage et lavées avec de l'eau contenant quelques gouttes d'acide phénique. Le membre qui se refroidit sera entouré de flanelle chaude, et des embrocations huileuses et stimulantes réveilleront sa vitalité.

Si le blessé est un enfant ou un être débile, ou si la morsure a son siége sur un point qui en augmente le danger et que personne n'ait le courage de sucer la plaic, il faudra recourir à la cautérisation par le fer rouge et d'une manière énergique. On ne saurait trop recommander ce moyen contre la morsure des serpents étrangrers de la puissanc’ du naja ou des crotales, et c'est le seul remède certain de la rage (1). Le cautère à blane désorgranise avec rapidité, mais à une profondeur insuftisante; il vaut mieux qu'il soit chauffé au rouge cerise. Un couteau, un gros clou, un fer à gaufrer, sont des instruments que l'on trouve prartout el qui sont excellents pour pratiquer celte opération. Trop tardive, elle devient inutile.

Il est pareillement facile de se procurer du vin, de l'eau-de-

(1) Dans la rage, la succion serait dangereuse, et aucune substance employée topiquement n'a de valeur cortaine; on ne sanrait lone hésiter à user du fer rouge. 
vie, du café, du bouillon gras et des infusions aromatiques. Pour favoriser l'effet de ces stimulants et de ces toniques, qui seront donnés à fortes doses, le blessé sera mis au lit, enveloppé de couvertures chaudes, et entouré de bouteilles d'eau bouillante. Quelques gouttes d'alcali dans une infusion sudorifique ne nous paraissent pas contre-indiquées et favoriseront la sueur.

Ces moyens généraux sont presque les seuls à employer lorsqu'on est appelé pendant la période des vomissements et de l'adynamie.

La douleur de l'épigastre sera calmée par l'application d'un sinapisme loco dolenti, et les complications seront traitées par des remèdes appropriés : ainsi, l'excès d'inflammation par les émollients, la gangrène par les préparations de quinquina, la surexcitation nerveuse par les antispasmodiques, etc.

La médication la plus difficile est celle de la convalescence, lorsque les premiers soins ont été négligés. Les forces seront soutenues par des aliments réparateurs, du vin de Bordeaux et des toniques. On donnera avec avantage, deux fois par jour, dans une tasse de café de glands doux, une cuillerée de la solution suivante :

Extrail de mou de quinquina.... 4 grammes.

Eau ...................... 100 grammes.

Nous recommandons aussi le vin à l'aristoloche odorante dont nous avons donné la formule (page 173).

L'iodure de potassium est un dépuratif et un fondant bien indiqué contre l'œdème consécutif, se prolongeant parfois pendant des semaines entières.

Les sudorifiques sont aussi d'une utilité incontestable contre cette tuméfaction persistante; ainsi, l'administration à l'intérieur du polygala de Virginie, de l'esprit de Mindérérus, et 
l'emploi local de coton cardé (1) et de taffetas gommé, donnen d'excellents résultats. Les liquides dits résolutifs : eau-de-vie camphrée, eau blanche, liniment à l'huile de térébenthine, vin scillitique, etc., favorisent aussi le dégorgement de la partie malade, qui sera tenue dans une position élevée, et autant que possible dans l'immobilité.

Quant aux moyens de combattre la cachexie échidnique, ils consistent surtout en toniques amers (quinquina, colombo, etc.) et en ferrugineux. Parmi ces derniers nous citerons l'eau d'Orezza comme produisant d'heureux effets.

Uni de nos malades, dont le sang était profondément altéré, éprouva une amélioration très-grande d'une saison à Royat, et il est regrettable qu'il n'y soit pas retourné une seconde fois.

(1) Les feuilles fraìches de bouillon blanc, à la campagne, peuvent au besoin remplacer le coton (v. page 89). 
Les méfaits des vipères sont si nombreux et si graves, et d'autre part si peu compensés par des services rendus à l'agriculture, qu'elles passent à juste titre pour les animaux les plus malfaísants de notre contrée.

Leurs ennemis sont donc intéressants à connaitre puisqu'ils sont nos alliés naturels; ils appartiennent à diverses classes.

Cerlains poissons, le brochet et l'anguille entre autres, avalent sans pitié les ophidiens qu'ils parviennent à saisir, mais ils doivent détruire plus de couleuvres que d'aspics et de péliades, ceux-ci étant de mours peu aquatiques. "Il n'est pas de pêcheur digne de ce nom, nous écrit de Champagné-les-Narais M. l'abbé Chabirand, qui n'ait vu un serpent dans la gueule ou l'estomac d'un brochet. "MII. de La Biliais ayant pris, à l'aide d'une nasse, une anguille de taille moyenne, dont le ventre était énorme, l'ouvrirent et y trouvèrent une volumineuse couleuvre.

Les ornithologistes signalent un grand nombre de rapaces diurnes, comme se nourrissant de reptiles, mais par ce mot reptiles il faut presque toujours entendre les sauriens et les batraciens. Les espèces à serres puissantes recherchent seules les ophidiens.

Parmi les aigles, citons l'aigle botté, Aquila pennata Brehm., el surtout le Jean-le-Blanc, Circaetus gallicus Vieillot. Ce dernier, 
qui niche dans nos grands bois, fait la chasse aux serpents et aux lézards, principalement à l'époque de sa couvée.

Un jour, sur les coteaux de Mauves, M. J. Blandin, auteur du Catalogue sur les Oiseaux de la Loire-Inférieure, aperçut planer à une grande élévation un oiseau de large envergure qu'il reconnut être un Jean-le-Blanc. Il le vit bientôt s'abattre sur la terre et remonter avec un serpent qu'il avala sans pour cela se donner la peine de redescendre.

M. A. de l'Isle a rencontré dans l'aire d'un circac̀te une couleuvre ayant les reins brisés, mais encore vivante.

Le 26 mai 1869, MN. G. et P. de l'Isle ont tué à la forèt d'Ancenis deux de ces oiseaux, dont l'un renfermait dans son estomac une vipère-aspic, née l'année précédente et encore très-reconnaissable.

Toutes les buses (la buse commune, Buteo vulgaris Ray., la buse pattue, B. lagopus Vieillot, et la bondrée, Pernis apivorus G. Cuv.) font la guerre aux serpents.

M. Alf. Pineau apercut, à Frossay, une cossarde ou buse commune entrainant dans les airs un long cordon. Il l'abattit d'un coup de feu, et, en tombant, elle laissa échapper' de ses serres une couleuvre à collier.

Un des fermiers de l'Ecorce, commune d'Aigrefeuille, voulant dénicher sur un arbre un nid de cossarde, y plongea la main et, au lieu d'œufs, en retira, plein d'cffroi, des quartier's de vipères et de couleuvres, parmi lesquels plusieurs têtes remuaient encore (M. Ch. Lemaignan de l'Ecorce).

Les busards (le busard des marais, Circus rufus Briss., l'oiseau de Saint-Martin, C. cyaneus Lath., et le busard montagu, C. cineracens Kieys. et Blas.), les milans, et surtout le milan royal, Milvus regalis Briss., doivent aussi être rangés parmi les ennemis de la vipère. 
Quant aux crécerelles, Falco Tinnunculus L., si communes dans les bois, les tours en ruines et les rochers, malgré leur audace, elles ne peuvent guère, à cause de la faiblesse de leurs armes, attaquer que les jeunes ophidiens, et se rejettent sur les lézards et les grenouilles.

On dit avoir trouvé des débris de vipères et de couleuvres dans les ossuaires de certains rapaces nocturnes et en particulier du grand-duc, Egolius Bubo Degl., qui se rencontre parfois dans les vieux châteaux de la Vendée : le fait est possible, mais il ne nous a été affirmé par aucun naturaliste en ayant été témoin, et l'on a très-bien pu prendre des morceaux de squelette d'orvet pour des débris de vrais serpents.

Les cigognes, Ciconia alba Briss. et C. nigra Bechst. sont rares dans nos départements où elles ne paraissent qu'au printemps et à l'automne; le rôle providentiel que leur attribue Linné, y est donc à peu près nul.

Les corbeaux, d'après MM. Blandin et L. Soubeiran, et en particulier le corbeau noir, Corvus Corax L., nous rendent sous ce rapport de meilleurs services.

On doit en dire autant des volailles de basse-cour.

- J'ai été souvent appelé, nous écrit M. de Laleu, par le langage particulier de mes poules, lorsqu'elles rencontraient un serpent, à observer ce g̣ui allait se passer. Quand le reptile était adulte et redoutable, elles se bornaient à l'entourer avec précaution, toujours parlant, comme pour avertir leurs compagnes qui se réunissaient à elles, mais sans oser l'attaquer; si, au contraire, il était jeune, elles se jetaient dessus, sans donner l'éveil, le frappaient du bec et finissaient par l'avaler.

- Elles ont ainsi effrayé les serpents et arrêté leur reproduction au voisinage de ma demeure, et bientôt elles en ont amené la disparition presque complète dans tout le rayon de leur par- 
cours, aidées par des canards du Labrador el des pintades que je laissais vivre en liberté. »

Les couleuvres, moins sauvages et plus agiles que les vipères, craignent beaucoup moins le voisinage des volailles, et nous les avons vues déposer leurs œufs dans le fumier même de certains poulaillers mal tenus (1).

Le hérisson doit-il ètre rangé parmi les ennemis des vipères, et est-ce pour cela qu'il a été muni de si remarquables moyens de défense?

“ Lorsqu'en 1859, dit M. de Laleu, j'achetai, avec l'intention d'y construire, les ruines du château de Sucé, les fossés d'enceinte taillés dans le roc étaient encombrés de pierres, de ronces et de broussailles, où abondaicnt à la fois hérissons et serpents. »

Cette cohabitation que nous trouvons plusieurs fois signalée dans nos notes, surtout pour les halliers du Bocage, ne prouve pas grand'chose. Si le hérisson fréquente les lieux où fournillent les vipères dans le but de se nourrir de celles-ci, il ne semble pas leur faire une guerre d'extermination, puisqu'elles continuent à vivre en grand nombre à ses côtés.

(1) Il existe en Afrique un oiseau pour lequel on a créé la famille des serpentaridées, et dont la nourriture se compose presque exclusivement de serpents venimeux; c'est le secretaire ou messager (Serpentarius reptilivorus Daud.). Il semble avoir reçu de Dieu la mission de mainteuir l'équilibre entre les reptiles dangereux el les animaux inoffensil's des réırions intertropicales. Ses pieds à ongles ćmoussés sont disposés pour une marche rapide, et c'est en courant qu'il va chercher sa proie. Il se sert, pour la frapper el l'élourdir, de ses ailes munies de proéıninences osseuses, et l'achève à coups de bec, en lui perçant le cràno.

On a vainement cherché jusqu'ici à acclimater cet animal à la Martinique en l'y transportant du Cap, dans le but de faire disparaitr? Ic bothrops lancéolé. 
D’après M. Béraud (1) cependant, un pépiniériste de Lyon, ayant mis quelques hérissons dans un terrain infesté de serpents, parvint à se débarrasser ainsi de ces hôles immondes.

Les premières expériences sur l'antagonisme de ces animaux datent déjà d'une trentaine d'années.

«Le 24 août, écrivait, en $\mathbf{1 8 3 2}$, le professeur Lenz, je plaçai un hérisson dans une grande cage; deux jours après, il mit bas six petits couverts de piquants, et leur prodigua tous ses soins. II mangeait avec plaisir les insectes, les vers, les petits rongeurs et même les orvets et les couleuvres.

"Le 30, pendant qu'il allaitait sa progéniture, je jetai près de lui une grande vipère; clle étail assurément venimeuse, car deux jours auparavant, elle avait tué une souris. Il s'approcha d'elle et la flaira sans se préoccuper de ses morsures, puis il la saisit à la tête qu'il broya entre ses dents et avala. Il revint ensuite se coucher auprès de sés petits et leur donner à téter. Le soir il mangea une autre vipère et ce qui restait de la première. Le lendemain deux vipereaux furent pareillement dévorés. Les blessures produites par les crochets n'étaient mêne pas tuméfiées, et le hérisson ne parut point souffrir d'un pareil régime. Ces combats se renouvelèrent pendant plusieurs semaines. Toujours il commençait par broyer la tête du rep̣tile, ce qu'il ne faisail pas quand il s'agissait d'une couleuvre. „

M. Cherblane, maire de Lentilly, a publié, dans le Salut public de Lyon, des faits presque semblables. "Qu'on se procure, écrit-il, un hérisson et une vipère, et qu’on les renferme ensemble; bientôt on verra le combat commencer et la vipère ne tardera pas

(1) Voir le Rapport sur les Vipères de France de M. Léon Soubeiran, auquel nous faisons ici de nombreux emprunts. Bulletin de la Société impériale d'acclimatation, t. X, p. 418. 
à avoir le dessous. Le hérisson rabat son casque épineux, se jette sur le reptile avec ses dents acérées, lui casse la colonne verté brale et lui brise la tête. »

Désireux de renouveler ces expériences, M. Gicquiau renferma les deux prétendus ennemis sous une cloche en verre. Effrayés sans doute par la vue des spectateurs, ils ne parurent point disposés à commencer la lutte; mis en rase campagne, ils ne cherchèrent qu'à s'échapper.

M. de Laleu, dans le même but, plaça dans une volière un hérisson, un aspic et un tropidonote. Le lendemain la vipère n'avait plus de tête; le second jour la coulcurre était morte et avait la queue rongée.

M. Pradal (1), ayant exposé un hérisson dans une cage où il avait déjà mis deux vipères conmunes, trouva le jour suivant l'animal épineux plein de vie, et ses adversaires divisés en tronçons et en partie dévorés.

Il serait téméraire de tirer une conclusion de ces luttes, dont le théâtre est une prison étroite, surtout après les histoires de souris et de lézard que nous avons racontées plus haut (pages 31 et 52).

Mais voici une observation prise sur des animaux en liberté.

Un de nos amis revenail, avec un autre hotaniste, d'herboriser aux bois de Verrières (Stine-et Oise). Il élait environ six lieures du soir et ils rejoignaient la grare de Scenux, quand, au moment de quitter la forêt, ils aperçurent le lonğ d’un terrier un hérisson qui se jeta sur une vipère el la coupa sous leurs yeux en deux morceaux. Craignant de manquer le train, ils ne purent malheureusement s'arrèter pour voir ce qui advint ensuite.

(1) Procés-verbaux de la section des sciences naturelles de la Société aculé. mique de la Loire-Inférieure. - Séance de juillet 1860. 
Le hérisson attaque donc parfois les vipères, et il est trèsrationnel de chercher à le multiplier là où les reptiles abondent; mais il ne faut pas s'illusionner sur l'étendue de ses services comme destructeur de serpents (I). Les philanthropes qui ont proposé de l'acclimater à la Nartinique pour l'opposer au fer-delance, pourraient bien en être pour leurs frais.

La belette, quelque peu parente de l'ichneumon ou rat de Pharaon (2), fait aussi bonne gucrre aux reptiles venimeux. Cela nous a été affirmé par plusieurs témoins de ses luttes. Tantôt l'adroite et courageuse bête attaque le serpent en pleine campagne et le saisit au cou avant qu'il ait le temps de se défendre, tantôt elle se jette sur lui quand il rentre dans son trou et qu'il ne peut se retourner pour mordre.

Le blaireau, animal omnivore, déchire aussi à belles dents les vipères qu'il trouve à sa portée. Son pelage grossier, sa peau épaisse et la couche graisseuse qu'elle recouvre, le protégent contre leurs crochets.

Les chiens indiquent assez bien l'aspic et le péliade et les arrêtent par leurs aboiements, mais ils sont de mauvais destructeurs. Quelques-uns d'entre cux saisissent toutefois ces reptiles à pleine gueule el finissent par les étourdir et les tuer en les secouant avec violence.

(1) Nos campagnards ont la stupidité de tuer le hérisson partout où ils le rencontrent, quoiqu'il ne vive que d'animaux nuisibles. Ils le considèrent comme un maudit, et leurs empiriques lui attribuent une ridicule influence sur la délivrance des vaches. Les zingari ou bohcimiens errants, plus esprits forts, le détruisent aussi, mais pour le manger.

(2) La mangouste mungo, du même genre que l'ichneumon, est dans l'Inde, nous écrit de Calcutta un de nos frères, d'une trìs-grande utiliti par le nombre de serpents venimeux el de scorpions qu'elle détruit. Mallıeureusement, comme les fouines et les putois, elle est d'un mauvais voisinage pour les basses-cours. 
Dans l'Inde, on dresse des chiens à combattre les najas, et ils deviennent alors des gardiens précieux pour les habitations.

Nous avons dẹjà dit un mot de l'adresse que déploient les chats pour s'emparer des serpents. Surpris par le reptile, ils manifestent une grande crainte, mais s'ils ont pu combiner à l'avance leur plan d'attaque, ils sont vraimént beaux à voir.

Au Brésil, les plus agiles couleuvres et le dangereux jararaca lui-même deviennent leur proie.

En Vendée, tout chat trop maigre passe pour s’être nourri de vipères. Il a mangé du vrin, disent nos paysans.

Les chats, quand ils se sont emparés d'une bète vivante, l'apportent à leur maître et jouent avec elle devant lui. Quelques. uns d'entre eux deviennent intolérables par l'habitude qu'ils ont d'introduire ainsi des serpents dans les maisons, et l'on est obligé de s'en débarrasser.

Voici un combat mémorable dans lequel la victoire faillit ne pas rester à l'agile quadrupède.

La scène s'est passée à Chantomnay et en présence de M. de Béjarry qui nous l'a racontée.

Un chat avait pris une longue couleurre. A l'aide d'une patte, il lui maintenait la tête sur le sol et jouait avee le reste de son corps, se complaisant dans les convulsions de sa victime. Le reptile se tordait et essayail en vain de s'échapper' à un moment donné, il s'enronla autour du cou de son bourreau. Le chat effrayé appliqua sa griffe plus fortement sur la tête de la couleurre, mais plus il pressait plus le noud vivant se resserrait. Baton hurlait d'une fagon étrange qui altira aulour des deux lutteurs un cerele de curieux. Après une dizaine de minutes, un jardinier cut pitié de lui, et d'un coup de pelle le délivra du serpent.

Le cochon et son frère sauvarge méritent ici une mention spéciale. 
Aux États-Unis et sur divers points de l'Amérique, on élève des porcs aux voisinages des cases pour en écarter les crotales.

A la vue d'un serpent, ils font entendre un grognement de satisfaction, qui paralyse de terreur leur adversaire. Ils le croquent alors avec une véritable volupté et sans paraître se préoccuper de ses morsures.

Le cultivateur vendéen évite de laisser manger des vipères à ses cochons, sous prétexte qu'un pareil régal les fait maigrir. Les bergers de l'Estramadure, au contraire, attribuent aux vipères avalées par les porcs de leurs sierras le goût exquis de leurs jambons.

Dans les bois où se mulliplie le sanglier, les vipères cessent d'être nombreuses.

* Le parc de Château-Vilain (Haute-Marne), agreste, sauvage et de plus de 200 hectares, fourmillait de vipères lorsqu'on mêla des sangliers aux cerfs, aux daims et aux chevreuils, qui en sont les habitants actuels. A peine y furent-ils, que les reptiles, sans disparaitre tout à fait, diminuèrent dans une telle proportion, que la promenade pouvait se faire sans inquiétude. Toutefois, comme l'endroit contenait de bonnes truffières, les sangliers ravagèrent tout pour y trouver et manger les truffes, ce qui força à tuer, en $18 \% 7$, le dernier de ces animaux. Depuis la destruction de leurs ennemis, les vipères reparaissent en tel nombre, que l'on a résolu de remettre des sangliers au parc pour pouvoir y maintenir un équilibre tolérable. - $\mathrm{M}^{\mathrm{me}}$ A. Passy, 183̋. „ Extrait du rapport de M. Léon Soubeiran.)

Les sangliers sont rares en Vendée, et l'on ne laisse guère errer le porc en liberté, car avec son groin il bouleverse les cultures.

Mais le plus grand destructeur des vipères, c'est l'homme. Dès 
les premiers jours, une inimitié profonde a été mise entre lui ct le serpent. Il le tue par instinct partout où il le rencontre, et le fait disparaître du voisinage de son habitation par les habitudes mêmes de sa vie.

Plus la culture devient générale et régulière dans un pays, plus on y voit diminuer le nombre des serpents.

C'est ce qui se produit pour nos contrées de l'Ouest, par rapport à l'aspic et au péliade. La destruction des halliers, l'ouverture de larges voies de communication, la disparition des jachères, ne permettent plus aux vipères d'y vivre en paix, et les laissent exposées aux attaques des buses et de leurs autres ennemis.

Est-ce à dire qu'il faille attendre l'extinction spontanće de cette race rampante et qu'aucune mesure administrative ne soit nécessaire? Hélas non! et chaque année des accidents cruels viennent nous le rappeler.

Aussi en terminant, en $\mathbf{1 8 6 1}$, la première édition de ces Études, proposions-nous à M. le préfet de la Loire-Inférieure, en réponse à la dernière question de son enquête :

$1^{0}$ La publication, par le Conseil d'hygiène et de salubrité, d'un opuscule du genre de celui que le docteur Fouré rédigea en 1809, à la demande de $\mathbf{M}$. de Celles. (Instructions sur la morsure des animaux enrayés et sur la morsure des vipères, par Fouré, membre du Jury de médecine et médecin des épidémies. 1869. Imprimerie Malassis.) Il serait mis au niveau de la science et répandu dans les campagnes afin d'éclairer les populations.

$2^{\circ}$ La création d'une prime par tête de vipère.

Le rapport sur les vipères de la Société d'acclimatation, qui parut peu de temps après (1863) avec des conclusions presque identiques, décida M. le préfet de la Vendée à prendre l'arrêté suivant : 
- Le préfet de la Vendée, officier de l’ordre impérial de la Légion d'honneur;

Vu la délibération du Conseil général du département en date du 29 août 1863 ;

Vu les lois des 22 décen:bre 1789 et 28 pluviôse an VIII;

Arrête :

Art. Ar $^{\text {er }}$ - Une prime de vingt-cinq centimes sera accordée pour la destruction de toute vipère ayant au moins trente centimètres de longueur.

Art. 2. - Les primes seront payées soit, sur la présentation à la préfecture, première division, du corps de la vipère tuée, soit sur le certificat d'un médecin ou d'un pharmacien constatant que les reptiles qui leùr sont présentés sont bien des vipères.

Le certifical attestera cn outre que la tète et la queue des vipères ont été écrasées en présence du médecin ou du pharmacien signataire du certificat.

Napoléon-Vendée, le 8 janvier 1864.

\section{Le préfet de la Vendée, G. DE Villesalson, ,}

Cet arrêté, par suite de quelques difficultés d'exécution, n’a pas donné tous les résultats qu'on en devait attendre.

Dans la Loire-Inférieure, où le mal du reste est moins grand, on a hésité jusqu’à ce jour à ćtablir la prime demandée, mạis M. le préfel, II. Chevreau, a réprondu à notre seconde proposition en faisant distribuer aux frais de l'administration départementale cent exemplaires de notre travail, aux divers médecins cantonaux.

Vers la même époque, la tète de la vipère était mise à prix dans les Deux-Sèvres, et, d’après Maitre Jacques, journal popu- 
laire d'agriculture très-répandu dans le Poitou, la dépense à laquelle cette proscription a donné lieu s'est élevée de 1864 à 1868 à 13,863 fr. ¿0 alloués en primes de 250 centimes, ce qui représente $气 3 \%, 402$ vipères détruites en cinq années dans ce département.

Ce chifirre est tellement élevé qu’il est impossible que quelques malheureusés couleurres ne soient pas venues le grossir.

Nos conclusions restent les mêmes.

L'Instruction sur les viperes devrait être courte, en langage vulgaire, et d'un prix minime. Elle serait distribuée gratis aux médecins des pauvres, aux instituteurs et aux autres personnes appelées à en profiter pour l'avantage de tous et à la propager'. Elle comprendrait une brève description de l'aspic et du péliade, quelques détails sur leurs mours, un tableau synoptique orné de planches permettant de distinguer les uns des autres les serpents du pays, les caractères de nos vipères, leurs morsures et les premiers soins à y opposer.

Quant à la prime, le chiffre de 203 cent. est suffisamment rémunérateur pour le chercheur de vipères et ne changera pas trop le budget, s’il n'est attribué qu'aux têtes d'aspies et de péliades. Ilais il faut se rappeler que,

\section{Petit serpent deviendra grand}

Pourvu que Dieu lui prête vie.

Une prime supplémentaire de 10 à 15 centimes devrait donc être établie pour les vipères moindres de 30 centimètres de lingueur, taille minimum indiquée par l'arrêté de M. de Villesaison. Sans cela, ainsi que le fait remarquer MI. Passy (1), les personnes dont le métier est de prendre les vipères auront bien soin

(1) Bulletin de la Société dacclimatation, t. VI, p. 233. - Séance du ̈̈ mars 1869.

A la même séance : M. Duchesne-Thoureau fait connaitre le moyen de 
de respecter les vipéreaux et les femelles pleines, et n'iront pas détruire leur gagne-pain de l'année suivante.

Les médecins et les pharmaciens sont parfaitement aptes par leurs connaissances spéciales et leur honorabilité à fournir aux chercheurs de vipères le certificat exigé pour la prime.

Mais il est un mécanisme plus simple. Si un grand nombre de communes n'ont point de médecin, toutes possèdent un maitre d'école, fonctionnaire instruit, dévoué, et qui, à l'aide de l'opuscule dont il a été question, arrivera, s’il ne le sait déjà, à distinguer avec facilité les vipères des couleuvres. Il est presque toujours en même temps secrétaire de la mairie. Ne pourrait-on pas, moyernant une faible augmentation d'appointements, le charger de délivrer le certificat du nombre des vipères tuées par chaque chasseur, certificat ayant la valeur d'un bon payable chez le percepteur du canton?

Les têtes recueillies dans un flacon plein d'eau additionnée de quelques goultes d'acide phénique serviraient de moyen de vérification.

Si les mêmes mesures élaient prises à la fois dans la Vendée, la Loire-Inférieure, le Maine-et-Loire et les Deux-Sèvres, peu d'années suffiraient pour faire disparaitre la vipère de celte parlie de la France.

prendre les vipères vivantes à l'aide d'un bâton et d'une bouteille, moyen qui est du reste celui dont use depuis longtemps notre collaborateur, M. Giequiau. M. Passy raconte que depuis deux ans, on emploie au domaine d'Arc, une femme de Champlitte, près Langres, qui force les vipères de sortir de leur trou en y insumant une liqueur dont la composition est son secret, ce qui lui a permıs d'en prendre en trois mois plus de huit cents. M. Millet rapporte que l'insufflation du tabac dans les trous de vipères les force rapidement à en sortir et qu'à l'aide d'une baguelte terminée par une éponge ou de l'étoupe imprégnée de benzine on arrive plus sûrement encore à ce résultat. 


\section{APPENDICES}

\section{I. - EMPlor de LA vipÈre ET DUU VENin dES SERPENTS COMME MOYENS THÉRAPEUTIQUES.}

- La chair des viperes eft chaude \& deficcatiue eftant aceoutree comme les anguilles auec eau, huile, fel, anet, pourreau, chacun mis felon fa proportion. Elle purge le corps vniuerfellement par les pores de la peau, ce que i'ay moymefme eftant encore ieune experimenté en noftre Afie. L'hiftoire eft telle, Vn de noftre compaignie eftant ladre, hanta \& conuerfa tant auec nous qu'aucuns en furent entachés, il estoit defia puant \& tout gafté : parquoy on luy baftit vne petite maisonnette à part, pres d'vn village, en vne colline où eftoit une fontaine : on luy portoit tous les iours à boire \& à manger tant qu'il luy eftoit de besoin. Auint qu'enuiron les iours caniculiers on apporta aux moiffonneurs qui moissonnoient près de là, de fort bon vin, lequel fut laisé là fur le champ. Quand le temps de boire fut venu, l'vn ver. lant du vin dans vne tasse (pour le tremper d'eau) auec le vin fortit une vipère morte, de quoy les moissonneurs estônés \& craignans que mal leur auinst f'ils en beuoyent, aimerent mieux boire de l'eau. Se retirans \& paffans par deuant la loge du ladre, esmeus de pitié luy donnerent ce vin, penfans qu'il luy valoit mieux mourir tost, que long temps languir en cette misere. Le- 
quel ayant beu ce vin, par vn grand miracle fut gucri : car toute cette craffe \& efpaiffeur de cuir luy tomba ne plus ne moins que la coque des cancres \& langouftes quand ils muent, la peau de deflous eftoit molle comme celle des animaux fufdits, leurs coques tombées. Pareil cas auint en la Mysie d'Afie pres de la ville d'où ie fuis. Vn homme ladre f'en ala baigner aux bains naturels \& chauds en penfant recoutrer quelque fanté. Il avoit pour chambriere une jeune femme belle, à laquelle plusieurs faisoient la court. La maison où il logeoit cependant qu'il vsait de ces bains, eftoit pres d'rn lieu ord \& sale, \& plein de vipères, l'vne defquelles par fortune se getla dans vn baril plein de vin qui eftoitdemouré debouché. Ce que voiant la fille pensant auoir moyen de se defpescher de son ladre, luy bailla à boire de ce vin, \& l'aiant beu il deuint fain comme le ladre de la loge. Voilà ce que Galenus en dit, lequel allegue autres expériences des ladres guéris par le moyen des vipères, lefquelles nous ne reciterons pas icy pour eftre plus briefs. " (Commentaires de P. A. Matthiole sur les six livres de Dioscoride, mis en francais sur la dernière édition latine de l'auteur, par Jean des Moulins._Lyon, MDLXXIX. page 214.)

Depuis Galien et sur son autorité, la vipère a été longtemps prescrite comme sudorifique et réputée le meilleur spécilique contre les maladies de la peau.

a Pline, au liv. 30, chap. 13, récite qu'Antoine Musa, médecin de Cefar Augulte, ordonnoit des viperes à manger à tous ceux qui auoient des vlceres autrement incurables \& les guériffoient par ce moyen fort foudainement. P'ource ie mefbahi fi Cardanus a tant eftimé la chair des viperes, comme très fingulière pour guerir les tabides \& ceux qui ont les poulmons ulcerés. Il en efcril ainsi en un conseil enuoyé à Iean archevefque de S. André en Efcoffe: a Ie vous dirai un trefgrand fecret guerif- 
fant entierement les tabides, les ladres, \&, qui contre toute efperance les engraiffe et guerit ceux qui font de tout abandonnés. Prenez done cette vipere qui eft rouge, groffe el courte \& que les Italiens appellent Milort, couppez lui la tefte \& la queue, efcorchez la auffi, gettez les entrailles \& gardez la graiffe à part; partiffez la vipere en tronęons comm'un anguille, faites la cuire en eau auec du benjoin \& du fel, en y aioutant peu après des feuilles de persil. Quand elle sera bien cuitte, coulez le ius par un linge, faites cuire dans iceluy vn ieune poulet, baillez à manger au malade du pain trempé dedans ce bouillon, \& la chair du poulet. De la graiffe gardée à part, oignez en l'efpine du dos, les autres iointures, les arteres qui battent es pieds \& mains, la poitrine aussi. Ce pendant le malade doit demeurer en vne cítuue \& ce continuer pendant fept iours. Pour ce remede les vlceres des poulmons sont chaffés jufques au cuir extéricur par des tubercules qui y furuiennent, les interieurs vlceres sont gueris \& les malades retournent à convalescence. " Matthiole, loco cit., p. 216).

Dans le Cours de chimie de N. Lemery (2º éd., p. 81:̈, Paris, 17:36) et dans la Pharmacopée universelle du même auteur ("3éd., t. II, P. $43 \%$, Paris, 176\%), nous trouvons indiquées diver'ses préparations médicinales de vipères :

$1^{0}$ La poudre, obtenue comme il suit :

an aura des vipères bien nourries et des plus vigoureuses; on en coupera la tête; on les écorchera; on en séparera les entrailles et l'on fera sécher les trones, les foies et les cours, en les attachant séparément à des ficelles et en les pendant au plancher. On coupera ensuite les trones en petits morceaux que l'on réduira en poudre subtile. , 
La poudre, préparée avec le foie et le cour du serpent, portait le nom de bézoard animal et passait pour la plus active.

$2^{\circ}$ Les trochisques, un des nombreux éléments de la thériaque. La poudre fraîche de tronc, de cœur et de foie de vipères était transformée en pâte dure dans un mortier de marbre, à l'aide d'un mucilage de gomme adragante au vin d'Espagne, puis disposée en trochisques que l'on faisait sécher à l'ombre et sur lesquels on répandait quelques gouttes de baume du Pérou.

Lemery ajoute: "Ils sont propres contre toutes les maladies où il y a malignité; ils chassent par la transpiration les mauvaises humeurs, ils résistent à la pourriture, ils purifient le sang et rétablissent les forces. La dose en est depuis demi-scrupule jusqu'à une drachme. »

Il avait plusieurs autres formules de ce médicament, et en particulier des trochisques au pain. Les Anciens apportaient un soin infini à sa préparation. Ainsi, de peur que les vipères ne conservassent quelque malignité, ils les flagellaient dans une bassine chaude "pour les irriter et exciter leur venin à couler vers la tête et la queue! » puis ils coupaient ces extrémités avant de se servir du corps de l'animal.

$3^{\circ}$ Le fiel frais. Il se donnait à la dose d'une à deux gouttes dans de l'eau de chardon bénit. Sudorifique et antiputride trèsprôné, surtout contre la petite vérole.

$4^{\circ}$ La graisse. Claire, semblable à de l'huile, elle s'administrait à l'intérieur pour remplir les mêmes indications et servait à com. poser plusieurs emplâtres ou onguents résolutifs, en particulier l'emplàtre dit de Vigo (Emplastrum de ranis, vulgo de Vigo cum mercurio); elle s'y trouvait unie, entre autres substances, à des grenouilles et à des vers de terre, cuits vivants.

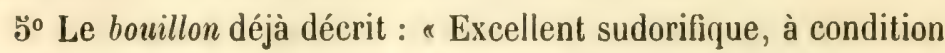
que le patient se soumette à un séjour plus ou moins prolongé 
à l'étuve. , Grâce à de semblables précautions, le bouillon de poulet, ou celui d'escargots aurait les mêmes vertus.

On obtenait par distillation un produit désigné sous le nom de sel volatil de vipère, et à la préparation duquel l'ancienne pharmacie employait des soins minutieux. Une fois cristallisé, il n'était autre que du carbonate d'ammoniaque impur, renfermant quelques traces de produits empyreumatiques. Véritable panacée, il se donnait dans les fièvres malignes, les affections virulentes, l'apoplexie, l'épilepsie, etc.

Il devait être fait avec des vipères vivantes, et Techmeyer raconte gravement qui un chimiste vit passer un tronçon de vipère vicant dans le réfrigérant de sa cormue. La plaisanterie est forte, mème quand il s'agit d'animaux à vie aussi dure.

Il y avait encore un vin, une gelée, et une huile essentielle de vipère (1).

Tout ceci est rapporté par Nicolas Lemery, docteur en médecine et membre de l'Académie royale des Sciences, dans ses livres, très-savants pour l'époque et dédiés à Messire Guy Cres. cent Fagon, conseiller d'État ordinaire et premier médecin du Roi.

Depuis que la science ne repose plus sur l'autorité du Maitre mais sur l'observation, la vipère a cessé d'ètre un médicament et les recettes que nous venons d'énumérer ne sont plus prescrites que par les empiriques et les prôneurs de remèdes secrets.

Il en reste cependant des traces dans nos campagnes.

A Aigrefeuille, quand vient mars, saison des amours des serpents, on irrite les vipères et on les tue. Elles sont ensuite dé-

(1) L'huile de spic, que nos paysans appellent huile d'aspic et qu'ils emploient contre les douleurs rhumatismales, n'est point fournie par un serpent, mais par une lavande, le Lavandula Spica L. 
pouillées de leur peau, mises deux jours à macérer dans du vinaigre très-fort, puis elles sont suspendues à une poutre à l'aide d'une ficelle, séchées et pulvérisées. Les paysans mangent cette poudre avec du pain et du beurre comme sudorifique et l'administrent à leurs bestiaux. Une vipère ainsi préparée se vend un franc ou un franc cinquante.

On a cherché aussi à utiliser le venin en thérapeutique et d'abord comme préservatif de l'envenimation elle-même.

D'après M. Bouchut (Nouveanx élémonts de pathologie générale, p. 41), les marchands de vipères, habitués à se faire mordre par les reptiles qu'ils attrapent, ne subissent plus l'influence de leur poison. Malgré l'opinion de ce savant professeur, les vraies causes de cette immunité nous paraissent être la ligature et la succion, auxquelles ils ont immédiatement recours.

Il n'est pas rare, au contraire, de voir des chiens succomber à une troisième ou quatrième rencontre avee le serpent.

Que penser alors des curados de culebras, de la côte orientale du Mexique, dont M. Jacolot (Arch. de méd. nav., 1867, t. VII, p. 390) raconte l'histoire?

Ils passent pour être complétement à l'abri des venins par suite des inoculations auxquelles ils se sont soumis.

L'un des plus célèbres, Martino Bocaneira, aurait été mordu par des corails (1), au su de tout Tuxpan, sans qu'il lui soit rien arrivé de fàcheux.

D'après ce même Bocaneira, voici comment procèdent les curados pour obtenir leur merveilleux privilége.

(1) Pourquoi ce choix du corail, comme serpent devant fournir le venin fail par tous les pröneurs de remèdes secrets de l'Amérique? Ne serait-ce pas parce qu'il est facile de lui substituer un reptile inoffensif ayant la même livrée? 
Le matin du jour de l'inoculation, qui est nécessairement un vendredi, le patient avale une quantité assez considérable d'eaude-vie, et de cinq à rquinze tubereules d'un Dorstenin, connu sous le nom vulgaire de mano de sapo ou main de crapaud (1). Les racines ont été récoltées un vendredi, et, s’il se peut, le premicr vendredi de mars; elles sont données par nombre impair et en aussi grande quantité que le permet la tolérance du malade. Eilles abaissent la température, ralentissent la circulation, et provoquent des nausées.

L'opération est praticquée à l'aide du crochet d'un crotale (cuatro narices) tué un vendredi. Le mème crochet sert plusieurs années à cet usage.

Les piquiures se font sur le dos du pied, au poignet, à la cuisse, au bras, au sternum et enfin à la langue. On ne doit pas cracher tout le jour, de peur de rejeter le renin! Des cataplasmes de mano de sapo ou de guaco sont appliqués sur les petites plaies.

Sept inoculations au minimum sont nécessaires, si l'on veut se mettre complétement à l'abri du maléfice, mais quelques individus en subissent jusqu'à quinze; ils restent alors comme hébétés.

Soumis à celte pratique, surtout si la lune est dans son plein, l'inoculé offre de l'exaltation, du besoin de mordre et une salivation extrême; il déchire avec ses dents les arbres et les animaux, et ses morsures les font mourir.

Les curados, toujours, au dire de Bocancira, pourraient seuls sucer sans crainte les moi'sures de crutales ct les guérir.

Il est diflicile de décourrir s'il y a quelque chose dont la science puisse tirer profit au milicu de ces pratiques supersti-

(1) Le mano de sapo ne serait-il point la mème plante que le contrayerva (Dorstenia Contrayerva L.), morée cultivée au Mexique et au Pérou, à cause de sa racine aromatique et stimulante administrée contre les morsures des serpents? 
tieuses. Les curados nous semblent avant tout d'habiles exploiteurs de la crédulité publique.

Le venin a-t-il la puissance de prévenir la rage, comme on le croit généralement en Vendée? Rien n'est moins démontré, et M. Nilcent, curé de Froidfond, nous a communiqué l'histoire d'un chien qu'il fallut abattre parce que, très-peu de jours après une piqûre de vipère, il présenta les premiers symptomes de l'hydrophobie.

Les essais de ce poison contre la maladie confirmée ont été tous infructueux. " J'ai vu, dit Mérat (Dict. des sc. méd., t. LVIII, p. 168, art. Vipère), employer à l'hôpital de la Charité la morsure de la vipère contre la rage mais sans succès. M. Cayol avoue le même résultat. MM. Poletta et Sornani n'ont pas été plus heureux, ils ont vu les deux maladies suivre leur cours sans se modifier l'une l'autre.

D'après le docteur Oheix, de Savenay, la tuméfaction inflammatoire produite par le venin aurait, dans le cas ci-après, été cause de la disparilion d'un oedème chronique.

- Maillard, âgé de soixante ans et d'une forte constitution, était atteint de rétrécissement mitral avec induration des vaisseaux el offrait un oedème des membres inférieur's, lorsqu'en 1864, il fut, aux environs de Saveray, blessé par une vipère. Je le vis environ vingt-cinq minutes après. Il présentait une prostration profonde, des défaillances el des vomissements, son pouls se sentait à peine ; l'œdème était généralisé, mais surtout prononcé au cou et à la firure, et la-respiration, anxieuse, comme croupale, faisait craindre une asphyxie prochaine.

, Les symptômes alarmants ne durèrent que deux heures. Des ventouses scarifiées appliquées sur la blessure et de l'ammoniaque administrée à l'intérieur et à l'extérieur, amenèrent le soulagement du malade. 
- Chose étrange, l'inliltration des extrémilés inférieures, qui s'était développée sous l'influence de la maladie cardiaque bien avant la morsure, se dissipa les jours qui suivirent, et la gêne de la circulation disparut presque complétement, sans doute sous l'influence de la dissolution du sang par le verin. Cette amélioration continuail encore deux ans plus tard, quand Maillard succomba à une apoplexie. »

Un médecin espagnol, cité par le Heraldo medico, a proposé l'inoculation du venin de l'ammodyte (I) contre le choléra.

II. Tel. Desmartis de Bordeaux, esprit extrêmement.original, dans un mémoire ayant pour titre de l'Emploi médical des venins, mémoire dont nous sommes loin d'adopter toutes les conclusions, dit avoir guéri par la piquûre de deux scorpions un cholérique qu'il considérait comme perdu. La prostration aurait fait place à une légère agitation, le pouls se serait relevé, et une réaction franche aurait sauvé le malade.

La piqûre très-douloureuse de l'arachnide aura sans doute agı à la manière des révulsifs.

M. Desmarlis emploie, dans sa pratique, le venin de divers

(1) Vipera ammodytes Dum., espèce qui n'est guère différenciée de l'aspic que par la pointe molie et écailleuse qu'elle porte sur le museau. Dans notre première édition, nous avions indiqué, d’après tous les auteurs (MIM. Dumérił et Bibron, Moquin-Tandon, L. Soubeiran, etc.), ce reptile comme un animal du sud-est de la France. Conscrvant des doutes sur son indigénat, nous sommes allé à sa recherche aux lieux qu'on lui donne pour patrie sans pouvoir le rencmutrer. M. W. Gerdy, médecin-inspecteur des

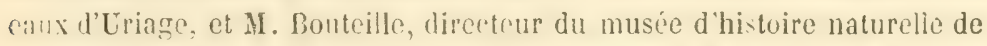
Gr'tioble, nous nnt afirmi qüil n’existe pas dans le Dauphiné. D’autre part, H. L. Soubeiran nous cieril que le docteur Ebrard lui a certifié qu’on ne rencontre jamais cetle vipire dans le dipartement de l'Ain. L'ammodyte est un serpent de l'E-pagne, de l'ttalie et de la partie méridionale de l'empire d'Autriche, mais il faut rayer son nom de la faune française. 
hyménoplères ef prescrit aux rhumatisants dix à douze guêpes, là où d'autres ordonneraient des sangsues.

Le poison des crotales a ćté conscillé au Brésil contre la lèpre. Sigaud rapporte l'histoire d'un malade qui, s'étant obstiné à recourir à ce note de traitement, périt victime de son imprudence.

Mais le point le plus curicux de la thérapeutique par les venins est leur inoculation proposćc comme moyen prophylactique de la fièvre jaune.

En 1847, M. G. de Humboldt, qu'il ne faut pas confondre avec l'auteur du Cosmos, dont ses partisans le disaient neveu, obtint du gouvernement mexicain de soirnner les condamnés aux présides de la Vera-Cruz et de Sainf-Jean d’Ulloa et suivit ces prisonniers d'Orizaba à leur destination.

Il dit avoir remarqué dans ce trajet que l'apparition du vomito coüncidait avec la piquâre d’une petite vịère et avoir confirmé son observation par des expériences sur des chiens.

Il voulut dès lor's utiliser ce qu'il appelait sa découverte et, pour miliger le poison devant servir à sa raccination préservative, il fit mordre six fois par six vipires un morceau de la glande hépatique d'un moulon. Puis il tenta trois ou quatre inoculations de ce putrilare sur des chiens qui en furent quittes pour quelques jours de fievre. Des chiens il passa aux condamnés, et leur fit (quatro pinqueres à chaque bras avec des résultats identiques.

Dès lor's l'engouemeni ne connut plus de bornes, et de 18000 à 1832, 1438 personnes se firent inoculer. Sept d'entre elles, raconte-t-il, emrent seules ensuite la fièvre jaune et d'une façon très-légère.

En 18\% on le retrouve à la Nouvelle-Orléans, d'où il adresse un mémoire à l'Académie des Sciences de la Havane, puis à 
Cuba, où le gouverineur l'aulorise à établir une maison d'inoculation, quatre médecins militaires ef deux cents personnes de l’ile s'étant déjà soumis à la vaceination préservative.

Mais la mystilication derait avoir un terme el M. G. de Humboldt allait trouver des juges.

En vain le docteur Manzi, avec une conviclion profonde, publiait-il à Paris, en 18:8, son Hisfoire de l'inoculation préservatrire te la fière joune, dans laquelle il considérail la fièvre d'inoculation comme élant un vomito en miniature et offrant avec la fière jaune les mêmes relations que la vaccine avec la variole, le rapprort du gouverneur général de Cuba fut écrasant et relui publić le 10 mai 186 par la commission mexicaine, plus défavorable encore.

Cette commission, composée de MII. Reyes, Iglesias, Angel et Jordanet, réfute un à un lous les faits avancés par M. G. de Humboldt, qu'elle traite d'erreurs grossières propagées par la bonne ou la mauvaise foi d'un seul.

Sans sattacher à combattre sa pathogénie fantastique de la fiivre jaune, ni vérifier si la prétendue vipère était bien venimeuse, ce qui était nié par les détracteurs du procédé, elle expose que ledit médecin a emprunté son prétendu venin au foic d'un seul mouton mordu par un scrpent et qu'il s'est servi pendant deux années de ce détritus pour toutes ses vaccinations. Il a done inoculé simplement une matière putride donnant lieu à quelques phénomènes réactionnels sains rapport avec la lièvre jaune et qui étaient combattus par de hautes doses de guaco, de sulfate de quinine d'indure de polassium. Les inocules ajoutent,

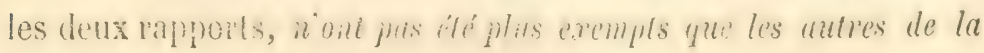
fièvre jaune et plusieurs en sont morts.

La fièvre jaune, le choléra, el autres aflections infectieuses, el d'autre part les maladies du coimr offrant quelỵues symptômes 
communs avec l'envenimation, les homœopathes leur opposent le venin de la vipère et celui de divers crotaliens, en particulier du Lachesis mutus. Ils administrent ces substances par la bouche et à doses dilućes, c'est-à-dire dans des conditions où elles ne peuvent avoir d'activité.

Quelle peut être, par exemple, l'action d'une goutte de poison du lachésis à la dix-millionième dilution ? Pareille formule cependant a été remise avec un certain sérieux à une dame de nos amies, se plaignant de troubles circulatoires.

Cet article peut done se résumer ainsi : Les parties qui constituent le corps de la vipère n'ont pas plus de valeur thérapeulique que les parties similaires de l'anguille ou de la lamproie, et le venin des serpents, malgré sa grande puissance, n’a pas été jusqu'ici utilisé avec fruit par l'art de guérir. 


\section{II. - TABleaU syYoptigee des SERPENTS DE LA VeNdéE}

\section{ET DE LA LOIRE-INFÉRIEURE}

Vermiforme, à reflets métalliques jaune argenté en dessus et noirâtre en dessous; écailles du dos et du ventre semblables; tête conique; wil petit à trois paupières mobiles; queue plus longue que le reste de l'animal.

I. - Orvet fragile, Anguis fragilis L., vulg. Anvin, Anvais, Nielle (1).

C. C. partout : dans les bois, les prés, les lieux pierreux.

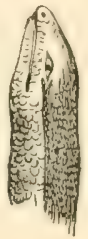

Dos couvert d'écailles imbriquées; dessous du corps revêtu de larges plaques transversales, simples sous le ventre et sur deux rangs sous la queue; œil entouré d'un cercle d'écailles immobiles; queue beaucoup plus courte que le corps. . . . . . . . . 2

Tête ovale, ornée de neuf grandes plaques en écusson; pupille ronde; dents toutes fixes, lisses et non perforées; écailles du dos et des flanes avec ou sans saillies longitudinales ou carène - Couleuvres 3

Tête élargie en arrière, aplatie, couverte soit entièrement de petites écailles, soit d'écailles et de trois plaques en écusson; pupille en fente verticale; mâchoire supérieure portant de chaque côté une longue dent mobile et perforée par un canal interne (crochet à venin); écailles du dos et des flancs carénées; queue très-courte.

Vipères

(1) La queue n'offre pas toujours les dimensions rilitives signalées ici : car elle se bris faclement, et apres la cassure ello se reproduit avec une moindre longueur. Les petits orvets different des auultes par la couleur. Ils sont blancs en dessus avec une ligne brune se bifurquant sur la nuqque et ont le ventre brun arduist. 
$3\{$ Écailles du dos et des flanes carénées. . . . 6

Écailles du dos et des flanes lisses. . . . . 4

Tête petite, comprimée latéralement, sans taches en dessus; trait noil vertical sous l'œil traversant les deux mâchoires; dos brun, olivâtre ou rousseâtre; plusieur's séries de points blanes sur les côtés du corps; ventre jaune paille; à l'union de la tête et du corps la teinte jaune du ventre s'avance sur les côtés du cou, en devenant plus foncée, mais sans former de collier complet; dents toutes semblables en dimension et en intervalle; longueur totale de l'adulte, 9ə̊ cent. à 1 mètre; queue formant à peine le cinquième de l'individu.

II. - Couleuvre d'Esculape, Elaphis Esculapii Dum., vulg. Sangle, Rouabe, Enfilandre, Esterlange (1).

Buissons et bois. A. C. mais pas partout.

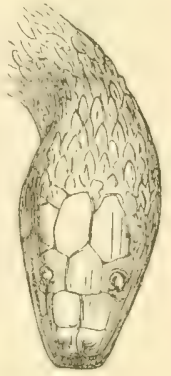

Taches noirâtres diverses sur le dessus de la tête; dents inégales.

(1) Les écailles de l'élaphe peuvent passer pour lisses; quelques-unes, it la région dorsale, présentent cependant un petit fubercule, rudinent de carène, d'autant plus marqué que l'animal est plus vieux.

Les ẻlaphes naissants offrent une teinte générale blanchâtre, qui devient grise en dessus. Sur ce fond de robe se dessinent au dos et aux flancs plusieurs séries de taches arrondies, ardoisées ou d'un gris bleuâtre.

M. Tréton du Mousseau, cité par M. Nillet (Faune de Maine-el-Loire), a trouvé à Saumur, et M. A. de l'Isle à l'étang de Chanvaux, pareillement en Haine-et-Loire, la curieuse variété à quatre raies de cette couleuvre (E. Esculapii var. quadrilineabus). 
Sur la tête, une large tache brunâtre échancrée en arrière sous forme de eccur ou d'U; ail placé dans une bande de même couleur ; queue formant à peine le cinquième de la longueur totale, qui est de 60 centimètres; dessus du corps gris ou rongecitre; ventre noirâtre ou rougeâtre; quatre rangogs de petites taches sur le corps; dents inégales en longueur, mais non en intervalle.

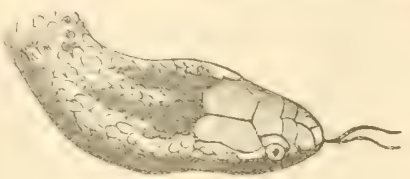

III. - Couleurre lisse, Coronella levis Laur. (1). $A$. C. Lieux secs et pierreux.

D'un vert noirâtre varié de lignes d'un beau jaune en dessus; jaune clail en dessous; partie supérieure de la tête mouchetée de jaune; queve formant plus du tiers de la longueur de l'animal; dimensions de l'adulte $1^{\mathrm{m}}, 40$ à $\mathbb{1}^{\mathrm{m}}, 80$; dernières dents sus-maxillaires plus longues que les autres dont elles sont séparées par un intervalle libre.

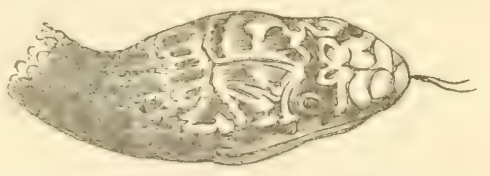

IV. - Couleuvre verte et Jaune, Zamenis viridiflavus

IVagl. (2).

C. Dans le sud de la Vendée, principalement dans les îlots calcaires de la Plaine et du Marais méridional.

(1) Cet animal inoffensif se rappruche des vipires par ses teintes winirales, mais en diffère par ses taches et par ses écailles.

Peut-être trouvera-t-on dans le sud de la Vendée une couleuvre voisine de celle. ci et, comme elle, à écailles larges et lisses, le Coronella girundica Dum. Elle a hutt plaques sus-labiales au lieu de sept, une seule série de taches noires sur le dos et des plaques ventrales et caudales à moitié noires.

(2) Les jeunes Zamenis ont donné le change à MMI. Mauduyt, Millet et Delalande, qui les ont décrits sous le nom de couleuvre glnucoüde. Ces jeunes serpents ont le corps sans taches, cendré bleuditre en dessus avec des écailles ombrées, et sont d'un bianc sale en dessous. Leur tête bleuâtre à sa partie postérieure est plus pâle en avant et marque de lignes irrérulières et de taches bianches, entuarees de noir funce. 
Sur la nuque, collier blanc, jaune pâle ou citrin, plus rarement orangé, suivi d"une large tache noire de chaque côté du cou; tête grise, sans tache en dessus; dos plus ou moins cendré, avec trois ou quatre rangées de petites taches noires; ventre noirâtre, tacheté de blane, surtout vers les flancs; longueur 60 centimètres à un mètre; dents postérieures plus longues, mais non séparées des précédentes par un intervalle libre.

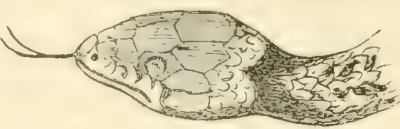
V. - Couleuvre a collier, Tropidonotus Natrix Kull, vulg. Couleuvre d'eau, Anguille de haies, etc.

C. C. partout.

Point de collier, mais deux taches noirâtres sur la nuque, imitant souvent par leur jonction la forme d'un $\mathrm{V}$ ouvert en arrière, autre tache noire derrière l'œil; dos grisâtre ou roussâtre, avec un zigzagr noir s'étetdant de la nuque à l'extrémilé de la queue; sur les flanes, série de taches noires entremêlées ordinairement de macules jaunes; ventre à taches ardoisées et grisâtres, ou ardoisées et jaunâtres, en damier; longueur ë0 à 6 š centimètres; dents disposées comme celles de l'espèce précédente.

VI. - Couleuvre vipérine, Tropidnnotus viperimus Schlegel, vulg. Aspic d'ean.

A. C. dans les ruisseaux, les étangs et les lieux frais (1).

(1) La couleuvre vipérine, par ses taches, ot en particulier par la ligne en zigzag de son dos, ressemble aux vipères, mais elle en differe par la teinte de sa robe, et surtout par les taches jaunes qu'elle présente.

Une variété fort distincte de ce reptile a été rencontrée, à Mauves, par l'abbé Delalande; elle porte sur le dos ileux lignes jaunes lungitud nales. Cette forme du midi do la France a été déerite par Wagler, sous le nom de Tropidonotus chersoides.

M. Delamare a donné à l'École de unidecino de Nantes une vipérine complétement noire, prise par lui i Orvault. 
Tète ovale-triangulaire recouverte d'écailles granuliformes, au centre desquelles se trouvent, entre les yeux, trois plaçues polygonales rapprochées en triangle; souvent une seule série d'écailles sépare l'œil des plaques labiales; museau droit, non bordé ; taches hiéroglyphiques ou en forme de lettres sur la tète; zigzag noiràtre le long du dos; bande de même couleur derrière l'oeil ordinairement interrompue au niveau du cou; série de taches de même couleur sur les flancs; longueur 28 à 60 centimètres.

VII. - VipÉre péliade ou a trois plaques, Vipera Berus Daudin, Pelias Berus Merrem, vulg. Petite Vipère (1).

Bois et endroits ombreux du nord de la Loire-Inférieure; dans les cantorss de Rougé, Derval, Moisdon, Nozay, Guémené, Saint-Nicolas de Redon, Saint-Gildas, Blain, Herbignac, etc.

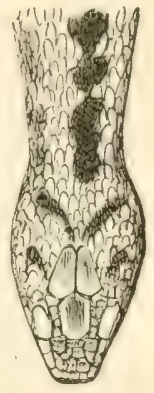

Tête triangulaire-cordiforme, entièrement recouverte de petites écailles, et nettement séparée du corps par un cou rétréci; museau retroussé en rebord saillant qui se prolonge jusqu'aux yeux; plusieurs rangées d'écailles séparent l'œil des plaques labiales; taches hiéroglyphiques sur la tête, zirgzirg du dos et taches latérales comme chez le péliade; bande post-oculaire ordinairement non interrompue au niveau du cou; longueur de l'animal 60 à 70 centimètres.

VIII. - VIPÈRe COMnune $V i$ pera Aspis Herrem, vulg. Vipère Aspic (9).

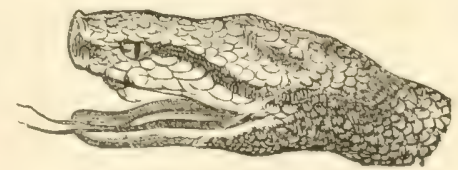

Trop commune dans les lieux secs et pierreux et dans les bnis, elle manque cependant dans certaines localités, et au nord de la LoireInfirieure est remplacee par le péliade.

(1 et 2) Voir les notes à la page suivante. 
(1) Les péliades ont les ćcailles qui recouvrent la partie supérieure de leur museau tantôt symétriquement, tantôt irrégulièrement dişosées. Le prince de Canino, exagérant l'importance de ce fait, a séparé à tort cette espèce en deux sous les noms de Pelias Berus et de P. Chersea.

Cette vipère présente trois variétés de pelage : la cinerea, grise ou verdâtre en dessus avec taches noires ou brunes et ventre noir; la tartarea, dont les taches sont fondues dans la couleur noire uniforme de la robe, et la rubiginosa, brune en dessus et en dessous et avec tatouage du dos et des flanes d'un brun plus foncé ou noirâtre.

(2) La vipère commune porte parfois entre les yeux une écaille développée au point de simuler une plaque. Ce caractère n'a rien de spécifique; le $V$. Chersea de Delalande ( $\boldsymbol{V}$. Blaniensis Leray), qui ne repose que sur lui, n'est point adopté par les erpétologistes comme une espèce distincte de l'aspic.

D'après sa coloration la vipère commune offre six variétés principales; mais elles ne méritent guẻre ce nom, car on trouve entre elles toutes les formes intermédiaires. Le type Aspis est plus ou moins rougeâtre en dessus avec zigzag à losanges séparés; la variété Chersea de la plupart des auteurs a le même fond de robe avec un zigzag continu; la variété Redii est grise à losanges continus, l'ocellata grise à zigzag interrompu; chaque tache chez cette dernière s'arrondit et devient plus foncée à sa circonférence. Dans le $\boldsymbol{V}$. Delalandei, dont la robe varie du gris au rougeâtre, les taches pâlissent et s'effacent et le zigzag lui-même disparaît; le V.Prcester est au contraire presque entièrement noir, les taches ayant envahi le fond de la robe. Cette dernière variété, très-rare dans l'Ouest, est assez commune dans le sud-est de la France, comme on peut s'en assurer d'après les échantillons déposés au musée de Grenoble par M. Bouteille. 


\section{Notes n'ayant pas trouvé place, à cause de leur longueur} à la fin des pages.

Note 1, page 143, De la prèparation du sung-sig, ou poison des Malais.

En 18\%9, l'Illustration a publié des extraits de lettres sur la Cochinchine, écrites en 1845 par un officier francais, H. Raoul de G., commandant le Tampire et chargé par la Compagnie des Indes de donner la chasse aux badjali ou ćcumeurs de mer, daus les détroits de la Sonde et de Malacca.

Ils contiennent, page 406 , les details suivants sur la fabrication du sung-sig.

"Un soir, écrit M. Raoul de G., on nous amena vingt pirates condamnés d'avance à itre pendus. Parmi cux se trouvaient des hommes de Bornéo et de Java, officiues oil se fabriquent les plus violents venius dont on puisse empoisonner une flèche ou un kriss.

„Je promis la vie sauve à qui en livrerait le secret. Ils refusèrent, et on les pendit un à un; au quinzième, quatre id'entre eux se décidèrent enfin à parler.

* Je choisis celui qui me paraissait le plus intelligent; c'ètait un pan. glina ou chef de tribu, originaire de Tolo, côte orientale des Célèbes.

"Il me demanda une lame de couteau, un petit vase de terre et un morceau de drap rouge, et, surveillé par deux hommes armés, se mit à la chasse aux serpents. Dix de ers reptiles (uuju, shoutur-sun, ulurlimp, etc.) lui tombèrent bientôt entre les mains.

„Dès qu'il rencontrait un de ces animaux, il l'excitait avec son morceau de drap rouge. Le serpent se jettait sur l'élofle et y enfonçait ses canines. Le pirate, souterant la main mpuldment, penversait en arriere la tète de l'animal pour bien la prendré avec sas crochets dans l'étoffe. De la main gauche, il saisissait alors près du col le reptile, qu'il lais- 
sait s'enrouler autour de son bras; puis il lui passait, de la main droite, une lame de couteau dans la gueule. Le serpent y mordail avec rage, laissant chaque fois des gouttes de venin. Celles-ci se coagulaient sur le fer, en prenant la consistance d'une boule de gomme de la grosseur d'un petit pois. Faute d'armes, pour se débarrasser du reptile, il lui écrasait ensuite la tète en la serrant entre ses dents.

- Quand il jugea avoir assez de venin pour tuer deux cents personnes, il recueillit le suc d'une euphorbe grasse et épineuse et celui du fameux upas ou antiaris de Java, puis la racine d'une liane à feuilles rondes et à fleurs blanches très-odorantes de la famille des strychnos.

"Les racines coupées et fendues en petits morceaux, il en mit une poignée dans le vase en terre et la fit bouillir dans la valeur de deux verres d'eau jusqu'a réduction de moitié. Puis il pila les racines et les comprima dans un linge pour en exprimer le jus, et le mélangea avec le venin et les sucs de l'euphorbe et de l'upas.

„Il prit ensuite une terre argileuse très-grasse, qu'il pétrit avec le suc de l'euphorbe et dont il forma un pelit vase qui dut sécher deux jours au soleil. Le vase cuit à point, il y mit une poignée de racines fraìches d'upas et de liane et la fit bouillir avec de l'eau jusqu'à réduction complete du liquide. Cette opération élait faite en vue d'imprégner le vase des principes toxiques de ces plantes, ou, pour se servir d'un terme de fumeur, de le culotter. Le vase refroidi, le poison y fut versé et mis au soleil, qui lui fit subir une légère fermentation.

" Un whang fut trempé dans ce mélange sirupeux et enfoncé sous la peau de la cuisse d'une vache. L'animal n'offrit aucun phénomène pendant onze minutes; à la douzième, il fut pris de frisson et se coucha. L'agitation augmenta rapidement et le tremblement devint effrayant. Il essaya en vain de se relever, la respiration se ralentit, et, à la quatorzième minute, il expirait dans des convulsions atroces.

- Plus le vase est vieux et culotté, plus le sung-sig ou poison a de puissance.

Des deux plantes citées dans cette lettre, l'une est l'. Intiaris toxicaria Lesch, de la famille des Artocarpées, dont le suc visqueux, connu sous le nom d'upas-antiar ou d'ipo, contrent un principe extrèmeınent vénéneux, l'antiarine. La liane est sans doute le Strychnos Tieuté Lesch., dont l'extrait mou, très-riche en strychnine, porte à Java le nom d'upas-tieuté ou 
de tjettek et est plus redoutable encore que l'upas-antiar (Succus, venenum atrocissimum, De Candolle).

Les symptômes observés sur la vache sont cenx de ces poisons végétaux et non ceux auxquels donnent lieu les venins.

Il en est de même des phénomènes qui suivent l'inoculation des véritables curares (poisons des Ticuñas, Macusis, Yaguas, otc.). Ils sont dus à la curarine et très-distincts des accidents échidniques.

Note 2, page 15ั5, Guérisseurs de venin et charmeurs de serpents.

Les guérisseurs de venins dans les départements de l'Ouest appartiennent à deux classes distinctes.

Les uns se bornent à prescrire une de ces recetles vineuses au galium ou au frêne dont nous avons parlé; ce sont les simples empiriques; ils agissent le plus souvent avec une entière bonne foi.

On ne peut en dire autant des conjureurs : ceux-ci joignent à leurs remèdes secrets de misérables jongleries. Ils ont certains mots à l'aide desquels ils rejettent le maléfice sur la vipere que l'on trouve morte non loin du théâtre de son crime.

Matthiole (loc. cit., p. 837) signale la formule suivante comme ayant de son temps un grand renom : "Caro caruze, sanum reduce, reputa sanum, Emmanuel Paracletus; nous ignorons si elle jouit encore d'une certaine vogue; mais le cercle magique dans lequel lę blessé doit placer nu le pied droit, tant que durent les invocations, est toujours en usage parmi ces charlatans.

Plusieurs, du reste, sont de vérilables sorciers sachant la composition des philtres et possédant le don du mauvais ail. Ils passent pour avoir le pouvoir de jeter et de détourner les sorts, de noner et de dénouer l'aiguillette, de faire pundre les poules, etc. Ils ne sont pas sans avoir eu, dans le cours de leur pratique, des démêlés avec la justice, et ils ont, en général, contre eux leur curé qui ne leur permet pas, pour le fait même de leur métier, de s'approcher des sacrements.

Tous racontent invariablement que, poursuivis par la Faculté jalouse, ils se şont fait mordre sous ses yeux par des vipères, et que, grice à leur 
antidote, ils sort sortis sains et saufs de cette ipreuve, à la confusion des médecins qui ont tout intérêt à nier la chose!

Ces histoires et autres du mème genre, colportées par des amis de cabaret, leur donnent, au loin surtout, un grand prestige.

Comme charmeurs de reptiles, ils offrent peu dintert; des conleuvres brandies à pleines mains devant le public citonne, des viperes saisies par la queue quand elles rentrent dans leurs trous el lenues ainsi à hout de bras sans qu'elles puissent se redresser puur mordre, des serpents chassés de leur tanière par des insulflations de tabac, voila leurs principaux tours.

Tous prétendent attirer les aspies en mettant à bouillir dı lait au milieu des champs, et, si cela ne suffit pas, en plongeant dans le liquide une vipère dont les sifflements servent d'appeau pour ses compagnes.

Certains d'entre eux disent avoir un autre moyen de faire venir les reptiles; c'est un siflement module et rhyhmique, accompagné d'un claquement de langue; qu'ils anpelent cri du serpent et qui ressemble au coassement des grenouilles quand elles se recherchent. Un homme digne de foi nous a dit avoir vu tenter l'expérience par un artiste de ses amis, mais qui n'avai rien de commun avec les conjureurs; l'air sifflé était tiré du répertoire de Robert-le-Diable. Les reptiles, les couleuvres surtout commencèrent à arriver, et l'enchanteur', tout en continuańt à siffler, en soulevait quelques-uns sur son bâton sans qu'ils parussent s'en effrayer. Le spectateur, mal à l'aise en frareille compagnie, demanda la fin de l'expérience.

Plusicurs versets de la Bible font allusion à des charmeurs de serpents bien plus remarquables, les enchanteurs (incantatores), dont l'industrie s'est conservée de nos jours sur les bords du Gange et de l'Indus et sur ceux du Nil.

Dans l'Inde ces hommes portent le nom de gouni; ils jonglent avec le capelle ou serpent à lunettes (Naja tripudians, Merr.), et M. Léon Bureau nous a donné une note intéressante sur leurs exercices.

Loin des grandes villes, et par là même de l'œil de la police, ils se servent de capelles parfailement munis de crochets (quibus non evellerint, diraient les Septante). Avant de s'exposer à jouer avec eux, ils leur font cracher leur venin pour prouver qu'ils sont intucts et les rendre moins à craindre. 
Puis le gouni tire de son sac deux petites divinités en chiffon, MoutouMary et Ramsamy. Il les balance au-dessus des paniers à serpents; leur adresse des invocations el les place l'une à sa droile, l'autre à sa gauche, en leur administrant à chacune une chiquenaude. Les dieux y répondent par un eri aigu bien connu des eapelles, poussé par le jungleur lui-même, mais qui par un effet de ventriloquie parait sorlir des poupées.

Ces précautions prises, !'Indou, pres(fue nu, embouche sa musette, fait d'un tour de main sauter les convercles des paniers, n'en gardant Iqu'un seul dont il se sert comme d'un bouclier ế se met à moduler des sons qui ressemblent à ceux du bignou. Les najas irritées se dressent à moitié de leur longueur, enflent les membranes qu'elles ont au-dessous de la tîte et s'élaneent sur le bateleur dont le talent est d'autant plus apprécii qu'il met plus d'adresse à parer leurs coups. Pendant toule la durée de cet exercice le gouni fixe continuellementles serpents des yeux et ne cesse de jouer de la muselte. Il fait en sorte qu'ils ne s'écartent pas de lui, ce qu'il obtient à l'aide du regard, des mouvements de son corps et des sons de son instrument. Le spectacle dure de cinq a dix miuutes, après quoi le jongleur recouvre l'une après l'autre ses najas avec une dextérité étonnante et les replace dans leurs paniers.

Ces jeux ne sont pas sans péril pour les spectateurs. P'endant le séjour de M. L. Bureau à P’ondichéry, une naja récalcilrante s'échappa dans la foule et mordit à la gorge une jeune fille, qui mourut deux heures après.

Les psylles modernes ont conservé rfuelques-uns des secrets des magiciens de Pharaon. Ils transforment l'aspic de Cléopitre (Tajiy Haje Dum.) en baguelte inflexible, en lui pressant avec force le cou entre les doigts. Le reptile tombe en catalepsie el devient insensible ct roide. En hui pinçant la queve, on lui rend la sensibilité et le mouvement. E. Geoffroy SaintIIlaire (Reptiles it Egynte) raconte quayunt surpris la maniere dont ces hommes s'y prenaient, il a pu rendre, comme eux, l'haje cataleptique. Ces psylles paraissaicnt stupéfiés de son audace, car is croyaient ou feignaient de croire que cette action sur les serpents étail un privilége de leur race. Ils jonglent aussi arec d'inoffensifs irsy sur les tètes desuluels ils ont enté des ergots de coqs et qu'ils lont passer puur des cérastes.

En Algerie, les membres d'une secte de fanatiqques, appelís Aissaona, 
s'exposentimpunément, parait-il, aux morsures les plus venimeuses, quand, à l'aide de certaines drogues et dlu haschich en particulier, ils se sont mis dans une exaltation cérébrale suffisante.

Note 3, pages 181, 183, 194 et 197, Essai de diverses méthorles de traitement contre la morsure de la vipère.

Depuis la publication de la première édition de ces Études, nous nous sommes livré à une série d'expériences sur les divers remèdes à employer pour détruire le venin sur place. Voici en abrégé celles qui nous ont offert les particularilés les plus intéressantes.

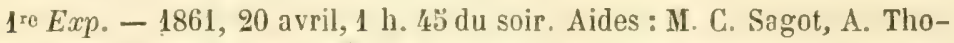
mas et Em. Letard. Une ligature est placée sur l'aine gauche d'un lapin de forte race, âgé de trois mois, et la ('uisse de l'animal non dépouillée de ses poils est mise sous le museau d'une vipère-aspic de couleur rousse, prise l'avant-veille; la vipère appuie ses màchoires sur la partie qui lui est présentíe, près d'une demi-minute. Pas de cri, pas d'écoulement sanguin, on cherche en vain les traces de la morsure, ce qui fait croire que les poils ont empêché la pénétration des crochets. La cuisse est en partie rascée et mordue de nouveau par le reptile. Cri aigu, agitation, les deux petites plaies, presque imperceptibles et distantes l'une de l'autre de quatre millimètres, sont réunies par une incision profonde qui donne peu de sang et dans laquelle nous injectons dix gouttes de la solution iodo-ioduréede Brainard. Sept minutes plus tard, soit un quart d'heure après la première morsure, le lien inguinal est enlevé. L'animal court en se servant de sa palte; il recherche les endroits obscurs; sa resuriration s'accélère et l'on compte cent mouvements inspiratoires par minute. A 2 h. 23 , nouvel examen : on découvre parmi les poils, à quatre millimètres l'une de l'autre, deux petites taches violacées, tuméfiées, et dont le centre offre un point ineurtri. Elles sont évidemment les traces du premier coup de crochets; une incision les réunit et nous y injectons quelques goultes de la solution; le mème liquide est déposé dans des scarifications faites au voisinage. L'animal haletant refuse de manger et se refroidit. Il reste étendu dans un coin, puis semble se réveiller et essaie de courir, mais ne s'appuie pas sur sa patte qui 
se tuméfie et devient de plus en plus froide. A $3 \mathrm{~h}$. des ecchymoses se remarquent sur le membre blessé et le ventre. Pas de vomissements, lígère déjection alvine, contracture du côté malade. Mlort à 4 h., soit deux heures el quart après le début de l'expérience. Dans la soirée, un portier nous demande le lapin, qui est déjà rigide, et s'en régale avec sa famille.

La solution iodo-iodurée introduite dans les piqùres trois quarts d'heure après la pénétration des crochets (laps de temps écoulé entre la première morsure et son trailement) n'entrave donc chez le lapin aucun des accidents de l'envenimation, puisque tout s'est passé ici comme si le mal avait été abandonné aux seules forces de la nature.

2 ${ }^{\circ}$ Exp. - Hême jour, 3 h. $1 / 2$ du soir. Un pigeon de taille assez forte est plumé à la cuisse droite et une ligature est placée au-dessus de l'aine. Un coup de ciseaux prive de sa màchoire inférieure la tête d'une vipère grise, morte la veille, et les crochets saillants du reptile sont enfoncés profondément dans les chairs, tandis qu'à l'aide d'uin bec de corbin , M. A. Thomas presse sur les parotides. Une des canines se luxe dans celte opération, tant est grande la force employée. Le débridement des piqûres donne un peu de sang; lavage à grande eau, injection de dix gouttes du liquide de Brainard, puis, deux minutes après la blessure, enlèvement du lien constricteur.

Le pigeon n'offre aucun symplôme local ni général d'empoisonnement. Au bout de cinq jours, il est atteint de la pépie pour avoir manqué d'eau. L'enlèvement de la muqueuse desséchée de la langue le guérit de celte affection, et le huitième jour il s'envole et rejoint son pigeonnier.

Le succès a été complet; mais il arrive parfois que chez les serpents, au moment de la mort, du sang s'épanche dans le conduit excréteur de la glande toxigène, et se coagulant vient laire bouchon dans la cavité de la canine qui ne laisse plus passer le venin.

$3^{\circ}$ Exp. - 1866, mai. Aides : MII. Gicquiau et Curet, professeurs au collége Saint-Stanislas. La cuisse droite d'un fort pigeon est plumée et une ligature placée sur l'aine. On fait mordre la partie dénudée par un aspic de couleur grise. Les empreintes des crochets sont élargies et nous y introduisons quelques goultes d'une solution bromo-bromurée. L'animal devient triste, comme accablé, il se refroidit, mais les phénomènes locaux sont presque nuls. On lui ingurgite des boulettes de pain imbibées d'eaude-vie éleudue. Nous pensions le sauver, quand il succomba an bout de 
trente-six heures sans nouveaux symptôm s. Rigidité cadavérique rapide.

Ainsi, mort tardive pour un pigeon et presque sans symptômes locaux. Ceci rappelle les faits observés par M. Weir Nitchell à la suite de l'emploi des solutions iodées el bromées contre la morsure des crotales.

Divers autres essais entrepris par nous en $\mathbf{1 8 6 6}$ avec ces solutions ont toujours eu des résultats malheureux.

4. $\operatorname{Exp.~-~1867,~} 18$ mai, 8 h. 20 du soir. Aides : MM. Gicquiau, Goglet et Dauffy et Dupont, ce dernier interne à l'Hòtel-Dieu. (Dans cette expérience, et toutes celles faites cette année et la suivante, une ligature provisoire a été placée avant la morsure et enlevée aussitôt après l'apıllication du remède; les dents de l'aspic ont porté sur une partie préalablement dép uillée de ses poils ou de ses plumes, el la substance médicamenteuse a été introduite à l'aide du flacon à bouchon-plongeur.)

Lapin mordu une fois par une forte vipère. Cri très-aigu; on ne peut découvrir que l'empreinte d'un seul crochel. Incision, instillation iodoiodurée. Un quart d'heure après, relus de nourriture, embarras et accélération des mouvements respiratoires; le lapin n'urine pas pendant l'exfrérience; il recherche les lieux obscurs: maladie locale peu marquée. Il meurt vingt minutes après; rigidité cadavérique presque immédiate.

$5^{\text {e }}$ Exp. - 20 mai, 4 h. 1/2 du soir. Un jeune pigeon, mangeant à peine seul, est mordu avec rage par un aspic rouge à la partie antérieure de la cuisse. Incision; nous suçons la plaie sans remarquer de goût au venin. Trombus et gonflement du inembre inordu accompagnés d'un léger refroidissement. L'animal ne peut s'appuyer sur sa patte. Malaise; la température générale semble un peu abaissée. L'oiseau est tenu le plus chaudement possible. On lui ingurgite du millet dans la soirée, et il boit seul. Le lendemain il roucoule; on le fait encore manger. Il court à cloche-pied; sajambe est toujours d'un noir ecchymotique ; léger suintement de la blessure. Le jour suivant il mange seul, s'appuie sur le membre blessé, et, à parı un peu de gonflement très-localisé, doit être considéré comme guéri. Il s'est noyé l'année suivante en voulant boire sur le bord d'un bassin. L'opérateur, quoique ayant les gencives saignantes, n’a éprouvé aucun accident de la succion.

L'aspiration a ici empêché l'envenimation générale. Le troinbus peut être attribué tout aussi bien à la succion qu'à l'effet du poison. 
$6{ }^{0}$ Exp. - 25 mai, 3 h. du soir. H. Gicquiau fait mordre un lapin à la cuisse par une vipère grise de moyenne grosseur. Incision amenant une perte de sang assez eonsidérable; emploi de la solution Brainard. Agitation, accélération de la respiration qui devient un peu anxieuse. La tumélaction et les phénomènes locaux sont nuls. Une demi-heure apres, le lapin mange gaiement, et le lendemain on ne se douterait pas, à le voir, de ce qui lui est arrivé.

L'écoulement sanguin assez notable en entrainant le venin, suffit, en dehors du remèle, pour expliquer celte prompte guérison. La vipère était bien venimeuse; la veille elle avait tué un moineau et depuis elle a lait périr d'autres lapins.

$7^{\text {e }}$ Exp. - 10r juin, midi 1/2. Jême lapin mordu par une très-grosse vipère rouge n'ayant pas cncore servi. Le reptile fait coup sur coup deux morsures. Cri déchirant. L'une des morsures n'est reconnue qu'un peu lard. Incision. Solution iodo-iodurée. Tuméfaction rapide de la jambe, qui devient noire et froide en moins d'un quart d'heure. Respiration anxieuse; le train postirieur se paralyse; la température générale du corps s'abaisse. Quelques gottes d'alcali sont administrées à l'intérieur dans un peu d'eau. En moins d'une heure et demie l'animul succombe et devient presque aussitôt rigide.

$8^{\circ} \operatorname{Exp}$. - Vieux pigeon mordu le mème jour par la même vipère. Incision, justillation de la solution Brainard. Hort en une demi-heure avec peu de symptômes locaux el en particulier une tuméfaction très-modćrée. Rigidité cadavérique quelques heures après.

9. $\operatorname{Exp}$. - 4 juin, 2 h. - Petit lapin de deux mois mordu par la même vipère. Incision sur les piqûres; ceuulement sanguin, traitement iodé. Pas de cris, selles involontaires, accélération du pouls el des mouvements thoraciques, refroidissement. Le lapin lèche sa plaie; tuméfaction et lividité de la cuisse peu marquées; mort le soir ; rigidité cadavérique presque immédiate.

10 Exp. - Même jour. - Jeune pigeon mordu par la même vipère; même traitement. Nausées, régurgitations, refroidissement, prostration. IIort un quart d'heure après, toujours sans grands phénomènes à la cuisso blessée. Prompte rigidité.

Les victimes de ces quatre deruières expériences on étr mangées par 
M. Dupont et divers sous-offeiers à la cantine du réginent. Ils ne leur ont trouvé aucun goût désagréable.

Nos autres expériences de 1867 ne sont que la répétition de celles-ci, el se sont terminées par la mort, malgré l'emploi de la solution Brainard.

11 Exp. $-1868,6$ mars, 5ै h. 1/2. Aides : M. Gicquiau, et MII. Lamy et Cado, étudiants en médecine. Jeune lapin nordu deux fois à la jambe par une vipère rouge, le membre ayant été préalablement lié et rasé. Instillation de quelques gouttes d'acide phénique dans les deux morsures incisées. Pas de cris, pas de tuméfaction, mais refroidissement de la jambe. L'animal se mel à manger cinq minutes après la morsure; il urine en abondance, et ses urines traitées par la liqueur de Felhing ne donnent pas de traces d'albumine ni de glucose. A 7 h. 1/2 aucun phénomène d'intoxication ne s'est encore manifesté; le lapin broute avec plaisir des choux el des feuilles de fraisiers.

Le lendemain il offre un abcès de la cuisse el est présenté au cours de Pathologie interne. Oublic à l'École de Médecine, il mange la tête d'un pigeon renfermé avec lui. It résiste toutefois à ce surcroît d'épreuves, maigrit considérablement et a des abcès prolunds. Sa jambe devient insensible et desséchée, la substance caustique ayant été employée sans mélange et en trop graıde quantité. Il reste pendant quelques jours dans une sorte d'etat d'abaltement, mais au bout d'une quinzaine, il reprend ses habitudes avec l'insouciance propre à sa race. Sa jambe redevient à son volume primitil et les poils repoussent au lieu mème de la morsure.

Cas extrêmement curieux. Rien dans les accidents cilés ne ressemble aux phénomènes de l'échidnisme; le lapin n’a éprouvé que des symptômes dus à l'acide phénique et à la privation d'aliments.

$12^{\text {e }}$ Exp. - Mème jour. - Pigeon mordu par une vipère et traité par l'acide phénique, mais avec plus de prudence. Léger écoulement sanguin pendant que l'on débride les piqûres. Pas la moindre tumélaction le jour même, pas d'empoisonnement genéral. Le lendemain le pigeon a la cuisse noire et un peu oedématiée. 11 est présentí au cours avec le lapin, est oublié comme lui dans un panier et a la têle dévorée par son compagnon d'infortune.

130 Exp. - 9 juin, 10 h. 30 du matin. - Une ligature est placée sur le haut de la cuisse rasée d'un jeune lapin màle qui est ensuite mordu avec force par une vipère-aspic ronge n'ayanı pas eu l'occasion de dépenser 
son venin depuis deux jours, mais s'élant donné à elle-même un coup de crochet au moment de l'expérience. Aucun cri. On débride la plise quui laisse suinter quelques gouttes de sang; l'empreinte du crochet gauche a été assez difficile à découvrir. Dans chaque piquire nous diposons une goutle d'acide phénique étendu d'un quart d"alcool et la ligature est enlevée. L'animal paraît un peu abattu; il mange cependant des feuilles de chou. A $10 \mathrm{~h}$. 50, accélération de la respiration (128 m. r.), anxiélé; il se couche sur le ventre et lèche ses plaies. Il traîne sa patte avec peine, elle n'est du reste ni refroidie ni tuméfiée. Dans la soirée rien de bien nouveau, il est moins triste et moins abattu.

10 juin. - Le lapin ne présente aucun accident.

11 juin et jours suivants. - Il mange, court, et parait gai; des eschares assez larges se-montrent aux points oì a touché l'acide; elles se détacheut bientôt en donnant lieu à un peu de suppuration, mais sans altérer la santé du blessé, qui a servi à d'autres expériences.

14 Exp. - 13 juin, 4 h. 50. - La cuisse d'une jeune femelle de lapin est rasée, serrée à sa partie supérieure par une ligature et présentée à un aspic de couleur grise. La vipère, qui paraissait peu disposée à mordre, $\mathrm{y}$ enfonce deux fois de suite ses crochets. Son peu d'entrain ayant fait croire à l'un de nous qu'elle n'était pas venimeuse, les piqûres ne sont point agrandies et l'on se borne à déposer sur chacune d'elles une trèspelite goultelette d'acide phénique étendu d'alcool.

L'animal au premier abord ne parait pas malade, mais bientôt la respiration s'accélère et marque 14'; elle devient saccadée. Pas de congestion des oreilles; pas de gonflement du membre blessé. Chaleur normale, pas d'urine; stupeur.

Dans la soirée il y a queliues alternatives, mais la respiration reste toujours embarrassée. Le lapin refuse la nourriture qui lui est offerte.

14 juin. - L'état s'est amélioré et l'animal semble rétabli.

15 juin. - Il mange, boit, paraît gai et s'accouple avec un autre lapin, ayant servi à une expérience analogue.

18 juin. - Il est trouvé mort sans avoır eprouvé d'autre accident.

L'autopsie malheureusement :n'a pu ẽtre faite; des carriers bretons ayant demandé le sujet et l'ayant mangé en gibelotte.

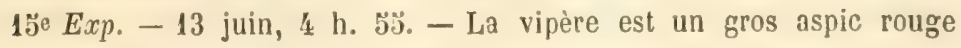
n'ayant pas mordu depuis te 9 juill; le sujet, une vieille femelle de lapin 
de furte race; les préparatifs ont été faits comme de coutume. L'aspic saisi au cou avec des pinces mord avec rage la cuisse privée de ses poils. Pas de cri, mais agitation; les plaies agrandies ミaignent peu. Une gouttelette d'un mélange à parties égales d'acide phénique et d'alcool y est introduite à l'aide du bouchon-plongeur, puis la ligature est enlevée.

Un quart d'heure après, le lapin parait assez souffrant; le pouls est petit, concentré; la respiration, saccadée et si précipitée qu'on ne peut la compter. Angoisse; l'animal se couche sur le côté sain et change continuellement de place. Pas d'urine ni de garde-robe, congestion des oreilles. Pas de tuméfaction ni de refroidissement dı membre blessé.

5 h. 40̈. État général meilleur, quoique les mouvements respiratoires dépassent encore le chilfre 100. Cuisse rouge, gonflée, très-sensible; le blessé tremble dès qu'on l'approche. Il refuse de manger.

14 juin et jours suivants. - Les accidents généraux disparaissent, la cuisse guérit peu à peu sans eschares et le 30 juin le rétablissement est complet.

16e Exp. - Mordue de nouveau au mois de juillet et traitée avec des gouttes plus grosses d'acide phénique simplement coupé d'alcool au quart, la mème femelle de lapin guérit sans présenter le moindre symplôme d'empoisonnement, s'accouple peu de temps après et devient pleine.

17 et 18 e Exp. - Deux petils lapins sont mordus à la cuisse, l'un trois fois, l'autre deux fois, au mois de juillet de la même année. Nous les croyons perdus à cause de leur âge el du nombre de leurs morsures, aussi l'acide phénique est-il employé largement. Les symplômes locaux sont ceux d'une forte cautérisation et non d'un empoisonnement venimeux. Les deux lapins urinent en abondance et broutent des feuilles de laiteron qu'ils trouvent à leur portée, ce qui nous rend un peu d'espoir. $\mathrm{Au}$ bout d'une demi-heure, leur respiration s'accélère et s'embarrasse et ils meurent l'un et l'autre dans la nuit.

Cet insuccès doit-il être attribué à l'action éloignée du venin ou à celle de l'acide phénique?

19, 200 et 210 Exp. - Juillet. Trois lapins mordus chacun une fois par une vipère et trailés par un mélange de trois parties d'acide phénique contre une d'alcool guérissent, ayant offert pour tout ș̣mptòme pendant quelqques heures un peu d'accablement et quelques troubles respiratoires. 22e Exp. - Juillet. M. Gicquiau, en face de ces résultats si différents de 
ceux que nous avaient dommis l'iode et le brome, conçnit des doute's sur la force du venin de nos vipères el les croit épuisées. Il fait mordre par l'une d'elles, à l'oreille, un de ces lapins. Les crochets traversent le lobe et laissent une gouttelette de venin en contact avec chaque plaie.

Le blessé offre une maladie assez légère de l'oreille, mais pas d'accidents généraux, quoiquaucun traitement ne lui aitété fait.

D'où venait cette innocuitr? Avait-elle pour cause l'envenimation antérieure et devait-elle être rapprochée des cas d'immunité par suite de morsures précédentes que semble admettre M. le professeur Bouchut?

23e Exp. - Pour nous en assurer nous faisons mordre, deux jours après, un de ces trois lapins par la même vipère, mais à la cuisse, ct nous le laissons sans aucun soin. Il nieurt en quelques heures avec tous les symptòmes de l'échidnisme, et la rigidité cadavérique est presque immédiate.

Le résultat de l'expérience précédente tient done uniquement an siege de la morsure, les blessures envenimées à l'oreille, sans qu'on siche pourquoi, étant au nombre des moins graves; particularité que Funtana a bien: démontrée.

24. Exp. - 1869, 9 mai, 5’ h. 3/4 du soir. (Communiquée ainsi que les suivantes par M. Gicquiau, qui les a failes sans nous, mais d'après nos avis et en négligeant la ligature artérieure.)

Jeune lapin mordu par un aspic à la cuisse. Des goutles nombreuses de la solution de perchlorure de fer de Rodet sont versées dans les piqùres agrandies. Urines abondantes, deux selles solides.

$6 \mathrm{~h}$. La respiration marque 90 ; l'animal lèche ses plaies, il est abattu et triste. Lavage à grande eau pour enlever le perchlorure en excès.

7 h. Le lapin broute une l'euille de chou, et paraît mienx; il ne présente ancun pliénomène local d'envenimation et lu lendemain a repris sis vie ordinaire. Malheureusement le eaustique donne hıeu à une suppuraliou abondante et à de tels décollements que quinze jours apris la morsure l'opérateur par pitié abat l'animal.

$2{ }^{2}$ Exp. - 10 mai, 2 h. 1/2. Jeune lapin. Impossible de retrouver à la cuisse dénudée la marque des deux croche:s; des incisions sont pratiquées sur leur siẻge probable et l'on y instille du perchlorure de fer. L'animal laisse tomber sa tète comıne s'il se mourait; puis reprent un pen de vie. 
fait quelques pas et se couche en se roulant par terre. 115 mouvements respiratoires par minute; congestion et chaleur des oreilles.

$3 \mathrm{~h} .1 / 4.80$ respirations par minute, il commence à lécher sa plaie à plusieurs reprises. En lavant la cuisse, on retrouve les véritables traces de la morsure que l'on incise et dans lesquelles quelques gouttes de perchlorure de fer sont instillées.

$4 \mathrm{~h}$. 10. Les pulsations sont si petites et si irrégulières qu’il est impossible de les compter. La respiration offre les mêmes désordres; aucune tuméfaction inflammatoire.

4 h. 35. Abattement, refroidissement.

5 h. 10. Ces symptômes augmentent d'intensité, el la mort a lieu vers la nuit. Rigidité cadavérique dès le lendemain.

Le perchlorure, qui est un contre-poison et non un antidote, n'a pu suffisamment agir, n'ayant pas été déposé tout d'abord dans la plaie ellemême; il semble cependant avoir modifié les symptômes locaux.

$26^{\circ}$ Exp. - 1ə̆ mai 1869, כ̋ h. 10. Lapin mordu et soigné par quelques gouttes seulement de perchlorure. Il est d'abord triste' et abatlu et refuse de manger. Sa respiration est tris-accélérée. Peu d'inflammation lucale et elle parait surtout due à la cautérisation. A $6 \mathrm{~h}$., le mieux commence à se faire sentir; à $7 \mathrm{~h}$., le lapin broute quelques herbes; le lendemain matin, il est guéri, mais la cautérisation a donné lieu à une eschare qu'une inflammation suppurative détache au bout de quelques jours et qui guérit sans amener d'accident.

27॰ Exp. - 15 mai 1869, 5 h. 15. Jeune lapin mordu par un seul crochet, par une vipère-aspic et traité par une simple goutte de la solution de Rodet instillée dans la piqùre agrandie. Dix minutes après il se remet à ınanger. Pas d'accidents généraux, si cen'est une respiration très-prompte. Le lendemain il a repris ses habitudes. Une très-petite plaque gangréneuse, due au perchlorure de fer, donne lieu pendant quelques jours à de la suppuration; ce qui n’a pas de suites fâcheuses.

Ces deux derniers lapins vivent encore au moment où nous terminons ce travail (1 1 lapins de la même portée. 


\section{PRINGIPAUX OUVRAGES CONSULTES $\left({ }^{1}\right)$}

ADDy. Alcoholic stimuli in snake bite. Nedical time and Gazette, 1850 .

Avdrieux. Coup d'ail sur les accidents causés par la morsure des serpents venimeux; émumération des divers moyens employés pour les combattre. Journ. des Con. méd. et pharm. 1849.

Essåi du guaco contre la morsure de la vipère.

Aubinals. De la morsure de la vipere et de son traitement. Courrier de Nantes, 28 août $\mathbf{1 8 4 5}$.

L'auteur, à l'occasion de trois piqùres d'aspic ayant causé la mort chez des laboureurs de l'arrondissement de Paimbœuf, fait connaitre les caractères zoologiques de cette vipère, dit quelques mots sur ses mœurs et formule le traitement à opposer à ses morsures.

Beauregard. Observations. Anc. journ. de méd., t. VI, $178 ̈ 7$. Conseille l'emploi du jus de frêne.

Bernard (Cl.). Action physiologique des venins. Mém. de la Soc. de Biologie, juin 1849.

Leçons sur les effets des substances toxiques et mélicamenteuses. 1857, p. 389 .

Blanche. Note sur le Pelias Berus. Soc. des Amis des Sc. nat. de Rouen, t. I, p. 109.1865.

Indique le péliade comme plus commun que l'aspic dans la Seine-Infé.

1. Pour plus grands détails bibliographiques, voir Erpétologie générale de MIM. Duméril et Bibron, t. VI, p. 2I.̈, et thèse inaugurale de M. Léon Soubeiran : De la Vipère, de son venin et de sa morsure, ch. vil, Bibliographie, p. 129. 
rieure, et signale une anomalie dans la disposition des plaques syncipitales (la présence d'une petite écaille centrale).

Blaud (IV.). On the bite of the verenous serpents of Australia. Australian medical journal, 1861 .

Conseille l'emploi de vins généreux.

Bonaparte (CH.) Iconografia della fauma italica. 1832-41, t. II. Anfibi.

Étudie les vipères en zoologriste; des planches accompagnent ses descriptions.

Bonaparte (Luc.). Gazetla toscana delle scienze medicofisice, 1843 , p. 169.

Analyse du venin et découverte de la vipérine.

Bouchut. Nouveaux éléments de pathologie générale, 18577. Note page 41, puis pages 199 et suivantes el page 424 .

Action des venins sur l'économie, immunité acquise par envenimation antérieure, analyse du mémoire de G. Humboldt sur la vaccination prophylactique de la fièvre jaune, etc.

Brainard (DANIEL). Essay on a new method of treating serpent bite, and oter poisoned wounds. Chicago, 18 š4.

Les venins el le curare, qui n'est pour lui qu'un venin conservé à l'aide d'extraits de diverses plantes, altèrent les globules du sang el les déforment. Les solutions iodo-iodurées décomposent ces poisons et sont les meilleurs remèdes à leur opposer.

Bunnett (J. -W.). The poison of the rattlesnale. Boston, Soc. nat. hist., 1854.

Le poison des crotales rend le sang diffuent; chloroformisation du serpent pour s'emparer de son venin.

CAyol. Rage communiquée par la morsure d'un chien; essais de traitement par l'arsenic, l'hydrogène sulfuré et par le venin de la 
vipère; mort 70 heures après l'invasion des premiers symplomes. Revue médicale, 1831 ,t. III, p. 387.

CELSE. De re medica; de medicamentis, I. V, ch. II, sect. 12.

Indique la succion comme le meilleur remède contre les morsures des serpents et les plaies empoisonnées par les flèches des Gaulois.

Charas (Moïse). Nouvelles expériences sur la vipère. Paris, 1669 , et Suite des nouvelles expériences sur la vipère. 1772.

Étaient en France avant le traité de Fontana les ouvrages classiques sur la vipère.

Conbiot (J.-B.). Revue sur le système d'inoculations curatives du $D^{r}$ Télèphe Desmartis. Bordeaux, 1862.

Daudin (F.-MI.). Histoire naturelle générale et particulière des reptiles, an $\mathrm{X}$.

Davasse. Les Aïssaoua ou charmeurs de serpents. $2^{\text {mo }}$ édit. Paris, 1862.

Delalande (J.-B.). Une première excursion dans la CharenteInféripure. Nantes, 1848.

Donne (page 18) les caractères d'une couleuvre prise par lui près de Rochelort et qu'il appelle avec MII. Mauduyt et Millet coulesvre glaucö̈de.

Demeunat (L.). Observation d'accidents développés ì la suite d'une morsure de vipère, se reproduisant depuis trente-neuf ans d'une manière parfaitement périodique. Gaz. hebd. 6 nov. 1863.

Desilantis (ThélèpIe). Action modificatrice que les venins penvent exercer dans certains cus morbides. Rev. thér. du Midi, $183 ̋$ ä, t. IX, p. 26 อ̆.

Nouvelle vaccination préservatrice de la fière jaune et du choléra. Montpellier, 1855.

De la tolérance au point de vue médical. Montpellier, 1857.

Parle de la tolérance du venin des serpents que posséderaient ceux qui ont èté anciennement inoculés, cl soutient les opinions de M. G. de IIun- 
boldt quant à la prophylaxie de la fièvre jaune; signale les venins comme moyen curatifs dans certaines maladies.

Dugès (Alfred). Sur les Vipères Aspis et Pelias. Mém. de la Soc. de Biol., 1850, t. II, p. 115.

Duméril (Const.) et Bibnon (E.). Erpétologie générale, t. VI et VII.

Ouvrage capital pour qui veut étudier les serpents. La classification des ophidiens, telle qu'elle a été remaniée par Mil. Duméril à la mort de Bibron, se trouve exposée sous forme de tableau, t. VII, p. 14. L'observation de la morsure de M. Duméril père par un péliade est donnée in estenso, mème tome, p. 1399.

Duméral (Auguste). Notice historique sur la Ménagerie des reptiles du Muséum. Paris, $185 ̆ 4$.

Curieuses observations, toules nouvelles sur les serpents.

Dusound. Effets remarquables de l'huile d'olive employée à l'intévieur et à l'extérieur dans les cas de morsure de vipère. Bull. de thér., t. XXVII, p. 489, 1849.

Encognère (JacQues). Des accidents causés par la piquire des serpents de la Martinique et de leur traitement. Montpellier, 1863.

A grande foi dans les alcooliques à fortes doses.

Fabas (P.-X.). Notice sur le choléra asiatique et sur l'identité des symptômes qui le caractérisent, comparés à ceux produits par la morsure de la vipère et son traitement abortif et curatif. Tarbes, 18307.

Propose l'ammoniaque contre le choléra parce qu'elle réussit, dit-il, contre l'envenimation.

Fontana (Félix). Traité du venin de la vipère. Florence, 1781.

Admirable ouvrage contenant plus de 6,000 expériences'et faisant encore loi de nos jours.

Fontenelle de Vaudoré (DE). Statistique ou description du dé- 
partement de la V'endée par J.-A. Cavoleau. $2^{\text {me }}$ édit. revue par M. de Fontenelle de Vaudoré, 1844.

Donne (page 46々) un catalogue trìs-incomplet des serpents de la Vendée.

Founc. Instruction sur le traitement it employer contre les mor. sures des vipères. Nantes, 1809.

Gage (L.). Du venin des crapauds et des serpents. Répertoire de pharmacie, 1867, t. XXIV, p. 180.

Une note publiée dans un des numéros suivants du Répertoire de Pharmacie (mème tome, p. 230̈), dil que cet article est en partie une analyse du travail que nous avions publié nous-même dans la Gazette des Hópitaux, au mois d'août 1867, no. 92 et 93, suus le titre de Venin de la Vipere.

Gimonniène (DE LA). Heureux effets de l'action des alcooliques portés jusqu'à l'ivresse dans les cas de morsure par certains serpents. Compt. rend. de l'Ac. des sc., t. LII, p. 740.

Geofrnoy et Hunauld. Mémoire dans lequel on examine si l'huile d'olive est un spécifique contre les morsures des vipères. Némoires de l'Ac. des sc., 1737, p. 183.

Les rapporteurs concluent par la négative.

Grignon-Dunoulin (Gustate). Lettre sur les maurs des vipères. Union Bretonne, 31 déc. 1867.

Délails intéressants sur les mœurs de ces animaux, en liberté et en captivité.

Gruère. Des venins et des animaux venimeux. Paris, 18504.

Est un des meilleurs travaux à consulter sur les venins.

Guyon (J.). Des accidents produits dans les trois premieres classes de vertébrés et plus particulierement chez l'homme par le venin de la vipère fer de lance. Montpellier, 1833.

Le venin des serpents exerce-t-il sur eux-mémes l'action qu'il 
exerce sur les autres animaux. Compt. rend. de l'Acad. des sc., 1861, t. LIII.

M. Guyon a aussi publié en 1863 dans les Comptes rendus de l'Académie des sciences de très-bonnes recherches sur les accidents occasionnés par la piqûre des scorpions.

II annemann. Dissertatio de vipere morsu. Miscell. nat. cur. 1689. Herran. Graine du cédron employée dans l'Amérique tropicale comme remède contre les morsures des serpents. Journ. de pharm., 1850, t. XVIII, p. 296.

Jacolot. Note sur les curados de colubras recueillie à Tuxpan (golfe du Mexique). Arch. de méd. nav., 1867, t. VII, p. 390.

Jussieu (Benv.). Sur l'effet de l'eau de Luce contre les morsures de vipères. Mém. de l’Acad. roy. des sc., 1749, p. כ̆4.

Conclut à l'affirmative d'après une seule observation, termince, il est vrai, par la guérison, mais ayant offert des accidents graves.

Larrey (le baron Hipp.). Compte rendu d'un rapport de la section médicale de Mexico sur la prétendue prophylaxie de la fièvre jaune par la morsure des serpents, 1865.

Rejette avec M. Jordanet, rapporteur de la commission mexicaine, cette prétendue prophylaxie comme une mystification.

Lemane (Jules). De l'acide phénique, de son action sur les végétaux, les animaux, les ferments, les venins et les virus. $2^{\text {me }}$ élit., 1865.

Le préconise contre les venins.

Lemery (Nicolas). Traité de Chymie, $2^{\text {me }}$ édit., Paris, 1766, et Pharmacopée universelle, כّ ${ }^{\text {me }}$ édit., Paris, 1764.

Quelques détails sur la vipère, ses morsures et leur traitement. Différents produits médicamenteux qu elle fournit.

MangiLi (GIaG.). Sul veneno della vipera. Paris, 1809. 
Manzı. Histoire de l'inoculation préservative de la fiève jaune. Paris, 18 85.

Croil à la valeur du procédé de G. de Humboldı el raconte ce qu'il a vu à la Havane sur l'inoculation et ses résultats.

Matthiole (Pienne-André). Commentaires sur les six lirres de Ped. Dioscoride, Anazarbeen de la matière médicale, mis en français sur la dernière édition latine par Jean des Noulins, docteur en médecine. Lyon, 1579.

Page 214: De la vipère et de ses préparations pharmaceutiques. Page 833 et suivantes: Traitement des morsures envenimées.

Mauduyt. Herpétologie de la Vienne. Poitiers, 1844.

Décrit avec de curieuses observations les serpents de ce département et y signale la vipère à trois plaques sous le nom d'Echidnoüles trilamina; considère le jeune Zamenis viridillavus comme une espèce nouvelle qu'il appelle couleuvre glancoïde.

Mead (Richand). Observationes de veneno viperce. 17ä0. Lugduni Batavorum.

Merhem (Blasius). Tentamen systematis amphibiorum. 1820.

Mrluet. Faune de Maine-et-Loire. Anger's, 1828.

Cetle faune contient, p. 614 el suivantes, une excellente étude sur les serpents de l'Anjou. La synonymie de l'auteur pour les vipères n'a pas prévalu. On trouve dans cet ouvrage l'indication de deux cas de mort par morsure envenimée.

Morseau (A.). Dissertations sur les animaux venimeux de la Vendée et sur le traitement à employer contre leurs morsures et piquires. Paris, an XI.

Travail consciencieux, mais dans lequel l'auteur se borne à constaler des faits déjà admis, à les débarrasser des fables populaires et à prouver l'efficacilé de l'ammoniaque.

Moqun-Tandon. Elements de Zoologie médicale. Paris, 1860. 
Des planches intercalćes dans le texte représentent d'une manière trèsfidèle les trois vipères européennes et l'appareil venimeux du péliade.

Eléments de Botanique médicale. Paris, 1861.

Détails intéressants sur les plantes employées comme antidote des venins.

Patenson (Williais). Quatre voyages au pays des Ilotlentots. 1791.

Prône les pilules de Tanjore el à leur défaut les alcooliques contre l'envenimation.

Piet (Francois). Recherches topographiques, statistiques et historiques sur l'île de Noirmoutier. $2^{\text {me }}$ édit. annotée par son fils. Nantes, 1863.

Constate l'absence dans cette ile de toute espèce de vipère; y signale pour tout serpent l'orvet et deux couleuvres.

Pravaz. Moyens mécaniques propres à prévenir l'absorption des virus. Acad. de Méd. sept. 1828.

Propose l'électricité.

Priou. Observation sur une morsure grave de vipère, suivie de réflexions sur divers moyens employés jusqu'à ce jour contre cet accident. Journ. de la sect. de méd. de la Soc. acad. de la Loire-Infé. rieure, 1828, t. IV, p. 201.

Redi (Franç.). Experimentu naturalia. Amsterdam, 1675.

La première partie, intitulée Experimenta circa varias res naturales, speciatim illas qui ex Indis afferuntur, contient des expériences négatives sur les pierres à serpents.

La seconde, sous le nom d'Observationes de viperis, est entièrement con. sacrée aux vipères.

La troisième, Epistola de quibusdam objectionibus contra suas de viperis observationes, est une réponse à Charas.

Rousseau (Emm.). Signes extérieurs pouvant servir $i$ distinguer 
les serpents venimeux de nos pays des serpents dont la morsure est innocente. Compt. rend. de l'Acad. des Sc., t. III, p. 3830.

Rurz. Enquéte sur le serpent de la Martinique. Paris, 1830.

Bonne monographie du bothrops lancéolé et de ses morsures.

Severino (Mahc.-Aur.). Vipera Pythia, seu de vipera natura veneno, etc. $165 \% 1$.

Monographie de la vipère et de ses morsures.

Sornani. Expériences faites sur l'hydrophobie acec le venin de la vipère. Bull. de thérap:, 1837, t. XII, p. 294.

L'envenimation n'a pas entravé la marche de la rage.

Soubeiran (LÉon). De la vipère, de son venin et de sa morsure. Paris, 185 .

Contient une bonne description des diverses espèces de vipères, de curieux détails sur leurs glandes à venin et un grand nombre de faits nouveaux et peu connus, ayant rapport aux morsures de ces serpents et à leur traitement.

Rapport sur les vipères de France. Bull. de la Soc. d'accl., 1863, t. X, p. 386 .

Excellent résumé des travaux envoyés à la Sociétẻ d'acclimalation à la suite de son enquête sur les vipères. Il doit être lu par quiconque veut étudier les vipères, soit au point de vue médical, soit au point de vue des mesures administratives à prendre à leur sujet.

Vauvert de Méan. Remède contre la morsure des serpents. Land and water, 1867.

Préconise la cendre de pipe en application sur la blessure.

War (A. V.). The New-Orléans méd. and. surgic. Mars, 1861.

Emploi des alcooliques contre la morsure des crotales.

WeIr MITchell. Researches upon the venom of the rattlesnalies. Washington, Smithsonian Institution, 1860 et 1861. 
M. Weir Mitchell a refait pour les crotales le travail de Fontana sur la vipère en utilisant pour cela toutes les ressources de la scignce moderne. On trouve dans cette remarquable étude une analyse du venin de ces animaux.

On the treatment of rattlesnake bites, with experimental criticism upon the various remedies now in use. Philadelphie, 1864.

Ouvrage complémentaire du précédent et comme lui marqué au sceau dujugement le plus sûr et de la plus grande honnêteté scientifique.

Qu'il nous soit permis, en terminant, de témoigner notre gra titude à notre ami le docteur E. Le Sourd, pour avoir bien voulu publier une partie de ces Études dans la Revue de Paris, dont il était alors directeur, et dans la Gazette des Hôpitaux.

Ne pouvant, à notre grand regret, citer toutes les personnes qui nous ont envoyé d'utiles observations, nous les prions d'agréer ici nos remerciments. Nous en offrons de tout particuliers à MM. J.-H. Midolle et L. Viau, auxquels nous devons les dessins intercalés dans le texte, et à M. A. Guitton, pour nous avoir aidé à mettre en ordre les notes qui ont servi à ce travail.

\section{ERRATA et ADDENDA}

Page 36, ligne 23, au lieu de la prime de 50 cent., lire la prime de 25 cent. Page 46, ligne 17, au lieu de 1867, 1837.

Page 111. M. Sevète, 'curé de Paulx, nous communique au moment où nous revoyons ces épreuves, l'observation d'un cinquantième cas de mort par la vipère, celui de Josephin Longépée. Cet enfant de 10 ans, atteint trois fois au pied par un aspic, le 29 juin 1869, et traité intus et extra à l'aide ảu vin de thériaque, a succombé $36 \mathrm{~h}$. après cette blessure.

Page 201, ligne 21, au lieu de du naja, de la naja.

Page 239, ligne de titre, au lieu de Poslles, Psylles. 


\section{TABLE DES MATIERES}

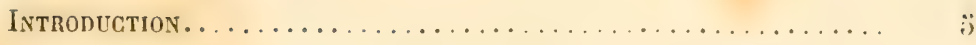

$1^{\text {ro }}$ PARTiE. - Considéralions sur les serpents non venimeux de la Vendée et de la Loire-Inférieure et sur leurs morsures....... t;

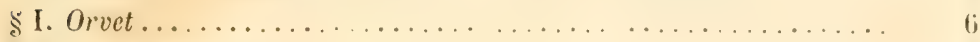

II. Couleuvres........................... 9

10 Classification et description des espèces.............. 9

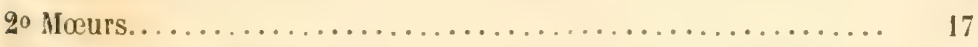

2 e PARTIE. - Histoire naturelle des serpents venimeux indigène's. 27

$\S \mathrm{I}$. Des vipères et de leur caractères zoologiques.............. פT

10 Classification et description des espèces............. 27

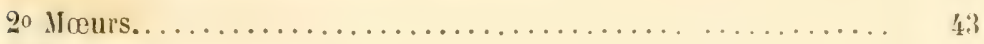

II. Appareil venimeux....................... (i)

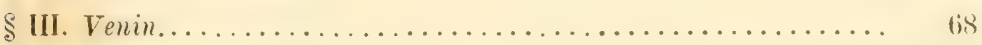

3e partie. - Considerations médico-chnurgicales sur les morsures

de vipères dans la Vendée et la Loire-Inférieure............ \$

§. Examen comparatif des cas observés................. 91

§II. Description de l'affection venimeuse................ 118

10 Symptômes primitifs ou de blessure................. 119

20 Symptòmes secondaires...................... 120

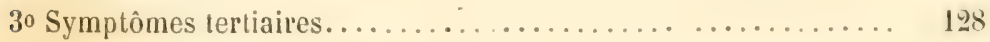

40 Marche, durée, terminaison.................. 1:31

$\tilde{j}^{0}$ Pronostic................................ 132

60 Diagnostic. . . . . . . . . . . . . . . . . . . . 139

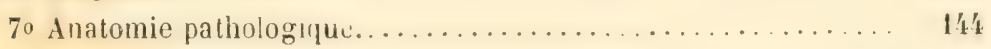

so Pathologie compare....................... 14;

\$III. Traitement......................... 1\%

10 Examen des divers remèdes prônés contre les morsures de vipères.............................. liti

1. Emploi de la vipère elle-mème............... 1:57

2. Spécifiques végétaux, $a$ indigènes............. 18 il

$b$ exotiques............... 16 ' 
3. Tabac.............................. 167

4. Ammoniacaux.......................... 167

5. Alcooliques......................... 171

6. Café................................ 174

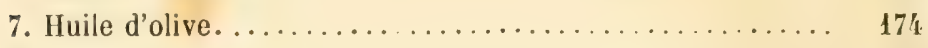

8. Arsenic............................. 175

9. Chlore, iode, brome.................... 176

10. Perchlorure de fer.................... 183

11. Électricité........................... 184

12. Applications froides.................... 18 .

13. Incisions et scarifications................. $18 \ddot{0}$

14. Ligature........................... 185

15. Succion............................ 186

16. Sangsues........................... 195

17. Cautérisation...................... 196

18. Acide phénique....................... 196

19. Ablation. ......................... 199

20 Traitement rationnel des morsures de vipères............ 199

40 PARTie. - Des ennemis de la vipère el des moyens de la détruire. $\quad 20 \%$

A P PENDICES

I. De l'emploi de la vipère et du venin des serpents comme moyen thé-

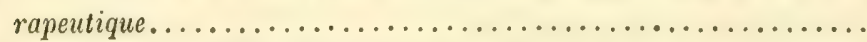

II. Tableau synoptique des serpents de la Vendée et de la Loire-Inférieure.

NOTES

10 De la préparation du sung-sig, ou poison des Malais........ 233

$2 \circ$ Guérisseurs de venin et charmeurs de serpents........... 237

3 Essai de diverses méthodes de traitement contre la morsure de

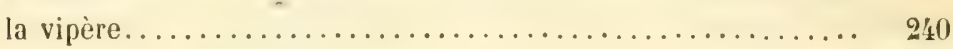

Principaux ouvrages consultés...................... 248

Errata el Addenda................................ 258

TABLE ...................................... 259 




QL Viaud-Grand-Marais,

666 Ambroise.

0 6V62 Études médicales sur

Rept. les serpents de $1 a$ vendéé et de la LoireInferieure. 


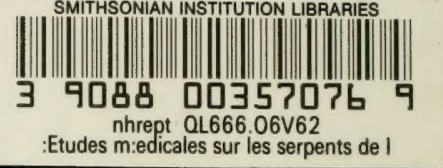

